\title{
Evaluated kinetic and photochemical data for atmospheric chemistry: Volume III - gas phase reactions of inorganic halogens
}

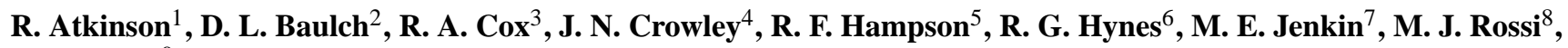 \\ and J. Troe ${ }^{9}$ \\ ${ }^{1}$ Air Pollution Research Center, University of California, Riverside, California 92521, USA \\ ${ }^{2}$ School of Chemistry, University of Leeds, Leeds LS2 9JT, UK \\ ${ }^{3}$ Centre for Atmospheric Science, Dept. of Chemistry, University of Cambridge, Lensfield Road Cambridge CB2 1EP, UK \\ ${ }^{4}$ Max-Planck-Institut für Chemie, Division of Atmospheric Chemistry, Postfach 3060, 55020 Mainz, Germany \\ ${ }^{5}$ U.S. Dept. of Commerce, National Institute of Standards and Technology, Bldg. 221, Rm A111, Gaithersburg, MD 20899, \\ USA \\ ${ }^{6}$ CSIRO Energy Technology, Lucas Heights Science and Technology Centre, Building 2, PMB 7, Bangor, NSW 2234, \\ Australia \\ ${ }^{7}$ Dept. of Environmental Science and Technology, Imperial College London, Silwood Park, Ascot, Berkshire SL5 7PY UK \\ ${ }^{8}$ Laboratoire Pollution Atmospherique et Sol LPAS/ ENAC, CH-H5 Station 6 EPFL,CH 1015 Lausanne, Switzerland \\ ${ }^{9}$ Institute of Physical Chemistry, University of Göttingen, Tammannstr. 6, 37077 Göttingen, Germany \\ *The IUPAC Subcommittee on Gas Kinetic Data Evaluation for Atmospheric Chemistry
}

Received: 18 October 2005 - Published in Atmos. Chem. Phys. Discuss.: 7 April 2006

Revised: 13 October 2006 - Accepted: 24 October 2006 - Published: 22 February 2007

\begin{abstract}
This article, the third in the series, presents kinetic and photochemical data evaluated by the IUPAC Subcommittee on Gas Kinetic Data Evaluation for Atmospheric Chemistry. It covers the gas phase and photochemical reactions of inorganic halogen species, which were last published in J. Phys. Chem. Ref. Data, in 2000 (Atkinson et al., 2000), were updated on the IUPAC website in 2003 and are updated again in the present evaluation. The article consists of a summary sheet, containing the recommended kinetic parameters for the evaluated reactions, and five appendices containing the data sheets, which provide information upon which the recommendations were made.
\end{abstract}

\section{Introduction}

In the mid 1970s it was appreciated that there was a need for the establishment of an international panel to produce a set of critically evaluated rate parameters for reactions of interest for atmospheric chemistry. To this end the CODATA Task Group on Chemical Kinetics, under the auspices of the International Council of Scientific Unions (ICSU), was con-

Correspondence to: R. A. Cox

(rac26@cam.ac.uk) stituted in 1977 and tasked to produce an evaluation of relevant, available kinetic and photochemical data. The first evaluation by this international committee was published in J. Phys. Chem. Ref. Data in 1980 (Baulch et al., 1980), followed by Supplements in 1982 (Baulch et al., 1982) and 1984 (Baulch et al., 1984). In 1986 the IUPAC Subcommittee on Data Evaluation superseded the original CODATA Task Group for Atmospheric Chemistry, and the Subcommittee has continued its data evaluation program with Supplements published in 1989 (Atkinson et al., 1989), 1992 (Atkinson et al., 1992), 1997 (Atkinson et al., 1997a), 1997 (Atkinson et al., 1997b), 1999 (Atkinson et al., 1999) and 2000 (Atkinson et al., 2000). Following the last of these reports, Supplement VIII (Atkinson et al., 2000), the evaluation has continued to be updated and published on the worldwide web (http://www.iupac-kinetic.ch.cam.ac.uk/). The IUPAC website hosts an interactive database with a search facility and implemented hyperlinks between the summary table and the data sheets, both of which can be downloaded as individual PDF or word files. In order to further enhance the accessibility of this updated material to the scientific community, the evaluation is being published as a series of articles in Atmospheric Chemistry and Physics. This article is the third of the series, Volume III.

Published by Copernicus GmbH on behalf of the European Geosciences Union. 
2 Summary of recommended rate coefficients for inorganic halogen reactions

The ordering of families in the Summary Table is: $\mathrm{FO}_{\mathrm{x}}$ (Appendix 1), $\mathrm{ClO}_{\mathrm{x}}$ (Appendix 2), $\mathrm{BrO}_{\mathrm{x}}$ (Appendix 3) and $\mathrm{IO}_{\mathrm{x}}$ (Appendix 4). Photochemical processes are listed in Appendix 5. The reactions are numbered sequentially for the whole Volume. Within each family, reactions are listed in the order: $\mathrm{O}\left({ }^{3} \mathrm{P}\right), \mathrm{O}\left({ }^{1} \mathrm{D}\right)$, halogen atom, $\mathrm{OH}$ radical, $\mathrm{NO}_{3}$ radical and halogen oxide reactions. Chemical reactions are listed as first reactant (usually an atom or radical) + second reactant (usually a molecule). Each datasheet has a unique identifier: "Volume: Appendix: reaction number". For example, the first reaction in the summary sheet below refers to Datasheet "III.A1.1".

Table 1. Summary of recommended rate coefficients for inorganic halogen reactions

\begin{tabular}{|c|c|c|c|c|c|c|c|}
\hline $\begin{array}{l}\text { Reaction } \\
\text { number }\end{array}$ & Reaction & $\begin{array}{l}k_{298} / \\
\mathrm{cm}^{3} \text { molecule }^{-1} \mathrm{~s}^{-1}\end{array}$ & & $\Delta \log k_{298}^{\mathrm{a}}$ & $\begin{array}{l}\text { Temp. dependence of } \\
k / \mathrm{cm}^{3} \text { molecule }^{-1} \mathrm{~s}^{-1}\end{array}$ & $\begin{array}{l}\text { Temp. } \\
\text { range/K }\end{array}$ & $\Delta(E / R) / \mathrm{K}^{a}$ \\
\hline \multicolumn{8}{|c|}{ FO $O_{\mathrm{X}}$ Reactions: based on data sheets in Appendix 1} \\
\hline 1 & $\mathrm{O}+\mathrm{FO} \rightarrow \mathrm{O}_{2}+\mathrm{F}$ & $2.7 \times 10^{-11}$ & & \pm 0.3 & & & \\
\hline 2 & $\mathrm{O}+\mathrm{FO}_{2} \rightarrow \mathrm{O}_{2}+\mathrm{FO}$ & $5 \times 10^{-11}$ & & \pm 0.7 & & & \\
\hline \multirow[t]{3}{*}{3} & $\mathrm{O}\left({ }^{1} \mathrm{D}\right)+\mathrm{HF} \rightarrow \mathrm{HO}+\mathrm{F}$ & $1.5 \times 10^{-11}$ & & \pm 0.1 & & & \\
\hline & $\rightarrow \mathrm{O}\left({ }^{3} \mathrm{P}\right)+\mathrm{HF}$ & $3.6 \times 10^{-11}$ & & \pm 0.1 & & & \\
\hline & overall & $5.1 \times 10^{-11}$ & & \pm 0.2 & & & \\
\hline 4 & $\mathrm{~F}+\mathrm{H}_{2} \rightarrow \mathrm{HF}+\mathrm{H}$ & $2.4 \times 10^{-11}$ & & \pm 0.1 & $1.1 \times 10^{-10} \exp (-450 / T)$ & $190-380$ & \pm 100 \\
\hline 5 & $\mathrm{~F}+\mathrm{H}_{2} \mathrm{O} \rightarrow \mathrm{HF}+\mathrm{HO}$ & $1.4 \times 10^{-11}$ & & \pm 0.1 & $1.4 \times 10^{-11}$ & $240-380$ & \pm 200 \\
\hline \multirow[t]{3}{*}{6} & $\mathrm{~F}+\mathrm{O}_{2}+\mathrm{M} \rightarrow \mathrm{FO}_{2}+\mathrm{M}$ & $5.8 \times 10^{-33}\left[\mathrm{~N}_{2}\right]$ & $\left(k_{0}\right)$ & \pm 0.3 & $5.8 \times 10^{-33}(T / 300)^{-1.7}\left[\mathrm{~N}_{2}\right]$ & $100-380$ & $\Delta n= \pm 0.5$ \\
\hline & & $1.2 \times 10^{-10}$ & $\left(k_{\infty}\right)$ & \pm 0.3 & $1.2 \times 10^{-10}$ & $100-380$ & $\Delta n= \pm 1$ \\
\hline & & $F_{c}=0.5$ & & & $F_{c}=0.5$ & $100-380$ & \\
\hline \multirow[t]{3}{*}{7} & $\mathrm{FO}_{2}+\mathrm{M} \rightarrow \mathrm{F}+\mathrm{O}_{2}+\mathrm{M}$ & $1.5 \times 10^{-17}\left[\mathrm{~N}_{2}\right]$ & $\left(k_{0} / \mathrm{s}^{-1}\right)$ & \pm 0.3 & $\begin{array}{l}8.4 \times 10^{-9}(T / 300)^{-1.25} \times \\
\exp (-5990 / T)\left[\mathrm{N}_{2}\right]\end{array}$ & $310-420$ & \pm 500 \\
\hline & & $3.1 \times 10^{5}$ & $\left(k_{\infty} / \mathrm{s}^{-1}\right)$ & \pm 0.3 & $\begin{array}{l}1.7 \times 10^{14}(T / 300)^{0.45} \times \\
\exp (-5990 / T)\end{array}$ & $310-420$ & \pm 500 \\
\hline & & $F_{c}=0.5$ & & & $F_{c}=0.5$ & $310-420$ & \\
\hline 8 & $\mathrm{~F}+\mathrm{O}_{3} \rightarrow \mathrm{FO}+\mathrm{O}_{2}$ & $1.0 \times 10^{-11}$ & & \pm 0.25 & $2.2 \times 10^{-11} \exp (-230 / T)$ & $250-370$ & \pm 200 \\
\hline 9 & $\mathrm{~F}+\mathrm{HONO}_{2} \rightarrow \mathrm{HF}+\mathrm{NO}_{3}$ & $2.3 \times 10^{-11}$ & & \pm 0.1 & $6.0 \times 10^{-12} \exp (400 / T)$ & $260-320$ & \pm 200 \\
\hline 10 & $\mathrm{FO}+\mathrm{O}_{3} \rightarrow$ products & $<1 \times 10^{-14}$ & & & & & \\
\hline 11 & $\mathrm{FO}+\mathrm{NO} \rightarrow \mathrm{F}+\mathrm{NO}_{2}$ & $2.2 \times 10^{-11}$ & & \pm 0.15 & $8.2 \times 10^{-12} \exp (300 / T)$ & $290-850$ & \pm 200 \\
\hline 12 & $\mathrm{FO}+\mathrm{FO} \rightarrow$ products & $1.0 \times 10^{-11}$ & & \pm 0.2 & $1.0 \times 10^{-11}$ & $290-440$ & \pm 250 \\
\hline 13 & $\mathrm{FO}_{2}+\mathrm{O}_{3} \rightarrow$ products & $<4 \times 10^{-16}$ & & & & & \\
\hline 14 & $\mathrm{FO}_{2}+\mathrm{NO} \rightarrow \mathrm{FNO}+\mathrm{O}_{2}$ & $7.5 \times 10^{-13}$ & & \pm 0.3 & $7.5 \times 10^{-12} \exp (-690 / T)$ & $190-300$ & \pm 400 \\
\hline 15 & $\mathrm{FO}_{2}+\mathrm{NO}_{2} \rightarrow$ products & $4.0 \times 10^{-14}$ & & \pm 0.3 & $3.8 \times 10^{-11} \exp (-2040 / T)$ & $260-320$ & \pm 500 \\
\hline \multicolumn{8}{|c|}{ ClO $_{\mathrm{x}}$ Reactions: based on data sheets in Appendix 2} \\
\hline 16 & $\mathrm{O}+\mathrm{HOCl} \rightarrow \mathrm{HO}+\mathrm{ClO}$ & $1.7 \times 10^{-13}$ & & \pm 0.5 & $1.7 \times 10^{-13}$ & $210-300$ & \pm 300 \\
\hline 17 & $\mathrm{O}+\mathrm{ClO} \rightarrow \mathrm{Cl}+\mathrm{O}_{2}$ & $3.7 \times 10^{-11}$ & & \pm 0.6 & $2.5 \times 10^{-11} \exp (110 / T)$ & $220-390$ & \pm 50 \\
\hline 18 & $\mathrm{O}+\mathrm{OClO} \rightarrow \mathrm{O}_{2}+\mathrm{ClO}$ & $1.0 \times 10^{-13}$ & & \pm 0.3 & $2.4 \times 10^{-12} \exp (-960 / T)$ & $240-400$ & \pm 300 \\
\hline \multirow[t]{3}{*}{19} & $\mathrm{O}+\mathrm{OClO}+\mathrm{M} \rightarrow \mathrm{ClO}_{3}+\mathrm{M}$ & $1.9 \times 10^{-31}\left[\mathrm{~N}_{2}\right]$ & $\left(k_{0}\right)$ & \pm 0.3 & $1.9 \times 10^{-31}(T / 298)^{-1}\left[\mathrm{~N}_{2}\right]$ & $240-320$ & $\Delta n= \pm 0.5$ \\
\hline & & $2.8 \times 10^{-11}$ & $\left(k_{\infty}\right)$ & \pm 0.3 & $2.8 \times 10^{-11}$ & $240-320$ & $\Delta n= \pm 1$ \\
\hline & & $F_{c}=0.5$ & & & $F_{c}=0.5$ & $240-320$ & \\
\hline 20 & $\mathrm{O}+\mathrm{Cl}_{2} \mathrm{O} \rightarrow \mathrm{ClO}+\mathrm{ClO}$ & $4.5 \times 10^{-12}$ & & \pm 0.15 & $2.7 \times 10^{-11} \exp (-530 / T)$ & $230-380$ & \pm 200 \\
\hline 21 & $\mathrm{O}+\mathrm{ClONO}_{2} \rightarrow$ products & $2.2 \times 10^{-13}$ & & \pm 0.08 & $4.5 \times 10^{-12} \exp (-900 / T)$ & $200-330$ & \pm 150 \\
\hline 22 & $\mathrm{Cl}+\mathrm{H}_{2} \rightarrow \mathrm{HCl}+\mathrm{H}$ & $1.7 \times 10^{-14}$ & & \pm 0.1 & $3.9 \times 10^{-11} \exp (-2310 / T)$ & $200-310$ & \pm 200 \\
\hline \multirow[t]{3}{*}{23} & $\mathrm{Cl}+\mathrm{HO}_{2} \rightarrow \mathrm{HCl}+\mathrm{O}_{2}$ & $3.4 \times 10^{-11}$ & & \pm 0.2 & & & \\
\hline & $\rightarrow \mathrm{ClO}+\mathrm{HO}$ & $9.3 \times 10^{-12}$ & & \pm 0.2 & $6.3 \times 10^{-11} \exp (-570 / T)$ & $230-420$ & \pm 200 \\
\hline & $\rightarrow$ all products & $4.4 \times 10^{-11}$ & & & $4.4 \times 10^{-11}$ & $230-420$ & \\
\hline 24 & $\mathrm{Cl}+\mathrm{H}_{2} \mathrm{O}_{2} \rightarrow \mathrm{HCl}+\mathrm{HO}_{2}$ & $4.1 \times 10^{-13}$ & & \pm 0.2 & $1.1 \times 10^{-11} \exp (-980 / T)$ & $260-430$ & \pm 500 \\
\hline \multirow[t]{2}{*}{25} & $\mathrm{Cl}+\mathrm{O}_{2}+\mathrm{M} \rightarrow \mathrm{ClOO}+\mathrm{M}$ & $1.4 \times 10^{-33}\left[\mathrm{~N}_{2}\right]$ & $\left(k_{0}\right)$ & \pm 0.2 & $1.4 \times 10^{-33}(T / 300)^{-3.9}\left[\mathrm{~N}_{2}\right]$ & $160-300$ & $\Delta n= \pm 1$ \\
\hline & & $1.6 \times 10^{-33}\left[\mathrm{O}_{2}\right]$ & $\left(k_{0}\right)$ & \pm 0.2 & $1.6 \times 10^{-33}(T / 300)^{-2.9}\left[\mathrm{O}_{2}\right]$ & $160-300$ & $\Delta n= \pm 1$ \\
\hline 26 & $\mathrm{ClOO}+\mathrm{M} \rightarrow \mathrm{Cl}+\mathrm{O}_{2}+\mathrm{M}$ & $6.2 \times 10^{-13}\left[\mathrm{~N}_{2}\right]$ & $\left(k_{0} / \mathrm{s}^{-1}\right)$ & \pm 0.3 & $2.8 \times 10^{-10} \exp (-1820 / T)\left[\mathrm{N}_{2}\right]$ & $160-300$ & \pm 200 \\
\hline 27 & $\mathrm{Cl}+\mathrm{CO}+\mathrm{M} \rightarrow \mathrm{ClCO}+\mathrm{M}$ & $1.3 \times 10^{-33}\left[\mathrm{~N}_{2}\right]$ & $\left(k_{0}\right)$ & \pm 0.3 & $1.3 \times 10^{-33}(T / 300)^{-3.8}\left[\mathrm{~N}_{2}\right]$ & $180-300$ & $\Delta n= \pm 1$ \\
\hline 28 & $\mathrm{ClCO}+\mathrm{M} \rightarrow \mathrm{Cl}+\mathrm{CO}+\mathrm{M}$ & $2.0 \times 10^{-14}\left[\mathrm{~N}_{2}\right]$ & $\left(k_{0} / \mathrm{s}^{-1}\right)$ & \pm 0.4 & $4.1 \times 10^{-10} \exp (-2960 / T)\left[\mathrm{N}_{2}\right]$ & $180-300$ & \pm 200 \\
\hline 29 & $\mathrm{Cl}+\mathrm{O}_{3} \rightarrow \mathrm{ClO}+\mathrm{O}_{2}$ & $1.2 \times 10^{-11}$ & & \pm 0.06 & $2.8 \times 10^{-11} \exp (-250 / T)$ & $180-300$ & $\begin{array}{l}+100 \\
{ }_{-150}\end{array}$ \\
\hline 30 & $\mathrm{Cl}+\mathrm{HONO}_{2} \rightarrow \mathrm{HCl}+\mathrm{NO}_{3}$ & $<2 \times 10^{-16}$ & & & & & \\
\hline 31 & $\mathrm{Cl}+\mathrm{NO}_{3} \rightarrow \mathrm{ClO}+\mathrm{NO}_{2}$ & $2.4 \times 10^{-11}$ & & \pm 0.2 & $2.4 \times 10^{-11}$ & $200-300$ & \pm 400 \\
\hline 32 & $\mathrm{Cl}+\mathrm{OClO} \rightarrow \mathrm{ClO}+\mathrm{ClO}$ & $5.7 \times 10^{-11}$ & & \pm 0.1 & $\left.3.2 \times 10^{-11} \exp (170) T\right)$ & $220-430$ & \pm 200 \\
\hline 33 & $\mathrm{Cl}+\mathrm{Cl}_{2} \mathrm{O} \rightarrow \mathrm{Cl}_{2}+\mathrm{ClO}$ & $9.6 \times 10^{-11}$ & & \pm 0.1 & $6.2 \times 10^{-11} \exp (130 / T)$ & $230-380$ & \pm 130 \\
\hline 34 & $\mathrm{Cl}+\mathrm{Cl}_{2} \mathrm{O}_{2} \rightarrow \mathrm{Cl}_{2}+\mathrm{ClOO}$ & $9.5 \times 10^{-11}$ & & \pm 0.2 & $7.6 \times 10^{-11} \exp (65 / T)$ & $220-300$ & \pm 150 \\
\hline 35 & $\mathrm{Cl}+\mathrm{ClONO}_{2} \rightarrow \mathrm{Cl}_{2}+\mathrm{NO}_{3}$ & $1.0 \times 10^{-11}$ & & \pm 0.1 & $6.2 \times 10^{-12} \exp (145 / T)$ & $190-360$ & \pm 50 \\
\hline
\end{tabular}




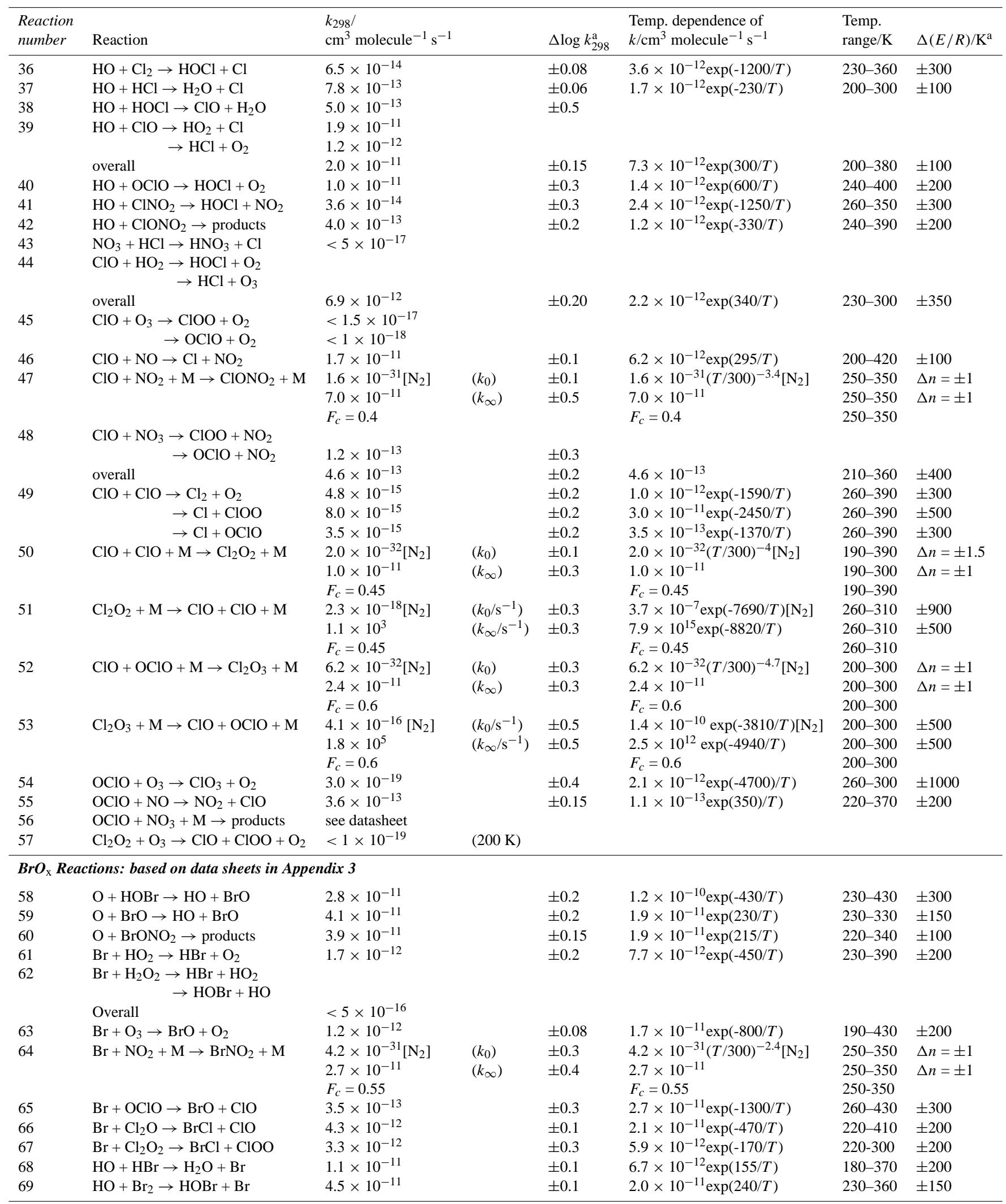


R. Atkinson et al.: Evaluated kinetic and photochemical data for atmospheric chemistry

\begin{tabular}{|c|c|c|c|c|c|c|c|}
\hline $\begin{array}{l}\text { Reaction } \\
\text { number }\end{array}$ & Reaction & $\begin{array}{l}k_{298} / \\
\mathrm{cm}^{3} \text { molecule } \\
\end{array}$ & & $\Delta \log k_{298}^{\mathrm{a}}$ & $\begin{array}{l}\text { Temp. dependence of } \\
k / \mathrm{cm}^{3} \text { molecule }^{-1} \mathrm{~s}^{-1}\end{array}$ & $\begin{array}{l}\text { Temp. } \\
\text { range/K }\end{array}$ & $\Delta(E / R) / \mathrm{K}^{\mathrm{a}}$ \\
\hline 70 & $\mathrm{HO}+\mathrm{BrO} \rightarrow$ products & $4.1 \times 10^{-11}$ & & \pm 0.3 & $1.8 \times 10^{-11} \exp (250 / T)$ & $230-350$ & \pm 300 \\
\hline 71 & $\mathrm{Br}+\mathrm{NO}_{3} \rightarrow \mathrm{BrO}+\mathrm{NO}_{2}$ & $1.6 \times 10^{-11}$ & & \pm 0.3 & & & \\
\hline 72 & $\mathrm{BrO}+\mathrm{NO}_{3} \rightarrow \mathrm{BrOO}+\mathrm{NO}_{2}$ & $1.0 \times 10^{-12}$ & & \pm 0.5 & & & \\
\hline 73 & $\mathrm{NO}_{3}+\mathrm{HBr} \rightarrow \mathrm{HNO}_{3}+\mathrm{Br}$ & $<1 \times 10^{-16}$ & & & & & \\
\hline \multirow[t]{2}{*}{74} & $\begin{aligned} \mathrm{BrO}+\mathrm{HO}_{2} & \rightarrow \mathrm{HOBr}+\mathrm{O}_{2} \\
& \rightarrow \mathrm{HBr}+\mathrm{O}_{3}\end{aligned}$ & & & & & & \\
\hline & Overall & $2.4 \times 10^{-11}$ & & \pm 0.3 & $4.5 \times 10^{-12} \exp (500 / T)$ & $210-360$ & \pm 200 \\
\hline 75 & $\mathrm{BrO}+\mathrm{O}_{3} \rightarrow$ products & $<2 \times 10^{-17}$ & & & & & \\
\hline 76 & $\mathrm{BrO}+\mathrm{NO} \rightarrow \mathrm{Br}+\mathrm{NO}_{2}$ & $2.1 \times 10^{-11}$ & & \pm 0.1 & $8.7 \times 10^{-12} \exp (260 / T)$ & $220-430$ & \pm 100 \\
\hline \multirow[t]{3}{*}{77} & $\mathrm{BrO}+\mathrm{NO}_{2}+\mathrm{M} \rightarrow \mathrm{BrONO}_{2}+\mathrm{M}$ & $4.7 \times 10^{-31}\left[\mathrm{~N}_{2}\right]$ & $\left(k_{0}\right)$ & \pm 0.1 & $4.7 \times 10^{-31}(T / 300)^{-3.1}\left[\mathrm{~N}_{2}\right]$ & $240-350$ & $\Delta n= \pm 1$ \\
\hline & & $1.8 \times 10^{-11}$ & $\left(k_{\infty}\right)$ & \pm 0.1 & $1.8 \times 10^{-11}$ & $240-350$ & $\Delta n= \pm 1$ \\
\hline & & $F_{c}=0.4$ & & & $F_{c}=0.4$ & $240-350$ & \\
\hline \multirow[t]{3}{*}{78} & $\mathrm{BrO}+\mathrm{ClO} \rightarrow \mathrm{Br}+\mathrm{OClO}$ & $6.8 \times 10^{-12}$ & & \pm 0.1 & $1.6 \times 10^{-12} \exp (430 / T)$ & $220-400$ & \pm 200 \\
\hline & $\rightarrow \mathrm{Br}+\mathrm{ClOO}$ & $6.1 \times 10^{-12}$ & & \pm 0.1 & $2.9 \times 10^{-12} \exp (220 / T)$ & $220-400$ & \pm 200 \\
\hline & $\rightarrow \mathrm{BrCl}+\mathrm{O}_{2}$ & $1.0 \times 10^{-12}$ & & \pm 0.1 & $5.8 \times 10^{-13} \exp (170 / T)$ & $220-400$ & \pm 200 \\
\hline \multirow[t]{2}{*}{79} & $\mathrm{BrO}+\mathrm{BrO} \rightarrow 2 \mathrm{Br}+\mathrm{O}_{2}$ & $2.7 \times 10^{-12}$ & & \pm 0.1 & $2.7 \times 10^{-12}$ & $250-390$ & \pm 200 \\
\hline & $\rightarrow \mathrm{Br}_{2}+\mathrm{O}_{2}$ & $4.8 \times 10^{-13}$ & & \pm 0.1 & $\left.2.9 \times 10^{-14} \exp (840) / T\right)$ & $250-390$ & \pm 200 \\
\hline \multicolumn{8}{|c|}{ IO $O_{\mathrm{x}}$ Reactions: based on data sheets in Appendix 4} \\
\hline 80 & $\mathrm{O}+\mathrm{I}_{2} \rightarrow \mathrm{IO}+\mathrm{I}$ & $1.25 \times 10^{-10}$ & & \pm 0.1 & & & \\
\hline 81 & $\mathrm{O}+\mathrm{IO} \rightarrow \mathrm{O}_{2}+\mathrm{I}$ & $1.4 \times 10^{-10}$ & & \pm 0.2 & & & \\
\hline 82 & $\mathrm{I}+\mathrm{HO}_{2} \rightarrow \mathrm{HI}+\mathrm{O}_{2}$ & $3.8 \times 10^{-13}$ & & \pm 0.3 & $1.5 \times 10^{-11} \exp (-1090 / T)$ & $280-360$ & \pm 500 \\
\hline 83 & $\mathrm{I}+\mathrm{O}_{3} \rightarrow \mathrm{IO}+\mathrm{O}_{2}$ & $1.3 \times 10^{-12}$ & & \pm 0.05 & $2.1 \times 10^{-11} \exp (-830 / T)$ & $230-370$ & \pm 150 \\
\hline \multirow{3}{*}{84} & $\mathrm{I}+\mathrm{NO}+\mathrm{M} \rightarrow \mathrm{INO}+\mathrm{M}$ & $1.8 \times 10^{-32}\left[\mathrm{~N}_{2}\right]$ & $\left(k_{0}\right)$ & \pm 0.1 & $1.8 \times 10^{-32}(T / 300)^{-1.0}\left[\mathrm{~N}_{2}\right]$ & $290-450$ & $\Delta n= \pm 0.5$ \\
\hline & & $1.7 \times 10^{-11}$ & $\left(k_{\infty}\right)$ & \pm 0.5 & $1.7 \times 10^{-11}$ & $300-400$ & $\Delta n= \pm 1$ \\
\hline & & $F_{c}=0.6$ & & & $F_{c}=0.6$ & $300-400$ & \\
\hline \multirow[t]{3}{*}{85} & $\mathrm{I}+\mathrm{NO}_{2}+\mathrm{M} \rightarrow \mathrm{INO}_{2}+\mathrm{M}$ & $3.0 \times 10^{-31}\left[\mathrm{~N}_{2}\right]$ & $\left(k_{0}\right)$ & \pm 0.2 & $3.0 \times 10^{-31}(T / 300)^{-1.0}\left[\mathrm{~N}_{2}\right]$ & $290-450$ & $\Delta n= \pm 1$ \\
\hline & & $6.6 \times 10^{-11}$ & $\left(k_{\infty}\right)$ & \pm 0.3 & $6.6 \times 10^{-11}$ & $290-450$ & $\Delta n= \pm 1$ \\
\hline & & $F_{c}=0.63$ & & & $F_{c}=0.63$ & $290-450$ & \\
\hline 86 & $\mathrm{I}+\mathrm{NO}_{3} \rightarrow \mathrm{IO}+\mathrm{NO}_{2}$ & No recommendation & & & & & \\
\hline 87 & $\mathrm{I}_{2}+\mathrm{NO}_{3} \rightarrow \mathrm{I}+\mathrm{IONO}_{2}$ & $1.5 \times 10^{-12}$ & & 0.5 & & & \\
\hline 88 & $\mathrm{HO}+\mathrm{HI} \rightarrow \mathrm{H}_{2} \mathrm{O}+\mathrm{I}$ & $7.0 \times 10^{-11}$ & & \pm 0.3 & $1.6 \times 10^{-11} \exp (440 / T)$ & $240-360$ & \pm 400 \\
\hline 89 & $\mathrm{HO}+\mathrm{I}_{2} \rightarrow \mathrm{HOI}+\mathrm{I}$ & $2.1 \times 10^{-10}$ & & \pm 0.15 & $2.1 \times 10^{-10}$ & $240-350$ & \pm 300 \\
\hline 90 & $\mathrm{NO}_{3}+\mathrm{HI} \rightarrow \mathrm{HNO}_{3}+\mathrm{I}$ & No recommendation & & & & & \\
\hline 91 & $\mathrm{IO}+\mathrm{HO}_{2} \rightarrow \mathrm{HOI}+\mathrm{O}_{2}$ & $8.4 \times 10^{-11}$ & & \pm 0.2 & $1.4 \times 10^{-11} \exp (540 / T)$ & $270-380$ & \pm 300 \\
\hline \multirow[t]{2}{*}{92} & $\mathrm{IO}+\mathrm{O}_{3} \rightarrow \mathrm{I}+2 \mathrm{O}_{2}$ & $<1.0 \times 10^{-15}$ & & & & & \\
\hline & $\rightarrow \mathrm{OIO}+\mathrm{O}_{2}$ & $<2.0 \times 10^{-16}$ & & & & & \\
\hline \multirow[t]{4}{*}{93} & $\mathrm{IO}+\mathrm{CIO} \rightarrow \mathrm{ICl}+\mathrm{O}_{2}$ & $2.4 \times 10^{-12}$ & & & & & \\
\hline & $\rightarrow \mathrm{Cl}+\mathrm{I}+\mathrm{O}_{2}$ & $3.0 \times 10^{-12}$ & & & & & \\
\hline & $\rightarrow \mathrm{I}+\mathrm{OClO}$ & $6.6 \times 10^{-12}$ & & & & & \\
\hline & overall & $1.2 \times 10^{-11}$ & & \pm 0.1 & $4.7 \times 10^{-12} \exp (280 / T)$ & $200-370$ & \pm 100 \\
\hline \multirow[t]{2}{*}{94} & $\mathrm{IO}+\mathrm{BrO} \rightarrow \mathrm{Br}+\mathrm{OIO}$ & $6.8 \times 10^{-11}$ & & & & & \\
\hline & overall & $8.5 \times 10^{-11}$ & & \pm 0.1 & $1.5 \times 10^{-11} \exp (510 / T)$ & $200-390$ & \pm 350 \\
\hline \multirow[t]{2}{*}{95} & $\mathrm{IO}+\mathrm{IO} \rightarrow \mathrm{I}+\mathrm{OIO}$ & $3.8 \times 10^{-11}(1 \mathrm{bar})$ & & & & & \\
\hline & overall & $9.9 \times 10^{-11}$ & & \pm 0.1 & $5.4 \times 10^{-11} \exp (180 / T)$ & $250-320$ & \pm 200 \\
\hline 96 & $\mathrm{IO}+\mathrm{NO} \rightarrow \mathrm{I}+\mathrm{NO}_{2}$ & $1.95 \times 10^{-11}$ & & \pm 0.15 & $7.15 \times 10^{-12} \exp (300 / T)$ & $240-370$ & \pm 100 \\
\hline \multirow[t]{3}{*}{97} & $\mathrm{IO}+\mathrm{NO}_{2}+\mathrm{M} \rightarrow \mathrm{IONO}_{2}+\mathrm{M}$ & $7.7 \times 10^{-31}\left[\mathrm{~N}_{2}\right]$ & $\left(k_{0}\right)$ & \pm 0.3 & $7.7 \times 10^{-31}(T / 300)^{-5}\left[\mathrm{~N}_{2}\right]$ & $250-360$ & $\Delta n= \pm 2$ \\
\hline & & $1.6 \times 10^{-11}$ & $\left(k_{\infty}\right)$ & \pm 0.3 & $1.6 \times 10^{-11}$ & $250-360$ & $\Delta n= \pm 1$ \\
\hline & & $F_{c}=0.4$ & & & $F_{c}=0.4$ & $250-360$ & \\
\hline 98 & $\mathrm{IONO}_{2}+\mathrm{M} \rightarrow$ products & $2.9 \times 10^{-3}(1 \mathrm{bar})$ & $\left(k / \mathrm{s}^{-1}\right)$ & \pm 1.0 & $1.1 \times 10^{15} \exp (-12060 / T)$ & $240-305$ & \pm 500 \\
\hline 99 & $\mathrm{INO}+\mathrm{INO} \rightarrow \mathrm{I}_{2}+2 \mathrm{NO}$ & $1.3 \times 10^{-14}$ & & \pm 0.4 & $8.4 \times 10^{-11} \exp (-2620 / T)$ & $300-450$ & \pm 600 \\
\hline 100 & $\mathrm{INO}_{2}+\mathrm{INO}_{2} \rightarrow \mathrm{I}_{2}+2 \mathrm{NO}_{2}$ & $1.7 \times 10^{-15}$ & & \pm 0.7 & $4.7 \times 10^{-13} \exp (-1670 / T)$ & $270-350$ & \pm 1000 \\
\hline 101 & $\mathrm{OIO}+\mathrm{NO} \rightarrow \mathrm{IO}+\mathrm{NO}_{2}$ & $6.7 \times 10^{-12}$ & & \pm 0.3 & $1.1 \times 10^{-12} \exp (542 / T)$ & $240-320$ & \pm 250 \\
\hline
\end{tabular}




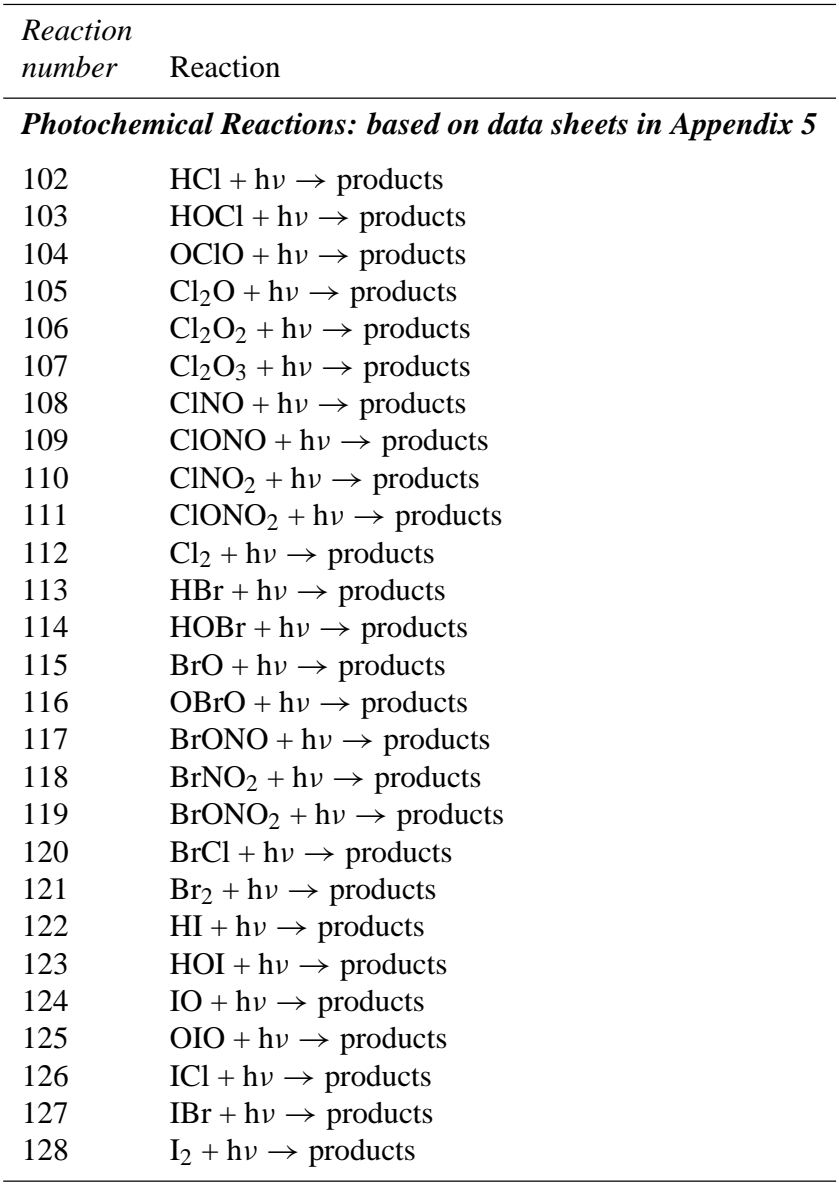

\section{Guide to the data sheets}

The data sheets are principally of two types: (i) those for individual thermal reactions and (ii) those for the individual photochemical reactions.

\subsection{Thermal reactions}

The data sheets begin with a statement of the reactions including all pathways which are considered feasible. This is followed by the corresponding enthalpy changes at $298 \mathrm{~K}$, calculated from the enthalpies of formation summarized in the Thermodynamics Data Summary, which is provided on the IUPAC website.

The available kinetic data on the reactions are summarized under two headings: (i) Absolute Rate Coefficients, and (ii) Relative Rate Coefficients. Under these headings, we include new data which have been published since the last published IUPAC evaluation as well as the data used in deriving the preferred values. Under both of the headings above, the data are presented as absolute rate coefficients. If the temperature coefficient has been measured, the results are given in a temperature dependent form over a stated temperature range. For bimolecular reactions, the temperature dependence is usually expressed in the normal Arrhenius form,
$k=A \exp (-B / T)$, where $B=E / R$. For a few bimolecular reactions, we have listed temperature dependences in the alternative form, $k=A^{\prime} T^{-n}$ or $C T^{n} \exp (-D / T)$, where the original authors have found this to give a better fit to the data. For pressure dependent combination and dissociation reactions, generally the non-Arrhenius temperature dependence is used. This is discussed more fully in a subsequent section of this Introduction.

Single temperature data are presented as such and wherever possible the rate coefficient at, or close to, $298 \mathrm{~K}$ is quoted directly as measured by the original authors. This means that the listed rate coefficient at $298 \mathrm{~K}$ may differ slightly from that calculated from the Arrhenius parameters determined by the same authors. Rate coefficients at $298 \mathrm{~K}$ marked with an asterisk indicate that the value was calculated by extrapolation of a measured temperature range which did not include $298 \mathrm{~K}$. The tables of data are supplemented by a series of comments summarizing the experimental details. The following list of abbreviations, relating to experimental techniques, is used in the Techniques and Comments sections:

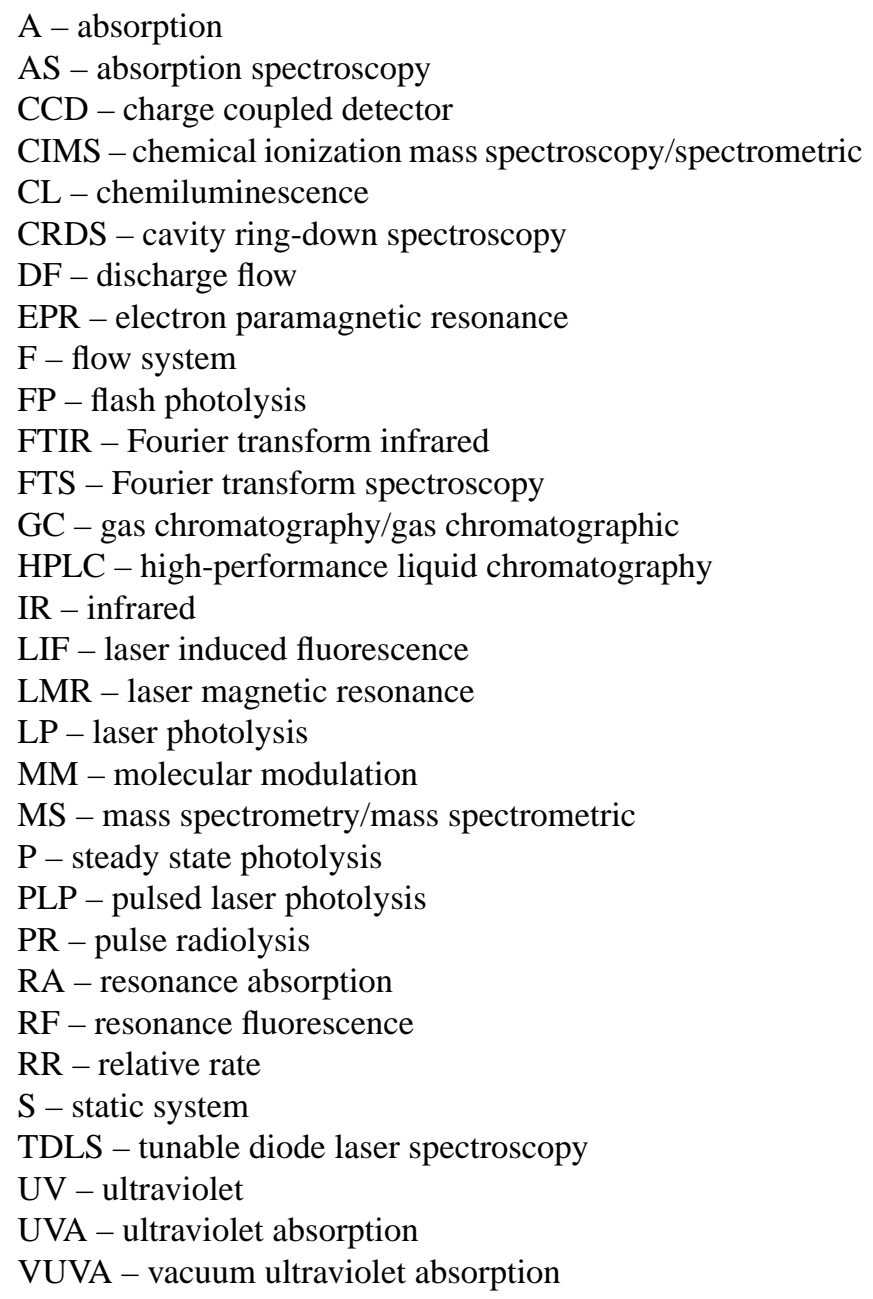

For measurements of relative rate coefficients, wherever possible the comments contain the actual measured ratio of rate 
coefficients together with the rate coefficient of the reference reaction used to calculate the absolute rate coefficient listed in the data table. The absolute value of the rate coefficient given in the table may be different from that reported by the original author owing to a different choice of rate coefficient of the reference reaction. Whenever possible the reference rate data are those preferred in the present evaluation.

The preferred rate coefficients are presented (i) at a temperature of $298 \mathrm{~K}$ and (ii) in temperature dependent form over a stated temperature range. This is followed by a statement of the uncertainty limits in $\log k$ at $298 \mathrm{~K}$ and the uncertainty limits either in $(E / R)$ or in $n$, for the mean temperature in the range. Some comments on the assignment of uncertainties are given later in this Introduction.

The "Comments on Preferred Values" describe how the selection was made and give any other relevant information. The extent of the comments depends upon the present state of our knowledge of the particular reaction in question. The data sheets are concluded with a list of the relevant references.

\subsection{Conventions concerning rate coefficients}

All of the reactions in the table are elementary processes. Thus the rate expression is derived from a statement of the reaction, e.g.

$\mathrm{A}+\mathrm{A} \rightarrow \mathrm{B}+\mathrm{C}$

$-\frac{1}{2} \frac{\mathrm{d}[\mathrm{A}]}{\mathrm{d} t}=\frac{\mathrm{d}[\mathrm{B}]}{\mathrm{d} t}=\frac{\mathrm{d}[\mathrm{C}]}{\mathrm{d} t}=k[\mathrm{~A}]^{2}$.

Note that the stoichiometric coefficient for A, i.e. 2, appears in the denominator before the rate of change of [A] (which is equal to $2 k[\mathrm{~A}]^{2}$ ) and as a power on the righthand side.

Representations of $k$ as a function of temperature characterize simple "direct" bimolecular reactions. Sometimes it is found that $k$ also depends on the pressure and the nature of the bath gas. This may be an indication of complex formation during the course of the bimolecular reaction, which is always the case in combination reactions. In the following sections, the representations of $k$ which are adopted in these cases are explained.

\subsection{Treatment of combination and dissociation reactions}

Unlike simple bimolecular reactions such as those considered in Sect. 3.2, combination reactions

$\mathrm{A}+\mathrm{B}+\mathrm{M} \rightarrow \mathrm{AB}+\mathrm{M}$

and the reverse dissociation reactions

$\mathrm{AB}+\mathrm{M} \rightarrow \mathrm{A}+\mathrm{B}+\mathrm{M}$

are composed of sequences of different types of physical and chemical elementary processes. Their rate coefficients reflect the more complicated sequential mechanism and depend on the temperature, $T$, and the nature and concentration of the third body, $[\mathrm{M}]$. In this evaluation, the combination reactions are described by a formal second-order rate law:

$\frac{\mathrm{d}[\mathrm{AB}]}{\mathrm{d} t}=k[\mathrm{~A}][\mathrm{B}]$

while dissociation reactions are described by a formal firstorder rate law:

$\frac{-\mathrm{d}[\mathrm{AB}]}{\mathrm{d} t}=k[\mathrm{AB}]$

In both cases, $k$ depends on the temperature and on [M].

In order to rationalize the representations of the rate coefficients used in this evaluation, we first consider the Lindemann-Hinshelwood reaction scheme. The combination reactions follow an elementary mechanism of the form,

$$
\begin{aligned}
& \mathrm{A}+\mathrm{B} \rightarrow \mathrm{AB}^{*} \\
& \mathrm{AB}^{*} \rightarrow \mathrm{A}+\mathrm{B} \\
& \mathrm{AB}^{*}+\mathrm{M} \rightarrow \mathrm{AB}+\mathrm{M}
\end{aligned}
$$

while the dissociation reactions are characterized by:

$$
\begin{aligned}
& \mathrm{AB}+\mathrm{M} \rightarrow \mathrm{AB}^{*}+\mathrm{M} \\
& \mathrm{AB}^{*}+\mathrm{M} \rightarrow \mathrm{AB}+\mathrm{M} \\
& \mathrm{AB}^{*} \rightarrow \mathrm{A}+\mathrm{B}
\end{aligned}
$$

Assuming quasi-stationary concentrations for the highly excited unstable species $\mathrm{AB}^{*}$ (i.e. that $\mathrm{d}\left[\mathrm{AB}^{*}\right] / \mathrm{d} t \approx 0$ ), it follows that the rate coefficient for the combination reaction is given by:

$k=k_{1}\left(\frac{k_{2}[\mathrm{M}]}{k_{-1}+k_{2}[\mathrm{M}]}\right)$

while that for the dissociation reaction is given by:

$k=k_{-2}[\mathrm{M}]\left(\frac{k_{-1}}{k_{-1}+k_{2}[\mathrm{M}]}\right)$

In these equations the expressions before the parentheses represent the rate coefficients of the process initiating the reaction, whereas the expressions within the parentheses denote the fraction of reaction events which, after initiation, complete the reaction to products.

In the low pressure limit $([\mathrm{M}] \rightarrow 0)$ the rate coefficients are proportional to $[\mathrm{M}]$; in the high pressure limit ([M] $\rightarrow \infty$ ) they are independent of [M]. It is useful to express $k$ in terms of the limiting low pressure and high pressure rate coefficients,

$$
\begin{array}{ccc}
k_{0}=\lim k([\mathrm{M}]) & \text { and } & k_{\infty}=\lim k([\mathrm{M}]), \\
{[\mathrm{M}] \rightarrow 0} & {[\mathrm{M}] \rightarrow \infty}
\end{array}
$$

respectively. From this convention, the LindemannHinshelwood equation is obtained

$k=\frac{k_{o} k_{\infty}}{k_{o}+k_{\infty}}$ 
It follows that for combination reactions, $k_{0}=k_{1} k_{2}[\mathrm{M}] / k_{-1}$ and $k_{\infty}=k_{1}$, while for dissociation reactions, $k_{0}=k_{-2}[\mathrm{M}]$ and $k_{\infty}=k_{-1} k_{-2} / k_{2}$. Since detailed balancing applies, the ratio of the rate coefficients for combination and dissociation at a fixed $T$ and [M] is given by the equilibrium constant $K_{c}=k_{1} k_{2} / k_{-1} k_{-2}$.

Starting from the high-pressure limit, the rate coefficients fall off with decreasing third body concentration [M] and the corresponding representation of $k$ as a function of [M] is termed the "falloff curve" of the reaction. In practice, the above Lindemann-Hinshelwood expressions do not suffice to characterize the falloff curves completely. Because of the multistep character of the collisional deactivation $\left(k_{2}[\mathrm{M}]\right)$ and activation $\left(k_{-2}[\mathrm{M}]\right)$ processes, and energy- and angular momentum-dependencies of the association $\left(k_{1}\right)$ and dissociation $\left(k_{-1}\right)$ steps, as well as other phenomena, the falloff expressions have to be modified. This can be done by including a broadening factor $F$ to the Lindemann-Hinshelwood expression (Troe, 1979):

$k=\frac{k_{o} k_{\infty}}{k_{o}+k_{\infty}} F=k_{o}\left(\frac{1}{1+\frac{k_{o}}{k_{\infty}}}\right) F=k_{\infty}\left(\frac{\frac{k_{o}}{k_{\infty}}}{1+\frac{k_{o}}{k_{\infty}}}\right) F$

The broadening factor $F$ depends on the ratio $k_{0} / k_{\infty}$, which is proportional to $[\mathrm{M}]$, and can be used as a measure of "reduced pressure". The first factors on the right-hand side represent the Lindemann-Hinshelwood expression and the additional broadening factor $F$, at not too high temperatures, is approximately given by (Troe, 1979):

$\log F \cong \frac{\log F_{c}}{1+\left[\log \left(k_{0} / k_{\infty}\right) / N\right]^{2}}$

where $\log =\log _{10}$ and $N \approx\left[0.75-1.27 \log F_{c}\right]$. In this way the three quantities $k_{0}, k_{\infty}$, and $F_{c}$ characterise the falloff curve for the present application.

The given approximate expression for the broadening factor $F$ was obtained from statistical unimolecular rate theory in its simplest form (Troe, 1979). More rigorous representations require detailed information on the potential energy surfaces and on the collisional energy transfer step of the reaction. If this information is not available, one may assume typical behaviour and rely on the theoretical analysis given by Cobos and Troe (2003). For $T=200-300 \mathrm{~K}$ and the collider $\mathrm{M}=\mathrm{N}_{2}$ (with a collision efficiency $\beta_{c} \approx 0.3$ ), this treatment predicts $F_{c} \approx 0.49,0.44,0.39$, and 0.35 , if the reactants $\mathrm{A}$ and $\mathrm{B}$ in total have $r=3,4,5$, or 6 rotational degrees of freedom, respectively (e.g. for the reaction $\mathrm{HO}+\mathrm{NO}_{2}$, one would have $r=5$ and hence $F_{c} \approx 0.39$ ). It is also predicted that $F_{c}$, for the present applications, should be nearly temperature independent. Finally, more rigorous expressions for the broadening factors $F$ are given in Cobos and Troe (2003) which, in general do not differ from the above formula by more than about 10 percent. Since the special properties of each reaction system may lead to some deviations from the given values of $F_{c}$, these should only be used for a first orientation. Larger deviations of experimentally fitted $F_{c}$-values from the given "standard values", however, may be an indication for inadequate falloff extrapolations to $k_{0}$ and $k_{\infty}$. In this case, the apparent values for $F_{c}, k_{0}$, and $k_{\infty}$ obtained by fitting still can provide a satisfactory representation of the considered experimental data, in spite of the fact that inadequate values of $k_{0}$ and $k_{\infty}$ are obtained by extrapolation.

If a given falloff curve is fitted in different ways, changes in $F_{c}$ require changes in the limiting $k_{0}$ and $k_{\infty}$ values. For the purpose of this evaluation, this is irrelevant if the preferred $k_{0}$ and $k_{\infty}$ are used consistently together with the preferred $F_{c}$ values. If the selected $F_{c}$ value is too large, the values of $k_{0}$ and $k_{\infty}$ obtained by fitting the falloff expression to the experimental data are underestimated. If $F_{c}$ is too small, $k_{0}$ and $k_{\infty}$ are overestimated. However uncertainties in $F_{c}$ influence the fitted $k_{0}$ and $k_{\infty}$ in different ways. A simpler policy of fitting falloff was chosen by the NASA/JPL panel (Sander et al., 2003) in putting $F=0.6$ and $\mathrm{N}=1$. This generally leads to different values of the fitted $k_{0}$ and $k_{\infty}$ and their temperature dependencies than derived here, although experimental data over the range of atmospheric interest can generally be reproduced equally well. However the derived $k_{0}$ and $k_{\infty}$ may differ from the true limiting rate coefficients and thus should be interpreted by theory only with caution.

In the present evaluation, we generally follow the experimentally fitted values for $F_{c}, k_{0}$, and $k_{\infty}$, provided $F_{c}$ does not differ too much from the values given above. If large deviations are encountered, the experimental data are reevaluated using the given $F_{c}$-values given above.

Besides the energy-transfer mechanism, i.e. Reactions (1), $(-1)$, and (2), a second mechanism appears to be relevant for some reactions considered here. This is the radical-complex (or chaperon) mechanism

$$
\begin{aligned}
& \mathrm{A}+\mathrm{M} \rightarrow \mathrm{AM} \\
& \mathrm{AM} \rightarrow \mathrm{A}+\mathrm{M} \\
& \mathrm{B}+\mathrm{AM} \rightarrow \mathrm{AB}+\mathrm{M}
\end{aligned}
$$

which, in the low pressure range, leads to

$k_{0}=\left(k_{3} / k_{-3}\right) k_{4}[\mathrm{M}]$.

For some tri- and tetra-atomic adducts $\mathrm{AB}$, e.g. $\mathrm{O}+\mathrm{O}_{2}$ $\rightarrow \mathrm{O}_{3}$ and $\mathrm{Cl}+\mathrm{O}_{2} \rightarrow \mathrm{ClOO}$, this value of $k_{0}$ may exceed that from the energy-transfer mechanism and show stronger temperature dependencies (Luther et al., 2005). This mechanism may also influence high pressure experiments when $k_{O}$ from the radical-complex mechanism exceeds $\mathrm{k}_{\infty}$ from the energy-transfer mechanism (Oum et al., 2003). In this case falloff over wide pressure ranges cannot be represented by contributions from the energy-transfer mechanism alone, in particular when measurements at pressures above about 10 bar are taken into consideration. 
The dependence of $k_{0}$ and $k_{\infty}$ on the temperature $T$ is represented in the form $k \propto T^{-n}$ except for cases with an established energy barrier in the potential. We have used this form of temperature dependence because it usually gives a better fit to the data over a wider range of temperature than does the Arrhenius expression. It should be emphasised that the chosen form of the temperature dependence is often only adequate over limited temperature ranges such as $200-300 \mathrm{~K}$. Obviously, the relevant values of $n$ are different for $k_{0}$ and $k_{\infty}$. In this evaluation, values of $k_{0}$ are given for selected examples of third bodies $\mathrm{M}$, and if possible for $\mathrm{M}=\mathrm{N}_{2}, \mathrm{O}_{2}$ or air.

\subsection{Treatment of complex-forming bimolecular reactions}

Bimolecular reactions may follow the "direct" pathway

$\mathrm{A}+\mathrm{B} \rightarrow \mathrm{C}+\mathrm{D}$

and/or involve complex formation,

$$
\begin{gathered}
\mathrm{A}+\mathrm{B} \Leftrightarrow \underset{\mathrm{M}}{ } \mathrm{AB}^{*} \rightarrow \mathrm{C}+\mathrm{D} \\
\mathrm{AB}
\end{gathered}
$$

We designate the rate coefficients of the individual steps as in Sect. 3.3, above:

$\mathrm{A}+\mathrm{B} \rightarrow \mathrm{AB}^{*}$

$\mathrm{AB}^{*} \rightarrow \mathrm{A}+\mathrm{B}$

$\mathrm{AB}^{*}+\mathrm{M} \rightarrow \mathrm{AB}+\mathrm{M}$

$\mathrm{AB}^{*} \rightarrow \mathrm{C}+\mathrm{D}$

Assuming quasi-stationary concentrations of $\mathrm{AB}^{*}$ (i.e. $\mathrm{d}\left[\mathrm{AB}^{*}\right] / \mathrm{d} t \approx 0$ ), a Lindemann-Hinshelwood type of analysis leads to,

$$
\begin{aligned}
& \frac{\mathrm{d}[\mathrm{AB}]}{\mathrm{d} t}=k_{S}[\mathrm{~A}][\mathrm{B}] \\
& \frac{\mathrm{d}[\mathrm{C}]}{\mathrm{d} t}=k_{D}[\mathrm{~A}][\mathrm{B}] \\
& \frac{\mathrm{d}[\mathrm{A}]}{\mathrm{d} t}=-\left(k_{S}+k_{D}\right)[\mathrm{A}][\mathrm{B}]
\end{aligned}
$$

where

$$
k_{S}=k_{1}\left(\frac{k_{2}}{k_{-1}+k_{2}+k_{3}}\right)
$$

$k_{D}=k_{1}\left(\frac{k_{3}}{k_{-1}+k_{2}+k_{3}}\right)$

Note that since $k_{2}$ is proportional to [M], $k_{S}$ and $k_{D}$ are dependent on the nature and concentration of the third body $\mathrm{M}$, in addition to their temperature dependence. In reality, as for the combination and dissociation reactions, the given expressions for $k_{S}$ and $k_{D}$ have to be extended by suitable broadening factors $F$ in order to account for the multistep character of process (2) and the energy and angular momemtum dependencies of processes (1), (-1) and (3). These broadening factors, however, differ from those for combination and dissociation reactions. For simplicity, they are ignored in this evaluation such that $k_{D}$ at high pressure approaches

$k_{D} \rightarrow k_{1} k_{3} / k_{2}$

which is inversely proportional to [M]. $k_{D}$ may also be expressed by

$k_{D} \approx k_{D 0} k_{S} / k_{S 0}$

where $k_{D 0}$ and $k_{S 0}$ are the respective limiting low-pressure rate coefficients for the formation of $\mathrm{C}+\mathrm{D}$ or $\mathrm{A}+\mathrm{B}$ at the considered $[\mathrm{M}]$. When it is established that complex-formation is involved, this equation is used to characterize the increasing suppression of $\mathrm{C}+\mathrm{D}$ formation with increasing $[\mathrm{M}]$. One should also note that bimolecular reactions may have contributions from direct as well as complex-forming pathways leading to identical or different products.

\subsection{Photochemical reactions}

The data sheets begin with a list of feasible primary photochemical transitions for wavelengths usually down to $170 \mathrm{~nm}$, along with the corresponding enthalpy changes at $0 \mathrm{~K}$ where possible or alternatively at $298 \mathrm{~K}$, calculated from the data in the Thermodynamic Data summary. Calculated threshold wavelengths corresponding to these enthalpy changes are also listed, bearing in mind that the values calculated from the enthalpy changes at $298 \mathrm{~K}$ are not true "threshold values".

This is followed by tables which summarise the available experimental data for: (i) absorption cross sections and (ii) quantum yields. These data are supplemented by a series of comments.

The next table lists the preferred absorption cross section data and the preferred quantum yields at appropriate wavelength intervals. For absorption cross sections the intervals are usually $1 \mathrm{~nm}, 5 \mathrm{~nm}$ or $10 \mathrm{~nm}$. Any temperature dependence of the absorption cross sections is also given where possible. The aim in presenting these preferred data is to provide a basis for calculating atmospheric photolysis rates. For absorption continua the temperature dependence is often represented by Sulzer-Wieland type expressions (Astholz et al., 1981). Alternately a simple empirical expression of the form: $\log _{10}\left(\sigma_{T 1} / \sigma_{T 2}\right)=\mathrm{B}\left(T_{1}-T_{2}\right)$ is used.

The comments again describe how the preferred data were selected and include other relevant points. The photochemical data sheets are concluded with a list of references. 


\subsection{Conventions concerning absorption cross sections}

These are presented in the data sheets as "absorption cross sections per molecule, base e." They are defined according to the equations:

$\mathrm{I} / \mathrm{I}_{0}=\exp (-\sigma[\mathrm{N}] l)$

$\sigma=\{1 /([\mathrm{N}] l)\} \ln \left(\mathrm{I}_{0} / \mathrm{I}\right)$,

where $\mathrm{I}_{0}$ and $\mathrm{I}$ are the incident and transmitted light intensities, $\sigma$ is the absorption cross section per molecule (expressed in this paper in units of $\left.\mathrm{cm}^{2}\right),[\mathrm{N}]$ is the number concentration of absorber (expressed in molecule $\mathrm{cm}^{-3}$ ), and $l$ is the path length (expressed in $\mathrm{cm}$ ). Other definitions and units are frequently quoted. The closely related quantities "absorption coefficient" and "extinction coefficient" are often used, but care must be taken to avoid confusion in their definition. It is always necessary to know the units of concentration and of path length and the type of logarithm (base e or base 10) corresponding to the definition. To convert an absorption cross section to the equivalent Naperian (base e) absorption coefficient (expressed in $\mathrm{cm}^{-1}$ ) of a gas at a pressure of one standard atmosphere and temperature of $273 \mathrm{~K}$, multiply the value of $\sigma$ in $\mathrm{cm}^{2}$ by $2.69 \times 10^{19}$.

\subsection{Assignment of uncertainties}

Under the heading "reliability," estimates have been made of the absolute accuracies of the preferred values of $k$ at $298 \mathrm{~K}$ and of the preferred values of $E / R$ over the quoted temperature range. The accuracy of the preferred rate coefficient at $298 \mathrm{~K}$ is quoted as the term $\Delta \log k$, where $\Delta \log k=D$ and $D$ is defined by the equation, $\log _{10} k=C \pm D$. This is equivalent to the statement that $k$ is uncertain to a factor of $F$, where $D=\log _{10} F$. The accuracy of the preferred value of $E / R$ is quoted as the term $\Delta(E / R)$, where $\Delta(E / R)=G$ and $G$ is defined by the equation $E / R=H \pm G . D$ and $G$ are expanded uncertainties corresponding approximately to a $95 \%$ confidence limit.

For second-order rate coefficients listed in this evaluation, an estimate of the uncertainty at any given temperature within the recommended temperature range may be obtained from the equation:

$$
\Delta \log k(T)=\Delta \log k(298 \mathrm{~K})+0.4343\{\Delta E / R(1 / T-1 / 298)\}
$$

The assignment of these absolute uncertainties in $k$ and $E / R$ is a subjective assessment of the evaluators. They are not determined by a rigorous, statistical analysis of the database, which is generally too limited to permit such an analysis. Rather, the uncertainties are based on a knowledge of the techniques, the difficulties of the experimental measurements, the potential for systematic errors, and the number of studies conducted and their agreement or lack thereof. Experience shows that for rate measurements of atomic and free radical reactions in the gas phase, the precision of the measurement, i.e. the reproducibility, is usually good. Thus, for single studies of a particular reaction involving one technique, standard deviations, or even $90 \%$ confidence limits, of $\pm 10 \%$ or less are frequently reported in the literature. Unfortunately, when evaluators compare data for the same reaction studied by more than one group of investigators and involving different techniques, the rate coefficients often differ by a factor of 2 or even more. This can only mean that one or more of the studies has involved large systematic uncertainty which is difficult to detect. This is hardly surprising since, unlike molecular reactions, it is not always possible to study atomic and free radical reactions in isolation, and consequently mechanistic and other difficulties frequently arise.

On the whole, our assessment of uncertainty limits tends towards the cautious side. Thus, in the case where a rate coefficient has been measured by a single investigation using one particular technique and is unconfirmed by independent work, we suggest that minimum uncertainty limits of a factor of 2 are appropriate.

In contrast to the usual situation for the rate coefficients of thermal reactions, where intercomparison of results of a number of independent studies permits a realistic assessment of reliability, for many photochemical processes there is a scarcity of reliable data. Thus, we do not feel justified at present in assigning uncertainty limits to the parameters reported for the photochemical reactions.

Acknowledgements. The Chairman and members of the Committee wish to express their appreciation to I.U.P.A.C. for the financial help which facilitated the preparation of this evaluation. We also acknowledge financial support from the following organisations: EU Framework Program 6, ACCENT network of excellence; University of California Agricultural Experiment Station; the UK Natural Environmental Research Council; the Standard Reference Data Program (N.I.S.T); the Fonds National Suisse de la Recherche Scientifique (F.N.S.R.S.) and the Office Fédéral de l'Education et de la Science, andthe Deutsche Forschungsgemeinschaft (SFB 357). We also thank B. Cox for her work in preparing and editing the manuscript.

Edited by: W. T. Sturges

\section{References}

Astholz, D. C., Brouwer, L., and Troe, J.: High-Temperature Ultraviolet-Absorption Spectra of Polyatomic Molecules in Shock Waves, Ber. Bunsenges. Phys. Chem., 85, 559-564, 1981. Atkinson, R., Baulch, D. L., Cox, R. A., Hampson, Jr., R. F., Kerr, J. A., and Troe, J.: Evaluated Kinetic and Photochemical Data for Atmospheric Chemistry: Supplement III, IUPAC Subcommittee on Gas Kinetic Data Evaluation for Atmospheric Chemistry, J. Phys. Chem. Ref. Data, 18, 881-1097, 1989.

Atkinson, R., Baulch, D. L., Cox, R. A., Hampson, Jr., R. F., Kerr, J. A., and Troe, J.: Evaluated Kinetic and Photochemical Data for Atmospheric Chemistry: Supplement IV, IUPAC Subcommittee on Gas Kinetic Data Evaluation for Atmospheric Chemistry, J. Phys. Chem. Ref. Data, 21, 1125-1568, 1992. 
Atkinson, R., Baulch, D. L., Cox, R. A., Hampson, Jr., R. F., Kerr, J. A., Rossi, M., and Troe, J.: Evaluated Kinetic, Photochemical, and Heterogeneous Data for Atmospheric Chemistry: Supplement V, IUPAC Subcommittee on Gas Kinetic Data Evaluation for Atmospheric Chemistry, J. Phys. Chem. Ref. Data, 26, 5211011, 1997a.

Atkinson, R., Baulch, D. L., Cox, R. A., Hampson, Jr., R. F., Kerr, J. A., Rossi, M. J., and Troe, J.: Evaluated Kinetic and Photochemical Data for Atmospheric Chemistry: Supplement VI, IUPAC Subcommittee on Gas Kinetic Data Evaluation for Atmospheric Chemistry, J. Phys. Chem. Ref. Data, 26, 1329-1499, 1997 b.

Atkinson, R., Baulch, D. L., Cox, R. A., Hampson, Jr., R. F., Kerr, J. A., Rossi, M. J., and Troe, J.: Evaluated Kinetic and Photochemical Data for Atmospheric Chemistry: Supplement VII, IUPAC Subcommittee on Gas Kinetic Data Evaluation for Atmospheric Chemistry, J. Phys. Chem. Ref. Data, 28, 191-393, 1999.

Atkinson, R., Baulch, D. L., Cox, R. A., Hampson, Jr., R. F., Kerr, J. A., Rossi, M. J., and Troe, J.: Evaluated Kinetic and Photochemical Data for Atmospheric Chemistry, Supplement VIII, IUPAC Subcommittee on Gas Kinetic Data Evaluation for Atmospheric Chemistry, J. Phys. Chem. Ref. Data, J. Phys. Chem. Ref. Data, 29, 167-266, 2000.

Baulch, D. L., Cox, R. A., Hampson, Jr., R. F., Kerr, J. A., Troe, J., and Watson, R. T.: Evaluated Kinetic and Photochemical Data for Atmospheric Chemistry, CODATA Task Group on Chemical Kinetics, J. Phys. Chem. Ref. Data, 9, 295-471, 1980.

Baulch, D. L., Cox, R. A., Crutzen, P. J., Hampson, Jr., R. F., Kerr,
J. A., Troe, J., and Watson, R. T.: Evaluated Kinetic and Photochemical Data for Atmospheric Chemistry: Supplement I, CODATA Task Group on Chemical Kinetics, J. Phys. Chem. Ref. Data, 11, 327-496, 1982.

Baulch, D. L., Cox, R. A., Hampson, Jr., R. F., Kerr, J. A., Troe, J., and Watson, R. T.: Evaluated Kinetic and Photochemical Data for Atmospheric Chemistry: Supplement II, CODATA Task Group on Gas Phase Chemical Kinetics, J. Phys. Chem. Ref. Data, 13, 1259-1380, 1984.

Cobos, C. J. and Troe, J.: Prediction of Reduced Falloff Curves for Recombination Reactions at Low Temperatures, Z. Phys. Chem., 217, 1-14, 2003.

Luther, K., Oum, K. and Troe, J.: The Role of the Radical-Complex Mechanism in the Ozone Recombination/Dissociation Reaction. Phys. Chem. Chem. Phys., 7, 2764-2770, 2005.

Sander, S. P., Friedl, R. R., Golden, D. M., Kurylo, M. J., Huie, R. E., Orkin, V. L., Moortgat, G. K., Ravishankara, A. R., Kolb, C. E., Molina, M. J., and Finlayson-Pitts, B. J.: Chemical Kinetics and Photochemical Data for Use in Atmospheric Studies. NASA Panel for Data Evaluation, Evaluation Number 14., JPL Publication 02-25, 2003.

Oum, K., Sekiguchi, K., Luther, K., and Troe, J.: Observation of Unique Pressure Effects in the Combination Reaction of Benzyl Radicals in the Gas to Liquid Transition Region, Phys. Chem. Chem. Phys., 5, 2931-2933, 2003.

Troe, J.: Predictive Possibilities of Unimolecular Rate Theory, J. Phys. Chem., 83, 114-126, 1979. 


\section{Appendix 1: FO $_{\mathrm{x}}$ Reactions}

III.A1.1

$$
\mathbf{O}+\mathbf{F O} \rightarrow \mathbf{O}_{2}+\mathbf{F}
$$

$\Delta H^{\circ}=-279 \mathrm{~kJ} \mathrm{~mol}^{-1}$

\section{Rate coefficient data}

\begin{tabular}{lllc}
\hline$k / \mathrm{cm}^{3}$ molecule ${ }^{-1} \mathrm{~s}^{-1}$ & Temp./K & Reference & Technique/Comments \\
\hline $\begin{array}{l}\text { Absolute Rate Coefficients } \\
(2.7 \pm 0.2) \times 10^{-11}\end{array}$ & 298 & Bedzhanyan et al., 1993 & DL-LMR (a) \\
\hline
\end{tabular}

\section{Comments}

(a) Pseudo-first-order decays of FO radicals in the presence of excess $\mathrm{O}\left({ }^{3} \mathrm{P}\right)$ atoms were monitored by LMR. $\mathrm{O}\left({ }^{3} \mathrm{P}\right)$ atom concentrations were determined by EPR.

\section{Preferred Values}

$k=2.7 \times 10^{-11} \mathrm{~cm}^{3}$ molecule $\mathrm{e}^{-1} \mathrm{~s}^{-1}$ at $298 \mathrm{~K}$.

\section{Reliability}

$\Delta \log k= \pm 0.3$ at $298 \mathrm{~K}$.

\section{Comments on Preferred Values}

The preferred value is based on the results of the study of Bedzhanyan et al. (1993), the sole study of this reaction. The temperature dependence of the rate constant is expected to be small for such an atom-radical process, as for the analogous $\mathrm{ClO}$ radical reaction.

\section{References}

Bedzhanyan, Y. R., Markin, E. M., Politenkova, G. G., and Gershenzon, Y. M.: Kinet. Catal., 33, 797, 1993; original pages 998-1003, 1992. 
III.A1.2

$$
\mathrm{O}+\mathrm{FO}_{2} \rightarrow \mathrm{O}_{2}+\mathrm{FO}
$$

$\Delta H^{\circ}=-166 \mathrm{~kJ} \mathrm{~mol}^{-1}$

Rate coefficient data: no available experimental data.

\section{Preferred Values}

$k=5 \times 10^{-11} \mathrm{~cm}^{3}$ molecule ${ }^{-1} \mathrm{~s}^{-1}$ at $298 \mathrm{~K}$.

Reliability

$\Delta \log k= \pm 0.7$ at $298 \mathrm{~K}$.

Comments on Preferred Values

There are no experimental data for this reaction. The rate constant for such a radical-atom process is expected to approach the gas collision frequency and is not expected to exhibit a strong temperature dependence. 
III.A1.3

$$
\begin{aligned}
\mathrm{O}\left({ }^{1} \mathrm{D}\right)+\mathrm{HF} & \rightarrow \mathrm{HO}+\mathrm{F} \\
& \rightarrow \mathrm{O}\left({ }^{3} \mathrm{P}\right)+\mathrm{HF}
\end{aligned}
$$

$\Delta H^{\circ}(1)=-49 \mathrm{~kJ} \mathrm{~mol}^{-1}$

$\Delta H^{\circ}(2)=-189.7 \mathrm{~kJ} \mathrm{~mol}^{-1}$

\begin{tabular}{|c|c|c|c|}
\hline $\mathrm{k} / \mathrm{cm}^{3}$ molecule $^{-1} \mathrm{~s}^{-1}$ & Temp./K & Reference & Technique/Comments \\
\hline $\begin{array}{l}\text { Relative Rate Coefficients } \\
(5.1 \pm 1.0) \times 10^{-11}\end{array}$ & 298 & Sorokin et al., 1998; 1999 & PLP-LMR (a) \\
\hline $\begin{array}{l}\text { Branching Ratios } \\
k_{1} / k=0.30 \pm 0.02 \\
k_{2} / k=0.70 \pm 0.02\end{array}$ & $\begin{array}{l}298 \\
298\end{array}$ & Sorokin et al., 1998; 1999 & PLP-LMR (a) \\
\hline
\end{tabular}

Rate coefficient data $\left(k=k_{1}+k_{2}\right)$

\section{Comments}

(a) Measured rate coefficient ratio of $k\left(\mathrm{O}\left({ }^{1} \mathrm{D}\right)+\mathrm{HF}\right) / k\left(\mathrm{O}\left({ }^{1} \mathrm{D}\right)+\mathrm{NF}_{3}\right)$ was placed on an absolute basis by use of the rate coefficient for the reference reaction $k\left(\mathrm{O}\left({ }^{1} \mathrm{D}\right)+\mathrm{NF}_{3}\right)=1.15 \times 10^{-11} \mathrm{~cm}^{3}$ molecule ${ }^{-1} \mathrm{~s}^{-1}$ at $298 \mathrm{~K}$ (Sorokin et al., 1998, 1999). Pressure in the reactor was $\sim 13$ mbar.

\section{Preferred Values}

$k=5.1 \times 10^{-11} \mathrm{~cm}^{3}$ molecule $\mathrm{s}^{-1} \mathrm{~s}^{-1}$ at $298 \mathrm{~K}$.

$k_{1} / k=0.30$ at $298 \mathrm{~K}$.

$k_{2} / k=0.70$ at $298 \mathrm{~K}$.

\section{Reliability}

$\Delta \log k= \pm 0.2$ at $298 \mathrm{~K}$.

$\Delta\left(k_{1} / k\right)=\Delta\left(k_{2} / k\right)= \pm 0.1$

\section{Comments on Preferred Values}

The preferred values of $k, k_{1} / k$ and $k_{2} / k$ are based on the results reported by Sorokin et al. (1998, 1999). These results are given in the only published journal articles presenting a systematic study of this system. In a published paper on the reactions of $\mathrm{O}\left({ }^{1} \mathrm{D}\right)$ with $\mathrm{HCl}$ and $\mathrm{HBr}$, Wine et al. (1986), because of uncertainties in the HF concentration, report for the reaction $\mathrm{O}\left({ }^{1} \mathrm{D}\right)+\mathrm{HF}$ only a highly uncertain rate constant in the range $(6-24) \times 10^{-11} \mathrm{~cm}^{3}$ molecule $\mathrm{s}^{-1}$ at room temperature.

\section{References}

Sorokin, V. I., Gritsan, N. P., and Chichinin, A. I.: J. Chem. Phys., 108, 8995, 1998.

Sorokin, V. I., Gritsan, N. P., and Chichinin, A. I.: Chem. Phys. Reports 17, 2217, 1999.

Wine, P. H., Wells, J. R., and Ravishankara, A. R.: J. Chem. Phys., 84, 1349, 1986. 
III.A1.4

$$
\mathbf{F}+\mathbf{H}_{2} \rightarrow \mathbf{H F}+\mathbf{H}
$$

$\Delta H^{\circ}=-134.7 \mathrm{~kJ} \mathrm{~mol}^{-1}$

\section{Rate coefficient data}

\begin{tabular}{lllc}
\hline$k / \mathrm{cm}^{3}$ molecule ${ }^{-1} \mathrm{~s}^{-1}$ & Temp./K & Reference & Technique/Comments \\
\hline Absolute Rate Coefficients & & & \\
$1.0 \times 10^{-10} \exp [-(433 \pm 51) / T]$ & $190-359$ & Wurzberg and Houston, 1980 & PLP-CL \\
$(2.27 \pm 0.18) \times 10^{-11}$ & 297 & & \\
$(2.55 \pm 0.11) \times 10^{-11}$ & 298 & Clyne and Hodgson, 1985 & DF-LIF (a) \\
$1.2 \times 10^{-10} \exp [-(470 \pm 30) / T]$ & $221-376$ & Stevens et al., 1989 & DF-RF (b) \\
$(2.48 \pm 0.09) \times 10^{-11}$ & 298 & & \\
\hline
\end{tabular}

\section{Comments}

(a) $\mathrm{F}$ atoms were reacted with $\mathrm{Br}_{2}$ to form $\mathrm{BrF}$ which was detected by LIF.

(b) Discharge flow system. $\mathrm{F}$ atoms were converted to $\mathrm{D}$ atoms by reaction with $\mathrm{D}_{2}$ downstream of the reaction zone, and the $\mathrm{D}$ atoms monitored by resonance fluorescence.

\section{Preferred Values}

$k=2.4 \times 10^{-11} \mathrm{~cm}^{3}$ molecule $\mathrm{e}^{-1} \mathrm{~s}^{-1}$ at $298 \mathrm{~K}$.

$k=1.1 \times 10^{-10} \exp (-450 / T) \mathrm{cm}^{3}$ molecule $\mathrm{s}^{-1} \mathrm{~s}^{-1}$ over the temperature range 190-380 K.

\section{Reliability}

$\Delta \log k= \pm 0.1$ at $298 \mathrm{~K}$.

$\Delta(E / R)= \pm 100 \mathrm{~K}$.

\section{Comments on Preferred Values}

This evaluation accepts the recommended values given in the critical review of Persky and Kornweitz (1997). The preferred values are based on the results of Wurzberg and Houston (1980), Clyne and Hodgson (1985) and Stevens et al. (1989).

\section{References}

Clyne, M. A. A. and Hodgson, A.: J. Chem. Soc. Faraday Trans., 2, 81, 443, 1985.

Persky, A. and Kornweitz, H.: Int. J. Chem. Kinet., 29, 67, 1997.

Stevens, P. S., Brune, W. H., and Anderson, J. G.: J. Phys. Chem., 93, 4068, 1989.

Wurzberg, E. and Houston, P. L.: J. Chem. Phys., 72, 4811, 1980. 
III.A1.5

$$
\mathbf{F}+\mathrm{H}_{2} \mathrm{O} \rightarrow \mathbf{H F}+\mathrm{HO}
$$

$\Delta H^{\circ}=-73.7 \mathrm{~kJ} \mathrm{~mol}^{-1}$

\section{Rate coefficient data}

\begin{tabular}{lllc}
\hline$k / \mathrm{cm}^{3}$ molecule $\mathrm{s}^{-1} \mathrm{~s}^{-1}$ & Temp./K & Reference & Technique/Comments \\
\hline Absolute Rate Coefficients & & & \\
$4.2 \times 10^{-11} \exp [-(400 \pm 70) / T]$ & $243-369$ & Walther and Wagner, 1983 & DF-MS \\
$(1.1 \pm 0.1) \times 10^{-11}$ & 300 & & \\
$(1.3 \pm 0.1) \times 10^{-11}$ & $298 \pm 4$ & Frost et al., 1986 & PLP-CL (a) \\
$1.6 \times 10^{-11} \exp [-(28 \pm 42) / T]$ & $240-373$ & Stevens et al., 1989 & DF-RF (b) \\
$(1.42 \pm 0.06) \times 10^{-11}$ & 298 & & \\
\hline
\end{tabular}

\section{Comments}

(a) Pulsed laser photolysis of $\mathrm{F}_{2}-\mathrm{H}_{2} \mathrm{O}-\mathrm{He}$ mixtures at $308 \mathrm{~nm}$, with $\mathrm{HF}$ chemiluminescence being monitored.

(b) Discharge flow system. $\mathrm{F}$ atoms were converted to $\mathrm{D}$ atoms by reaction with $\mathrm{D}_{2}$ downstream of the reaction zone. $\mathrm{D}$ atoms were monitored by resonance fluorescence.

\section{Preferred Values}

$k=1.4 \times 10^{-11} \mathrm{~cm}^{3}$ molecule $\mathrm{e}^{-1} \mathrm{~s}^{-1}$, independent of temperature over the range $240-380 \mathrm{~K}$.

\section{Reliability}

$\Delta \log k= \pm 0.1$ at $298 \mathrm{~K}$.

$\Delta(E / R)= \pm 200 \mathrm{~K}$.

\section{Comments on Preferred Values}

The recommended temperature-independent value is based on the study of Stevens et al. (1989). This value is in good agreement with the room temperature results of Walther and Wagner (1983) and Frost et al. (1986). Walther and Wagner (1983) reported an $E / R$ value of $400 \mathrm{~K}$. Although their data (Walther and Wagner, 1983) have not been used in the derivation of the preferred values, with the exception of the one low temperature $(243 \mathrm{~K})$ data point, they agree with the preferred values within the stated uncertainties.

\section{References}

Frost, R. J., Green, D. S., Osborn, M. K., and Smith, I. W. M.: Int. J. Chem. Kinet., 18, 885, 1986.

Stevens, P. S., Brune, W. H., and Anderson, J. G.: J. Phys. Chem., 93, 4068, 1989.

Walther, C.-D. and Wagner, H. Gg.: Ber. Bunsenges. Phys. Chem., 87, 403, 1983. 
III.A1.6

$$
\mathbf{F}+\mathbf{O}_{2}+\mathbf{M} \rightarrow \mathbf{F O}_{2}+\mathbf{M}
$$

$\Delta H^{\circ}=-54.0 \mathrm{~kJ} \mathrm{~mol}^{-1}$

\section{Low-pressure rate coefficients}

\section{Rate coefficient data}

\begin{tabular}{|c|c|c|c|}
\hline$k_{0} / \mathrm{cm}^{3}$ molecule $^{-1} \mathrm{~s}^{-1}$ & Temp./K & Reference & Technique/Comments \\
\hline \multicolumn{4}{|l|}{ Absolute Rate Coefficients } \\
\hline $5.2 \times 10^{-34} \exp (656 / T)[\mathrm{He}]$ & $272-362$ & Zetzsch, 1973 & DF-MS (a) \\
\hline $4.7 \times 10^{-33}[\mathrm{He}]$ & 298 & & \\
\hline$(7 \pm 2) \times 10^{-33}[\mathrm{He}]$ & 293 & Arutyunov et al., 1976 & DF-EPR \\
\hline$(1.4 \pm 0.4) \times 10^{-32}\left[\mathrm{~N}_{2}\right]$ & 293 & & (b) \\
\hline$(6 \pm 2) \times 10^{-33}[\mathrm{Ar}]$ & 293 & & \\
\hline$(5.4 \pm 0.6) \times 10^{-33}[\mathrm{He}]$ & 298 & Chen et al., 1977 & $\mathrm{FP}(\mathrm{c})$ \\
\hline$(1.5 \pm 0.3) \times 10^{-32}\left[\mathrm{O}_{2}\right]$ & 298 & & \\
\hline$(5.0 \pm 0.6) \times 10^{-33}\left[\mathrm{~F}_{2}\right]$ & 298 & & \\
\hline$(8.4 \pm 0.9) \times 10^{-33}[\mathrm{Ar}]$ & 298 & & \\
\hline $2.8 \times 10^{-34} \exp (906 / T)[\mathrm{Ar}]$ & $223-293$ & Shamonima and Kotov, 1979 & DF-EPR \\
\hline$(6.1 \pm 1.8) \times 10^{-33}[\mathrm{Ar}]$ & 293 & & (d) \\
\hline$(1.0 \pm 0.3) \times 10^{-32}\left[\mathrm{O}_{2}\right]$ & 298 & Chebotarev, 1979 & PLP (e) \\
\hline$(3.2 \pm 2.1) \times 10^{-33}[\mathrm{Ar}]$ & 298 & Smith and Wrigley, 1980 & (f) \\
\hline$(3.7 \pm 2.4) \times 10^{-33}[\mathrm{Ar}]$ & 298 & Smith and Wrigley, 1981 & (f) \\
\hline$(4.3 \pm 0.4) \times 10^{-33}(T / 300)^{-1.6}[\mathrm{Ar}]$ & $295-359$ & Pagsberg et al., 1987 & PR (g) \\
\hline$(2.8 \pm 0.2) \times 10^{-33}[\mathrm{He}]$ & 298 & Lyman and Holland, 1988 & PLP(h) \\
\hline$(3.1 \pm 0.2) \times 10^{-33}[\mathrm{Ar}]$ & 298 & & \\
\hline $1.4 \times 10^{-32}\left[\mathrm{SF}_{6}\right]$ & 295 & Ellermann et al., 1994 & PR (i) \\
\hline $5.8 \times 10^{-33}(T / 300)^{-1.7}\left[\mathrm{~N}_{2}\right]$ & $100-373$ & Campuzano-Jost et al., 1995 & PLP (j) \\
\hline
\end{tabular}

\section{Comments}

(a) Detection of $\mathrm{F}$ atoms and $\mathrm{FO}_{2}$ radicals.

(b) Detection of F atoms.

(c) Detection of vibrationally excited HF by IR chemiluminescence.

(d) Detection of $\mathrm{F}$ atoms in the presence of excess $\mathrm{O}_{2}$ and Ar. Experimental conditions were varied over only limited ranges; for example, $\left[\mathrm{O}_{2}\right]$ was varied by a factor of 2 and the total pressure was fixed. The third-order rate coefficient reported for $\mathrm{Ar}$ as the diluent gas may be somewhat overestimated as $\mathrm{O}_{2}$ ranged from $\sim 12 \%$ to $\sim 25 \%$ of the total pressure. The stoichiometry was assumed to be 2 (i.e., $-\mathrm{d}[\mathrm{F}] / \mathrm{dt}=2 k[\mathrm{~F}]\left[\mathrm{O}_{2}\right][\mathrm{M}]$ ) due to secondary removal of atomic fluorine by reaction with the primary product $\mathrm{FO}_{2}$.

(e) Photolysis of $\mathrm{WF}_{6}-\mathrm{H}_{2}-\mathrm{O}_{2}-\mathrm{He}$ mixtures at $\sim 200 \mathrm{~nm}$, with detection of $\mathrm{HF}$ by IR chemiluminescence. The relative efficiencies of $\mathrm{M}$ were reported to be $\mathrm{O}_{2}: \mathrm{Ar}=1.4: 1.0$.

(f) Laser photolysis of $\mathrm{F}_{2}-\mathrm{HCl}-\mathrm{Ar}$ mixtures in the presence of $\mathrm{O}_{2}$ at pressures of $100-150$ mbar. Vibrational chemiluminescence of HF monitored.

(g) Experiments were carried out in $\mathrm{Ar}-\mathrm{F}_{2}-\mathrm{O}_{2}$ mixtures with detection of $\mathrm{FO}_{2}$ by absorption at $220 \mathrm{~nm}$. The rate coefficient and the equilibrium constant were determined by varying the $\mathrm{O}_{2}$ concentration. A value of $\Delta H^{\circ}(298 \mathrm{~K})=-52.8 \mathrm{~kJ} \mathrm{~mol}^{-1}$ was derived. 
(h) Photolysis of $\mathrm{F}_{2}$ at $248 \mathrm{~nm}$ in the presence of $\mathrm{O}_{2}$ and bath gases. The reaction mechanism with 6 reactions was followed via the analysis of transient absorption signals at $215 \mathrm{~nm}$. The forward and backward rate coefficients of the reactions $\mathrm{F}+\mathrm{O}_{2}+\mathrm{M} \rightarrow \mathrm{FO}_{2}+\mathrm{M}$ and $\mathrm{F}+\mathrm{FO}_{2}+\mathrm{M} \rightarrow \mathrm{F}_{2} \mathrm{O}_{2}+\mathrm{M}$ were determined. A value of $\Delta H^{\circ}(298 \mathrm{~K})=-(56.4 \pm 1.7) \mathrm{kJ}$ mol ${ }^{-1}$ was derived.

(i) Experiments with $\mathrm{SF}_{6}-\mathrm{O}_{2}$ mixtures at $0.20-1.0$ bar total pressure with kinetic $\mathrm{UV}$ spectroscopic detection of $\mathrm{FO}_{2}$ radicals between 215 and $254 \mathrm{~nm}$. Falloff extrapolations were made with $F_{c}=0.6$.

(j) $\mathrm{FO}_{2}$ radicals were detected by $\mathrm{UV}$ absorption. Experiments were carried out at total pressures up to 1000 bar of the bath gases $\mathrm{He}, \mathrm{Ar}$, and $\mathrm{N}_{2}$. Measurements of the equilibrium constant lead to $\Delta H^{\circ}(0 \mathrm{~K})=-49.8 \mathrm{~kJ} \mathrm{~mol}^{-1}$. Falloff extrapolations were made with $F_{c}$ near 0.5 .

\section{Preferred Values}

$k_{0}=5.8 \times 10^{-33}(T / 300)^{-1.7}\left[\mathrm{~N}_{2}\right] \mathrm{cm}^{3}$ molecule $^{-1} \mathrm{~s}^{-1}$ over the temperature range $100-380 \mathrm{~K}$.

\section{Reliability}

$\Delta \log k_{0}= \pm 0.3$ at $298 \mathrm{~K}$.

$\Delta n= \pm 0.5$.

\section{Comments on Preferred Values}

Because of the large database from the study of Campuzano-Jost et al. (1995), their rate coefficients values are preferred and are in reasonable agreement with earlier work. Falloff curves were constructed with $F_{c}$ near 0.5 .

\section{High-pressure rate coefficients}

\section{Rate coefficient data}

\begin{tabular}{lllc}
\hline$k_{\infty} / \mathrm{cm}^{3}$ molecule $\mathrm{s}^{-1}$ & Temp./K & Reference & Technique/Comments \\
\hline Absolute Rate Coefficients & & & \\
$2.0 \times 10^{-12}$ & 295 & Ellermann et al., 1994 & PR (a) \\
$1.2 \times 10^{-10}$ & $100-373$ & Campuzano-Jost et al., 1995 & PLP (b) \\
\hline
\end{tabular}

\section{Comments}

(a) See comment (i) for $k_{0}$.

(b) See comment (j) for $k_{0}$.

\section{Preferred Values}

$k_{\infty}=1.2 \times 10^{-10} \mathrm{~cm}^{3}$ molecule ${ }^{-1} \mathrm{~s}^{-1}$, independent of temperature over the range 100-380 $\mathrm{K}$.

\section{Reliability}

$\Delta \log k_{\infty}= \pm 0.3$ over the temperature range $100-380 \mathrm{~K}$.

$\Delta n= \pm 1$. 


\section{Comments on Preferred Values}

Because of the large pressure range studied by Campuzano-Jost et al. (1995), a reliable falloff extrapolation towards $k_{\infty}$ was possible. The data of Campuzano-Jost et al. (1995) are therefore preferred together with values of $F_{c}$ near 0.5.

\section{Intermediate Falloff Range}

\section{Rate coefficient data}

\begin{tabular}{|c|c|c|c|c|c|}
\hline$k / \mathrm{cm}^{3}$ molecule ${ }^{-1} \mathrm{~s}^{-1}$ & P/Torr & $\mathrm{M}$ & Temp./K & Reference & Technique/Comments \\
\hline \multicolumn{6}{|l|}{ Absolute Rate Coefficients } \\
\hline $2.4 \times 10^{-13}$ & $600 \mathrm{mbar}$ & $\mathrm{SF}_{6}$ & 298 & Wallington and Nielsen, 1991 & PR (a) \\
\hline$(2.35 \pm 0.2) \times 10^{-13}$ & 600 mbar & $\mathrm{SF}_{6}$ & 298 & Wallington et al., 1992 & PR (b) \\
\hline
\end{tabular}

\section{Comments}

(a) Experiments were carried out in mixtures of $\mathrm{SF}_{6}$ and $\mathrm{O}_{2}(6.1-20 \mathrm{mbar}) . \mathrm{FO}_{2}$ radicals were monitored by $\mathrm{UV}$ absorption at $220 \mathrm{~nm}$.

(b) Experiments were carried out in mixtures of $\mathrm{SF}_{6}$ and $\mathrm{O}_{2}$ (2.5-15 mbar). $\mathrm{FO}_{2}$ radicals were monitored by UV absorption at $220 \mathrm{~nm}$. The results were analyzed together with those of Lyman and Holland (1988).

\section{References}

Arutyunov, V. S., Popov, L. S., and Chaikin, A. M.: Kinet. Catal., 17, 251, 1976.

Campuzano-Jost, P., Croce, A. E., Hippler, H., Siefke, M. and Troe, J.: J. Chem. Phys., 102, 5317, 1995.

Chebotarev, N. F.: Kinet. Catal., 20, 1141, 1979.

Chen, H.-L., Trainor, D. W., Center, R. E., and Fyfe, W. L.: J. Chem. Phys., 66, 5513, 1977.

Ellermann, T., Sehested, J., Nielsen, O. J., Pagsberg, P., and Wallington, T. J.: Chem. Phys. Lett., 218, 287, 1994.

Lyman, J. L. and Holland, R.: J. Phys. Chem., 92, 7232, 1988.

Pagsberg, P., Ratajczak, E., Sillesen, A., and Jodkowski, J. T.: Chem. Phys. Lett., 141, 88, 1987.

Shamonima, N. F. and Kotov, A. G.: Kinet. Catal., 20, 187, 1979.

Smith, I. W. M. and Wrigley, D. J.: Chem. Phys. Lett., 70, 481, 1980.

Smith, I. W. M. and Wrigley, D. J.: Chem. Phys., 63, 321, 1981.

Wallington, T. J. and Nielsen, O. J.: Int. J. Chem. Kinet., 23, 785, 1991.

Wallington, T. J., Maricq, M. M., Ellermann, T., and Nielsen, O. J.: J. Phys. Chem., 96, 982, 1992.

Zetzsch, C.: First European Symposium on Combustion, edited by: Weinberg, F. S., Academic press, London, p. 35 , 1973. 
III.A1.7

$$
\mathbf{F O}_{2}+\mathbf{M} \rightarrow \mathbf{F}+\mathbf{O}_{2}+\mathbf{M}
$$

$\Delta H^{\circ}=54.0 \mathrm{~kJ} \mathrm{~mol}^{-1}$

\section{Low-pressure rate coefficients}

\section{Rate coefficient data}

\begin{tabular}{llll}
\hline$k_{0} / \mathrm{s}^{-1}$ & Temp./K & Reference & Technique/Comments \\
\hline Absolute Rate Coefficients & & & \\
$1.8 \times 10^{-17}[\mathrm{Ar}]$ & 295 & Pagsberg et al., 1987 & PR (a) \\
$3.1 \times 10^{-11}[\mathrm{Ar}]$ & 312.5 & & \\
$2.8 \times 10^{-16}[\mathrm{Ar}]$ & 359 & & PLP (b) \\
$(2.5 \pm 1.0) \times 10^{-18}[\mathrm{He}]$ & 298 & Lyman and Holland, 1988 & PLP (c) \\
$1.0 \times 10^{-5} T^{-1.25} \exp (-5990 / T)\left[\mathrm{N}_{2}\right]$ & $315-420$ & Campuzano-Jost et al., 1995 & \\
$1.5 \times 10^{-17}\left[\mathrm{~N}_{2}\right]$ & 298 & & \\
\hline
\end{tabular}

\section{Comments}

(a) Experiments were carried out in $\mathrm{Ar}-\mathrm{F}_{2}-\mathrm{O}_{2}$ mixtures with detection of $\mathrm{FO}_{2}$ by absorption at $220 \mathrm{~nm}$. The rate of approach to equilibrium was monitored and the equilibrium constant measured. A value of $\Delta H^{\circ}(298 \mathrm{~K})=52.8 \mathrm{~kJ} \mathrm{~mol}^{-1}$ was derived by a third-law analysis.

(b) Photolysis of $F_{2}$ at $248 \mathrm{~nm}$ in the presence of $\mathrm{O}_{2}$ and bath gases. Transient absorptions at $215 \mathrm{~nm}$ were monitored and the approach to equilibrium was analyzed. A value of $\Delta H^{\circ}(298 \mathrm{~K})=56.4 \mathrm{~kJ} \mathrm{~mol}^{-1}$ was derived.

(c) The kinetics were followed by monitoring the $\mathrm{FO}_{2}$ radical by UV absorption. Experiments were carried out between $100 \mathrm{~K}$ and $375 \mathrm{~K}$ at total pressures between $1 \mathrm{bar}$ and $1000 \mathrm{bar}$, and in the bath gases $\mathrm{He}, \mathrm{Ar}$, and $\mathrm{N}_{2}$. Measurements of the equilibrium constant lead to $\Delta H^{\circ}(0 \mathrm{~K})=49.8 \mathrm{~kJ} \mathrm{~mol}^{-1}$. Falloff extrapolations were carried out with a value of $F_{c}$ near 0.5. The expression for $k_{0}$ was derived from the recombination rate coefficients of the reverse reaction and the equilibrium constants.

\section{Preferred Values}

$k_{0}=1.5 \times 10^{-17}\left[\mathrm{~N}_{2}\right] \mathrm{s}^{-1}$ at $298 \mathrm{~K}$.

$k_{0}=8.4 \times 10^{-9}(T / 300)^{-1.25} \exp (-5990 / T)\left[\mathrm{N}_{2}\right] \mathrm{s}^{-1}$ over the temperature range $310-420 \mathrm{~K}$.

\section{Reliability}

$\Delta \log k_{0}= \pm 0.3$ at $298 \mathrm{~K}$.

$\Delta(E / R)= \pm 500 \mathrm{~K}$.

\section{Comments on Preferred Values}

The results of Campuzano-Jost et al. (1995) are in reasonable agreement with those of Pagsberg et al. (1987), but differ at $298 \mathrm{~K}$ by a factor of 6 with the data from Lyman and Holland (1988). The preferred values are based on the data of Campuzano-Jost et al. (1995). 


\section{High-pressure rate coefficients}

\section{Rate coefficient data}

\begin{tabular}{lclc}
\hline$k_{\infty} / \mathrm{s}^{-1}$ & Temp./K & Reference & Technique/Comments \\
\hline $\begin{array}{l}\text { Absolute Rate Coefficients } \\
1.3 \times 10^{13} T^{0.45} \exp (-5990 / T)\end{array}$ & $315-420$ & Campuzano-Jost et al., 1995 & PLP (a) \\
\hline
\end{tabular}

\section{Comments}

(a) See comment (c) for $k_{0}$.

\section{Preferred Values}

$k_{\infty}=3.1 \times 10^{5} \mathrm{~s}^{-1}$ at $298 \mathrm{~K}$.

$k_{\infty}=1.7 \times 10^{14}(T / 300)^{0.45} \exp (-5990 / T) \mathrm{s}^{-1}$ over the temperature range $310-420 \mathrm{~K}$.

Reliability

$\Delta \log k_{\infty}= \pm 0.3$ at $298 \mathrm{~K}$.

$\Delta(E / R)= \pm 500 \mathrm{~K}$.

Comments on Preferred Values

Because of the large pressure range studied by Campuzano-Jost et al. (1995), a reliable falloff extrapolation towards $k_{\infty}$ was possible. The data of Campuzano-Jost et al. (1995) are therefore preferred, together with $F_{c}$ values near 0.5.

\section{References}

Campuzano-Jost, P., Croce, A. E., Hippler, H., Siefke, M., and Troe, J.: J. Chem. Phys., 102, 5317, 1995.

Lyman, J. L. and Holland, R.: J. Phys. Chem., 92, 7232, 1988.

Pagsberg, P., Ratajczak, E., Sillesen, A., and Jodkowski, J. T.: Chem. Phys. Lett., 141, 88, 1987. 
III.A1.8

$$
\mathbf{F}+\mathbf{O}_{3} \rightarrow \mathbf{F O}+\mathbf{O}_{2}
$$

$\Delta H^{\circ}=-113 \mathrm{~kJ} \mathrm{~mol}^{-1}$

\section{Rate coefficient data}

\begin{tabular}{lllc}
\hline$k / \mathrm{cm}^{3}$ molecule ${ }^{-1} \mathrm{~s}^{-1}$ & Temp./K & Reference & Technique/Comments \\
\hline Absolute Rate Coefficients & & & \\
$2.8 \times 10^{-11} \exp [-(226 \pm 200) / T]$ & $253-365$ & Wagner et al., 1972 & DF-MS (a) \\
$1.3 \times 10^{-11}$ & 298 & & \\
$(6.2 \pm 0.3) \times 10^{-12}$ & 298 & Bedzhanyan et al., 1993 & DF-LMR (b) \\
\hline
\end{tabular}

\section{Comments}

(a) MS detection of $\mathrm{O}_{3}$ decay in the presence of an excess of $\mathrm{F}$ atoms. The temporal profiles of $\mathrm{F}, \mathrm{FO}$ and $\mathrm{O}_{3}$ were monitored by MS.

(b) Discharge flow system with excess of $\mathrm{O}_{3}$ over $\mathrm{F}$ atoms. Rate of formation of FO radicals was monitored by LMR.

\section{Preferred Values}

$k=1.0 \times 10^{-11} \mathrm{~cm}^{3}$ molecule $\mathrm{e}^{-1} \mathrm{~s}^{-1}$ at $298 \mathrm{~K}$.

$k=2.2 \times 10^{-11} \exp (-230 / T) \mathrm{cm}^{3}$ molecule ${ }^{-1} \mathrm{~s}^{-1}$ over the temperature range $250-370 \mathrm{~K}$.

\section{Reliability}

$\Delta \log k= \pm 0.25$ at $298 \mathrm{~K}$.

$\Delta(E / R)= \pm 200 \mathrm{~K}$.

\section{Comments on Preferred Values}

The preferred room temperature value is the average of the $298 \mathrm{~K}$ values from the two studies of Wagner et al. (1972) and Bedzhanyan et al. (1993). The temperature dependence is taken from Wagner et al. (1972) and the $A$-factor is fitted to the preferred $298 \mathrm{~K}$ value. The preferred value at room temperature is supported by values of $k$ derived indirectly in studies of the reactions of $\mathrm{CF}_{3} \mathrm{O}$ and $\mathrm{CF}_{3} \mathrm{O}_{2}$ radicals with $\mathrm{O}_{3}$ by Nielsen and Sehested (1993) and Maricq and Szente (1993).

\section{References}

Bedzhanyan, Yu. R., Markin, E. M., and Gershenzon, Y. M.: Kinet. Catal., 33, 594, 1993; original pages 744-752, 1992.

Maricq, M. M. and Szente, J. J.: Chem. Phys. Lett., 213, 449, 1993.

Nielsen, O. J. and Sehested, J.: Chem. Phys. Lett., 213, 433, 1993.

Wagner, H. G., Zetzsch, C., and Warnatz, J. Ber. Bunsenges. Phys. Chem., 76, 526, 1972. 
III.A1.9

$$
\mathrm{F}+\mathrm{HONO}_{2} \rightarrow \mathrm{HF}+\mathrm{NO}_{3}
$$

$\Delta H^{\circ}=-143.9 \mathrm{~kJ} \mathrm{~mol}^{-1}$

\section{Rate coefficient data}

\begin{tabular}{lllc}
\hline$k / \mathrm{cm}^{3}$ molecule & \\
\hline Absolute Rate Coefficients & Temp./K & Reference & Technique/Comments \\
$(2.7 \pm 0.5) \times 10^{-11}$ & & & \\
$(2.1 \pm 1.0) \times 10^{-11}$ & 298 & Mellouki et al., 1987 & DF-EPR \\
$6.0 \times 10^{-12} \exp [(400 \pm 120) / T]$ & 298 & Rahman et al., 1988 & DF-MS \\
$(2.3 \pm 0.3) \times 10^{-11}$ & 298 & & PLP-A (a) \\
$(2.2 \pm 0.2) \times 10^{-11}$ & 298 & Becker et al., 1998 & \\
$(2.3 \pm 0.2) \times 10^{-11}$ & 298 & Becker et al., 1991 & DF-MS \\
\hline
\end{tabular}

\section{Comments}

(a) Pulsed laser photolysis of $\mathrm{F}_{2}-\mathrm{HONO}_{2}-\mathrm{He}$ mixtures at $351 \mathrm{~nm}$, with detection of $\mathrm{NO}_{3}$ radicals by long-path laser absorption at $662 \mathrm{~nm}$. At higher temperatures $(335-373 \mathrm{~K})$ the rate coefficient was observed to be independent of temperature with a value of $(2.0 \pm 0.3) \times 10^{-11} \mathrm{~cm}^{3}$ molecule $\mathrm{s}^{-1}$.

\section{Preferred Values}

$k=2.3 \times 10^{-11} \mathrm{~cm}^{3}$ molecule $\mathrm{e}^{-1} \mathrm{~s}^{-1}$ at $298 \mathrm{~K}$.

$k=6.0 \times 10^{-12} \exp (400 / T) \mathrm{cm}^{3}$ molecule $\mathrm{e}^{-1} \mathrm{~s}^{-1}$ over the temperature range $260-320 \mathrm{~K}$.

\section{Reliability}

$\Delta \log k= \pm 0.1$ at $298 \mathrm{~K}$.

$\Delta(E / R)= \pm 200 \mathrm{~K}$.

\section{Comments on Preferred Values}

The recommendation is based on the results of the temperature-dependent study of Wine et al. (1988) and the room temperature results of Mellouki et al. (1987), Rahman et al. (1988) and Becker et al. (1991). The values at room temperature are in good agreement. The study of Wine et al. (1988) was over the temperature range 260-373 K; below $320 \mathrm{~K}$ the authors fitted their data with the Arrhenius expression recommended here, whereas at higher temperatures a temperature-independent value was found, suggesting the occurrence of different mechanisms in the two temperature regimes.

\section{References}

Becker, E., Benter, T., Kampf, R., Schindler, R. N., and Wille, U.: Ber. Bunsenges. Phys. Chem., 95, 1168, 1991. Mellouki, A., Le Bras, G., and Poulet, G.: J. Phys. Chem., 91, 5760, 1987.

Rahman, M. M., Becker, E., Benter, T., and Schindler, R. N.: Ber. Bunsenges. Phys. Chem., 92, 91, 1988.

Wine, P. H., Wells, J. R., and Nicovich, J. M.: J. Phys. Chem., 92, 2223, 1988. 
III.A1.10

$$
\begin{aligned}
\mathbf{F O}+\mathrm{O}_{3} & \rightarrow \mathbf{F}+2 \mathrm{O}_{2} \\
& \rightarrow \mathbf{F O}_{2}+\mathbf{O}_{2}
\end{aligned}
$$

$\Delta H^{\circ}(1)=-172 \mathrm{~kJ} \mathrm{~mol}^{-1}$

$\Delta H^{\circ}(2)=-226 \mathrm{~kJ} \mathrm{~mol}^{-1}$

\begin{tabular}{|c|c|c|c|}
\hline$k / \mathrm{cm}^{3}$ molecule $^{-1} \mathrm{~s}^{-1}$ & Temp./K & Reference & Technique/Comments \\
\hline \multicolumn{4}{|c|}{ Absolute Rate Coefficients } \\
\hline$<1.2 \times 10^{-12}$ & 298 & Sehested et al., 1994 & PR-UVA (a) \\
\hline$<1 \times 10^{-14}$ & 298 & Li et al., 1995 & DF-MS (b) \\
\hline
\end{tabular}

Rate coefficient data $\left(k=k_{1}+k_{2}\right)$

\section{Comments}

(a) Pulse radiolysis-UV absorption spectroscopy technique at 18 bar total pressure. $\mathrm{FO}_{2}$ radicals and $\mathrm{O}_{3}$ were monitored by absorption at $220 \mathrm{~nm}$ and $288 \mathrm{~nm}$, respectively.

(b) Discharge flow-mass spectrometric technique at $1 \mathrm{mbar}$ total pressure. FO radicals were produced in the reaction of $\mathrm{F}$ atoms with excess $\mathrm{O}_{3}$. No appreciable decay of $\mathrm{FO}$ radicals was observed, only a small increase in $\mathrm{FO}_{2}$ radical concentrations was detected, and the concentration of $\mathrm{O}_{3}$ was unchanged, allowing the uppper limit to $k$ tabulated above to be derived.

\section{Preferred Values}

$k<1 \times 10^{-14} \mathrm{~cm}^{3}$ molecule $\mathrm{e}^{-1} \mathrm{~s}^{-1}$ at $298 \mathrm{~K}$.

\section{Comments on Preferred Values}

The recommended upper limit to the rate coefficient is based on the results of Li et al. (1995). A much higher upper limit was reported by Sehested et al. (1994). A much lower upper limit was derived by Colussi and Grela (1994) from a re-analysis of data that had been reported by Staricco et al. (1962) for ozone destruction quantum yields in the $\mathrm{F}_{2}$-photosensitized decomposition of ozone. Results of the more direct study of Li et al. (1995) are preferred over the much earlier results reported by Staricco et al. (1962).

\section{References}

Colussi, A. J. and Grela, M. A.: Chem. Phys. Lett., 229, 134, 1994.

Li, Z., Friedl, R. R., and Sander, S. P.: J. Phys. Chem., 99, 13445, 1995.

Sehested, J., Sehested, K., Nielsen, O. J., and Wallington, T. J.: J. Phys. Chem., 98, 6731, 1994.

Staricco, E. H., Sicre, J. E., and Schumacher, H. J.: Z. Physik. Chem. N.F., 31, 385, 1962. 


\section{III.A1.11}

$$
\mathrm{FO}+\mathrm{NO} \rightarrow \mathrm{F}+\mathrm{NO}_{2}
$$

$\Delta H^{\circ}=-87 \mathrm{~kJ} \mathrm{~mol}^{-1}$

\section{Rate coefficient data}

\begin{tabular}{lllc}
\hline$k / \mathrm{cm}^{3}$ molecule ${ }^{-1} \mathrm{~s}^{-1}$ & Temp./K & Reference & Technique/Comments \\
\hline Absolute Rate Coefficients & & & \\
$(2.6 \pm 0.5) \times 10^{-11}$ & 298 & Ray and Watson, 1981 & DF-MS \\
$1.86 \times 10^{-11}(T / 300)^{-(0.66 \pm 0.13)}$ & $300-845$ & Bedzhanyan et al., 1993 & DF-LMR \\
$(1.9 \pm 0.4) \times 10^{-11}$ & 300 & & \\
\hline
\end{tabular}

\section{Preferred Values}

$k=2.2 \times 10^{-11} \mathrm{~cm}^{3}$ molecule $\mathrm{e}^{-1} \mathrm{~s}^{-1}$ at $298 \mathrm{~K}$.

$k=8.2 \times 10^{-12} \exp (300 / T) \mathrm{cm}^{3}$ molecule $\mathrm{e}^{-1} \mathrm{~s}^{-1}$ over the temperature range 290-850 K.

\section{Reliability}

$\Delta \log k= \pm 0.15$ at $298 \mathrm{~K}$.

$\Delta(E / R)= \pm 200 \mathrm{~K}$.

\section{Comments on Preferred Values}

The preferred room temperature value is the average of the room temperature values from the studies of Ray and Watson (1981) and Bedzhanyan et al. (1993). The temperature dependence is derived from a fit to the data of Bedzhanyan et al. (1993) and the $A$-factor is fitted to the preferred $298 \mathrm{~K}$ value. The temperature dependence is similar to those for the analogous $\mathrm{ClO}$ and $\mathrm{BrO}$ radical reactions.

\section{References}

Bedzhanyan, Y. R., Markin, E. M., and Gershenzon, Y. M.: Kinet. Catal., 34, 1, 1993; original pages 7-10, 1993. Ray, G. W. and Watson, R. T.: J. Phys. Chem., 85, 2955, 1981. 
III.A1.12

$$
\begin{aligned}
\mathbf{F O}+\mathbf{F O} & \rightarrow 2 \mathbf{F}+\mathbf{O}_{2} \\
& \rightarrow \mathbf{F O}_{2}+\mathbf{F} \\
& \rightarrow \mathbf{F}_{2}+\mathbf{O}_{2}
\end{aligned}
$$

$\Delta H^{\circ}(1)=-59 \mathrm{~kJ} \mathrm{~mol}^{-1}$

$\Delta H^{\circ}(2)=-113 \mathrm{~kJ} \mathrm{~mol}^{-1}$

$\Delta H^{\circ}(3)=-218 \mathrm{~kJ} \mathrm{~mol}^{-1}$

Rate coefficient data $\left(k=k_{1}+k_{2}+k_{3}\right)$

\begin{tabular}{lllc}
\hline$k / \mathrm{cm}^{3}$ molecule $\mathrm{s}^{-1}$ & Temp./K & Reference & Technique/Comments \\
\hline Absolute Rate Coefficients & & & \\
$(8.5 \pm 2.8) \times 10^{-12}$ & 298 & Clyne and Watson, 1974 & DF-MS \\
$1.0 \times 10^{-11}(T / 300)^{(0.85 \pm 0.5)}$ & $300-435$ & Bedzhanyan et al., 1993 & DF-LMR \\
\hline
\end{tabular}

\section{Preferred Values}

$k=1.0 \times 10^{-11} \mathrm{~cm}^{3}$ molecule $\mathrm{e}^{-1} \mathrm{~s}^{-1}$, independent of temperature over the range $290-440 \mathrm{~K}$.

\section{Reliability}

$\Delta \log k= \pm 0.2$ at $298 \mathrm{~K}$.

$\Delta(E / R)= \pm 250 \mathrm{~K}$.

\section{Comments on Preferred Values}

The recommended value is based on the results of Clyne and Watson (1974) and Bedzhanyan et al. (1993). In a less direct study, Wagner et al. (1972) reported a factor of 3 higher value. Although Bedzhanyan et al. (1993) reported a weak temperature dependence, a temperature-independent rate coefficient fits their data equally well and is recommended in this evaluation. The study of Bedzhanyan et al. (1993) showed that the predominant reaction channel is that to produce $2 \mathrm{~F}+\mathrm{O}_{2}$.

\section{References}

Bedzhanyan, Y. R., Markin, E. M., and Gershenzon, Y. M.: Kinet. Catal., 33, 601, 1993; original pages 753-759 , 1992.

Clyne, M. A. A. and Watson, R. T.: J. Chem. Soc. Faraday Trans., 1, 70, 1109, 1974.

Wagner, H. G., Zetzsch, C., and Warnatz, J.: Ber. Bunsenges. Phys. Chem., 76, 526, 1972. 
III.A1.13

$$
\mathrm{FO}_{2}+\mathbf{O}_{3} \rightarrow \text { products }
$$

\section{Rate coefficient data}

\begin{tabular}{|c|c|c|c|}
\hline$k / \mathrm{cm}^{3}$ molecule $^{-1} \mathrm{~s}^{-1}$ & Temp./K & Reference & Technique/Comments \\
\hline \multicolumn{4}{|l|}{ Absolute Rate Coefficients } \\
\hline$<3.4 \times 10^{-16}$ & 298 & Sehested et al., 1994 & PR-UVA (a) \\
\hline$<3 \times 10^{-15}$ & 298 & Li et al., 1995 & DF-MS (b) \\
\hline
\end{tabular}

\section{Comments}

(a) Pulse radiolysis of $\mathrm{O}_{3}-\mathrm{O}_{2}-\mathrm{SF}_{6}$ mixtures in a high pressure cell at 18 bar of $\mathrm{SF}_{6}$. The decay of $\mathrm{FO}_{2}$ radicals was monitored by absorption at $220 \mathrm{~nm}$.

(b) First-order decay rate of $\mathrm{FO}_{2}$ in the presence of excess $\mathrm{O}_{3}$ at 1.3 mbar (1 Torr) total pressure was monitored by mass spectrometry.

\section{Preferred Values}

$k<4 \times 10^{-16} \mathrm{~cm}^{3}$ molecule $\mathrm{e}^{-1} \mathrm{~s}^{-1}$ at $298 \mathrm{~K}$.

\section{Comments on Preferred Values}

The preferred room temperature upper limit to the rate coefficient is based on results of the pulse radiolysis-UV absorption study of Sehested et al. (1994). A higher upper limit was reported by Li et al. (1995).

\section{References}

Li, Z., Friedl, R. R., and Sander, S. P.: J. Phys. Chem., 99, 13445, 1995.

Sehested, J., Sehested, K., Nielsen, O. J., and Wallington, T. J.: J. Phys. Chem., 98, 6731, 1994. 


\section{III.A1.14}

$$
\mathrm{FO}_{2}+\mathrm{NO} \rightarrow \mathrm{FNO}+\mathrm{O}_{2}
$$

$\Delta H^{\circ}=-182 \mathrm{~kJ} \mathrm{~mol}^{-1}$

\section{Rate coefficient data}

\begin{tabular}{lllc}
\hline$k / \mathrm{cm}^{3}$ molecule ${ }^{-1} \mathrm{~s}^{-1}$ & Temp./K & Reference & Technique/Comments \\
\hline $\begin{array}{l}\text { Absolute Rate Coefficients } \\
(1.5 \pm 0.5) \times 10^{-12}\end{array}$ & 298 & Sehested et al., 1994 & PR-UVA (a) \\
$7.5 \times 10^{-12} \exp [-(688 \pm 377) / T]$ & $190-298$ & Li et al., 1995 & DF-MS (b) \\
$(8.5 \pm 1.3) \times 10^{-13}$ & 298 & & \\
\hline
\end{tabular}

\section{Comments}

(a) Pulse radiolysis of $\mathrm{NO}-\mathrm{O}_{2}-\mathrm{SF}_{6}$ mixtures at 1 bar $\mathrm{SF}_{6}$. The formation of $\mathrm{FNO}$ was monitored by absorption at $310.5 \mathrm{~nm}$. The yield of FNO was determined to be $100 \pm 14 \%$.

(b) First-order decay rates of $\mathrm{FO}_{2}$ in the presence of excess $\mathrm{NO}$ were monitored by mass spectrometry at a total pressure of 1.3 mbar He. The yield of FNO was found to be nearly $100 \%$.

\section{Preferred Values}

$k=7.5 \times 10^{-13} \mathrm{~cm}^{3}$ molecule $\mathrm{e}^{-1} \mathrm{~s}^{-1}$ at $298 \mathrm{~K}$.

$k=7.5 \times 10^{-12} \exp (-690 / T) \mathrm{cm}^{3}$ molecule ${ }^{-1} \mathrm{~s}^{-1}$ over the temperature range $190-300 \mathrm{~K}$.

\section{Reliability}

$\Delta \log k= \pm 0.3$ at $298 \mathrm{~K}$.

$\Delta(E / R)= \pm 400 \mathrm{~K}$.

\section{Comments on Preferred Values}

The preferred values are based on results of the temperature-dependent study of Li et al. (1995). The higher room temperature rate coefficient of Sehested et al. (1994) is encompassed within the assigned uncertainty limits. The low barrier to form FNO may indicate that the reaction proceeds via formation of a short lived FOONO complex (Dibble and Francisco, 1997).

\section{References}

Dibble, T. S. and Francisco, J. S.: J. Am Chem. Soc., 119, 2894, 1997.

Li, Z., Friedl, R. R., and Sander, S. P.: J. Phys. Chem., 99, 13445, 1995.

Sehested, J., Sehested, K., Nielsen, O. J., and Wallington, T. J.: J. Phys. Chem., 98, 6731, 1994. 
III.A1.15

$$
\mathrm{FO}_{2}+\mathrm{NO}_{2} \rightarrow \text { products }
$$

\section{Rate coefficient data}

\begin{tabular}{lllc}
\hline$k / \mathrm{cm}^{3}$ molecule ${ }^{-1} \mathrm{~s}^{-1}$ & Temp./K & Reference & Technique/Comments \\
\hline Absolute Rate Coefficients & & & \\
$(1.05 \pm 0.15) \times 10^{-13}$ & 298 & Sehested et al., 1994 & PR-UVA (a) \\
$3.8 \times 10^{-11} \exp [-(2042 \pm 456) / T]$ & $260-315$ & Li et al., 1995 & DF-MS (b) \\
$(4.2 \pm 0.8) \times 10^{-14}$ & 298 & & \\
\hline
\end{tabular}

\section{Comments}

(a) Pulse radiolysis of $\mathrm{NO}_{2}-\mathrm{O}_{2}-\mathrm{SF}_{6}$ mixtures. The decay of $\mathrm{NO}_{2}$ was monitored by absorption at $400 \mathrm{~nm}$, and that of $\mathrm{FO}_{2}$ radicals at $220 \mathrm{~nm}$. The rate coefficient showed no dependence on pressure over the pressure range 1-18 bar of $\mathrm{SF}_{6}$.

(b) First-order decay rate of $\mathrm{FO}_{2}$ radicals in the presence of excess $\mathrm{NO}_{2}$ was monitored by mass spectrometry at a total presssure of 1.3 mbar $\mathrm{He}$.

\section{Preferred Values}

$k=4.0 \times 10^{-14} \mathrm{~cm}^{3}$ molecule $\mathrm{s}^{-1} \mathrm{~s}^{-1}$ at $298 \mathrm{~K}$.

$k=3.8 \times 10^{-11} \exp (-2040 / T) \mathrm{cm}^{3}$ molecule ${ }^{-1} \mathrm{~s}^{-1}$ over the temperature range $260-320 \mathrm{~K}$.

\section{Reliability}

$\Delta \log k= \pm 0.3$ at $298 \mathrm{~K}$.

$\Delta(E / R)= \pm 500 \mathrm{~K}$.

\section{Comments on Preferred Values}

The preferred values are based on results of the temperature-dependent study of Li et al. (1995). The higher room temperature result of Sehested et al. (1994) might be attributable to a small NO impurity in the $\mathrm{NO}_{2}$ sample used. The observed positive temperature dependence suggests that reaction occurs primarily by a simple bimolecular mechanism yielding $\mathrm{FNO}_{2}+\mathrm{O}_{2}$.

\section{References}

Li, Z., Friedl, R. R., and Sander, S. P.: J. Phys. Chem., 99, 13445, 1995.

Sehested, J., Sehested, K., Nielsen, O. J., and Wallington, T. J.: J. Phys. Chem., 98, 6731, 1994. 


\section{Appendix 2: $\mathrm{ClO}_{\mathrm{x}}$ Reactions}

III.A2.16

$$
\mathrm{O}+\mathrm{HOCl} \rightarrow \mathrm{HO}+\mathrm{ClO}
$$

$\Delta H^{\circ}=-32 \mathrm{~kJ} \mathrm{~mol}^{-1}$

\section{Rate coefficient data}

\begin{tabular}{|c|c|c|c|}
\hline$k / \mathrm{cm}^{3}$ molecule $^{-1} \mathrm{~s}^{-1}$ & Temp./K & Reference & Technique/Comments \\
\hline $\begin{array}{l}\text { Absolute Rate Coefficients } \\
(1.3 \pm 0.2) \times 10^{-13}\end{array}$ & 298 & Vogt and Schindler, 1992 & DF-MS \\
\hline$(1.7 \pm 0.3) \times 10^{-13}$ & $213-298$ & Schindler et al., 1996 & DF-MS \\
\hline
\end{tabular}

\section{Preferred Values}

$k=1.7 \times 10^{-13} \mathrm{~cm}^{3}$ molecule $\mathrm{e}^{-1} \mathrm{~s}^{-1}$ at $298 \mathrm{~K}$, independent of temperature over the range $210-300 \mathrm{~K}$.

\section{Reliability}

$\Delta \log k= \pm 0.5$ at $298 \mathrm{~K}$.

$\Delta(E / R)= \pm 300 \mathrm{~K}$.

\section{Comments on Preferred Values}

The preferred values are based on the results of the study of Schindler et al. (1996) in which $k$ was found to be independent of temperature over the range $213-298 \mathrm{~K}$. These results are preferred over those of the previous study of Vogt and Schindler (1992) from the same laboratory, which was only at room temperature. In the most recent study (Schindler et al., 1996), product analysis using ${ }^{18} \mathrm{O}$ atoms and ab-initio model calculations indicate that $\mathrm{Cl}$ atom abstraction is the predominant primary reaction channel.

\section{References}

Schindler, R. N., Dethlefs, J., and Schmidt, M.: Ber. Bunsenges. Phys. Chem., 100, 1242, 1996.

Vogt, R. and Schindler, R. N.: Geophys. Res. Lett., 19, 1935, 1992. 
III.A2.17

$$
\mathrm{O}+\mathrm{ClO} \rightarrow \mathrm{Cl}+\mathrm{O}_{2}
$$

$\Delta H^{\circ}=-229.5 \mathrm{~kJ} \mathrm{~mol}^{-1}$

\section{Rate coefficient data}

\begin{tabular}{lllc}
\hline$k / \mathrm{cm}^{3}$ molecule $\mathrm{s}^{-1}$ & Temp./K & Reference & Technique/Comments \\
\hline Absolute Rate Coefficients & & & \\
$(5.3 \pm 0.8) \times 10^{-11}$ & 298 & Bemand et al., 1973 & DF-RF \\
$(5.7 \pm 2.3) \times 10^{-11}$ & 298 & Bemand et al., 1973 & DF-MS \\
$1.07 \times 10^{-10} \exp [-(224 \pm 76) / T]$ & $220-426$ & Clyne and Nip, 1976 & DF-RF \\
$(5.2 \pm 1.6) \times 10^{-11}$ & 298 & & \\
$5.2 \times 10^{-11} \exp [-(96 \pm 20) / T]$ & $236-422$ & Leu, 1984 & DF-RF \\
$(3.6 \pm 0.7) \times 10^{-11}$ & 296 & & \\
$(4.2 \pm 0.8) \times 10^{-11}$ & $241-298$ & Margitan, 1984 & PLP-RF \\
$(3.5 \pm 0.5) \times 10^{-11}$ & $252-347$ & Schwab et al., 1984 & DF-RF/RA/LMR (a) \\
$1.55 \times 10^{-11} \exp [(263 \pm 60) / T]$ & $231-367$ & Nicovich et al., 1988 & PLP-RF (b) \\
$(3.8 \pm 0.6) \times 10^{-11}$ & 298 & & \\
$3.0 \times 10^{-11} \exp [(75 \pm 40) / T]$ & $227-362$ & Goldfarb et al., 2001 & PLP-RF (c) \\
$(3.9 \pm 0.6) \times 10^{-11}$ & 298 & & \\
Relative Rate Coefficients & & & \\
$4.5 \times 10^{-11} \exp [-(14 \pm 120) / T]$ & $218-295$ & Zahniser and Kaufman, 1977 & RR (d) \\
$(4.3 \pm 0.7) \times 10^{-11}$ & 295 & & \\
$2.6 \times 10^{-11} \exp [(97 \pm 64) / T]$ & $220-387$ & Ongstad and Birks, 1986 & RR (e) \\
$(3.8 \pm 0.6) \times 10^{-11}$ & 298 & & \\
\hline
\end{tabular}

\section{Comments}

(a) Discharge flow system with LMR detection of $\mathrm{ClO}$ radicals and resonance fluorescence detection of $\mathrm{O}\left({ }^{3} \mathrm{P}\right)$ and $\mathrm{Cl}$ atoms. Pseudo-first order decay of $\mathrm{O}\left({ }^{3} \mathrm{P}\right)$ atoms in the presence of excess $\mathrm{ClO}$ and decay of $\mathrm{ClO}$ in the presence of excess $\mathrm{O}\left({ }^{3} \mathrm{P}\right)$ gave good agreement for the rate coefficent $k$. There was no discernable temperature dependence over the range studied. The total pressure was in the range $1.1-2.7$ mbar.

(b) Dual pulsed laser photolysis system with resonance fluorescence detection in a slow flow reactor. $\mathrm{ClO}$ radicals were produced by reaction of excess $\mathrm{Cl}$, produced by $351 \mathrm{~nm}$ excimer laser photolysis of $\mathrm{Cl}_{2}$, with known concentrations of $\mathrm{O}_{3} . \mathrm{O}\left({ }^{3} \mathrm{P}\right)$ atoms were produced by $266 \mathrm{~nm}$ laser photolysis of $\mathrm{ClO}$ after appropriate delay time, and were monitored by resonance fluorescence. The measured $\mathrm{O}\left({ }^{3} \mathrm{P}\right)$ atom decay rate was corrected for losses due to reaction with $\mathrm{Cl}_{2}$ and other routes. The total pressure was in the range $33 \mathrm{mbar}$ to $667 \mathrm{mbar}$, and no effect of pressure on the rate coefficient $k$ was observed.

(c) Discharge flow tube coupled to a pulsed laser photolysis-resonance fluorescence apparatus. O atoms were produced by $\mathrm{PLP}$ of $\mathrm{ClO}$ at $308 \mathrm{~nm}$, and their pseudo-first-order decay in excess $\mathrm{ClO}$ was monitored by $\mathrm{RF}$. $\mathrm{ClO}$ radicals were produced by reaction of excess $\mathrm{Cl}$ atoms with $\mathrm{O}_{3}$ or $\mathrm{Cl}_{2} \mathrm{O}$. Cl atoms were produced in the microwave discharge of a $\mathrm{Cl}_{2}-\mathrm{He}$ mixture. The total pressure was in the range 7-29 mbar. In this paper the authors, on the basis of a careful analysis of their data and the existing literature data on this reaction (see Comments on Preferred Values), proposed a temperature-dependent expression to be used for atmospheric calculations.

(d) The rate coefficient $k$ was measured relative to $k\left(\mathrm{Cl}+\mathrm{O}_{3}\right)$ using the discharge flow technique in conjunction with resonance fluorescence monitoring of $\mathrm{Cl}$ atom concentrations and resonance absorption monitoring of $\mathrm{O}\left({ }^{3} \mathrm{P}\right)$ atom concentrations in a system where $\mathrm{O}\left({ }^{3} \mathrm{P}\right), \mathrm{Cl}, \mathrm{ClO}$ and $\mathrm{O}_{3}$ had reached a steady-state condition. The tabulated Arrhenius expression is obtained by combining the experimentally determined ratio of $k(\mathrm{O}+\mathrm{ClO}) / k\left(\mathrm{Cl}+\mathrm{O}_{3}\right)=1.55 \exp [(246 \pm 30) / T]$ with the rate coefficient of $k\left(\mathrm{Cl}+\mathrm{O}_{3}\right)=2.9 \times 10^{-11} \exp (-260 / T) \mathrm{cm}^{3}$ molecule $^{-1} \mathrm{~s}^{-1}$ (IUPAC, 2003). 
(e) Discharge flow system with detection of $\mathrm{O}\left({ }^{3} \mathrm{P}\right)$ atoms by $\mathrm{O}+\mathrm{NO}+\mathrm{M}$ chemiluminescence in the presence of excess $\mathrm{ClO}$. The $\mathrm{ClO}$ radical concentrations were determined indirectly by in situ conversion to $\mathrm{NO}_{2}$ by addition of $\mathrm{NO}$ and $k$ measured relative to $k\left(\mathrm{O}+\mathrm{NO}_{2} \rightarrow \mathrm{NO}+\mathrm{O}_{2}\right)=6.58 \times 10^{-12} \exp [-(142 \pm 23) / T] \mathrm{cm}^{3}$ molecule ${ }^{-1} \mathrm{~s}^{-1}$, determined concurrently in the same system. The total pressure was 3.1 mbar. No effect of $\mathrm{O}_{2}$ was observed at $230 \mathrm{~K}$.

\section{Preferred Values}

$k=3.7 \times 10^{-11} \mathrm{~cm}^{3}$ molecule ${ }^{-1} \mathrm{~s}^{-1}$ at $298 \mathrm{~K}$.

$k=2.5 \times 10^{-11} \exp (110 / T) \mathrm{cm}^{3}$ molecule $\mathrm{e}^{-1} \mathrm{~s}^{-1}$ over the temperature range $220-390 \mathrm{~K}$.

\section{Reliability}

$\Delta \log k= \pm 0.06$ at $298 \mathrm{~K}$.

$\Delta(E / R)= \pm 50 \mathrm{~K}$.

\section{Comments on Preferred Values}

The preferred value accepts the recommendation of Goldfarb et al. (2001) based on a careful analysis of their data and data published in previous studies. The data used in the analysis were those published in Zahniser and Kaufman (1977), Margitan (1984), Schwab et al. (1984), Ongstad and Birks (1986), Nicovich et al. (1988) and Goldfarb et al. (2001). On the basis of newer information, the rate coefficients reported by Zahniser and Kaufman (1977), Margitan (1984) and Ongstad and Birks (1986) were adjusted (Goldfarb et al., 2001). Leu and Yung (1987) have shown that the yields of $\mathrm{O}_{2}\left({ }^{1} \Delta\right)$ and $\mathrm{O}_{2}\left({ }^{1} \Sigma\right)$ in the reaction are $<2 \times 10^{-2}$ and $(4.4 \pm 1.1) \times 10^{-4}$, respectively.

\section{References}

Bemand, P. P., Clyne, M. A. A., and Watson, R. T.: J. Chem. Soc. Faraday Trans., 1, 69, 1356, 1973.

Clyne, M. A. A. and Nip, W. S.: J. Chem. Soc. Faraday Trans., 1, 72, 2211, 1976.

Goldfarb, L., Burkholder, J. B., and Ravishankara, A. R.: J. Phys. Chem. A, 105, 5402, 2001.

IUPAC: http://www.iupac-kinetic.ch.cam.ac.uk/, 2003.

Leu, M.-T.: J. Phys. Chem., 88, 1394, 1984.

Leu, M.-T. and Yung, Y. L.: Geophys. Res. Lett., 14, 949, 1987.

Margitan, J. J.: J. Phys. Chem., 88, 3638, 1984.

Nicovich, J. M., Wine, P. H., and Ravishankara, A. R.: J. Chem. Phys., 89, 5670, 1988.

Ongstad, A. P. and Birks, J. W.: J. Chem. Phys., 85, 3359, 1986.

Schwab, J. J., Toohey, D. W., Brune, W. H., and Anderson, J. G.: J. Geophys. Res., 89, 9581, 1984.

Zahniser, M. S. and Kaufman, F.: J. Chem. Phys., 66, 3673, 1977. 
III.A2.18

$$
\mathrm{O}+\mathrm{OClO} \rightarrow \mathrm{O}_{2}+\mathrm{ClO}
$$

$\Delta H^{\circ}=-242.2 \mathrm{~kJ} \mathrm{~mol}^{-1}$

\section{Rate coefficient data}

\begin{tabular}{|c|c|c|c|}
\hline$k / \mathrm{cm}^{3}$ molecule $^{-1} \mathrm{~s}^{-1}$ & Temp./K & Reference & Technique/Comments \\
\hline $\begin{array}{l}\text { Absolute Rate Coefficients } \\
(5 \pm 2) \times 10^{-13}\end{array}$ & 298 & Bemand et al., 1973 & DF-RF/MS (a) \\
\hline$(1.6 \pm 0.4) \times 10^{-13}$ & 298 & Colussi, 1990 & PLP-RF (b) \\
\hline See Comment & $248-312$ & Colussi et al., 1992 & PLP-RF (c) \\
\hline $2.4 \times 10^{-12} \exp [-(960 \pm 120) / T]$ & $243-400$ & Gleason et al., 1994 & $\mathrm{DF}-\mathrm{RF}(\mathrm{d})$ \\
\hline$(1.0 \pm 0.3) \times 10^{-13}$ & 298 & & \\
\hline
\end{tabular}

\section{Comments}

(a) Discharge flow system. Two independent methods were used: $\mathrm{O}\left({ }^{3} \mathrm{P}\right)$ atom decay in excess $\mathrm{OClO}$ monitored by resonance fluorescence, and $\mathrm{OClO}$ decay in excess $\mathrm{O}\left({ }^{3} \mathrm{P}\right)$ determined by MS. There was only fair agreement between the two methods.

(b) Pulsed laser photolysis of $\mathrm{OClO}$ at $308 \mathrm{~nm}$, with the $\mathrm{O}\left({ }^{3} \mathrm{P}\right)$ atom decay being determined by resonance fluorescence. The results were extrapolated to zero laser pulse intensity. Measurements were made over the pressure range $13 \mathrm{mbar}$ to $1040 \mathrm{mbar}$ of Ar. The observed rate coefficients were pressure dependent, indicating the presence of a termolecular association reaction. The value reported for the bimolecular component was not directly measured but was derived from fitting a falloff curve to the experimental data over the entire pressure range.

(c) Pulsed laser photolysis of $\mathrm{OClO}$ at $308 \mathrm{~nm}$, with the $\mathrm{O}\left({ }^{3} \mathrm{P}\right)$ atom decay being determined by resonance fluorescence. The observed rate coefficients were pressure dependent, indicating the presence of a termolecular association reaction. A negative temperature dependence was observed for the bimolecular component, with the reported values of $k$ increasing from $1.5 \times 10^{-13} \mathrm{~cm}^{3}$ molecule $\mathrm{s}^{-1} \mathrm{~s}^{-1}$ at $312 \mathrm{~K}$ to $4.0 \times 10^{-13} \mathrm{~cm}^{3}$ molecule ${ }^{-1} \mathrm{~s}^{-1}$ at $248 \mathrm{~K}$. These values for the bimolecular component were not directly measured but were derived quantities which are consistent with falloff curves fitted to the experimental data over the pressure range $26 \mathrm{mbar}$ to $800 \mathrm{mbar}$ of Ar.

(d) Discharge flow system with resonance fluorescence detection of $\mathrm{O}\left({ }^{3} \mathrm{P}\right)$ atoms. The total pressure was $1 \mathrm{mbar}$ to $7 \mathrm{mbar}$. Measurements were made over the temperature range $200 \mathrm{~K}$ to $400 \mathrm{~K}$. The data for the temperature range $243 \mathrm{~K}$ to $400 \mathrm{~K}$ were fitted with the Arrhenius expression given in the table. Data at lower temperatures showed a negative temperature dependence.

\section{Preferred Values}

$k=1.0 \times 10^{-13} \mathrm{~cm}^{3}$ molecule ${ }^{-1} \mathrm{~s}^{-1}$ at $298 \mathrm{~K}$.

$k=2.4 \times 10^{-12} \exp (-960 / T) \mathrm{cm}^{3}$ molecule $\mathrm{s}^{-1}$ over the temperature range $240-400 \mathrm{~K}$.

\section{Reliability}

$\Delta \log k= \pm 0.3$ at $298 \mathrm{~K}$.

$\Delta(E / R)= \pm 300 \mathrm{~K}$.

\section{Comments on Preferred Values}

The preferred values are based on the results of the discharge flow-resonance fluorescence study of Gleason et al. (1994). Over the temperature range of the recommendation ( $240 \mathrm{~K}$ to $400 \mathrm{~K})$, the data of Gleason et al. (1994) were well fit by the Arrhenius expression given, but at lower temperatures down to $200 \mathrm{~K}$ there was an abrupt change to a negative temperature 
dependence (Gleason et al., 1994). It appears that the experiments of Bemand et al. (1973) were complicated by secondary chemistry. The experiments of Colussi (1990) and Colussi et al. (1992) over an extended pressure range demonstrate the importance of the termolecular reaction (see separate data sheet on $\mathrm{O}+\mathrm{OClO}+\mathrm{M}$ ). However, the extrapolated low pressure rate coefficients of Colussi (1990) and Colussi et al. (1992) show a negative temperature dependence over the range $248 \mathrm{~K}$ to $312 \mathrm{~K}$, in contrast to the data of Gleason et al. (1994). Mauldin et al. (1997) have studied the mechanism and products of this system at $260 \mathrm{~K}$ and a total pressure of $430 \mathrm{mbar}$ of $\mathrm{N}_{2}$. Under these conditions the value of the rate coefficient for the reaction $\mathrm{O}+\mathrm{OClO}$ $\rightarrow$ products was reported to be $1.9 \times 10^{-12} \mathrm{~cm}^{3}$ molecule ${ }^{-1} \mathrm{~s}^{-1}$ (Mauldin et al., 1997). Combining this overall rate coefficient with the observation that the yield of $\mathrm{ClO}$ radicals under these conditions is $<5 \%$ (Mauldin et al., 1997), leads to an upper limit of $k\left(\mathrm{O}+\mathrm{OClO} \rightarrow \mathrm{O}_{2}+\mathrm{ClO}\right)<1 \times 10^{-13} \mathrm{~cm}^{3}$ molecule $\mathrm{e}^{-1} \mathrm{~s}^{-1}$ at $260 \mathrm{~K}$. This upper limit to the rate coefficient is consistent with the value of Gleason et al. (1994), but not with the extrapolated values of Colussi et al. (1992).

\section{References}

Bemand, P. P., Clyne, M. A. A., and Watson, R. T.: J. Chem. Soc. Faraday Trans., 1, 69, 1356, 1973.

Colussi, A. J.: J. Phys. Chem., 94, 8922, 1990.

Colussi, A. J., Sander, S. P., and Friedl, R. R.: J. Phys. Chem., 96, 4442, 1992.

Gleason, J. F., Nesbitt, F. L., and Stief, L. J.: J. Phys. Chem., 98, 126, 1994.

Mauldin III, R. L., Burkholder, J. B., and Ravishankara, A. R.: Int. J. Chem. Kinet., 29, 139, 1997. 
III.A2.19

$$
\mathrm{O}+\mathrm{OClO}+\mathrm{M} \rightarrow \mathrm{ClO}_{3}+\mathrm{M}
$$

$\Delta H^{\circ}=-126.6 \mathrm{~kJ} \mathrm{~mol}^{-1}$

\section{Low-pressure rate coefficients}

\section{Rate coefficient data}

\begin{tabular}{llll}
\hline$k_{0} / \mathrm{cm}^{3}$ molecule ${ }^{-1} \mathrm{~s}^{-1}$ & Temp./K & Reference & Technique/Comments \\
\hline Absolute Rate Coefficients & & & \\
$(1.4 \pm 0.3) \times 10^{-31}[\mathrm{Ar}]$ & 298 & Colussi, 1990 & PLP-RF (a) \\
$1.9 \times 10^{-31}(T / 298)^{-1.1}[\mathrm{Ar}]$ & $248-312$ & Colussi et al., 1992 & PLP-RF (b) \\
\hline
\end{tabular}

\section{Comments}

(a) Pulsed laser photolysis of $\mathrm{OClO}$ at pressures of Ar between 10 and 1000 mbar. The oxygen atoms produced were detected by resonance fluorescence. Fit of the falloff curve used $F_{c}=0.6$.

(b) See comment (a). The falloff curves were fitted with $F_{c}=0.5$ at $248 \mathrm{~K}, 0.48$ at $273 \mathrm{~K}$, and 0.45 at $312 \mathrm{~K}$.

\section{Preferred Values}

$k_{0}=1.9 \times 10^{-31}(T / 298)^{-1}\left[\mathrm{~N}_{2}\right] \mathrm{cm}^{3}$ molecule ${ }^{-1} \mathrm{~s}^{-1}$ over the temperature range $240-320 \mathrm{~K}$.

\section{Reliability}

$\Delta \log k_{0}= \pm 0.3$ at $298 \mathrm{~K}$.

$\Delta n= \pm 0.5$

\section{Comments on Preferred Values}

The preferred values are based on the data of Colussi et al. (1992) using falloff extrapolations with a fitted value of $F_{c}=0.5$ at $298 \mathrm{~K}$. Low pressure experiments by Gleason et al. (1994) (1.3-7 mbar) indicate the presence of the reaction O+OClO $\rightarrow$ $\mathrm{ClO}+\mathrm{O}_{2}$.

\section{High-pressure rate coefficients}

\section{Rate coefficient data}

\begin{tabular}{llll}
\hline$k_{\infty} / \mathrm{cm}^{3}$ molecule ${ }^{-1} \mathrm{~s}^{-1}$ & Temp./K & Reference & Technique/Comments \\
\hline Absolute Rate Coefficients & & & \\
$(3.1 \pm 0.8) \times 10^{-11}$ & 298 & Colussi, 1990 & PLP-RF (a) \\
$2.8 \times 10^{-11}$ & $248-312$ & Colussi et al., 1992 & PLP-RF (b) \\
\hline
\end{tabular}

\section{Comments}

(a) See comment (a) for $k_{0}$.

(b) See comment (b) for $k_{0}$. 


\section{Preferred Values}

$k_{\infty}=2.8 \times 10^{-11} \mathrm{~cm}^{3}$ molecule $\mathrm{e}^{-1} \mathrm{~s}^{-1}$, independent of temperature over the range 240-320 K.

\section{Reliability}

$\Delta \log k_{\infty}= \pm 0.3$ at $298 \mathrm{~K}$.

$\Delta n= \pm 1$.

\section{Comments on Preferred Values}

See comments on $k_{0}$. The rate coefficients of Colussi et al. (1992) were confirmed by measurements carried out by Mauldin et al. (1997) at $260 \mathrm{~K}$ and $430 \mathrm{mbar}$ of $\mathrm{N}_{2}$. Under these conditions ( $260 \mathrm{~K}$ and $430 \mathrm{mbar}$ of $\mathrm{N}_{2}$ ), Mauldin et al. (1997) observed that the reaction led to the formation of $\mathrm{ClO}$ radicals with a yield of $<5 \%$. Mauldin et al. (1997) concluded that the combination reaction may involve the intermediate formation of a species such as $\mathrm{O} . . . \mathrm{OClO}$ which is different from $\mathrm{ClO}_{3}$ and which does not rearrange to give $\mathrm{O}_{2}+\mathrm{ClO}$.

Theoretical modelling of the reaction by Zhu and Lin (2002) led to values of $k_{\infty}$ which were a factor of 5-7 higher than obtained from the measurements. As the measurements of Colussi et al. (1992) look well-behaved, they are preferred to the modeling. There is also some dispute about the heat of reaction, see the calculations by Sicre and Cobos (2003).

\section{References}

Colussi, A. J.: J. Phys. Chem., 94, 8922, 1990.

Colussi, A. J., Sander, S. P., and Friedl, R. R.: J. Phys. Chem., 96, 4442, 1992.

Gleason, J. F., Nesbitt, F. L., and Stief, L. J.: J. Phys. Chem., 98, 126, 1994.

Mauldin III, R. L., Burkholder, J. B., and Ravishankara, A. R.: Int. J. Chem. Kinet., 29, 139, 1997.

Sicre, J. E. and Cobos, C. J.: J. Mol. Struct. (Theochem), 620, 215, 2003.

Zhu, R. S. and Lin, M. C.: J. Phys. Chem., A 106, 8386, 2002. 
III.A2.20

$$
\mathrm{O}+\mathrm{Cl}_{2} \mathrm{O} \rightarrow \mathrm{ClO}+\mathrm{ClO}
$$

$\Delta H^{\circ}=-123 \mathrm{~kJ} \mathrm{~mol}^{-1}$

\section{Rate coefficient data}

\begin{tabular}{lllc}
\hline$k / \mathrm{cm}^{3}$ molecule ${ }^{-1} \mathrm{~s}^{-1}$ & Temp./K & Reference & Technique/Comments \\
\hline Absolute Rate Coefficients & & & \\
$2.7 \times 10^{-11} \exp [-(560 \pm 80) / T]$ & $236-295$ & Miziolek and Molina, 1978 & DF-CL \\
$(4.1 \pm 0.5) \times 10^{-12}$ & 295 & & \\
$3.3 \times 10^{-11} \exp [-(700 \pm 150) / T]$ & $237-297$ & Wecker et al., 1982 & DF-EPR \\
$(3.1 \pm 0.5) \times 10^{-12}$ & 297 & & \\
$2.7 \times 10^{-11} \exp [-(510 \pm 30) / T]$ & $230-380$ & Stevens and Anderson, 1992 & DF-RF \\
$(4.7 \pm 0.2) \times 10^{-12}$ & 298 & & \\
\hline
\end{tabular}

\section{Preferred Values}

$k=4.5 \times 10^{-12} \mathrm{~cm}^{3}$ molecule $\mathrm{e}^{-1} \mathrm{~s}^{-1}$ at $298 \mathrm{~K}$.

$k=2.7 \times 10^{-11} \exp (-530 / T) \mathrm{cm}^{3}$ molecule $\mathrm{s}^{-1} \mathrm{~s}^{-1}$ over the temperature range $230-380 \mathrm{~K}$.

\section{Reliability}

$\Delta \log k= \pm 0.15$ at $298 \mathrm{~K}$.

$\Delta(E / R)= \pm 200 \mathrm{~K}$.

\section{Comments on Preferred Values}

The preferred value at $298 \mathrm{~K}$ is based on the results of Stevens and Anderson (1992) and Miziolek and Molina (1978), which are in good agreement. The significantly lower values of Wecker et al. (1982) are not included, nor are earlier, higher results of Freeman and Phillips (1968) and Basco and Dogra (1971).

\section{References}

Basco, N. and Dogra, S. K.: Proc. Roy. Soc. London A, 323, 29, 1971.

Freeman, C. G. and Phillips, L. F.: J. Phys. Chem., 72, 3025, 1968.

Miziolek, A. W. and Molina, M. J.: J. Phys. Chem., 82, 1769, 1978.

Stevens, P. S. and Anderson, J. G.: J. Phys. Chem., 96, 1708, 1992.

Wecker, D., Johanssen, R., and Schindler, R. N.: Ber. Bunsenges. Phys. Chem., 86, 532, 1982. 
III.A2.21

$$
\begin{aligned}
\mathrm{O}+\mathrm{ClONO}_{2} & \rightarrow \mathrm{ClO}+\mathrm{NO}_{3} \\
& \rightarrow \mathrm{OClO}+\mathrm{NO}_{2} \\
& \rightarrow \mathrm{O}_{2}+\mathrm{ClONO}
\end{aligned}
$$

$\Delta H^{\circ}(1)=-96.7 \mathrm{~kJ} \mathrm{~mol}^{-1}$

$\Delta H^{\circ}(2)=-144.3 \mathrm{~kJ} \mathrm{~mol}^{-1}$

$\Delta H^{\circ}(3)=-216 \mathrm{~kJ} \mathrm{~mol}^{-1}$

Rate coefficient data $\left(k=k_{1}+k_{2}+k_{3}\right)$

\begin{tabular}{lllc}
\hline$k / \mathrm{cm}^{3}$ molecule ${ }^{-1} \mathrm{~s}^{-1}$ & Temp./K & Reference & Technique/Comments \\
\hline $\begin{array}{l}\text { Absolute Rate Coefficients } \\
(2.0 \pm 0.2) \times 10^{-13}\end{array}$ & 245 & Ravishankara et al., 1977 & \\
$3.4 \times 10^{-12} \exp [-(840 \pm 60) / T]$ & $213-295$ & Molina et al., 1977 & FP-RF \\
$(2.0 \pm 0.4) \times 10^{-13}$ & 295 & & DF-CL \\
$1.9 \times 10^{-12} \exp [-(692 \pm 167) / T]$ & $225-273$ & Kurylo, 1977 & \\
$1.8 \times 10^{-13}$ & $298^{*}$ & & FP-RF \\
$(2.3 \pm 0.6) \times 10^{-13}$ & 298 & Adler-Golden and Wiesenfeld, 1981 & FP-RA \\
$(2.4 \pm 0.4) \times 10^{-13}$ & 298 & Tyndall et al., 1997 & PLP-RF \\
$4.5 \times 10^{-12} \exp [-(900 \pm 80) / T]$ & $202-325$ & Goldfarb et al., 1998 & PLP-RF/A \\
$(2.2 \pm 0.2) \times 10^{-13}$ & 298 & & (a) \\
\hline
\end{tabular}

\section{Comments}

(a) $k$ was measured by two independent techniques: (1) pulsed laser photolysis with time-resolved resonance fluorescence detection of O-atom decay, and (2) pulsed laser photolysis with time-resolved long-path absorption at $662 \mathrm{~nm}$ by the product $\mathrm{NO}_{3}$ radical. The yield of $\mathrm{NO}_{3}$ radicals produced in the reaction was also measured in the long-path absorption apparatus.

\section{Preferred Values}

$k=2.2 \times 10^{-13} \mathrm{~cm}^{3}$ molecule $\mathrm{e}^{-1} \mathrm{~s}^{-1}$ at $298 \mathrm{~K}$.

$k=4.5 \times 10^{-12} \exp (-900 / T) \mathrm{cm}^{3}$ molecule $\mathrm{s}^{-1} \mathrm{~s}^{-1}$ over the temperature range 200-330 K.

\section{Reliability}

$\Delta \log k= \pm 0.08$ at $298 \mathrm{~K}$.

$\Delta(E / R)= \pm 150 \mathrm{~K}$.

\section{Comments on Preferred Values}

The preferred values are based on the results of the study of Goldfarb et al. (1998). This study encompassed the broadest range of experimental conditions and used two completely different techniques. Results obtained by these two techniques were in complete agreement. Results of the earlier temperature dependent studies of Molina et al. (1977) and Kurylo (1977) and the room temperature studies of Adler-Golden and Wiesenfeld (1981) and Tyndall et al. (1997) are in good agreement with the preferred values.

Using the long-path absorption apparatus to monitor $\mathrm{NO}_{3}$ radicals, Goldfarb et al. (1998) measured the yield of the $\mathrm{NO}_{3}$ radical produced in this reaction to be approximately unity. Allowing for uncertainties in the measurements Goldfarb et al. (1998) concluded that $\mathrm{NO}_{3}$ and $\mathrm{ClO}$ radicals are the primary products of this reaction and account for at least $70 \%$ of the reaction over the temperature range studied ( $248 \mathrm{~K}$ to $298 \mathrm{~K})$. 


\section{References}

Adler-Golden, S. M. and Wiesenfeld, J. R.: Chem. Phys. Lett., 82, 281, 1981.

Goldfarb, L., Harwood, M. H., Burkholder, J. B., and Ravishankara, A. R.: J. Phys. Chem. A, 102, 8556, 1998.

Kurylo, M. J.: Chem. Phys. Lett., 49, 467, 1977.

Molina, L. T., Spencer, J. E., and Molina, M. J.: Chem. Phys. Lett., 45, 158, 1977.

Ravishankara, A. R., Davis, D. D., Smith, G., Tesi, G., and Spencer, J.: Geophys. Res. Lett., 4, 7, 1977.

Tyndall, G. S., Kegley-Owen, C. S., Orlando, J. J., and Calvert, J. G.: J. Chem. Soc. Faraday Trans., 93, $2675,1997$. 
III.A2.22

$$
\mathbf{C l}+\mathbf{H}_{2} \rightarrow \mathbf{H C l}+\mathbf{H}
$$

$\Delta H^{\circ}=4.4 \mathrm{~kJ} \mathrm{~mol}^{-1}$

\section{Rate coefficient data}

\begin{tabular}{lllc}
\hline$k / \mathrm{cm}^{3}$ molecule $\mathrm{s}^{-1}$ & Temp./K & Reference & Technique/Comments \\
\hline Absolute Rate Coefficients & & & \\
$2.0 \times 10^{-11} \exp [-(2164 \pm 101) / T]$ & $251-456$ & Westenberg and de Haas, 1968 & DF-EPR \\
$(1.35 \pm 0.07) \times 10^{-14}$ & 297 & & \\
$(1.26 \pm 0.10) \times 10^{-14}$ & 298 & Davis et al., 1970 & FP-RF (a) \\
$5.5 \times 10^{-11} \exp [-(2391 \pm 50) / T]$ & $213-350$ & Watson et al., 1975 & FP-RF \\
$(1.80 \pm 0.2) \times 10^{-14}$ & 298 & & \\
$2.66 \times 10^{-11} \exp [-(2230 \pm 60) / T]$ & $200-500$ & Lee et al., 1977 & FP-RF \\
$(1.77 \pm 0.13) \times 10^{-14}$ & 302 & & \\
$3.65 \times 10^{-11} \exp [-(2310 \pm 20) / T]$ & $199-499$ & Miller and Gordon, 1981 & FP-RF \\
$(1.49 \pm 0.07) \times 10^{-14}$ & $298.1 \pm 0.5$ & & \\
$6.00 \times 10^{-11} \exp [-(2470 \pm 100) / T]$ & $297-425$ & Kita and Stedman, 1982 & DF-RF \\
$(1.46 \pm 0.22) \times 10^{-14}$ & 297 & & \\
$4.4 \times 10^{-11} \exp (-2568 / T)$ & $291-1283$ & Adusei and Fontijn, 1994, & FP/PLP-RF \\
$8.1 \times 10^{-15}$ & 291 & & \\
$(1.68 \pm 0.22) \times 10^{-14}$ & 296 & Kumaran et al., 1994 & PLP-RA (b) \\
\hline
\end{tabular}

\section{Comments}

(a) Rate coefficient has been decreased by $10 \%$, as recommended by the NASA evaluation panel (NASA, 1997).

(b) Rate coefficients also measured over the temperature range 699-2939 K, and a combination of the $296 \mathrm{~K}$ and $699-2939 \mathrm{~K}$ rate coefficients resulted in $k=4.78 \times 10^{-16} T^{1.58} \exp (-1610 / T) \mathrm{cm}^{3}$ molecule $\mathrm{s}^{-1} \mathrm{~s}^{-1}$.

\section{Preferred Values}

$k=1.7 \times 10^{-14} \mathrm{~cm}^{3}$ molecule $\mathrm{e}^{-1} \mathrm{~s}^{-1}$ at $298 \mathrm{~K}$.

$k=3.9 \times 10^{-11} \exp (-2310 / T) \mathrm{cm}^{3}$ molecule ${ }^{-1} \mathrm{~s}^{-1}$ over the temperature range $200-310 \mathrm{~K}$.

\section{Reliability}

$\Delta \log k= \pm 0.1$ at $298 \mathrm{~K}$.

$\Delta(E / R)= \pm 200 \mathrm{~K}$.

\section{Comments on Preferred Values}

The preferred values are derived from a least-squares fit to the rate coefficients measured at $\leq 302 \mathrm{~K}$ by Watson et al. (1975), Lee et al. (1977), Miller and Gordon (1981), Kita and Stedman (1982) and Kumaran et al. (1994). The results of these studies are in excellent agreement below $\sim 300 \mathrm{~K}$; at higher temperatures the data are in poorer agreement. The two studies of Miller and Gordon (1981) and Kita and Stedman (1982) have measured both the forward and reverse rates and have shown that the rate coefficient ratio agrees with equilibrium constant data. The room temperature rate coefficients of Adusei and Fontijn (1994) are in reasonable agreement with the preferred values. 


\section{References}

Adusei, G. Y. and Fontijn, A.: 25th International Symposium on Combustion, 1994; The Combustion Institute, Pittsburgh, PA, pp. 801-808, 1994.

Davis, D. D., Braun, W., and Bass, A. M.: Int. J. Chem. Kinet., 2, 101, 1970.

Kita, D. and Stedman, D. H.: J. Chem. Soc. Faraday Trans., 2 78, 1249, 1982.

Kumaran, S. S., Lim, K. P., and Michael, J. V.: J. Chem. Phys., 101, 9487, 1994.

Lee, J. H., Michael, W. A., Payne, Stief, L. J., and Whytock, D. A.: J. Chem. Soc. Faraday Trans. 1, 73, 1530, 1977.

Miller, J. C. and Gordon, R. J.: J. Chem. Phys., 75, 5305, 1981.

NASA: Evaluation No. 12, 1997 (see references in Introduction).

Watson, R. T., Machado, E. S., Schiff, R. L., Fischer, S., and Davis, D. D.: Proceedings of the 4th CIAP Conference, DOTOST-75, 1975.

Westenberg, A. A. and de Haas, N.: J. Chem. Phys., 48, 4405, 1968. 
III.A2.23

$$
\begin{aligned}
\mathrm{Cl}+\mathrm{HO}_{2} & \rightarrow \mathrm{HCl}+\mathrm{O}_{2} \\
& \rightarrow \mathrm{ClO}+\mathrm{HO}
\end{aligned}
$$

$\Delta H^{\circ}(1)=-228.2 \mathrm{~kJ} \mathrm{~mol}^{-1}$

$\Delta H^{\circ}(2)=2.9 \mathrm{~kJ} \mathrm{~mol}^{-1}$

Rate coefficient data $\left(k=k_{1}+k_{2}\right)$

\begin{tabular}{lllc}
\hline$k / \mathrm{cm}^{3}$ molecule ${ }^{-1} \mathrm{~s}^{-1}$ & Temp./K & Reference & Technique/Comments \\
\hline Absolute Rate Coefficients & & & \\
$(4.2 \pm 0.7) \times 10^{-11}$ & $250-414$ & Lee and Howard, 1982 & DF-LMR (a) \\
$k_{1}=(4.4 \pm 1.5) \times 10^{-11}$ & 308 & Cattell and Cox, 1986 & MM (b) \\
$k_{2}=(9.4 \pm 1.9) \times 10^{-12}$ & 308 & & \\
$3.8 \times 10^{-11} \exp [(40 \pm 90) / T]$ & $230-360$ & Riffault et al., 2001 & DF-MS (c) \\
$(4.4 \pm 0.5) \times 10^{-11}$ & 300 & & \\
$k_{2}=8.6 \times 10^{-11} \exp [-(660 \pm 100) / T]$ & $230-360$ & & \\
$k_{2}=(9.9 \pm 2.8) \times 10^{-12}$ & 295 & & \\
$2.8 \times 10^{-11} \exp [(123 \pm 15) / T]$ & $246-296$ & Hickson and Keyser, 2005 & DF-RF (d) \\
$(4.3 \pm 0.1) \times 10^{-11}$ & 296 & & \\
$k_{1}=1.6 \times 10^{-11} \exp [(249 \pm 34) / T]$ & $226-336$ & & \\
$k_{1}=(3.6 \pm 0.1) \times 10^{-11}$ & 296 & & \\
& & & \\
Branching Ratio & & & \\
$k_{2} / k=1.09 \exp [-(478 \pm 17) / T]$ & $250-420$ & Lee and Howard, 1982 & \\
$k_{2} / k=0.210 \pm 0.016$ & 297 & & \\
$k_{1} / k=0.34 \exp [(222 \pm 17) / T]$ & $256-296$ & Hickson and Keyser, 2005 (a) & DF-RF/TDLS (d) \\
$k_{1} / k=0.724 \pm 0.020$ & 296 & & \\
$k_{2} / k=2.4 \exp [-(733 \pm 41) / T]$ & $226-336$ & & \\
$k_{2} / k=0.189 \pm 0.003$ & 296 & & \\
\hline
\end{tabular}

\section{Comments}

(a) On the basis of the temperature independent overall rate coefficient and the temperature dependent branching ratio, the authors derived the rate coefficient expressions $k_{1}=1.8 \times 10^{-11} \exp [(170 \pm 80) / T] \mathrm{cm}^{3} \mathrm{molecule}^{-1} \mathrm{~s}^{-1}$ and $k_{2}=4.1 \times 10^{-11} \exp [-(450 \pm 60) / T] \mathrm{cm}^{3}$ molecule ${ }^{-1} \mathrm{~s}^{-1}$.

(b) Rate coefficients were derived from the observed time-concentration behavior of $\mathrm{HO}_{2}$ and $\mathrm{ClO}$ radicals using numerical simulations and a 25-step reaction mechanism. Because of uncertainties in the $\mathrm{Cl}$ atom concentrations, the rate coefficients $k_{1}$ and $k_{2}$ cited above (for 1 bar total pressure) may be low by a factor of 2 and high by a factor of 2, respectively (Cattell and Cox, 1986). The reaction was also studied over the pressure range $67 \mathrm{mbar}$ to $1013 \mathrm{mbar}$, and no pressure dependence of either $k_{1}$ or $k_{2}$ over this range was evident.

(c) $k$ was determined under pseudo-first order conditions with either $\mathrm{HO}_{2}$ or $\mathrm{Cl}$ in excess. Because the reported weak temperature dependence is not significantly different from zero, a temperature independent rate coefficient of $k=(4.4 \pm 0.6) \times 10^{-11} \mathrm{~cm}^{3}$ molecule ${ }^{-1} \mathrm{~s}^{-1}$ was also reported for the temperature range $230-360 \mathrm{~K} . k_{2}$ was determined from the formation kinetics of both $\mathrm{HO}$ and $\mathrm{ClO}$.

(d) $\mathrm{HO}_{2}$ radicals were detected by titration to $\mathrm{HO}$, following reaction with NO. $k$ and $k_{1}$ were determined under pseudo-first order conditions in experiments with $\mathrm{Cl}$ and $\mathrm{HO}_{2}$ in excess, respectively. Because the reported temperature dependence is weak, a temperature independent rate coefficient $k=(4.5 \pm 0.4) \times 10^{-11} \mathrm{~cm}^{3}$ molecule ${ }^{-1} \mathrm{~s}^{-1}$ was also reported for the studied temperature range. A value of $k_{2}=7.7 \times 10^{-11} \exp [-(708 \pm 29) / T]$ was inferred from the measurements of $k$ 
and $k_{1}$, for the temperature range $256-296 \mathrm{~K} . k_{1} / k$ and $k_{2} / k$ were determined from the respective yields of $\mathrm{HCl}$ (measured by TDLS) and $\mathrm{HO}$ at reaction completion, relative to initial $\left[\mathrm{HO}_{2}\right]$ in experiments with $\mathrm{Cl}$ in excess.

\section{Preferred Values}

$k=4.4 \times 10^{-11} \mathrm{~cm}^{3}$ molecule $\mathrm{e}^{-1} \mathrm{~s}^{-1}$ independent of temperature over the range $230-420 \mathrm{~K}$.

$k_{2} / k=0.21$ at $298 \mathrm{~K}$.

$k_{2} / k=1.7 \exp (-620 / T) \mathrm{cm}^{3}$ molecule ${ }^{-1} \mathrm{~s}^{-1}$ over the temperature range $230-420 \mathrm{~K}$.

\section{Reliability}

$\Delta \log k= \pm 0.1$ at $298 \mathrm{~K}$.

$\Delta \log \left(k_{2} / k\right)= \pm 0.1$ at $298 \mathrm{~K}$.

$\Delta\left(E_{2} / R\right)= \pm 200 \mathrm{~K}$.

\section{Comments on Preferred Values}

The preferred values for $k$ and $k_{2} / k$ are based on results of the direct studies of Lee and Howard (1982), Riffault et al. (2001) and Hikson and Keyser (2005), which are in very good agreement. Although all three of these studies report very small negative temperature dependences for the overall $k$, each also recommends a temperature independent value for the studied temperature range. The preferred value of $k$ is the mean of these temperature independent values. The preferred value of $k_{2} / k$ at $298 \mathrm{~K}$ is the mean of the values reported by Lee and Howard (1982) and Hickson and Keyser (2005) and that derived from the $k$ and $k_{2}$ values reported by Riffault et al. (2001); the room temperature results of Cattell and Cox (1986) are also in reasonable agreement with this recommendation. The value of $E_{2} / R$, which defines the temperature dependence of $k_{2}$ and $k_{2} / k$, is the rounded mean of the values reported in the $k_{2} / k$ determinations of Lee and Howard (1982) and Hickson and Keyser (2005), and the $k_{2}$ determination of Riffault et al. (2001), with the pre-exponential factor adjusted to give the preferred value of $k_{2} / k$ at 298 $\mathrm{K}$. The values of $k_{1}$ and $k_{1} / k$ which can be calculated from the preferred values of $k$ and $k_{2} / k$, are also in acceptable agreement with those reported by Hickson et al. (2005). Based on the combined results of the available studies, neither channel shows any pressure dependence between 1 mbar and 1 bar, showing that stabilization of the $\mathrm{HOOCl}^{*}$ intermediate does not occur, the two bimolecular channels making up the entire reaction pathway. Dobis and Benson (1993) report a total rate coefficient in good agreement with the preferred value but a significantly lower value of the branching ratio $k_{2} / k$. Results of earlier indirect studies (Leu and DeMore, 1976; Poulet et al., 1978, Burrows et al., 1979 and Cox, 1980) were not used in the evaluation of the preferred values.

\section{References}

Burrows, J. P., Cliff, D. I., Harris, G. W., Thrush, B. A., and Wilkinson, J. P. T. : Proc. Roy. Soc. (London) A368, 463, 1979. Cattell, F. C. and Cox, R. A.: J. Chem. Soc. Faraday Trans. 2, 82, 1413, 1986.

Cox, R. A.: Int. J. Chem. Kinet., 12, 649, 1980.

Dobis, O. and Benson, S. W.: J. Am. Chem. Soc., 115, 8798, 1993.

Hickson, K. M. and Keyser, L. F.: J. Phys. Chem. A., 109, 6887, 2005.

Lee, Y.-P. and Howard, C. J.: J. Chem. Phys., 77, 756, 1982.

Leu, M.-T. and DeMore, W. B.: Chem. Phys. Lett., 41, 121, 1976.

Poulet, G., Le Bras, G., and Combourieu, J.: J. Chem. Phys., 69, 767, 1978.

Riffault, V., Bedjanian, Y., and Le Bras, G.: Int. J. Chem. Kinet., 33, 317, 2001. 


\section{III.A2.24}

$$
\mathrm{Cl}+\mathrm{H}_{2} \mathrm{O}_{2} \rightarrow \mathrm{HCl}+\mathrm{HO}_{2}
$$

$\Delta H^{\circ}=-62.7 \mathrm{~kJ} \mathrm{~mol}^{-1}$

\section{Rate coefficient data}

\begin{tabular}{lllc}
\hline$k / \mathrm{cm}^{3}$ molecule $\mathrm{s}^{-1} \mathrm{~s}^{-1}$ & Temp./K & Reference & Technique/Comments \\
\hline Absolute Rate Coefficients & & & \\
$\left(5.8_{-2.9}^{+5.8}\right) \times 10^{-13}$ & 298 & Watson et al., 1976 & FP-RF (a) \\
$(6.2 \pm 1.5) \times 10^{-13}$ & 295 & Leu and DeMore, 1976 & DF-MS \\
$1.24 \times 10^{-12} \exp [-(384 \pm 168) / T]$ & $265-400$ & Michael et al., 1977 & FP-RF (b) \\
$(3.64 \pm 0.52) \times 10^{-13}$ & 299 & & \\
$(4.0 \pm 0.4) \times 10^{-13}$ & 298 & Poulet et al., 1978 & DF-MS \\
$1.05 \times 10^{-11} \exp [-(982 \pm 102) / T]$ & $298-424$ & Keyser, 1980 & DF-RF \\
$(4.1 \pm 0.2) \times 10^{-13}$ & 298 & & \\
\hline
\end{tabular}

\section{Comments}

(a) A recalculated rate coefficient of $\left(5.2_{-2.6}^{+5.2}\right) \times 10^{-13} \mathrm{~cm}^{3}$ molecule $\mathrm{e}^{-1} \mathrm{~s}^{-1}$ is cited in Michael et al. (1977).

(b) Obtained using $\mathrm{H}_{2} \mathrm{O}_{2}$ concentrations measured after the reaction cell. Using an average of the $\mathrm{H}_{2} \mathrm{O}_{2}$ concentrations measured in the reactant flow prior to and after the reaction cell, a rate coefficient of $k=(3.14 \pm 0.56) \times 10^{-13} \mathrm{~cm}^{3}$ molecule $\mathrm{e}^{-1} \mathrm{~s}^{-1}$, independent of temperature over the range $265-400 \mathrm{~K}$, was obtained.

\section{Preferred Values}

$k=4.1 \times 10^{-13} \mathrm{~cm}^{3}$ molecule ${ }^{-1} \mathrm{~s}^{-1}$ at $298 \mathrm{~K}$.

$k=1.1 \times 10^{-11} \exp (-980 / T) \mathrm{cm}^{3}$ molecule $\mathrm{e}^{-1} \mathrm{~s}^{-1}$ over the temperature range $260-430 \mathrm{~K}$.

\section{Reliability}

$\Delta \log k= \pm 0.2$ at $298 \mathrm{~K}$.

$\Delta(E / R)= \pm 500 \mathrm{~K}$.

\section{Comments on Preferred Values}

The room temperature rate coefficients measured by Watson et al. (1976), Leu and DeMore (1976), Michael et al. (1977), Poulet et al. (1978) and Keyser (1980) cover the range (3.6-6.2) $\times 10^{-13} \mathrm{~cm}^{3}$ molecule $\mathrm{s}^{-1}$. The studies of Michael et al. (1977), Poulet et al. (1978) and Keyser (1980) are considered to be the most reliable. The recommended Arrhenius expression is that reported by Keyser (1980). The rate coefficient measured by Michael et al. (1977) at $265 \mathrm{~K}$ is in good agreement with the recommendation; however, the $A$-factor reported is considerably lower than that expected from theoretical considerations and may be attributed to decomposition of $\mathrm{H}_{2} \mathrm{O}_{2}$ above $300 \mathrm{~K}$ (which was indeed observed, especially at $400 \mathrm{~K}$ ). More data are required before the Arrhenius parameters can be considered to be well established. Heneghan and Benson (1983), using mass spectrometry, confirmed that this reaction proceeds only by the H-atom abstraction mechanism.

\section{References}

Heneghan, S. P. and Benson, S. W.: Int. J. Chem. Kinet., 15, 1311, 1983.

Keyser, L. F.: J. Phys. Chem., 84, 11, 1980.

Leu, M.-T. and DeMore, W. B. : Chem. Phys. Lett., 41, 121, 1976.

Michael, J. V., Whytock, D. A., Lee, J. H., Payne, W. A., and Stief, L. J. : J. Chem. Phys., 67, 3533, 1977. 
Poulet, G., Le Bras, G., and Combourieu, J.: Chem. Phys., 69, 767, 1978.

Watson, R., Machado, G., Fischer, S., and Davis, D. D.: J. Chem. Phys., 65, 2126, 1976. 
III.A2.25

$$
\mathrm{Cl}+\mathrm{O}_{2}+\mathrm{M} \rightarrow \mathrm{ClOO}+\mathrm{M}
$$

$\Delta H^{\circ}=-23.8 \mathrm{~kJ} \mathrm{~mol}^{-1}$

\section{Low-pressure rate coefficients}

\section{Rate coefficient data}

\begin{tabular}{lllc}
\hline$k_{0} / \mathrm{cm}^{3}$ molecule ${ }^{-1} \mathrm{~s}^{-1}$ & Temp./K & Reference & Technique/Comments \\
\hline Absolute Rate Coefficients & & & \\
$5.6 \times 10^{-34}[\mathrm{Ar}]$ & $200-300$ & Clyne and Coxon, 1968 & DF (a) \\
$1.7 \times 10^{-33}\left[\mathrm{~N}_{2}+\mathrm{O}_{2}\right]$ & 300 & Nicholas and Norrish, 1968 & FP-UVA (b) \\
$(8.9 \pm 2.9) \times 10^{-33}\left[\mathrm{O}_{2}\right]$ & 186.5 & Nicovich et al., 1991 & PLP-RF (c) \\
$1.6 \times 10^{-33}(T / 300)^{-2.9}\left[\mathrm{O}_{2}\right]$ & $160-260$ & Baer et al., 1991 & PLP-UVA \\
$(6.3 \pm 1.2) \times 10^{-33}\left[\mathrm{O}_{2}\right]$ & 186.5 & & $(\mathrm{~d})$ \\
$1.4 \times 10^{-33}(\mathrm{~T} / 300)^{-3.9}\left[\mathrm{~N}_{2}\right]$ & $160-260$ & Baer et al., 1991 & PLP-UVA (d) \\
\hline
\end{tabular}

\section{Comments}

(a) Measurements attributed to D. H. Stedman. $\mathrm{Cl}$ atoms were monitored by chlorine afterglow emission.

(b) Rate coefficients were determined by a complex analysis of the time-resolved production of $\mathrm{ClO}$ radicals in the photolysis of $\mathrm{Cl}_{2}-\mathrm{O}_{2}$ mixtures. $\mathrm{ClO}$ radicals were measured by photographic recording of their absorption.

(c) Photolysis of $\mathrm{Cl}_{2}-\mathrm{O}_{2}$ mixtures at $181-200 \mathrm{~K}$ and with $\mathrm{O}_{2}$ pressures of $20-53$ mbar. Detection of $\left.\mathrm{Cl}^{2}{ }^{2} \mathrm{P}_{3 / 2}\right)$ atoms. An equilibrium constant for the reaction of $K_{p}=18.9 \mathrm{bar}^{-1}$ was determined at $185.4 \mathrm{~K}$.

(d) Photolysis of $\mathrm{Cl}_{2}-\mathrm{O}_{2}-\mathrm{M}$ mixtures with $\mathrm{M}=\mathrm{He}, \mathrm{Ar}, \mathrm{O}_{2}$ and $\mathrm{N}_{2}$, with detection of $\mathrm{ClOO}$ radicals. Redetermination of the $\mathrm{ClOO}$ radical absorption cross sections gave $\sigma(248 \mathrm{~nm})=3.4 \times 10^{-17} \mathrm{~cm}^{2}$ molecule ${ }^{-1}$. Measurements over the temperature range $160-260 \mathrm{~K}$ and the pressure range 1-1000 bar were in agreement with the data of Mauldin et al. (1992). Negligible deviations from third-order behavior were observed at pressures below 10 bar. At higher pressures, an anomalous transition to a high pressure plateau was observed. This and the anomalously strong temperature dependence suggest that the reaction proceeds on a radical-complex instead of the usual energy transfer mechanism. An equilibrium constant of $K_{p}=5.3 \times 10^{-6} \exp \left(23.4 \mathrm{~kJ} \mathrm{~mol}^{-1} / R T\right) \mathrm{bar}^{-1}$ was determined over the temperature range $180 \mathrm{~K}$ to $300 \mathrm{~K}$.

\section{Preferred Values}

$k_{0}=1.4 \times 10^{-33}(T / 300)^{-3.9}\left[\mathrm{~N}_{2}\right] \mathrm{cm}^{3}$ molecule ${ }^{-1} \mathrm{~s}^{-1}$ over the temperature range $160-300 \mathrm{~K}$.

$k_{0}=1.6 \times 10^{-33}(T / 300)^{-2.9}\left[\mathrm{O}_{2}\right] \mathrm{cm}^{3}$ molecule ${ }^{-1} \mathrm{~s}^{-1}$ over the temperature range 160-300 K.

\section{Reliability}

$\Delta \log k_{0}= \pm 0.2$ at $200 \mathrm{~K}$.

$\Delta n= \pm 1$.

\section{Comments on Preferred Values}

The two recent studies of Nicovich et al. (1991) and Baer et al. (1991) are in good agreement and are also consistent with the older data of Nicholas and Norrish (1968), if one takes into account the strong temperature dependence of $k_{0}$. The most extensive measurements of Baer et al. (1991) are the basis for the preferred values. No falloff expressions are reported here, because deviations from third-order behavior become apparent only at pressures higher than 10 bar and because the falloff formalism does not apply to the radical-complex mechanism which is probably operating in this case. 


\section{References}

Baer, S., Hippler, H., Rahn, R., Siefke, M., Seitzinger, N., and Troe, J.: J. Chem. Phys., 95, 6463, 1991. Clyne, M. A. A. and Coxon, J. A.: Proc. Roy. Soc. London, A303, 207, 1968.

Mauldin III, R. L., Burkholder, J. B., and Ravishankara, A. R.: J. Phys. Chem., 96, 2582, 1992.

Nicholas, J. E. and Norrish, R. G. W.: Proc. Roy. Soc. London, A, 307, 391, 1968.

Nicovich, J. M., Kreutter, K. D., Shackelford, C. J., and Wine, P. H.: Chem. Phys. Lett., 179, $367,1991$. 
III.A2.26

$$
\mathrm{ClOO}+\mathrm{M} \rightarrow \mathrm{Cl}+\mathrm{O}_{2}+\mathrm{M}
$$

$\Delta H^{\circ}=23.8 \mathrm{~kJ} \mathrm{~mol}^{-1}$

\section{Low-pressure rate coefficients}

\section{Rate coefficient data}

\begin{tabular}{lllc}
\hline$k_{0} / \mathrm{s}^{-1}$ & Temp./K & Reference & Technique/Comments \\
\hline Absolute Rate Coefficients & & & \\
$1.9 \times 10^{-14}\left[\mathrm{O}_{2}\right]$ & 185.4 & Nicovich et al., 1991 & PLP-RF (a) \\
$2.8 \times 10^{-10} \exp (-1820 / T)\left[\mathrm{N}_{2}\right]$ & $160-260$ & Baer et al., 1991 & PLP-UVA \\
$6.2 \times 10^{-13}\left[\mathrm{~N}_{2}\right]$ & $298^{*}$ & & (a) \\
$6.3 \times 10^{-10} \exp (-2030 / T)\left[\mathrm{O}_{2}\right]$ & $160-260$ & Baer et al., 1991 & PLP-UVA \\
$1.1 \times 10^{-14}\left[\mathrm{O}_{2}\right]$ & 185.4 & & (a) \\
\hline
\end{tabular}

\section{Comments}

(a) From measurements of the reverse reaction and the equilibrium constant.

\section{Preferred Values}

$k_{0}=6.2 \times 10^{-13}\left[\mathrm{~N}_{2}\right] \mathrm{s}^{-1}$ at $298 \mathrm{~K}$.

$k_{0}=2.8 \times 10^{-10} \exp (-1820 / T)\left[\mathrm{N}_{2}\right] \mathrm{s}^{-1}$ over the temperature range $160-300 \mathrm{~K}$.

\section{Reliability}

$\Delta \log k_{0}= \pm 0.3$ at $298 \mathrm{~K}$.

$\Delta(E / R)= \pm 200 \mathrm{~K}$.

\section{Comments on Preferred Values}

The preferred values are based on the extensive data of Baer et al. (1991). No deviations from third-order behavior were observed at pressures below 1 bar. The reaction probably does not proceed via an energy-transfer mechanism (see comments on the reverse reaction $\mathrm{Cl}+\mathrm{O}_{2}+\mathrm{M} \rightarrow \mathrm{ClOO}+\mathrm{M}$ ), but rather by a radical-complex mechanism.

\section{References}

Baer, S., Hippler, H., Rahn, R., Siefke, M., Seitzinger, N., and Troe, J.: J. Chem. Phys., 95, 6463, 1991. Nicovich, J. M., Kreutter, K. D., Shackelford, C. J., and Wine, P. H.: Chem. Phys. Lett., 179, 367, 1991. 
III.A2.27

$$
\mathrm{Cl}+\mathrm{CO}+\mathrm{M} \rightarrow \mathrm{ClCO}+\mathrm{M}
$$

$\Delta H^{\circ}=-32.6 \mathrm{~kJ} \mathrm{~mol}^{-1}$

\section{Low-pressure rate coefficients}

\section{Rate coefficient data}

\begin{tabular}{lllc}
\hline$k_{0} / \mathrm{cm}^{3}$ molecule ${ }^{-1} \mathrm{~s}^{-1}$ & Temp./K & Reference & Technique/Comments \\
\hline $\begin{array}{l}\text { Absolute Rate Coefficients } \\
(9.1 \pm 3.0) \times 10^{-34}[\mathrm{Ar}]\end{array}$ & 300 & Clark et al., 1966 & DF (a) \\
$1.05 \times 10^{-34} \exp [(810 \pm 70) / T]\left[\mathrm{N}_{2}\right]$ & $185-260$ & Nicovich et al., 1990 & PLP-RF (b) \\
$1.6 \times 10^{-33}\left[\mathrm{~N}_{2}\right]$ & 298 & & \\
& & & \\
$\begin{array}{l}\text { Relative Rate Coefficients } \\
(1.4 \pm 0.3) \times 10^{-33}\left[\mathrm{~N}_{2}\right]\end{array}$ & 298 & Hewitt et al., 1996 & (c) \\
\hline
\end{tabular}

\section{Comments}

(a) $\mathrm{Cl}$ atoms were generated from the photolysis of $\mathrm{Cl}_{2}-\mathrm{He}$ mixtures and were measured by titration with nitrosyl chloride using the red chlorine afterglow spectrum. The total pressure was 2.7-5.3 mbar. From additional experiments carried out at $195 \mathrm{~K}$, an activation energy of about $-8.4 \mathrm{~kJ} \mathrm{~mol}^{-1}$ was obtained.

(b) Pulsed laser photolysis of $\mathrm{Cl}_{2}-\mathrm{CO}-\mathrm{M}\left(\mathrm{M}=\mathrm{N}_{2}, \mathrm{CO}\right.$, Ar and $\left.\mathrm{CO}_{2}\right)$ mixtures at $355 \mathrm{~nm}$. The pressure was 19267 mbar. By second- and third-law analyses of the temperature dependence of the equilibrium constant, a value of $\Delta H^{\circ}(298 \mathrm{~K})=-(32.2 \pm 2.5) \mathrm{kJ} \mathrm{mol}^{-1}$ was derived. The relative collision efficiencies were $\beta_{c}\left(\mathrm{CO}_{2}\right): \beta_{c}\left(\mathrm{CO}, \mathrm{N}_{2}\right)$ : $\beta_{c}(\mathrm{Ar})=3.2: 1.0: 0.8$.

(c) Steady state photolysis of $\mathrm{Cl}_{2}$ in the presence of $\mathrm{CO}$ and a reference gas $\left(\mathrm{CH}_{4}\right.$ or $\left.\mathrm{CHCl}_{3}\right)$. Long-path FTIR spectroscopy of $\mathrm{CO}$ and $\mathrm{CO}_{2}$. Measurements of $k_{0}$ in 1 bar of air at $298 \mathrm{~K}$ relative to $k\left(\mathrm{Cl}+\mathrm{CH}_{4}\right)=1.0 \times 10^{-13} \mathrm{~cm}^{3}$ molecule $\mathrm{s}^{-1}$.

\section{Preferred Values}

$k_{0}=1.3 \times 10^{-33}(T / 300)^{-3.8}\left[\mathrm{~N}_{2}\right] \mathrm{cm}^{3}$ molecule ${ }^{-1} \mathrm{~s}^{-1}$ over the temperature range $180-300 \mathrm{~K}$.

\section{Reliability}

$\Delta \log k_{0}= \pm 0.3$ at $298 \mathrm{~K}$.

$\Delta n= \pm 1$.

\section{Comments on Preferred Values}

The recommended rate coefficients are based on the measurements of Nicovich et al. (1990) which agree well with the relative rate measurements from Hewitt et al. (1996). No signs of deviations from third-order behavior were detected. The large negative temperature coefficient may be a sign of a radical-complex mechanism.

\section{References}

Clark, T. C., Clyne, M. A. A., and Stedman, D. H.: Trans. Faraday Soc., 62, 3354, 1966.

Hewitt, A. D., Brahan, K. M., Boone, G. D., and Hewitt, S. A.: Int. J. Chem. Kinet., 28, 765, 1996.

Nicovich, J. M., Kreutter, K. D., and Wine, P. H.: J. Chem. Phys., 92, 3539, 1990. 
III.A2.28

$$
\mathrm{ClCO}+\mathrm{M} \rightarrow \mathrm{Cl}+\mathrm{CO}+\mathrm{M}
$$

$\Delta H^{\circ}=32.6 \mathrm{~kJ} \mathrm{~mol}^{-1}$

\section{Low-pressure rate coefficients}

\section{Rate coefficient data}

\begin{tabular}{lclc}
\hline$k_{0} / \mathrm{s}^{-1}$ & Temp./K & Reference & Technique/Comments \\
\hline $\begin{array}{l}\text { Absolute Rate Coefficients } \\
4.1 \times 10^{-10} \exp [-(2960 \pm 160) / T]\left[\mathrm{N}_{2}\right]\end{array}$ & $185-260$ & Nicovich et al., 1990 & PLP-RF (a) \\
\hline
\end{tabular}

\section{Comments}

(a) Pulsed laser photolysis of $\mathrm{Cl}_{2}-\mathrm{CO}-\mathrm{M}\left(\mathrm{M}=\mathrm{N}_{2}, \mathrm{CO}\right.$, $\mathrm{Ar}$ and $\left.\mathrm{CO}_{2}\right)$ mixtures at $355 \mathrm{~nm}$. The pressure was 19267 mbar. By second- and third-law analyses of the temperature dependence of the equilibrium constant, a value of $\Delta H^{\circ}(298 \mathrm{~K})=(32.2 \pm 2.5) \mathrm{kJ} \mathrm{mol}^{-1}$ was derived. The relative collision efficiencies were $\beta_{c}\left(\mathrm{CO}_{2}\right): \beta_{c}\left(\mathrm{CO}, \mathrm{N}_{2}\right): \beta_{c}(\mathrm{Ar})=$ $3.2: 1.0: 0.8$.

\section{Preferred Values}

$k_{0}=2.0 \times 10^{-14}\left[\mathrm{~N}_{2}\right] \mathrm{s}^{-1}$ at $298 \mathrm{~K}$.

$k_{0}=4.1 \times 10^{-10} \exp (-2960 / T)\left[\mathrm{N}_{2}\right] \mathrm{s}^{-1}$ over the temperature range 180-300 K.

\section{Reliability}

$\Delta \log k_{0}= \pm 0.4$ at $298 \mathrm{~K}$.

$\Delta(E / R)= \pm 200 \mathrm{~K}$.

\section{Comments on Preferred Values}

The preferred rate coefficients are based on the study of Nicovich et al. (1990).

\section{References}

Nicovich, J. M., Kreutter, K. D., and Wine, P. H.: J. Chem. Phys., 92, 3539, 1990. 
III.A2.29

$$
\mathrm{Cl}+\mathrm{O}_{3} \rightarrow \mathrm{ClO}+\mathrm{O}_{2}
$$

$\Delta H^{\circ}=-162.4 \mathrm{~kJ} \mathrm{~mol}^{-1}$

\section{Rate coefficient data}

\begin{tabular}{|c|c|c|c|}
\hline$k / \mathrm{cm}^{3}$ molecule $^{-1} \mathrm{~s}^{-1}$ & Temp./K & Reference & Technique/Comments \\
\hline \multicolumn{4}{|l|}{ Absolute Rate Coefficients } \\
\hline $\begin{array}{l}3.08 \times 10^{-11} \exp [-(290 \pm 25) / T] \\
(1.20 \pm 0.10) \times 10^{-11}\end{array}$ & $\begin{array}{l}220-350 \\
298\end{array}$ & Watson et al., 1976 & FP-RF \\
\hline $\begin{array}{l}2.17 \times 10^{-11} \exp [-(171 \pm 30) / T] \\
(1.23 \pm 0.25) \times 10^{-11}\end{array}$ & $\begin{array}{l}205-366 \\
298\end{array}$ & Zahniser et al., 1976 & DF-RF (a) \\
\hline $\begin{array}{l}2.72 \times 10^{-11} \exp [-(298 \pm 39) / T] \\
(1.02 \pm 0.15) \times 10^{-11}\end{array}$ & $\begin{array}{l}213-298 \\
298\end{array}$ & Kurylo and Braun, 1976 & FP-RF (a) \\
\hline $\begin{array}{l}5.18 \times 10^{-11} \exp [-(418 \pm 28) / T] \\
(1.33 \pm 0.26) \times 10^{-11}\end{array}$ & $\begin{array}{l}221-629 \\
298\end{array}$ & Clyne and Nip, 1976 & DF-RF \\
\hline$(1.3 \pm 0.3) \times 10^{-11}$ & 295 & Leu and DeMore, 1976 & DF-MS (b) \\
\hline$(1.3 \pm 0.2) \times 10^{-11}$ & 298 & Toohey et al., 1988 & DF-RF \\
\hline $2.49 \times 10^{-11} \exp [-(233 \pm 46) / T]$ & $269-385$ & Nicovich et al., 1990 & PLP-RF (c) \\
\hline $\begin{array}{l}1.19 \times 10^{-11} \exp [-(33 \pm 37) / T] \\
(1.14 \pm 0.17) \times 10^{-11}\end{array}$ & $\begin{array}{l}189-269 \\
298\end{array}$ & & \\
\hline $\begin{array}{l}1.59 \times 10^{-11} \exp [-(87 \pm 57) / T] \\
(1.21 \pm 0.13) \times 10^{-11}\end{array}$ & $\begin{array}{l}206-296 \\
295\end{array}$ & Seeley et al., 1996 & DF-RF (d) \\
\hline $\begin{array}{l}3.1 \times 10^{-11} \exp [-(280 \pm 100) / T] \\
(1.41 \pm 0.08) \times 10^{-11}\end{array}$ & $\begin{array}{l}184-298 \\
298\end{array}$ & Beach et al., 2002 & DF-RF \\
\hline \multicolumn{4}{|l|}{ Relative Rate Coefficients } \\
\hline $1.17 \times 10^{-11}$ & 197 & DeMore, 1991 & $\mathrm{RR}(\mathrm{e})$ \\
\hline $1.24 \times 10^{-11}$ & 217 & & \\
\hline
\end{tabular}

\section{Comments}

(a) The $A$-factors tabulated are $\sim 8 \%$ lower than those originally reported due to a revision of the value used for the $\mathrm{O}_{3}$ absorption cross sections.

(b) Discharge flow system with MS detection of $\mathrm{O}_{3}$.

(c) A change in slope of the Arrhenius plot was observed at $\sim 270 \mathrm{~K}$. The data were fitted to two separate Arrhenius expressions over the temperature ranges $189-269 \mathrm{~K}$ and $269-385 \mathrm{~K}$.

(d) Turbulent flow conditions were used with total pressures in the range 66 mbar to 330 mbar.

(e) Competitive chlorination of $\mathrm{O}_{3}-\mathrm{CH}_{4}$ mixtures. $\mathrm{Cl}$ atoms were produced by the photolysis of $\mathrm{Cl}_{2}$ at $300 \mathrm{~nm}$ to $400 \mathrm{~nm}$. The measured rate coefficient ratios $k\left(\mathrm{Cl}+\mathrm{O}_{3}\right) / k\left(\mathrm{Cl}+\mathrm{CH}_{4}\right)$ are placed on an absolute basis using a rate coefficient of $k\left(\mathrm{Cl}+\mathrm{CH}_{4}\right)=6.6 \times 10^{-12} \exp (-1240 / T) \mathrm{cm}^{3}$ molecule ${ }^{-1} \mathrm{~s}^{-1}$

(Vanderzanden and Birks, 1982).

\section{Preferred Values}

$k=1.2 \times 10^{-11} \mathrm{~cm}^{3}$ molecule $\mathrm{e}^{-1} \mathrm{~s}^{-1}$ at $298 \mathrm{~K}$.

$k=2.8 \times 10^{-11} \exp (-250 / T) \mathrm{cm}^{3}$ molecule $\mathrm{e}^{-1} \mathrm{~s}^{-1}$ over the temperature range $180-300 \mathrm{~K}$. 


\section{Reliability}

$\Delta \log k= \pm 0.06$ at $298 \mathrm{~K}$.

$\Delta(E / R)={ }_{-150}^{+100} \mathrm{~K}$.

\section{Comments on Preferred Values}

The majority of the rate coefficients for this reaction have been obtained at temperatures at and below $298 \mathrm{~K}$, and our evaluation is restricted to that temperature regime. The preferred value of $k$ at $298 \mathrm{~K}$ is the mean of the absolute room temperature rate coefficients of Watson et al. (1976), Zahniser et al. (1976), Kurylo and Braun (1976), Clyne and Nip (1976), Leu and DeMore (1976), Toohey et al. (1988), Nicovich et al. (1990) and Seeley et al. (1996), all of which are in excellent agreement. In the recent study of Beach et al. (2002) a slightly but significantly higher value was obtained at $298 \mathrm{~K}$, but the Arrhenius expression for $k$ derived by Beach et al. (2002) from the results over the whole temperature range covered gives a value of $k(298 \mathrm{~K})$ in excellent agreement with the recommended value. The Arrhenius temperature dependence of $k$ is obtained from a least-squares fit to all of the data at and below $298 \mathrm{~K}$ from the studies of Watson et al. (1976), Zahniser et al. (1976), Kurylo and Braun (1976), Clyne and Nip (1976), Leu and DeMore (1976), Toohey et al. (1988) and Beach et al. (2002). This temperature dependence is combined with a pre-exponential factor adjusted to fit the value of $k$ at $298 \mathrm{~K}$.

Nicovich et al. (1990) observed non-Arrhenius behavior in the temperature range studied (189 K to $385 \mathrm{~K}$ ). The data of Nicovich et al. (1990) are in excellent agreement with the present recommendation above $\sim 250 \mathrm{~K}$; at lower temperatures their data are higher than the recommendation although still within the stated uncertainty down to $\sim 220 \mathrm{~K}$.

Vanderzanden and Birks (1982) have interpreted their observation of oxygen atoms in this system as evidence for some production $(0.1 \%$ to $0.5 \%)$ of $\mathrm{O}_{2}\left({ }^{1} \Sigma_{g}\right)$ in this reaction. The possible production of singlet molecular oxygen in this reaction has also been discussed by DeMore (1981) in connection with the $\mathrm{Cl}_{2}$ photosensitized decomposition of ozone. However, Choo and Leu (1985) were unable to detect $\mathrm{O}_{2}\left({ }^{1} \Sigma\right)$ or $\mathrm{O}_{2}\left({ }^{1} \Delta\right)$ in the $\mathrm{Cl}+\mathrm{O}_{3}$ system and set upper limits to the branching ratios for their production of $5 \times 10^{-4}$ and $2.5 \times 10^{-2}$, respectively. A crossed molecular beam study (Zhang and Lee, 1997) also found no evidence for the production of electronically excited $\mathrm{O}_{2}$. Choo and Leu (1985) suggested two possible mechanisms for the observed production of oxygen atoms, involving reactions of vibrationally excited $\mathrm{ClO}$ radicals with $\mathrm{O}_{3}$ or with $\mathrm{Cl}$ atoms, respectively. Burkholder et al. (1989), in a study of infrared line intensities of the ClO radical, present evidence in support of the second mechanism. In their experiments with excess $\mathrm{Cl}$ atoms, the vibrationally excited $\mathrm{ClO}$ radicals produced in the $\mathrm{Cl}+\mathrm{O}_{3}$ reaction can react with $\mathrm{Cl}$ atoms to give $\mathrm{Cl}_{2}$ and oxygen atoms which can then remove additional $\mathrm{ClO}$ radicals (Burkholder et al., 1989). These authors (Burkholder et al., 1989) point out the possibility for systematic error from assuming a $1: 1$ stoichiometry for $[\mathrm{ClO}]:\left[\mathrm{O}_{3}\right]_{0}$ when using the $\mathrm{Cl}+\mathrm{O}_{3}$ reaction as a quantitative source of $\mathrm{ClO}$ radicals for kinetic and spectroscopic studies.

\section{References}

Beach, S. D., Smith, I. W. M., and Tuckett, R. P.: Int. J. Chem. Kinet., 34, 104, 2002.

Burkholder, J. B., Hammer, P. D., Howard, C. J., and Goldman, A.: J. Geophys. Res., 94, 2225, 1989.

Choo, K. Y. and Leu, M.-T.: J. Phys. Chem., 89, 4832, 1985.

Clyne, M. A. A. and Nip, W. S.: J. Chem. Soc. Faraday Trans., 2, 72, 838, 1976.

DeMore, W. B.: presented at 182nd National Meeting, American Chemical Society, New York, August, 1981.

DeMore, W. B. : J. Geophys. Res., 96, 4995, 1991.

Kurylo, M. J. and Braun, W.: Chem. Phys. Lett., 37, 232, 1976.

Leu, M.-T. and DeMore, W. B.: Chem. Phys. Lett., 41, 121, 1976.

Nicovich, J. M., Kreutter, K. D., and Wine, P. H.: Int. J. Chem. Kinet., 22, 399, 1990.

Seeley, J. V., Jayne, J. T., and Molina, M. J.: J. Phys. Chem., 100, 4019, 1996.

Toohey, D. W., Brune, W., and Anderson, J. G.: Int. J. Chem. Kinet., 20, 131, 1988.

Vanderzanden, J. W. and Birks, J. W.: Chem. Phys. Lett., 88, 109, 1982.

Watson, R. T., Machado, G., Fischer, S., and Davis, D. D.: J. Chem. Phys., 65, 2126, 1976.

Zahniser, M. S., Kaufman, F., and Anderson, J. G.: Chem. Phys. Lett., 37, 226, 1976.

Zhang, J. and Lee, Y. T.: J. Phys. Chem. A, 101, 6485, 1997. 
III.A2.30

$$
\mathrm{Cl}+\mathrm{HONO}_{2} \rightarrow \mathrm{HCl}+\mathrm{NO}_{3}
$$

$\Delta H^{\circ}=-4.8 \mathrm{~kJ} \mathrm{~mol}^{-1}$

\section{Rate coefficient data}

\begin{tabular}{lllc}
\hline$k / \mathrm{cm}^{3}$ molecule $\mathrm{s}^{-1} \mathrm{~s}^{-1}$ & Temp./K & Reference & Technique/Comments \\
\hline $\begin{array}{l}\text { Absolute Rate Coefficients } \\
<5 \times 10^{-16}\end{array}$ & & & \\
$<2.0 \times 10^{-16}$ & 293 & Zagogianni et al., 1987 & DF-EPR \\
\hline
\end{tabular}

\section{Comments}

(a) Pulsed laser photolysis of $\mathrm{Cl}_{2}-\mathrm{HNO}_{3}-\mathrm{He}$ mixtures at $351 \mathrm{~nm} . \mathrm{NO}_{3}$ radical concentrations were monitored using longpath absorption spectroscopy. Experiments in which $\mathrm{Cl}$ atom concentrations were measured by resonance fluorescence were also carried out, but were less sensitive and resulted in higher upper limits to the rate coefficient, of $k<1.3 \times 10^{-15} \mathrm{~cm}^{3}$ molecule ${ }^{-1} \mathrm{~s}^{-1}$ at $298 \mathrm{~K}$ and $k<1.0 \times 10^{-15} \mathrm{~cm}^{3}$ molecule ${ }^{-1} \mathrm{~s}^{-1}$ at $400 \mathrm{~K}$.

\section{Preferred Values}

$k<2 \times 10^{-16} \mathrm{~cm}^{3}$ molecule ${ }^{-1} \mathrm{~s}^{-1}$ at $298 \mathrm{~K}$.

Comments on Preferred Values

The preferred upper limit to the rate coefficient is that obtained by Wine et al. (1988), which receives support from the slightly higher value obtained by Zagogianni et al. (1987). Values from earlier studies (Leu and DeMore, 1976; Clark et al., 1982; Kurylo et al., 1983) are well above the preferred upper limit to the rate coefficient $k$.

\section{References}

Clark, R. H., Husain, D., and Jezequel, J. Y.: J. Photochem., 18, 39, 1982.

Kurylo, M. J., Murphy, J. L., and Knable, G. L.: Chem. Phys. Lett., 94, 281, 1983.

Leu, M.-T. and DeMore, W. B.: Chem. Phys. Lett., 41, 121,1976.

Wine, P. H., Wells, J. R., and Nicovich, J. M.: J. Phys. Chem., 92, 2223, 1988.

Zagogianni, H., Mellouki, A., and Poulet, G.: C. R. Acad. Sci., Series 2, 304, 573, 1987. 
III.A2.31

$$
\mathrm{Cl}+\mathrm{NO}_{3} \rightarrow \mathrm{ClO}+\mathrm{NO}_{2}
$$

$\Delta H^{\circ}=-60.2 \mathrm{~kJ} \mathrm{~mol}^{-1}$

\section{Rate coefficient data}

\begin{tabular}{lllc}
\hline$k / \mathrm{cm}^{3}$ molecule & & Technique/Comments \\
\hline Absolute Rate Coefficients & & & \\
$(2.6 \pm 0.5) \times 10^{-11}$ & 298 & Mellouki et al., 1987 & DF-EPR/MS \\
$(2.26 \pm 0.17) \times 10^{-11}$ & 298 & Becker et al., 1991 & DF-MS \\
\hline
\end{tabular}

\section{Preferred Values}

$k=2.4 \times 10^{-11} \mathrm{~cm}^{3}$ molecule ${ }^{-1} \mathrm{~s}^{-1}$, independent of temperature over the range 200-300 K.

\section{Reliability}

$\Delta \log k= \pm 0.2$ at $298 \mathrm{~K}$.

$\Delta(E / R)= \pm 400 \mathrm{~K}$.

\section{Comments on Preferred Values}

The preferred value at room temperature is based on the studies of Mellouki et al. (1987) and Becker et al. (1991). The results of these direct absolute rate studies are preferred over those of earlier relative rate studies (Cox et al., 1984; Burrows et al., 1985; Cox et al., 1987) in which $\mathrm{NO}_{3}$ was monitored by the photolysis of $\mathrm{Cl}_{2}-\mathrm{ClONO}_{2}-\mathrm{N}_{2}$ mixtures. The agreement among these earlier studies (Cox et al., 1984; Burrows et al., 1985; Cox et al., 1987) is not good and probably arises from complications in the chemistry of the systems used. This radical-radical reaction is expected to have a negligible temperature dependence, which is consistent with the results of Cox et al. (1987) over the temperature range $278 \mathrm{~K}$ to $338 \mathrm{~K}$.

\section{References}

Becker, E., Wille, U., Rahman, M. M., and Schindler, R. N.: Ber. Bunsenges. Phys. Chem., 95, 1173, 1991.

Burrows, J. P., Tyndall, G. S., and Moortgat, G. K. : J. Phys. Chem., 89, 4848, 1985.

Cox, R. A., Barton, R. A., Ljungstrøm, E., and Stocker, D. W.: Chem. Phys. Lett., 108, 228, 1984.

Cox, R. A., Fowles, M., Moulton, D., and Wayne, R. P.: J. Phys. Chem., 91, 3361, 1987.

Mellouki, A., Le Bras, G., and Poulet, G.: J. Phys. Chem., 91, 5760, 1987. 
III.A2.32

$$
\mathrm{Cl}+\mathrm{OClO} \rightarrow \mathrm{ClO}+\mathrm{ClO}
$$

$\Delta H^{\circ}=-12.6 \mathrm{~kJ} \mathrm{~mol}^{-1}$

\section{Rate coefficient data}

\begin{tabular}{lllc}
\hline$k / \mathrm{cm}^{3}$ molecule ${ }^{-1} \mathrm{~s}^{-1}$ & Temp./K & Reference & Technique/Comments \\
\hline Absolute Rate Coefficients & & & \\
$>8.3 \times 10^{-13}$ & 298 & Clyne and Coxon, 1968 & DF-UVA \\
$(8.5 \pm 1.2) \times 10^{-12}$ & $\sim 298$ & Basco and Dogra, 1971 & FP-UVA \\
$(5.9 \pm 0.9) \times 10^{-11}$ & $298-588$ & Bemand et al., 1973 & DF-RF/MS (a) \\
$3.0 \times 10^{-11} \exp (174 / T)$ & $229-428$ & Toohey, 1988 & DF-RF (b) \\
$(5.44 \pm 0.09) \times 10^{-11}$ & 298 & & \\
& & & \\
Relative Rate Coefficients & & & (c) \\
$3.7 \times 10^{-10} \operatorname{exp[-(3020\pm 101)/T]}$ & $338-365$ & Gritsan et al., 1975 & \\
\hline
\end{tabular}

\section{Comments}

(a) Discharge flow system with resonance fluorescence detection of $\mathrm{Cl}$ atom decay in excess $\mathrm{OClO}$ and MS measurement of $\mathrm{OClO}$ decay in excess $\mathrm{Cl}$.

(b) The measured rate coefficients $\left(\mathrm{cm}^{3}\right.$ molecule $\left.{ }^{-1} \mathrm{~s}^{-1}\right)$ were: $229 \mathrm{~K},(6.28 \pm 0.21) \times 10^{-11} ; 247 \mathrm{~K},(6.12 \pm 0.20) \times 10^{-11}$; $268 \mathrm{~K}, \quad(5.6 \pm 0.30) \times 10^{-11} ; \quad 298 \mathrm{~K},(5.44 \pm 0.09) \times 10^{-11} ; \quad 367 \mathrm{~K}, \quad(4.84 \pm 0.24) \times 10^{-11} ; \quad$ and $428 \mathrm{~K},(4.40 \pm 0.17)$ $\times 10^{-11}$. A unit-weighted least-squares analysis of these data, using the Arrhenius expression, leads to $k=3.0 \times 10^{-11} \exp (174 / T) \mathrm{cm}^{3}$ molecule $\mathrm{s}^{-1}$.

(c) Thermal decomposition of OClO. Complex chemical system.

\section{Preferred Values}

$k=5.7 \times 10^{-11} \mathrm{~cm}^{3}$ molecule ${ }^{-1} \mathrm{~s}^{-1}$ at $298 \mathrm{~K}$.

$k=3.2 \times 10^{-11} \exp (170 / T) \mathrm{cm}^{3}$ molecule $\mathrm{e}^{-1} \mathrm{~s}^{-1}$ over the temperature range $220-430 \mathrm{~K}$.

\section{Reliability}

$\Delta \log k= \pm 0.1$ at $298 \mathrm{~K}$.

$\Delta(E / R)= \pm 200 \mathrm{~K}$.

\section{Comments on Preferred Values}

The data of Toohey (1988) agree well with the earlier study of Bemand et al. (1973) at $298 \mathrm{~K}$, but show a small negative temperature dependence over a similar temperature range to that over which Bemand et al. (1973) saw little change in $k$. The preferred value is the average of the $298 \mathrm{~K}$ values from the two studies of Bemand et al. (1973) and Toohey (1988) and the temperature dependence of Toohey (1988) is accepted but with error limits covering the possibility that $k$ is independent of temperature. The earlier data of Clyne and Coxon (1968) and Basco and Dogra (1971) are rejected following the recommendation of Bemand et al. (1973).

\section{References}

Basco, N. and Dogra, S. K.: Proc. Roy. Soc. (London), A323, 417, 1971.

Bemand, P. P., Clyne, M. A. A., and Watson, R. T.: J. Chem. Soc. Faraday Trans., 1, 69, 1356, 1973. 
Clyne, M. A. A. and Coxon, J. A.: Proc. Roy. Soc. (London), A303, 207, 1968.

Gritsan, V. I., Panfilov, V. N., and Sukhanov, I. L.: Reaction Kinetics and Catalysis Letters, 2, 265, 1975.

Toohey, D. W.: Kinetic and Mechanistic Studies of Reactions of Bromine and Chlorine Species Important in the Earth's Stratosphere, Ph.D. Thesis, Harvard University, Cambridge, MA, 1988. 
III.A2.33

$$
\mathrm{Cl}+\mathrm{Cl}_{2} \mathrm{O} \rightarrow \mathrm{Cl}_{2}+\mathrm{ClO}
$$

$\Delta H^{\circ}=-96.9 \mathrm{~kJ} \mathrm{~mol}^{-1}$

\section{Rate coefficient data}

\begin{tabular}{lllc}
\hline$k / \mathrm{cm}^{3}$ molecule ${ }^{-1} \mathrm{~s}^{-1}$ & Temp./K & Reference & Technique/Comments \\
\hline Absolute Rate Coefficients & & & \\
$(9.33 \pm 0.54) \times 10^{-11}$ & 298 & Ray et al., 1980 & DF-MS \\
$(1.03 \pm 0.08) \times 10^{-10}$ & 298 & Ray et al., 1980 & DF-RF \\
$6.0 \times 10^{-11} \exp [(127 \pm 30) / T]$ & $233-373$ & Stevens and Anderson 1992 & DF-RF \\
$(9.1 \pm 0.4) \times 10^{-11}$ & 298 & & \\
\hline
\end{tabular}

\section{Preferred Values}

$k=9.6 \times 10^{-11} \mathrm{~cm}^{3}$ molecule $\mathrm{e}^{-1} \mathrm{~s}^{-1}$ at $298 \mathrm{~K}$.

$k=6.2 \times 10^{-11} \exp (130 / T) \mathrm{cm}^{3}$ molecule $\mathrm{e}^{-1} \mathrm{~s}^{-1}$ over the temperature range 230-380 K.

\section{Reliability}

$\Delta \log k= \pm 0.1$ at $298 \mathrm{~K}$.

$\Delta(E / R)= \pm 130 \mathrm{~K}$.

\section{Comments on Preferred Values}

The preferred room temperature value is the mean of the value reported by Stevens and Anderson (1992) and the values obtained by Ray et al. (1980) using two completely independent techniques. This value is confirmed by the relative rate study of Burrows and Cox (1981). The much lower value reported earlier by Basco and Dogra (1971) has been rejected. The recommended temperature dependence is from Stevens and Anderson (1992). There is apparently no pressure dependence over the range 1 mbar to 1 bar (Ray et al., 1980; Stevens and Anderson, 1992; Burrows and Cox, 1981).

\section{References}

Basco, N. and Dogra, S. K.: Proc. Roy. Soc. London A, 323, 401, 1971.

Burrows, J. P. and Cox, R. A.: J. Chem. Soc. Faraday Trans., 1, 77, 2465, 1981.

Ray, G. W., Keyser, L. F., and Watson, R. T.: J. Phys. Chem., 84, 1674, 1980.

Stevens, P. S. and Anderson, J. G.: J. Phys. Chem., 96, 1708, 1992. 


\section{III.A2.34}

$$
\mathrm{Cl}+\mathrm{Cl}_{2} \mathrm{O}_{2} \rightarrow \mathrm{Cl}_{2}+\mathrm{ClOO}
$$

$\Delta H^{\circ}=-151.4 \mathrm{~kJ} \mathrm{~mol}^{-1}$

\section{Rate coefficient data}

\begin{tabular}{lllc}
\hline$k / \mathrm{cm}^{3}$ molecule ${ }^{-1} \mathrm{~s}^{-1}$ & Temp./K & Reference & Technique/Comments \\
\hline $\begin{array}{l}\text { Absolute Rate Coefficients } \\
7.6 \times 10^{-11} \exp [(65.4 \pm 17.9) / T]\end{array}$ & $217-298$ & Ingham et al., 2005 & DF-MS (a) \\
$(9.30 \pm 0.95) \times 10^{-11}$ & 298 & & \\
$(9.51 \pm 1.17) \times 10^{-11}$ & 298 & & \\
& & & \\
$\begin{array}{l}\text { Relative Rate Coefficients } \\
(1.00 \pm 0.02) \times 10^{-10}\end{array}$ & 233 & Cox and Hayman, 1988 & (a) \\
\hline
\end{tabular}

\section{Comments}

(a) $k$ was determined from pseudo-first order decay of $\mathrm{Cl}_{2} \mathrm{O}_{2}$ in the presence of an excess of $\mathrm{Cl}$ atoms. [Cl] was determined after titration to either $\mathrm{BrCl}$ or vinyl chloride, following reaction with $\mathrm{Br}_{2}$ or vinyl bromide (the two presented values of $k$ at $298 \mathrm{~K}$ were reported for these respective titration reactions). The temperature dependence expression was obtained from fitting an Arrhenius expression to all the data.

(b) Static photolysis of $\mathrm{Cl}_{2}-\mathrm{Cl}_{2} \mathrm{O}-\mathrm{N}_{2}$ mixtures at $350 \mathrm{~nm}$. The time dependence of $\left[\mathrm{Cl}_{2} \mathrm{O}_{2}\right]$ and $\left[\mathrm{Cl}_{2} \mathrm{O}\right]$ were monitored by photodiode array UV spectroscopy, yielding $k\left(\mathrm{Cl}+\mathrm{Cl}_{2} \mathrm{O}\right) / 2 k=0.54 \pm 0.01$ at $233 \mathrm{~K}$. This rate coefficient ratio is placed on an absolute basis by use of a rate coefficient of $k\left(\mathrm{Cl}+\mathrm{Cl}_{2} \mathrm{O}\right)=1.08 \times 10^{-10} \mathrm{~cm}^{3}$ molecule ${ }^{-1} \mathrm{~s}^{-1}$

at $233 \mathrm{~K}$ (this evaluation).

\section{Preferred Values}

$k=9.5 \times 10^{-11} \mathrm{~cm}^{3}$ molecule $\mathrm{e}^{-1} \mathrm{~s}^{-1}$ at $298 \mathrm{~K}$.

$k=7.6 \times 10^{-11} \exp (65 / T) \mathrm{cm}^{3}$ molecule ${ }^{-1} \mathrm{~s}^{-1}$ over the range $220-300 \mathrm{~K}$.

\section{Reliability}

$\Delta \log k= \pm 0.2$ at $298 \mathrm{~K}$.

$\Delta(E / R)= \pm 150 \mathrm{~K}$.

Comments on Preferred Values

The preferred values are based on the direct study of Ingham et al. (2005), who report a very weak negative temperature dependence for the reaction. The rate coefficient at $233 \mathrm{~K}$ from the Ingham et al. (2005) rate expression is in excellent agreement with that derived from the earlier relative rate determination of Cox and Hayman (1988). Although there is no reported confirmation of the likely reaction products $\left(\mathrm{Cl}_{2}+\mathrm{ClOO}\right)$, Ingham et al. (2005) were able to rule out the alternative formation of $\mathrm{Cl}_{2} \mathrm{O}$ and $\mathrm{ClO}$ from a failure to detect $\mathrm{ClO}$ as a product under any of the conditions employed in their study.

\section{References}

Cox, R. A. and Hayman, G. D.: Nature, 332, 796, 1988.

Ingham, T., Sander, S. P. and Friedl, R. R., Faraday Discuss., 130, 89, 2005. 
III.A2.35

$$
\mathrm{Cl}+\mathrm{ClONO}_{2} \rightarrow \mathrm{Cl}_{2}+\mathrm{NO}_{3}
$$

$\Delta H^{\circ}=-70.5 \mathrm{~kJ} \mathrm{~mol}^{-1}$

\section{Rate coefficient data}

\begin{tabular}{lllc}
\hline$k / \mathrm{cm}^{3}$ molecule $\mathrm{s}^{-1}$ & Temp./K & Reference & Technique/Comments \\
\hline Absolute Rate Coefficients & & & \\
$6.3 \times 10^{-12} \exp (150 / T)$ & $219-298$ & Margitan, 1983 & FP-RF (a) \\
$(1.04 \pm 0.16) \times 10^{-11}$ & 298 & & \\
$7.3 \times 10^{-12} \exp (165 / T)$ & $220-296$ & Kurylo et al., 1983 & FP-RF (b) \\
$(1.20 \pm 0.24) \times 10^{-11}$ & 296 & & \\
$6.0 \times 10^{-12} \exp [(140 \pm 30) / T]$ & $195-298$ & Yokelson et al., 1995 & PLP-RF/TDLS (c) \\
$(9.6 \pm 1.0) \times 10^{-12}$ & 298 & & \\
$(9.1 \pm 1.2) \times 10^{-12}$ & 298 & Tyndall et al., 1997 & PLP-RF \\
\hline
\end{tabular}

\section{Comments}

(a) The $\mathrm{O}\left({ }^{3} \mathrm{P}\right)$ atom abstraction channel to give $\mathrm{ClO}+\mathrm{ClONO}$ was shown to be unimportant based on results of experiments with added $\mathrm{NO}$, in which $\mathrm{Cl}$ was not regenerated by the fast reaction $\mathrm{ClO}+\mathrm{NO} \rightarrow \mathrm{Cl}+\mathrm{NO}_{2}$.

(b) Supersedes earlier results from the same laboratory (Kurylo and Manning, 1977).

(c) Decays of $\mathrm{Cl}$ atoms were measured by $\mathrm{RF}$ over the temperature range $195-354 \mathrm{~K} \quad\left(k=6.5 \times 10^{-12}\right.$ $\exp [(120 \pm 20) / T] \mathrm{cm}^{3}$ molecule $\left.\mathrm{s}^{-1} \mathrm{~s}^{-1}\right)$ and formation of $\mathrm{NO}_{3}$ radicals were measured by tunable diode laser spectroscopy (TDLS) over the temperature range $200-298 \mathrm{~K}\left(k=6.0 \times 10^{-12} \exp [(140 \pm 30) / T] \mathrm{cm}^{3}\right.$ molecule $\left.^{-1} \mathrm{~s}^{-1}\right)$. The values cited in the table are the combined results of experiments using both detection systems for the temperature range $195-298 \mathrm{~K}$.

\section{Preferred Values}

$k=1.0 \times 10^{-11} \mathrm{~cm}^{3}$ molecule $\mathrm{e}^{-1} \mathrm{~s}^{-1}$ at $298 \mathrm{~K}$.

$k=6.2 \times 10^{-12} \exp (145 / T) \mathrm{cm}^{3}$ molecule $\mathrm{e}^{-1} \mathrm{~s}^{-1}$ over the temperature range 190-360 K.

\section{Reliability}

$\Delta \log k= \pm 0.1$ at $298 \mathrm{~K}$.

$\Delta(E / R)= \pm 50 \mathrm{~K}$.

\section{Comments on Preferred Values}

The recommended Arrhenius equation is derived from the studies of Margitan (1983) and Yokelson et al. (1995), which are in excellent agreement. The data of Kurylo et al. (1983) and Tyndall et al. (1997) agree with the preferred values within the recommended uncertainty limits. Margitan (1983) has shown that the reaction proceeds by Cl-atom abstraction rather than by O-atom abstraction and this was confirmed by Yokelson et al. (1995), who determined that more than $95 \%$ of the reaction formed $\mathrm{Cl}_{2}$ and $\mathrm{NO}_{3}$ at $298 \mathrm{~K}$.

\section{References}

Kurylo, M. J. and Manning, R. G.: Chem. Phys. Lett., 48, 279, 1977.

Kurylo, M. J., Knable, G. L., and Murphy, J. L.: Chem. Phys. Lett., 95, 9, 1983.

Margitan, J. J.: J. Phys. Chem., 87, 674, 1983. 
Tyndall, G. S., Kegley-Owen, C. S., Orlando, J. J., and Calvert, J. G.: J. Chem. Soc. Faraday Trans., 93, 2675, 1997.

Yokelson, R. J., Burkholder, J. B., Goldfarb, L., Fox, R. W., Gilles, M. K., and Ravishankara, A. R.: J. Phys. Chem., 99, $13976,1995$. 
III.A2.36

$\mathrm{HO}+\mathrm{Cl}_{2} \rightarrow \mathrm{HOCl}+\mathrm{Cl}$

$\Delta H^{\circ}=6 \mathrm{~kJ} \mathrm{~mol}^{-1}$

\section{Rate coefficient data}

\begin{tabular}{llll}
\hline$k / \mathrm{cm}^{3}$ molecule $\mathrm{s}^{-1}$ & Temp./K & Reference & Technique/Comments \\
\hline Absolute Rate Coefficients & & & \\
$(5.5 \pm 0.3) \times 10^{-14}$ & 298 & Leu and Lin, 1979 & DF-RF \\
$\sim 7.4 \times 10^{-14}$ & 298 & Ravishankara et al., 1983 & DF-RF \\
$(6.70 \pm 0.72) \times 10^{-14}$ & $298 \pm 3$ & Loewenstein and Anderson, 1984 & DF-RF \\
$1.7 \times 10^{-12} \exp [-(911 \pm 373) / T]$ & $253-333$ & Boodaghians et al., 1987 & DF-RF \\
$(6.8 \pm 1.0) \times 10^{-14}$ & $293 \pm 2$ & & \\
$3.77 \times 10^{-12} \exp [-(1228 \pm 140) / T]$ & $231-354$ & Gilles et al., 1999 & PLP-LIF \\
$(5.95 \pm 0.75) \times 10^{-14}$ & 298 & & \\
$3.09 \times 10^{-16} T^{1.35} \exp (-745 / T)$ & $297-826$ & Bryukov et al., 2004 & PLP-LIF (a) \\
$(6.34 \pm 0.18) \times 10^{-14}$ & 297 & & \\
\hline
\end{tabular}

\section{Comments}

(a) The cited $297 \mathrm{~K}$ rate coefficient is a weighted average of the two determinations at this temperature. Combining rate coefficient calculations with their data and those of Gilles et al. (1999) resulted in the expression $1.35 \times 10^{-16} T^{1.50}$ $\exp (-723 / T) \mathrm{cm}^{3}$ molecule ${ }^{-1} \mathrm{~s}^{-1}$, which was proposed to be applicable to the temperature range 200-3000 $\mathrm{K}$ (Bryukov et al., 2004).

\section{Preferred Values}

$k=6.5 \times 10^{-14} \mathrm{~cm}^{3}$ molecule $\mathrm{e}^{-1} \mathrm{~s}^{-1}$ at $298 \mathrm{~K}$.

$k=3.6 \times 10^{-12} \exp (-1200 / T) \mathrm{cm}^{3}$ molecule $\mathrm{s}^{-1} \mathrm{~s}^{-1}$ over the temperature range $230-360 \mathrm{~K}$.

\section{Reliability}

$\Delta \log k= \pm 0.08$ at $298 \mathrm{~K}$.

$\Delta(E / R)= \pm 300 \mathrm{~K}$.

Comments on Preferred Values

The preferred values are based on the data of Loewenstein and Anderson (1984), Boodaghians et al. (1987), Gilles et al. (1999) and Bryukov et al. (2004), which are in good agreement concerning the room temperature rate coefficient. Because of the more atmospherically relevant temperature range covered, the preferred temperature dependence is that reported by Gilles et al. (1999), with the pre-exponential factor, A, being adjusted to fit the preferred $298 \mathrm{~K}$ rate coefficient. Loewenstein and Anderson (1984) determined that the exclusive products are $\mathrm{HOCl}+\mathrm{Cl}$.

\section{References}

Boodaghians, R. B., Hall, I. W., and Wayne, R. P.: J. Chem. Soc. Faraday Trans., 2 83, 529, 1987.

Bryukov, M. G., Knyazev, V. D., Lomnicki, S. M., McFerrin, C. A. and Dellinger, B.: J. Phys. Chem. A 108, 10464, 2004. Gilles, M. K., Burkholder, J. B., and Ravishankara, A. R.: Int. J. Chem. Kinet., 31, 417, 1999.

Leu, M. T. and Lin, C. L.: Geophys. Res. Lett., 6, 425, 1979.

Loewenstein, L. M. and Anderson, J. G.: J. Phys. Chem., 88, 6277, 1984.

Ravishankara, A. R., Eisele, F. L., and Wine, P. H.: J. Chem. Phys., 78, 1140, 1983. 


\section{III.A2.37}

$$
\mathrm{HO}+\mathrm{HCl} \rightarrow \mathrm{H}_{2} \mathrm{O}+\mathrm{Cl}
$$

$\Delta H^{\circ}=-65.4 \mathrm{~kJ} \mathrm{~mol}^{-1}$

\section{Rate coefficient data}

\begin{tabular}{|c|c|c|c|}
\hline$k / \mathrm{cm}^{3}$ molecule ${ }^{-1} \mathrm{~s}^{-1}$ & Temp./K & Reference & Technique/Comments \\
\hline \multicolumn{4}{|l|}{ Absolute Rate Coefficients } \\
\hline $4.1 \times 10^{-12} \exp [-(529 \pm 24) / T]$ & $220-480$ & Smith and Zellner, 1974 & FP-RA \\
\hline$(6.9 \pm 1) \times 10^{-13}$ & 298 & & \\
\hline $2.0 \times 10^{-12} \exp [-(312 \pm 10) / T]$ & $224-440$ & Zahniser et al., 1974 & DF-RF \\
\hline$(6.7 \pm 0.4) \times 10^{-13}$ & 297 & & \\
\hline$(6.6 \pm 1.7) \times 10^{-13}$ & 293 & Hack et al., 1977 & DF-EPR (a) \\
\hline $3.3 \times 10^{-12} \exp [-(472 \pm 40) / T]$ & $250-402$ & Ravishankara et al., 1977 & FP-RF \\
\hline$(6.6 \pm 0.4) \times 10^{-13}$ & 298 & & \\
\hline$(6.66 \pm 0.52) \times 10^{-13}$ & 300 & Husain et al., 1981 & FP-RF \\
\hline$(6.8 \pm 0.25) \times 10^{-13}$ & $298 \pm 4$ & $\begin{array}{l}\text { Cannon et al., 1984; } \\
\text { Smith and Williams, } 1986\end{array}$ & FP-LIF \\
\hline $2.1 \times 10^{-12} \exp [-(285 \pm 40) / T]$ & $258-334$ & Keyser, 1984 & DF-RF \\
\hline$(7.9 \pm 0.4) \times 10^{-13}$ & $295 \pm 2$ & & \\
\hline $\begin{array}{l}4.6 \times 10^{-12} \exp [-(500 \pm 60) / T] \\
(8.5 \pm 1.5) \times 10^{-13}\end{array}$ & $\begin{array}{l}240-295 \\
295\end{array}$ & Molina et al., 1984 & PLP/FP-RF \\
\hline $\begin{array}{l}2.94 \times 10^{-12} \exp [-(446 \pm 32) / T] \\
(6.7 \pm 0.46) \times 10^{-13}\end{array}$ & $\begin{array}{l}300-700 \\
300\end{array}$ & Husain et al., 1984 & FP-RF \\
\hline $2.4 \times 10^{-12} \exp [-(327 \pm 28) / T]$ & $240-363$ & Ravishankara et al., 1985 & FP-RF/PLP-RF/ \\
\hline$(8.01 \pm 0.44) \times 10^{-13}$ & 298 & & PLP-LIF (b) \\
\hline$(7.8 \pm 0.3) \times 10^{-13}$ & 298 & Sharkey and Smith, 1993 & PLP-LIF \\
\hline$(5.4 \pm 0.25) \times 10^{-13}$ & 216 & & \\
\hline$(5.6 \pm 0.45) \times 10^{-13}$ & 178 & & \\
\hline$(5.2 \pm 0.3) \times 10^{-13}$ & 138 & & \\
\hline $3.28 \times 10^{-17} T^{1.66} \exp (184 / T)$ & $200-400$ & Battin-Leclerc et al., 1999 & PLP-LIF (c) \\
\hline$(7.96 \pm 0.60) \times 10^{-13}$ & 298 & & \\
\hline $3.2 \times 10^{-15} T^{0.99} \exp (-62 / T)$ & $298-1015$ & Bryukov et al., 2006 & PLP-LIF (d) \\
\hline$(7.39 \pm 0.11) \times 10^{-13}$ & 298 & & \\
\hline
\end{tabular}

\section{Comments}

(a) Rate coefficients also measured at $435 \mathrm{~K}$ and $567 \mathrm{~K}$ of $8.1 \times \quad 10^{-13} \mathrm{~cm}^{3} \mathrm{molecule}^{-1} \mathrm{~s}^{-1}$ and $1.25 \times 10^{-12} \mathrm{~cm}^{3}$ molecule $\mathrm{e}^{-1} \mathrm{~s}^{-1}$, respectively.

(b) Rate coefficients measured over the temperature range 240-1055 K. The Arrhenius plot of the rate coefficients measured over this extended temperature range is curved, with $k=4.5 \times 10^{-17} T^{1.65} \exp \left(112 / T\right.$ ) $\mathrm{cm}^{3}$ molecule ${ }^{-1} \mathrm{~s}^{-1}$ (Ravishankara et al., 1985).

(c) Over the limited temperature range $200-298 \mathrm{~K}$, the data were also fit to the Arrhenius expression, with $k=1.7 \times 10^{-12} \exp [-$ $(225 \pm 20) / T] \mathrm{cm}^{3}$ molecule $\mathrm{e}^{-1} \mathrm{~s}^{-1}$ (note that the publication (Battin-Leclerc et al., 1999) gives a pre-exponential factor in the Arrhenius expression of $1.7 \times 10^{-11} \mathrm{~cm}^{3}$ molecule ${ }^{-1} \mathrm{~s}^{-1}$ ). Rate coefficients were also measured for the reactions of the HO radical with DCl $(252-387 \mathrm{~K})$ and for the reactions of the DO radical with $\mathrm{HCl}(213-372 \mathrm{~K})$ and $\mathrm{DCl}(213-401 \mathrm{~K})$.

(d) The cited $298 \mathrm{~K}$ rate coefficient is the weighted average of the two measurements at $298 \mathrm{~K}$. Combining their data with those of Battin-Leclerc et al. (1999), Bryukov et al. (2006) derived the expression $k=6.64 \times 10^{-16} T^{1.20} \exp (72 / T) \mathrm{cm}^{3}$ molecule $\mathrm{e}^{-1} \mathrm{~s}^{-1}$ for the temperature range $200-1015 \mathrm{~K}$. 


\section{Preferred Values}

$k=7.8 \times 10^{-13} \mathrm{~cm}^{3}$ molecule $\mathrm{e}^{-1} \mathrm{~s}^{-1}$ at $298 \mathrm{~K}$.

$k=1.7 \times 10^{-12} \exp (-230 / T) \mathrm{cm}^{3}$ molecule $\mathrm{e}^{-1} \mathrm{~s}^{-1}$ over the temperature range $200-300 \mathrm{~K}$.

\section{Reliability}

$\Delta \log k= \pm 0.06$ at $298 \mathrm{~K}$.

$\Delta(E / R)= \pm 100 \mathrm{~K}$.

\section{Comments on Preferred Values}

The studies of Keyser (1984), Molina et al. (1984), Ravishankara et al. (1985) and Battin-Leclerc et al. (1999), in which careful attention was paid to the $\mathrm{HCl}$ present in the experiments, all show room temperature values somewhat higher than most other studies (Takacs and Glass, 1973; Smith and Zellner, 1974; Zahniser et al., 1974; Hack et al., 1977; Ravishankara et al., 1977; Husain et al., 1981, 1984; Cannon et al., 1984; Smith and Williams, 1986). Ravishankara et al. (1985) showed that $\mathrm{HCl}$ losses can be a problem, leading to erroneously low measured rate coefficients, and this is a plausible cause of these discrepancies. The rate coefficients obtained in the studies of Keyser (1984), Molina et al. (1984), Ravishankara et al. (1985), Battin-Leclerc et al. (1999) and Bryukov et al. (2006) are in good agreement. An Arrhenius plot of the rate coefficients from these five studies exhibits curvature (Battin-Leclerc et al., 1999; Bryukov et al., 2006). The preferred temperature-dependent expression for the range $200-300 \mathrm{~K}$ is obtained by a linear least-squares fit to the $\leq 299 \mathrm{~K}$ data from the studies of Keyser (1984), Molina et al. (1984), Ravishankara et al. (1985), Battin-Leclerc et al. (1999) and Bryukov et al. (2006). Over more extended temperature ranges the three parameter expression obtained by Bryukov et al. (2006), of $k=6.64 \times 10^{-16} T^{1.20}$ $\exp (72 / T) \mathrm{cm}^{3}$ molecule ${ }^{-1} \mathrm{~s}^{-1}(200-1015 \mathrm{~K}$ ), should be used. Results of the low temperature study of Sharkey and Smith (1993) are in good agreement with the recommended Arrhenius expression down to $216 \mathrm{~K}$, but are (as expected due to the non-Arrhenius behavior) significantly higher at $178 \mathrm{~K}$ and $138 \mathrm{~K}$.

\section{References}

Battin-Leclerc, F., Kim, I. K., Talukdar, R. K., Portmann, R. W., Ravishankara, A. R., Steckler, R., and Brown, D.: J. Phys. Chem. A, 103, 3237, 1999.

Bryukov, M. G., Dellinger, B. and Knyazev, V. D.: J. Phys. Chem. A 110, 936, 2006. Cannon, B. D., Robertshaw, J. S., Smith, I. W. M. and Williams, M. D.: Chem. Phys. Lett. 105, 380, 1984

Cannon, B. D., Robertshaw, J. S., Smith, I. W. M., and Williams, M. D.: Chem. Phys. Lett., 105, 380, 1984.

Hack, W., Mex, G., and Wagner, H. G.: Ber. Bunsenges. Phys. Chem., 81, 677, 1977.

Husain, D., Plane, J. M. C., and Slater, N. K. H.: J. Chem. Soc. Faraday Trans., 2 77, 1949, 1981.

Husain, D., Plane, J. M. C., and Xiang, C. C.: J. Chem. Soc. Faraday Trans., 2 80, 713, 1984.

Keyser, L. F.: J. Phys. Chem., 88, 4750, 1984.

Molina, M. J., Molina, L. T., and Smith, C. A.: Int. J. Chem. Kinet., 16, 1151, 1984.

Ravishankara, A. R., Smith, G., Watson, R. T., and Davis, D. D.: J. Phys. Chem., 81, 2220, 1977.

Ravishankara, A. R., Wine, P. H., Wells, J. R., and Thompson, R. L.: Int. J. Chem. Kinet., 17, 1281, 1985.

Sharkey, P. and Smith, I. W. M.: J. Chem. Soc. Faraday Trans., 89, 631, 1993.

Smith, I. W. M. and Zellner, R.: J. Chem. Soc. Faraday Trans., 2 70, 1045, 1974.

Smith, I. W. M and Williams, M. D.: J. Chem. Soc. Faraday Trans., 2 82, 1043, 1986.

Takacs, G. A. and Glass, G. P.: J. Phys. Chem., 77, 1948, 1973.

Zahniser, M. S., Kaufman, F., and Anderson, J. G.: Chem. Phys. Lett., 27, 507, 1974. 
III.A2.38

$$
\mathrm{HO}+\mathrm{HOCl} \rightarrow \mathrm{H}_{2} \mathrm{O}+\mathrm{ClO}
$$

$\Delta H^{\circ}=-99.4 \mathrm{~kJ} \mathrm{~mol}^{-1}$

\section{Rate coefficient data}

\begin{tabular}{lllc}
\hline$k / \mathrm{cm}^{3}$ molecule ${ }^{-1} \mathrm{~s}^{-1}$ & Temp./K & Reference & Technique/Comments \\
\hline $\begin{array}{l}\text { Absolute Rate Coefficients } \\
(1.7-9.5) \times 10^{-13}\end{array}$ & 298 & Ennis and Birks, 1988 & DF-RF/MS (a) \\
\hline
\end{tabular}

\section{Comments}

(a) $\mathrm{HO}$ radical decays in the presence of excess $\mathrm{HOCl}$ were monitored by resonance fluorescence. $\mathrm{HOCl}$ concentrations were measured by MS. The effects of the presence of $\mathrm{Cl}_{2} \mathrm{O}$ and $\mathrm{Cl}_{2}$ impurities in the $\mathrm{HOCl}$ and the occurrence of secondary reactions were investigated through numerical modeling, and the lower and upper limits to the rate coefficient $k$ cited in the table obtained.

\section{Preferred Values}

$k=5.0 \times 10^{-13} \mathrm{~cm}^{3}$ molecule ${ }^{-1} \mathrm{~s}^{-1}$ at $298 \mathrm{~K}$.

\section{Reliability}

$\Delta \log k= \pm 0.5$ at $298 \mathrm{~K}$.

\section{Comments on Preferred Values}

The only reported experimental value (Ennis and Birks, 1988) has a large uncertainty, and the preferred value is based on the mid-range value of $5 \times 10^{-13} \mathrm{~cm}^{3}$ molecule $\mathrm{e}^{-1} \mathrm{~s}^{-1}$ at $298 \mathrm{~K}$ from this study.

\section{References}

Ennis, C. A. and Birks, J. W.: J. Phys. Chem., 92, 1119, 1988. 
III.A2.39

$$
\begin{aligned}
\mathrm{HO}+\mathrm{ClO} & \rightarrow \mathrm{HO}_{2}+\mathrm{Cl} \\
& \rightarrow \mathrm{HCl}+\mathrm{O}_{2}
\end{aligned}
$$

$\Delta H^{\circ}(1)=-2.9 \mathrm{~kJ} \mathrm{~mol}^{-1}$

$\Delta H^{\circ}(2)=-231 \mathrm{~kJ} \mathrm{~mol}^{-1}$

\begin{tabular}{|c|c|c|c|}
\hline$k / \mathrm{cm}^{3}$ molecule ${ }^{-1} \mathrm{~s}^{-1}$ & Temp./K & Reference & Technique/Comments \\
\hline \multicolumn{4}{|l|}{ Absolute Rate Coefficients } \\
\hline$(9.1 \pm 1.3) \times 10^{-12}$ & 298 & Leu and Lin, 1979 & DF-RF \\
\hline$(1.17 \pm 0.33) \times 10^{-11}$ & $248-335$ & Ravishankara et al., 1983 & DF-RF \\
\hline$(1.19 \pm 0.09) \times 10^{-11}$ & $243-298$ & Burrows et al., 1984 & DF-RF (a) \\
\hline $8.0 \times 10^{-12} \exp [(235 \pm 46) / T]$ & $219-373$ & Hills and Howard, 1984 & DF-LMR (b) \\
\hline$(1.75 \pm 0.31) \times 10^{-11}$ & 298 & & \\
\hline$(1.94 \pm 0.38) \times 10^{-11}$ & 298 & Poulet et al., 1986 & DF-LIF (c) ) \\
\hline $5.5 \times 10^{-12} \exp [(292 \pm 72) / T]$ & $\begin{array}{l}205-298 \\
298\end{array}$ & Lipson et al., 1997 & DF-CIMS \\
\hline $\begin{array}{l}(1.46 \pm 0.23) \times 10^{-11} \\
k_{2}=1.7 \times 10^{-13} \exp [(363 \pm 50) / T]\end{array}$ & $\begin{array}{l}298 \\
210-298\end{array}$ & Lipson et al., 1997 & DF-CIMS (d) \\
\hline$k_{2}=5.7 \times 10^{-13}$ & 298 & & \\
\hline $\begin{array}{l}8.9 \times 10^{-12} \exp [(295 \pm 95) / T] \\
(2.44 \pm 0.63) \times 10^{-11}\end{array}$ & $\begin{array}{l}234-356 \\
298\end{array}$ & Kegley-Owen et al., 1999 & $\mathrm{DF}(\mathrm{e})$ \\
\hline$k_{2}=3.2 \times 10^{-13} \exp [(325 \pm 60) / T]$ & $207-298$ & Lipson et al., 1999 & F-CIMS (f) \\
\hline$k_{2}=(9.5 \pm 1.6) \times 10^{-13}$ & 298 & & \\
\hline $6.7 \times 10^{-12} \exp [(360 \pm 90) / T]$ & $230-360$ & Bedjanian et al., 2001 & DF-MS (g) \\
\hline$(2.2 \pm 0.4) \times 10^{-11}$ & 298 & & \\
\hline$k_{2}=9.7 \times 10^{-14} \exp [(600 \pm 120) / T]$ & $230-320$ & & \\
\hline$k_{2}=(7.3 \pm 2.2) \times 10^{-13}$ & 298 & & \\
\hline $7.2 \times 10^{-12} \exp [(333 \pm 70) / T]$ & $218-298$ & Wang and Keyser, 2001a & DF-RF/UVA (h) \\
\hline$(2.22 \pm 0.33) \times 10^{-11}$ & 298 & & \\
\hline$k_{2}=(1.25 \pm 0.45) \times 10^{-12}$ & 298 & Tyndall et al., 2002 & FP-IR (i) \\
\hline \multicolumn{4}{|l|}{ Branching Ratios } \\
\hline$k_{2} / k=0.05 \pm 0.02$ & 298 & Lipson et al., 1997 & DF-CIMS (j) \\
\hline$k_{2} / k=0.06 \pm 0.02$ & 210 & & \\
\hline$k_{2} / k=0.090 \pm 0.048$ & $218-298$ & Wang and Keyser, 2001b & DF-RF/IR/UVA (h,k) \\
\hline
\end{tabular}

Rate coefficient data $\left(k=k_{1}+k_{2}\right)$

\section{Comments}

(a) Rate coefficient ratio of $k_{1} / k=0.85 \pm 0.07$, independent of temperature over the range $243-298 \mathrm{~K}$, was determined from measurement of $\mathrm{HO}_{2}$ radical concentrations (after conversion to $\mathrm{HO}$ radicals by reaction with $\mathrm{NO}$ ).

(b) The rate coefficient ratio, $k_{1} / k$, was measured to be $k_{1} / k=0.86 \pm 0.14$ at $293 \mathrm{~K}$ from measurement of the $\mathrm{HO}_{2}$ radical concentrations by LMR.

(c) The rate coefficient ratio, $k_{1} / k$, was measured to be $0.98 \pm 0.12$ at $298 \mathrm{~K}$ from MS detection of $\mathrm{HCl}$.

(d) Measurements of the DCl product by CIMS in experiments using DO radicals. The overall rate coefficient measured for reaction of DO radicals with $\mathrm{ClO}$ radicals was $k=4.2 \times 10^{-12} \exp [(280 \pm 114) / T] \mathrm{cm}^{3}$ molecule $^{-1} \mathrm{~s}^{-1}$ over the temperature range $200 \mathrm{~K}$ to $298 \mathrm{~K}$, a factor of $1.35-1.4$ lower than the rate coefficient for the HO radical reaction. 
(e) $\mathrm{HO}$ radicals were generated by pulsed laser photolysis of $\mathrm{O}_{3}$ (or $\mathrm{ClO}$ ) at $248 \mathrm{~nm}$ and monitored by LIF. ClO radicals were generated by reaction of $\mathrm{Cl}$ atoms (produced by a microwave discharge in $\mathrm{Cl}_{2}-\mathrm{He}$ mixtures) with $\mathrm{O}_{3}$, and monitored by UV/visible absorption.

(f) Turbulent flow reactor operated at total pressures of $125 \mathrm{mbar}$ to $270 \mathrm{mbar}$. The measurements of the rate coefficients $k_{2}$ were combined with the overall rate coefficient $k=5.5 \times 10^{-12} \exp (292 / T) \mathrm{cm}^{3}$ molecule ${ }^{-1} \mathrm{~s}^{-1}$ previously determined by the same research group (Lipson et al., 1997) to derive the branching ratio $\mathrm{k}_{2} / k=0.07 \pm 0.03$, independent of temperature (207-298 K) and total pressure (125-270 mbar).

(g) $\mathrm{ClO}$ generated from $\mathrm{Cl}+\mathrm{O}_{3}$ (following discharge of $\mathrm{Cl}_{2}$ or $\mathrm{F}+\mathrm{Cl}_{2}$ ). $\mathrm{HO}$ was generated from $\mathrm{H}+\mathrm{NO}_{2}$ (following discharge of $\mathrm{H}_{2}$ ). $\mathrm{ClO}$ concentrations were measured directly at the parent peak. $\mathrm{HO}$ measured as $\mathrm{HOBr}^{+}$, following titration with $\mathrm{Br}_{2}$. Experiments carried out at 1 Torr under pseudo-first order conditions with $\mathrm{ClO}$ in excess. Direct measurement of $k_{2}$ from observed $\mathrm{HCl}$ formation is consistent with $k_{2} / k=0.035 \pm 0.010$ over the temperature range $230-320 \mathrm{~K}$.

(h) $\mathrm{ClO}$ generated from $\mathrm{Cl}+\mathrm{O}_{3}$ (following discharge of $\mathrm{Cl}_{2}$ ). $\mathrm{HO}$ was generated either from $\mathrm{F}+\mathrm{H}_{2} \mathrm{O}$ (following discharge of $\mathrm{F}_{2}$ ) or from $\mathrm{H}+\mathrm{NO}_{2}$ (following discharge of $\mathrm{H}_{2}$ ). $\mathrm{ClO}$ and $\mathrm{HO}$ concentrations measured by $\mathrm{UV}$ absorption and $\mathrm{RF}$, respectively. Experiments carried out at 1.3 mbar under pseudo-first order conditions with $\mathrm{ClO}$ in excess.

(i) $\mathrm{ClO}$ and $\mathrm{HO}$ generated from the $308 \mathrm{~nm}$ laser photolysis of $\mathrm{Cl}_{2}-\mathrm{O}_{3}-\mathrm{H}_{2} \mathrm{O}-\mathrm{He}$ mixtures at $\sim 40-55$ mbar. Initial concentrations of $\mathrm{ClO}$ and $\mathrm{HO}$ calculated from laser fluence and precursor concentrations. $\mathrm{HCl}$ production determined using time-resolved tunable diode laser spectroscopy. $k_{2}$ determined from simulation of the results of experiments performed with a range of starting conditions.

(j) From the rate coefficients $k_{2}$ and $k$ for the DO radical reaction.

(k) $\mathrm{HCl}$ measured using long-path tunable diode laser spectroscopy.

\section{Preferred Values}

$k=2.0 \times 10^{-11} \mathrm{~cm}^{3}$ molecule ${ }^{-1} \mathrm{~s}^{-1}$ at $298 \mathrm{~K}$.

$k=7.3 \times 10^{-12} \exp (300 / T) \mathrm{cm}^{3}$ molecule $\mathrm{s}^{-1} \mathrm{~s}^{-1}$ over the temperature range 200-380 K.

$k_{2} / k=0.06$, independent of temperature over the range $200-300 \mathrm{~K}$.

\section{Reliability}

$\Delta \log k= \pm 0.15$ at $298 \mathrm{~K}$.

$\Delta(E / R)= \pm 100 \mathrm{~K}$.

$\Delta\left(k_{2} / k\right)= \pm 0.04$ over the temperature range $200-300 \mathrm{~K}$.

\section{Comments on Preferred Values}

The preferred value of $k$ at $298 \mathrm{~K}$ is an average of the values reported by Hills and Howard (1984), Poulet et al. (1986), Lipson et al. (1997), Kegley-Owen et al. (1999), Bedjanian et al. (2001) and Wang and Keyser (2001a). The preferred Arrhenius expression is based on the mean of the $E / R$ values from the temperature dependence studies of Hills and Howard (1984), Lipson et al. (1997), Kegley-Owen et al. (1999), Bedjanian et al. (2001) and Wang and Keyser (2001a), combined with a preexponential factor adjusted to give the preferred value of $k$ at $298 \mathrm{~K}$. These studies are generally in good agreement, as reflected in the uncertainties assigned to $k$ and $E / R$. Values of the branching ratio, $k_{2} / k$, derived from both direct measurements of $k_{2}$ and $k$ (Lipson et al., 1997; Bedjanian et al., 2001) and from measurements of the branching ratio itself (Wang and Keyser, $2001 \mathrm{~b}$ ), yield values lying in the range $0.035-0.09$. The temperature independent preferred value of $k_{2} / k$ is based on the mean of these values, with the assigned uncertainty encompassing the extremes of the reported measurements.

\section{References}

Bedjanian, Y., Riffault, V., and Le Bras, G.: Int. J. Chem. Kinet., 33, 587, 2001.

Burrows, J. P., Wallington, T. J., and Wayne, R. P.: J. Chem. Soc. Faraday, 2, 80, 957, 1984.

Hills, A. J. and Howard, C. J.: J. Chem. Phys., 81, 4458, 1984. 
Kegley-Owen, C. S., Gilles, M. K., Burkholder, J. B., and Ravishankara, A. R.: J. Phys. Chem. A, 103, 5040, 1999.

Leu, M. T. and Lin, C. L.: Geophys. Res. Lett., 6, 425, 1979.

Lipson, J. B., Elrod, M. J., Beiderhase, T. W., Molina, L. T., and Molina, M. J.: J. Chem. Soc. Faraday Trans., 93, $2665,1997$.

Lipson, J. B., Beiderhase, T. W., Molina, L. T., Molina, M. J., and Olzmann, M.: J. Phys. Chem. A, 103, 6540, 1999.

Poulet, G. Laverdet, G., and Le Bras, G.: J. Phys. Chem., 90, 159, 1986.

Ravishankara, A. R., Eisele, F. L., and Wine, P. H.: J. Chem. Phys., 78, 1140, 1983.

Tyndall, G. S., Kegley-Owen, C. S., Orlando, J. J., and Fried, A.: J. Phys. Chem. A, 106, 1567, 2002.

Wang, J. J. and Keyser, L. F.: J. Phys. Chem. A, 105, 10544, 2001 a.

Wang, J. J. and Keyser, L. F.: J. Phys. Chem. A, 105, 6479, 2001 b. 
III.A2.40

$$
\begin{aligned}
\mathrm{HO}+\mathrm{OClO} & \rightarrow \mathrm{HOCl}+\mathrm{O}_{2} \\
& \rightarrow \mathrm{HO}_{2}+\mathrm{ClO}
\end{aligned}
$$

$\Delta H^{\circ}(1)=-210 \mathrm{~kJ} \mathrm{~mol}^{-1}$

$\Delta H^{\circ}(2)=-15.6 \mathrm{~kJ} \mathrm{~mol}^{-1}$

Rate coefficient data $\left(k=k_{1}+k_{2}\right)$

\begin{tabular}{lllc}
\hline$k / \mathrm{cm}^{3}$ molecule $\mathrm{s}^{-1}$ & Temp./K & Reference & Technique/Comments \\
\hline Absolute Rate Coefficients & & & \\
$4.50 \times 10^{-13} \exp [(804 \pm 114) / T]$ & $293-473$ & Poulet et al., 1986 & DF-LIF/EPR (a) \\
$(7.2 \pm 0.5) \times 10^{-12}$ & 293 & & \\
$1.43 \times 10^{-12} \exp [(597 \pm 36) / T]$ & $242-392$ & Gierczak et al., 2006 & PLP-LIF (b) \\
$(1.06 \pm 0.20) \times 10^{-11}$ & 296 & & \\
\hline
\end{tabular}

\section{Comments}

(a) $k$ was determined from pseudo-first order decay of $\mathrm{HO}$; pressure range 0.7-1.9 mbar. [OClO] determined from measured flow rates. $\mathrm{HOCl}$ was observed as a reaction product, using $\mathrm{MS}$, and its concentration determined using the $\mathrm{HO}+\mathrm{Cl}_{2} \rightarrow$ $\mathrm{HOCl}+\mathrm{Cl}$ reaction as a calibration source of $\mathrm{HOCl}$. Computer simulation of the reaction system indicated that $\mathrm{HOCl}$ is formed primarily in the $\mathrm{HO}+\mathrm{OClO}$ reaction [channel (1)] and not as a result of secondary reactions of the $\mathrm{HO}_{2}$ radical with $\mathrm{ClO}$, with $k_{1} / k \geq 0.80$ at room temperature.

(b) $k$ was determined from pseudo-first order decay of $\mathrm{HO}$, and was independent of pressure over the range 33-133 mbar (helium). [OClO] determined from in-situ measurements using FTIR and UV diode array spectroscopy.

\section{Preferred Values}

$k=1.0 \times 10^{-11} \mathrm{~cm}^{3}$ molecule ${ }^{-1} \mathrm{~s}^{-1}$ at $298 \mathrm{~K}$.

$k=1.4 \times 10^{-12} \exp (600 / T) \mathrm{cm}^{3}$ molecule $\mathrm{e}^{-1} \mathrm{~s}^{-1}$ over the temperature range $240-400 \mathrm{~K}$.

$k_{1} / k=1.0$

\section{Reliability}

$\Delta \log k_{1}= \pm 0.3$ at $298 \mathrm{~K}$.

$\Delta(E / R)= \pm 200 \mathrm{~K}$.

$\Delta \log \left(k_{1} / k\right)= \pm 0.2$ at $298 \mathrm{~K}$.

\section{Comments on Preferred Values}

The preferred values of $k$ are based on the study of Gierczak et al. (2006), in which concentrations of the excess reagent, $\mathrm{OClO}$, were determined by in-situ spectroscopic measurements, and which considered temperatures below room temperature. The earlier results of Poulet et al. (1986) are in reasonable agreement with the recommendation, and are encompassed by the assigned reliability limits. The preferred value of $k_{1} / k$ is based on the observation and interpretation of $\mathrm{HOCl}$ formation at room temperature, reported by Poulet et al. (1986).

$\mathrm{Xu}$ et al. (2003) have reported ab initio molecular orbital and variational RRKM theory calculations of the rate coefficient and product channels. The results yield rate coefficients of a similar magnitude to those obtained in the experimental studies, and also provide support for the dominance of channel (1), as reported by Poulet et al. (1986) at 1.3 mbar. Channel (2) is predicted to gain importance at elevated temperatures, and a pressure-dependent association channel to form $\mathrm{HOClO}_{2}$ is predicted to account for ca. $20 \%$ of the reaction at $130 \mathrm{mbar}$ and $300 \mathrm{~K}$, and to be the major channel at atmospheric pressure. However, no pressure dependence of $k$ was reported by Gierczak et al. (2006) for the range 33-133 mbar of helium, although experimental studies at higher pressures are ideally required to investigate the possible contribution of the association channel. 


\section{References}

Gierczak, T, Burkholder, J. B. and Ravishankara, A.R.: Int. J. Chem. Kinet., 38, 234, 2006.

Poulet, G., Zagogianni, H. and Le Bras, G.: Int. J. Chem. Kinet., 18, 847, 1986.

Xu, Z-F., Xu, R. and Lin, M.C.: J. Phys. Chem. A., 107, 1040, 2003. 


\section{III.A2.41}

$$
\mathrm{HO}+\mathrm{ClNO}_{2} \rightarrow \mathrm{HOCl}+\mathrm{NO}_{2}
$$

$\Delta H^{\circ}=-94 \mathrm{~kJ} \mathrm{~mol}^{-1}$

\section{Rate coefficient data}

\begin{tabular}{lllc}
\hline$k / \mathrm{cm}^{3}$ molecule ${ }^{-1} \mathrm{~s}^{-1}$ & Temp./K & Reference & Technique/Comments \\
\hline $\begin{array}{l}\text { Absolute Rate Coefficients } \\
(3.5 \pm 0.7) \times 10^{-14}\end{array}$ & 298 & Ganske et al., 1991 & DF-RF (a) \\
$2.4 \times 10^{-12} \exp [-(1250 \pm 155) / T]$ & $259-348$ & Ganske et al., 1992 & DF-RF/MS (a) \\
$(3.6 \pm 0.2) \times 10^{-14}$ & 298 & & \\
\hline
\end{tabular}

\section{Comments}

(a) Flow tube at 1.35 mbar. $\mathrm{HO}$ formed from $\mathrm{H}+\mathrm{NO}_{2}$ and detected by resonance fluorescence. Product analysis using mass spectrometry revealed $\mathrm{HOCl}$ to be the sole chlorine-containing product.

\section{Preferred Values}

$k=3.6 \times 10^{-14} \mathrm{~cm}^{3}$ molecule $\mathrm{e}^{-1} \mathrm{~s}^{-1}$ at $298 \mathrm{~K}$.

$k=2.4 \times 10^{-12} \exp (-1250 / T) \mathrm{cm}^{3}$ molecule ${ }^{-1} \mathrm{~s}^{-1}$ over the temperature range $260-350 \mathrm{~K}$.

\section{Reliability}

$\Delta \log k= \pm 0.3$ at $298 \mathrm{~K}$.

$\Delta(E / R)= \pm 300 \mathrm{~K}$.

\section{Comments on Preferred Values}

The preferred values are based on the results of the temperature-dependent study of Ganske et al. (1992). Mass spectrometric measurements (Ganske et al., 1991, 1992) showed HOCl to be the sole chlorine-containing product, with no evidence for production of $\mathrm{HONO}_{2}$ or $\mathrm{Cl}_{2}$, thereby showing that the only reaction pathway is that yielding $\mathrm{HOCl}+\mathrm{NO}_{2}$.

\section{References}

Ganske, J. A., Ezell, M. J., Berko, H. N., and Finlayson-Pitts, B. J.: Chem. Phys. Lett., 179, 204, 1991.

Ganske, J. A., Berko, H. N., Ezell, M. J., and Finlayson-Pitts, B. J.: J. Phys. Chem., 96, 2568, 1992. 
III.A2.42

$$
\begin{aligned}
\mathrm{HO}+\mathrm{ClONO}_{2} & \rightarrow \mathrm{HOCl}+\mathrm{NO}_{3} \\
& \rightarrow \mathrm{HO}_{2}+\mathrm{ClONO} \\
& \rightarrow \mathrm{HONO}_{2}+\mathrm{ClO}
\end{aligned}
$$

$$
\begin{aligned}
& \Delta H^{\circ}(1)=-64 \mathrm{~kJ} \mathrm{~mol}^{-1} \\
& \Delta H^{\circ}(2)=10 \mathrm{~kJ} \mathrm{~mol}^{-1} \\
& \Delta H^{\circ}(3)=-93.6 \mathrm{~kJ} \mathrm{~mol}^{-1}
\end{aligned}
$$

Rate coefficient data $\left(k=k_{1}+k_{2}+k_{3}\right)$

\begin{tabular}{lllc}
\hline$k / \mathrm{cm}^{3}$ molecule ${ }^{-1} \mathrm{~s}^{-1}$ & Temp./K & Reference & Technique/Comments \\
\hline Absolute Rate Coefficients & & & \\
$(3.7 \pm 0.2) \times 10^{-13}$ & 245 & Ravishankara et al., 1977 & FP-RF \\
$1.19 \times 10^{-12} \exp [-(333 \pm 22) / T]$ & $246-387$ & Zahniser et al., 1977 & DF-RF \\
$(3.93 \pm 0.11) \times 10^{-13}$ & 295 & & \\
\hline
\end{tabular}

\section{Preferred Values}

$k=4.0 \times 10^{-13} \mathrm{~cm}^{3}$ molecule $\mathrm{e}^{-1} \mathrm{~s}^{-1}$ at $298 \mathrm{~K}$.

$k=1.2 \times 10^{-12} \exp (-330 / T) \mathrm{cm}^{3}$ molecule $\mathrm{s}^{-1}$ over the temperature range $240-390 \mathrm{~K}$.

\section{Reliability}

$\Delta \log k= \pm 0.2$ at $298 \mathrm{~K}$.

$\Delta(E / R)= \pm 200 \mathrm{~K}$.

\section{Comments on Preferred Values}

The results of the only two reported studies of Ravishankara et al. (1977) and Zahniser et al. (1977) are in good agreement at $245 \mathrm{~K}$ (within 25\%), considering the difficulties associated with handling $\mathrm{ClONO}_{2}$. The preferred value is based on the temperature-dependent study of Zahniser et al. (1977). Neither study reported any data concerning the reaction products.

\section{References}

Ravishankara, A. R., Davis, D. D., Smith, G., Tesi, G., and Spencer, J.: Geophys. Res. Lett., 4, 7, 1977.

Zahniser, M. S., Chang, J. S., and Kaufman, F.: J. Chem. Phys., 67, 997, 1977. 
III.A2.43

$$
\mathrm{NO}_{3}+\mathrm{HCl} \rightarrow \mathrm{HNO}_{3}+\mathrm{Cl}
$$

$\Delta H^{\circ}=4.8 \mathrm{~kJ} \mathrm{~mol}^{-1}$

\section{Rate coefficient data}

\begin{tabular}{lllc}
\hline$k / \mathrm{cm}^{3}$ molecule ${ }^{-1} \mathrm{~s}^{-1}$ & Temp./K & Reference & Technique/Comments \\
\hline Absolute Rate Coefficients & & & \\
$<7 \times 10^{-18}$ & 298 & Cantrell et al., 1987 & (a) \\
$\leq 5 \times 10^{-17}$ & 298 & Mellouki et al., 1989 & DF-EPR (b) \\
$<2.4 \times 10^{-17}$ & 298 & Canosa-Mas et al., 1989 & DF-A (c) \\
\hline
\end{tabular}

\section{Comments}

(a) $\mathrm{NO}_{3}$ radical concentrations were derived from the measured $\mathrm{NO}_{2}$ and $\mathrm{N}_{2} \mathrm{O}_{5}$ concentrations in $\mathrm{N}_{2} \mathrm{O}_{5}-\mathrm{NO}_{2}-\mathrm{NO}_{3}-\mathrm{HCl}$-air mixtures, using the equilibrium constant of Graham and Johnston (1978). The upper limit to the rate coefficient cited above was derived from numerical fits of the time-concentration data for reactants and products monitored by FTIR absorption spectrometry.

(b) The upper limit to the rate coefficient cited above was derived from fitting the measured upper limit to the $\mathrm{ClO}$ radical concentration (determined by EPR after conversion to $\mathrm{Cl}$ atoms) to a complex mechanism.

(c) No reaction was observed at room temperature, leading to the upper limit to the rate coefficient cited above. At higher temperatures ( $333 \mathrm{~K}$ to $473 \mathrm{~K}$ ), rate coefficients derived from fitting to a complex mechanism yielded the Arrhenius expression of $k=4 \times 10^{-12} \exp (-3330 / T) \mathrm{cm}^{3}$ molecule $\mathrm{s}^{-1} \mathrm{~s}^{-1}$

\section{Preferred Values}

$k<5 \times 10^{-17} \mathrm{~cm}^{3}$ molecule $\mathrm{s}^{-1} \mathrm{~s}^{-1}$ at $298 \mathrm{~K}$

\section{Comments on Preferred Values}

The preferred value is the upper limit to the rate coefficient reported by Mellouki et al. (1989) in a study using the discharge flow-EPR technique. Somewhat lower upper limits have been reported by Cantrell et al. (1987) and by Canosa-Mas et al. (1989). Canosa-Mas et al. (1989) also reported Arrhenius parameters at higher temperatures (over the range $333 \mathrm{~K}$ to $473 \mathrm{~K})$. The preferred value indicates that this reaction is not important in the chemistry of the atmosphere.

\section{References}

Canosa-Mas, C. E., Smith, S. J., Toby, S., and Wayne, R. P.: J. Chem. Soc. Faraday Trans., 2, 85, 709, 1989.

Cantrell, C. A., Davidson, J. A., Shetter, R. E., Anderson, B. A., and Calvert, J. G.: J. Phys. Chem., 91, 6017, 1987.

Graham, R. A. and Johnston, H. S.: J. Phys. Chem., 82, 254, 1978.

Mellouki, A., Poulet, G., Le Bras, G., Singer, R., Burrows, J. P., and Moortgat, G. K.: J. Phys. Chem., 93, 8017, 1989. 
III.A2.44

$$
\begin{aligned}
\mathrm{ClO}+\mathrm{HO}_{2} & \rightarrow \mathrm{HOCl}+\mathrm{O}_{2} \\
& \rightarrow \mathrm{HCl}+\mathrm{O}_{3}
\end{aligned}
$$

$\Delta H^{\circ}(1)=-194 \mathrm{~kJ} \mathrm{~mol}^{-1}$

$\Delta H^{\circ}(2)=-65.8 \mathrm{~kJ} \mathrm{~mol}^{-1}$

Rate coefficient data $\left(k=k_{1}+k_{2}\right)$

\begin{tabular}{lllc}
\hline$k / \mathrm{cm}^{3}$ molecule ${ }^{-1} \mathrm{~s}^{-1}$ & Temp./K & Reference & Technique/Comments \\
\hline $\begin{array}{l}\text { Absolute Rate Coefficients } \\
(3.8 \pm 0.7) \times 10^{-12}\end{array}$ & 298 & Reimann and Kaufman, 1978 & DF-RF \\
$3.3 \times 10^{-11} \exp (850 / T)+$ & $235-393$ & Stimpfle et al., 1979 & DF-LMR \\
$\quad 4.5 \times 10^{-12}(T / 300)^{-3.7}$ & & & \\
$(6.43 \pm 0.96) \times 10^{-12}$ & 298 & & \\
$(4.5 \pm 0.9) \times 10^{-12}$ & 298 & Leck et al., 1980 & DF-MS \\
$\left(5.4_{-2}^{+4}\right) \times 10^{-12}$ & 300 & Burrows and Cox, 1981 & MM-UVA \\
$(6.2 \pm 1.5) \times 10^{-12}$ & 308 & Cattell and Cox, 1986 & MM-UVA (a) \\
$2.84 \times 10^{-12} \exp [(312 \pm 60) / T]$ & $203-364$ & Nickolaisen et al., 2000 & FP-UVA (b) \\
$(7.79 \pm 0.83) \times 10^{-12}$ & 299 & & (c) \\
$(8.26 \pm 1.38) \times 10^{-12}$ & 299 & & (d) \\
$7.1 \times 10^{-12} \exp [-(16 \pm 17) / T]$ & $215-298$ & Knight et al., 2000 & DF-MS (e) \\
$(7.1 \pm 1.8) \times 10^{-12}$ & 294 & & \\
& & & \\
Branching Ratios & & & \\
$k_{2} / k \leq 0.02$ & 298 & Leck et al., 2000 & (f) \\
$k_{2} / k \leq 0.015$ & 298 & Leu, 1980 & (f) \\
$k_{2} / k \leq 0.03$ & 248 & & (g) \\
$k_{2} / k \leq 0.003$ & 298 & Burrows and Cox, 1981 & (h) \\
$k_{1} / k \geq 0.95$ & $210-300$ & Finkbeiner et al., 1995 & \\
$k_{2} / k=0.05 \pm 0.02$ & 210 & & (f) \\
$k_{2} / k=0.02 \pm 0.01$ & 240 & & \\
$k_{2} / k \leq 0.01$ & $215-298$ & Knight et al., 2000 & \\
\hline
\end{tabular}

\section{Comments}

(a) $k$ independent of pressure over the range $65-1000$ mbar.

(b) $k$ independent of pressure over the range 65-930 mbar. Two chemical systems employed to generate $\mathrm{ClO}$ and $\mathrm{HO}_{2}$ : (i) the photolysis of $\mathrm{Cl}_{2}-\mathrm{Cl}_{2} \mathrm{O}-\mathrm{CH}_{3} \mathrm{OH}-\mathrm{O}_{2}-\mathrm{N}_{2}$ mixtures, and (ii) the photolysis of $\mathrm{F}_{2}-\mathrm{H}_{2}-\mathrm{O}_{2}-\mathrm{Cl}_{2} \mathrm{O}-\mathrm{N}_{2}$ mixtures. The latter system consistently yielded slightly higher values of $k$, although differences are well within error limits of each system. Unpublished results (Laszlo et al.) from the same laboratory using DF-MS at 1 Torr are also cited. The results give a near-zero temperature dependence over the range $233-380 \mathrm{~K}(E / R=72 \pm 42 \mathrm{~K})$, and a value of $k$ about a factor of 2 lower at $298 \mathrm{~K}$ compared with the FP-UVA measurement.

(c) $\mathrm{Cl}_{2}-\mathrm{Cl}_{2} \mathrm{O}-\mathrm{CH}_{3} \mathrm{OH}-\mathrm{O}_{2}-\mathrm{N}_{2}$ system.

(d) $\mathrm{Fl}_{2}-\mathrm{H}_{2}-\mathrm{O}_{2}-\mathrm{Cl}_{2} \mathrm{O}-\mathrm{N}_{2}$ system.

(e) $k$ measured in 1.4-2.2 mbar He. $\mathrm{ClO}$ and $\mathrm{HO}_{2}$ generated from five combinations of precursor reagents: (i) $\mathrm{CH}_{3} \mathrm{OH}-$ $\mathrm{Cl}_{2} \mathrm{O}$, (ii) $\mathrm{CH}_{3} \mathrm{OH}-\mathrm{OClO}$, (iii) $\mathrm{HCHO}-\mathrm{Cl}_{2} \mathrm{O}$, (iv) $\mathrm{HCHO}-\mathrm{OClO}$, and (v) $\mathrm{H}_{2} \mathrm{O}_{2}-\mathrm{OClO}$. Systems yielded consistent results. Additional experiments performed with related chemical systems involving presence of $\mathrm{O}_{3}$, generated higher values of 
$k$, described by the expression $(6.6 \pm 0.8) \times 10^{-12} \exp [(85 \pm 18) / T] \mathrm{cm}^{3}$ molecule ${ }^{-1} \mathrm{~s}^{-1}$, over the temperature range 223$333 \mathrm{~K}$. This was attributed to inefficient quenching at 1.3 mbar of the vibrationally excited $\mathrm{ClO}$ generated from the $\mathrm{Cl}+\mathrm{O}_{3}$ reaction.

(f) DF-MS detection of $\mathrm{O}_{3}$.

(g) MM-CL detection of $\mathrm{O}_{3}$.

(h) Flow system with steady-state photolysis $(310 \mathrm{~nm}$ to $400 \mathrm{~nm})$ of $\mathrm{Cl}_{2}-\mathrm{H}_{2}-\mathrm{Cl}_{2} \mathrm{O}-\mathrm{O}_{2}-\mathrm{Ar}$ mixtures at a total pressure of 910 mbar. $\mathrm{HOCl}$ and $\mathrm{O}_{3}$ products were monitored by matrix-isolation FTIR spectroscopy.

\section{Preferred Values}

$k=6.9 \times 10^{-12} \mathrm{~cm}^{3}$ molecule ${ }^{-1} \mathrm{~s}^{-1}$ at $298 \mathrm{~K}$.

$k=2.2 \times 10^{-12} \exp (340 / T) \mathrm{cm}^{3}$ molecule $\mathrm{e}^{-1} \mathrm{~s}^{-1}$ over the temperature range $230-300 \mathrm{~K}$.

\section{Reliability}

$\Delta \log k= \pm 0.2$ at $298 \mathrm{~K}$.

$\Delta(E / R)= \pm 350 \mathrm{~K}$.

\section{Comments on Preferred Values}

The reported studies have been carried out over a range of temperatures and pressures, using a variety of techniques. The room temperature values of $k$ cover a range of more than a factor of two. Systematic studies of the pressure dependence (Cattell and Cox, 1986; Nickolaisen et al., 2000) show no significant variation above $65 \mathrm{mbar}$, although the average of the published low pressure discharge flow measurements is slightly lower than the average of the higher pressure measurements. The recent studies of the temperature dependence (Nickolaisen et al., 2000; Knight et al., 2000) disagree with the previously reported (Stimpfle et al., 1979) strong negative temperature dependence at temperatures below $298 \mathrm{~K}$, and the associated non-linear Arrhenius behaviour. However, there is also substantial disagreement between the recent studies, which yield values of $E / R$ of $-312 \mathrm{~K}$ (Nickolaisen et al., 2000) and $16 \mathrm{~K}$ (Knight et al., 2000).

The preferred value at $298 \mathrm{~K}$ is based on the average of the room temperature data of Stimpfle et al. (1979), Cattell and Cox (1986), Nickolaisen et al. (2000) and Knight et al. (2000). The preferred value of $E / R$ is based on the average of the three temperature dependence studies, using Stimpfle et al. (1979) data for $T \leq 298 \mathrm{~K}$ (for which $E / R=-709 \mathrm{~K}$ ). The uncertainties in $k$ at $298 \mathrm{~K}$ and $E / R$ reflect the range of reported values.

All of the available data suggest that channel (1) is the dominant, if not sole, pathway over the temperature range of the preferred values With the exception of the matrix-isolation results of Finkbeiner et al. (1995) no evidence for channel (2) has been reported. Recent theoretical studies (Nickolaisen et al., 2000; Kaltsoyannis and Rowley, 2002) conclude that the contribution of channel (2) is essentially zero.

\section{References}

Burrows, J. P. and Cox, R. A.: J. Chem. Soc. Faraday Trans., 1, 77, 2465, 1981.

Cattell, F. C. and Cox, R. A.: J. Chem. Soc. Faraday Trans., 2, 82, 1413, 1986.

Finkbeiner, M., Crowley, J. N., Horie, O., Müller, R., Moortgat, G. K., and Crutzen, P. J.: J. Phys. Chem., 99, 16264, 1995.

Kaltsoyannis, N. and Rowley, D. M.: Phys. Chem. Chem. Phys., 4, 419, 2002.

Knight, G. P., Beiderhase, T., Helleis, F., Moortgat, G. K., and Crowley, J. N.: J. Phys. Chem. A, 104, 1674, 2000.

Laszlo, B., Friedl, R. R., and Sander, S. P.: unpublished results, cited in Nickolaisen et al., 2000.

Leck, T. J., Cook, J.-E. L., and Birks, J. W.: J. Chem. Phys., 72, 2364, 1980.

Nickolaisen, S. L., Roehl, C. M., Blakeley, L. K., Friedl, R. R., Francisco, J. S., Liu, R., and Sander, S. P. J.: Phys. Chem. A, 104, 308, 2000.

Reimann, B. and Kaufman, F.: J. Chem. Phys., 69, 2925, 1978.

Stimpfle, R. M., Perry, R. A., and Howard, C. J.: J. Chem. Phys., 71, 5183, 1979. 
III.A2.45

$$
\begin{aligned}
\mathrm{ClO}+\mathrm{O}_{3} & \rightarrow \mathrm{ClOO}+\mathrm{O}_{2} \\
& \rightarrow \mathrm{OClO}+\mathrm{O}_{2}
\end{aligned}
$$

$\Delta H^{\circ}(1)=-146.8 \mathrm{~kJ} \mathrm{~mol}^{-1}$

$\Delta H^{\circ}(2)=-149.7 \mathrm{~kJ} \mathrm{~mol}^{-1}$

\begin{tabular}{|c|c|c|c|}
\hline$k / \mathrm{cm}^{3}$ molecule ${ }^{-1} \mathrm{~s}^{-1}$ & Temp./K & Reference & Technique/Comments \\
\hline \multicolumn{4}{|l|}{ Absolute Rate Coefficients } \\
\hline$k_{2}<1 \times 10^{-18}$ & 298 & DeMore et al., 1975 & DF-MS \\
\hline$k_{2}<1 \times 10^{-18}$ & 298 & Wongdontri-Stuper et al., 1979 & FP-UVA (a) \\
\hline$k_{1}<1.3 \times 10^{-17}$ & 233 & Stevens and Anderson, 1990 & (b) \\
\hline$k_{1}<1.4 \times 10^{-17}$ & 298 & & \\
\hline$k_{1}=(4.0 \pm 2.0) \times 10^{-16}$ & 413 & & \\
\hline
\end{tabular}

Rate coefficient data $\left(k=k_{1}+k_{2}\right)$

\section{Comments}

(a) Flash photolysis of $\mathrm{Cl}_{2}-\mathrm{O}_{3}$ mixtures. Upper limit to the rate coefficient obtained expected to really refer to $k_{2}$ (Stevens and Anderson, 1990).

(a) Discharge flow system. Reaction channel (1) was followed by monitoring $\mathrm{ClO}$ produced from the thermal decomposition of the product $\mathrm{ClOO}$ in the presence of $\mathrm{O}_{3}$. The product $\mathrm{ClO}$ was distinguished from the reactant $\mathrm{ClO}$ through isotopic labelling.

\section{Preferred Values}

$k_{1}<1.5 \times 10^{-17} \mathrm{~cm}^{3}$ molecule $\mathrm{s}^{-1} \mathrm{~s}^{-1}$ at $298 \mathrm{~K}$.

$k_{2}<1 \times 10^{-18} \mathrm{~cm}^{3}$ molecule $\mathrm{s}^{-1} \mathrm{~s}^{-1}$ at $298 \mathrm{~K}$.

\section{Comments on Preferred Values}

The preferred upper limit for $k_{1}$ is based on the results of the study of Stevens and Anderson (1990). The preferred upper limit for $k_{2}$ is based on the data of DeMore et al. (1975) and Wongdontri-Stuper et al. (1979). The upper limit of Stevens and Anderson (1990) at room temperature can be combined with their measured rate coefficient at $413 \mathrm{~K}$ to derive $A_{1}=2 \times 10^{-12} \mathrm{~cm}^{3}$ molecule ${ }^{-1} \mathrm{~s}^{-1}$ and $E_{1} / R>3600 \mathrm{~K}$. For $k_{2}$ one can estimate $A_{2}=1 \times 10^{-12} \mathrm{~cm}^{3}$ molecule ${ }^{-1} \mathrm{~s}^{-1}$ and derive $E_{2} / R>4000 \mathrm{~K}$.

\section{References}

DeMore, W. B., Lin, C. L., and Jaffe, S.: presented at ACS National Meeting, Philadelphia, PA, 1975.

Stevens, P. S. and Anderson, J. G.: Geophys. Res. Lett., 17, 1287, 1990.

Wongdontri-Stuper, W., Jayanty, R. K. M., Simonaitis, R., and Heicklen, J.: J. Photochem., 10, 163, 1979. 
III.A2.46

$$
\mathrm{ClO}+\mathrm{NO} \rightarrow \mathrm{Cl}+\mathrm{NO}_{2}
$$

$\Delta H^{\circ}=-37.4 \mathrm{~kJ} \mathrm{~mol}^{-1}$

\section{Rate coefficient data}

\begin{tabular}{lllc}
\hline$k / \mathrm{cm}^{3}$ molecule ${ }^{-1} \mathrm{~s}^{-1}$ & Temp./K & Reference & Technique/Comments \\
\hline Absolute Rate Coefficients & & & \\
$(1.7 \pm 0.2) \times 10^{-11}$ & 298 & Clyne and Watson, 1974 & DF-MS \\
$5.72 \times 10^{-12} \exp [(296 \pm 20) / T]$ & $227-415$ & Leu and DeMore, 1978 & DF-MS \\
$(1.53 \pm 0.11) \times 10^{-11}$ & 299 & & \\
$(1.61 \pm 0.16) \times 10^{-11}$ & 295 & Clyne and MacRobert, 1980 & DF-MS \\
$(1.72 \pm 0.20) \times 10^{-11}$ & 298 & Ray and Watson, 1981 & DF-MS \\
$7.1 \times 10^{-12} \exp [(270 \pm 50) / T]$ & $202-393$ & Lee et al., 1982 & DF-LMR \\
$(1.84 \pm 0.03) \times 10^{-11}$ & 297 & & \\
\hline
\end{tabular}

\section{Preferred Values}

$k=1.7 \times 10^{-11} \mathrm{~cm}^{3}$ molecule ${ }^{-1} \mathrm{~s}^{-1}$ at $298 \mathrm{~K}$.

$k=6.2 \times 10^{-12} \exp (295 / T) \mathrm{cm}^{3}$ molecule $\mathrm{s}^{-1} \mathrm{~s}^{-1}$ over the temperature range 200-420 K.

\section{Reliability}

$\Delta \log k= \pm 0.1$ at $298 \mathrm{~K}$.

$\Delta(E / R)= \pm 100 \mathrm{~K}$.

\section{Comments on Preferred Values}

The room temperature rate coefficients reported by Clyne and Watson (1974), Leu and DeMore (1978), Clyne and MacRobert (1980), Ray and Watson (1981) and Lee et al. (1982) are in good agreement and are $30 \%$ lower than the value reported by Zahniser and Kaufman (1977) from a competitive study. The preferred values are derived from a least-squares fit to the data reported by Clyne and Watson (1974), Leu and DeMore (1978), Clyne and MacRobert (1980), Ray and Watson (1981) and Lee et al. (1982).

\section{References}

Clyne, M. A. A. and Watson, R. T.: J. Chem. Soc. Faraday Trans., 1, 70, 2250, 1974.

Clyne, M. A. A. and MacRobert, A. J.: Int. J. Chem. Kinet., 12, 79, 1980.

Lee, Y. P., Stimpfle, R. M., Perry, R. A., Mucha, J. A., Evenson, K. M., Jennings, D. A., and Howard, C. J.: Int. J. Chem. Kinet., 14, 711, 1982.

Leu, M. T. and DeMore, W. B. : J. Phys. Chem., 82, 2049, 1978.

Ray, G. W. and Watson, R. T.: J. Phys. Chem., 85, 2955, 1981.

Zahniser, M. S. and Kaufman, F.: J. Chem. Phys., 66, 3673, 1977. 
III.A2.47

$$
\mathrm{ClO}+\mathrm{NO}_{2}+\mathrm{M} \rightarrow \mathrm{ClONO}_{2}+\mathrm{M}
$$

$\Delta H^{\circ}=-111.9 \mathrm{~kJ} \mathrm{~mol}^{-1}$

\section{Low-pressure rate coefficients}

\section{Rate coefficient data}

\begin{tabular}{lllc}
\hline$k_{0} / \mathrm{cm}^{3}$ molecule ${ }^{-1} \mathrm{~s}^{-1}$ & Temp./K & Reference & Technique/Comments \\
\hline Absolute Rate Coefficients & & & \\
$(4.40 \pm 0.66) \times 10^{-33} \exp (1087 / T)\left[\mathrm{N}_{2}\right]$ & $250-356$ & Birks et al., 1977 & DF-MS (a) \\
$(1.52 \pm 0.23) \times 10^{-31}(T / 300)^{-3.15}\left[\mathrm{~N}_{2}\right]$ & $251-365$ & Zahniser et al., 1977 & DF-RF (b) \\
$(3.69 \pm 0.24) \times 10^{-33} \exp (1150 / T)\left[\mathrm{N}_{2}\right]$ & & Leu et al., 1977 & DF-MS (c) \\
$4.3 \times 10^{-33} \exp [(1085 \pm 86) / T]\left[\mathrm{N}_{2}\right]$ & $274-339$ & Cox and Lewis, 1979 & $(\mathrm{d})$ \\
$(1.5 \pm 0.12) \times 10^{-31}\left[\mathrm{~N}_{2}\right]$ & 298 & Molina et al., 1980 & PLP-UVA (e) \\
$(1.5 \pm 0.2) \times 10^{-31}\left[\mathrm{~N}_{2}\right]$ & 298 & Dasch et al., 1981 & PLP-UVA (f) \\
$2.8 \times 10^{-33} \exp (1090 / T)[\mathrm{He}]$ & $250-387$ & Lee et al., 1982 & DF-LMR \\
$3.5 \times 10^{-33} \exp (1180 / T)\left[\mathrm{O}_{2}\right]$ & $250-416$ & & $(\mathrm{~g})$ \\
$2.09 \times 10^{-31}\left[\mathrm{~N}_{2}\right]$ & 297 & & \\
$(1.8 \pm 0.4) \times 10^{-31}\left[\mathrm{~N}_{2}\right]$ & $270-295$ & Cox et al., 1984 & $(\mathrm{h})$ \\
$(1.6 \pm 0.2) \times 10^{-31}(T / 300)^{-3.0}\left[\mathrm{~N}_{2}\right]$ & $264-343$ & Handwerk and Zellner, 1984 & FP-UVA (i) \\
$(1.40 \pm 0.07) \times 10^{-31}\left[\mathrm{~N}_{2}\right]$ & 298 & Wallington and Cox, 1986 & $(\mathrm{j})$ \\
$(1.8 \pm 0.3) \times 10^{-31}(T / 300)^{-3.4}[$ air $]$ & $213-298$ & Percival et al., 1997 & $(\mathrm{k})$ \\
\hline
\end{tabular}

\section{Comments}

(a) Pressure range 1.3-7 mbar.

(b) Resonance fluorescence of $\mathrm{Cl}$ after conversion of $\mathrm{ClO}$ into $\mathrm{Cl}$. Pressure range 1.4-9 mbar. Measurement in $\mathrm{N}_{2}$ only at $300 \mathrm{~K}$, temperature coefficient taken from measurements in He.

(c) Pressure range 1.3-8 mbar.

(d) Modulated photolysis with UV absorption detection of ClO radicals. The pressure range studied was 33-815 mbar. Small deviations from third-order kinetics were observed near 1 bar.

(e) The $\mathrm{ClO}$ radical decay was monitored. FTIR spectroscopy was also used to monitor the reaction products.

(f) $\mathrm{ClO}$ radicals were generated from $\mathrm{Cl}_{2} \mathrm{O}$ and monitored at $258.2 \mathrm{~nm}$. The pressure range was $27-800 \mathrm{mbar}$.

(g) Detection of $\mathrm{ClO}\left(\mathrm{X}^{2} \Pi_{3 / 2}, \nu=0\right)$ with an optically pumped spectrometer. Measurements were carried out at pressures over the range $0.8-8.8$ mbar.

(h) Modulated photolysis of $\mathrm{Cl}_{2}-\mathrm{Cl}_{2} \mathrm{O}-\mathrm{NO}_{2}-\mathrm{N}_{2}$ mixtures. $\mathrm{ClONO}_{2}$ formation was followed by diode laser spectroscopy. This study ruled out the formation of isomers other than $\mathrm{ClONO}_{2}$.

(i) The pressure range was 23-1052 mbar, with experiments being conducted at $264 \mathrm{~K}, 298 \mathrm{~K}$ and $343 \mathrm{~K}$.

(j) Modulated photolysis of $\mathrm{OClO}-\mathrm{NO}_{2}-\mathrm{N}_{2}$ mixtures with detection of $\mathrm{ClO}$ radicals by $\mathrm{UV}$ absorption.

(k) Turbulent flow measurements at $213 \mathrm{~K}$ and $298 \mathrm{~K}$ with high pressure chemical ionization mass spectrometry over the pressure range 200-790 mbar. The falloff extrapolation used $F_{c}=0.6$, in agreement with earlier data. 


\section{Preferred Values}

$k_{0}=1.6 \times 10^{-31}(T / 300)^{-3.4}\left[\mathrm{~N}_{2}\right] \mathrm{cm}^{3}$ molecule ${ }^{-1} \mathrm{~s}^{-1}$ over the temperature range 250-350 K.

\section{Reliability}

$\Delta \log k_{0}= \pm 0.1$ at $298 \mathrm{~K}$.

$\Delta n= \pm 1$.

\section{Comments on Preferred Values}

There is excellent agreement between the various studies of this reaction in the falloff region close to the low pressure limit (Birks et al., 1977; Zahniser et al., 1977; Leu et al., 1977; Cox and Lewis, 1979; Molina et al., 1980; Dasch et al., 1981; Lee et al., 1982; Cox et al., 1984; Handwerk and Zellner, 1984; Wallington and Cox, 1986; Percival et al., 1997).

\section{High-pressure rate coefficients}

\section{Rate coefficient data}

\begin{tabular}{|c|c|c|c|}
\hline$k_{\infty} / \mathrm{cm}^{3}$ molecule ${ }^{-1} \mathrm{~s}^{-1}$ & Temp./K & Reference & Technique/Comments \\
\hline $\begin{array}{l}\text { Absolute Rate Coefficients } \\
(3-6) \times 10^{-12}\end{array}$ & 298 & Dasch et al., 1981 & PLP-UVA (a) \\
\hline$\left(1.2_{-0.6}^{+1.2}\right) \times 10^{-11}$ & $264-343$ & Handwerk and Zellner, 1984 & FP-UVA (b) \\
\hline$(1.5 \pm 0.7) \times 10^{-11}(T / 300)^{-1.9}$ & $213-298$ & Percival et al., 1997 & (c) \\
\hline
\end{tabular}

\section{Comments}

(a) See comment (f) for $k_{0}$. The extrapolation to $k_{\infty}$ is very uncertain, and the value of $F_{c}$ was unspecified.

(b) See comment (i) for $k_{0}$. The extrapolation to $k_{\infty}$ is very uncertain. The reported value of $k_{\infty}$ was based on theoretical predictions. Using the reported values of $k_{0}$ and $k_{\infty}$ and $F_{c}=0.55,0.50$ and 0.45 at $264 \mathrm{~K}, 298 \mathrm{~K}$ and $343 \mathrm{~K}$, respectively, falloff curves were obtained which are in good agreement with the majority of the available data.

(c) See comment (k) for $k_{0}$. The falloff extrapolation was carried out with $F_{c}=0.6$, independent of temperature.

\section{Preferred Values}

$k_{\infty}=7 \times 10^{-11} \mathrm{~cm}^{3}$ molecule ${ }^{-1} \mathrm{~s}^{-1}$, independent of temperature over the range $250-350 \mathrm{~K}$.

\section{Reliability}

$\Delta \log k_{\infty}= \pm 0.5$ over the temperature range $250-350 \mathrm{~K}$.

\section{Comments on Preferred Values}

Because there are no direct measurements of $k$ at pressures much above 1 bar, $k_{\infty}$ cannot be established with certainty. There are two alternatives for a representation of the rate data at pressures up to 1 bar. One may use the values chosen by Percival et al. (1997) with $F_{c}=0.6$ and a temperature dependent $k_{\infty}$ such as given in the table. Alternatively, one may follow our policy of choosing a more reasonable $F_{c}$ such as recommended by Cobos and Troe (2003) and then fit $k_{\infty}$. Using $F_{c}=0.4$ such as recommended also for $\mathrm{HO}+\mathrm{NO}_{2}(+\mathrm{M}) \rightarrow \mathrm{HONO}_{2}(+\mathrm{M})$, the rate data in the falloff range below 1 bar from Percival et al. (1997) are well reproduced with a temperature independent $k_{\infty}=(7 \pm 2) \times 10^{-11} \mathrm{~cm}^{3}$ molecule ${ }^{-1} \mathrm{~s}^{-1}$.

Because a value for $F_{c}$ smaller than 0.6 appears theoretically much more justified, we here adopt the second alternative. However, we emphasize that the two alternatives work equally well for the representation of data below 1 bar. 


\section{References}

Birks, J. W., Shoemaker, B., Leck, T. J., Borders, R. A., and Hart, L. J.: J. Chem. Phys., 66, 4591, 1977.

Cobos, C. J. and Troe, J.: Z. Phys. Chem., 217, 1031, 2003.

Cox, R. A. and Lewis, R.: J. Chem. Soc. Faraday Trans. 1, 75, 2649, 1979.

Cox, R. A., Burrows, J. P., and Coker, G. B.: Int. J. Chem. Kinet., 16, 445, 1984.

Dasch, W., Sternberg, K.-H., and Schindler, R. N.: Ber. Bunsenges. Phys. Chem., 85, 611, 1981.

Handwerk, V. and Zellner, R.: Ber. Bunsenges. Phys. Chem., 88, 405, 1984.

Lee, Y.-P., Stimpfle, R. M., Perry, R. A., Mucha, J. A., Evenson, K. M., Jennings, D. A., and Howard, C. J.: Int. J. Chem. Kinet., 14, 711, 1982.

Leu, M. T., Lin, C. L., and DeMore, W. B.: J. Phys. Chem., 81, 190, 1977.

Molina, M. J., Molina, M. T., and Ishiwata, T.: J. Phys. Chem., 84, 3100, 1980.

Percival, C. J., Smith, G. D., Molina, L. T., and Molina, M. J.: J. Phys. Chem. A, 101, 8830, 1997.

Wallington, T. J. and Cox, R. A.: J. Chem. Soc. Faraday Trans., 2, 82, 275, 1986.

Zahniser, M. S., Chang, J. S., and Kaufman, F.: J. Chem. Phys., 67, 977, 1977. 
III.A2.48

$$
\begin{aligned}
\mathrm{ClO}+\mathrm{NO}_{3} & \rightarrow \mathrm{ClOO}+\mathrm{NO}_{2} \\
& \rightarrow \mathrm{OClO}+\mathrm{NO}_{2}
\end{aligned}
$$

$\Delta H^{\circ}(1)=-44.7 \mathrm{~kJ} \mathrm{~mol}^{-1}$

$\Delta H^{\circ}(2)=-47.5 \mathrm{~kJ} \mathrm{~mol}^{-1}$

Rate coefficient data $\left(k=k_{1}+k_{2}\right)$

\begin{tabular}{lllc}
\hline$k / \mathrm{cm}^{3}$ molecule ${ }^{-1} \mathrm{~s}^{-1}$ & Temp./K & Reference & Technique/Comments \\
\hline $\begin{array}{l}\text { Absolute Rate Coefficients } \\
(4.0 \pm 1.6) \times 10^{-13}\end{array}$ & 296 & Cox et al., 1984 & MM-A \\
$1.6 \times 10^{-12} \exp [-(420 \pm 200) / T]$ & $278-338$ & Cox et al., 1987 & MM-A (a) \\
$4.0 \times 10^{-13}$ & 300 & & \\
$(5.0 \pm 1.4) \times 10^{-13}$ & $210-353$ & Biggs et al., 1991 & DF-A/MS (b) \\
$(4.61 \pm 0.60) \times 10^{-13}$ & 300 & Kukui et al., 1994 & DF-MS (c) \\
$k_{2}=(1.46 \pm 0.40) \times 10^{-13}$ & 300 & & \\
& & & \\
Branching Ratios & & & \\
$k_{1} / k=0.73$ & 300 & Cox et al., 1987 & MM-A (a) \\
$k_{2} / k=0.14 \pm 0.13$ & 353 & Biggs et al., 1991 & DF-A/MS (b) \\
$k_{2} / k=0.20 \pm 0.10$ & 297 & & \\
$k_{2} / k=0.035 \pm 0.050$ & 216 & & \\
\hline
\end{tabular}

\section{Comments}

(a) Derived from numerical analysis of the $\mathrm{NO}_{3}$ radical and $\mathrm{ClO}$ radical profiles.

(b) Pseudo-first-order decay of $\mathrm{NO}_{3}$ in excess $\mathrm{ClO}$ was determined by optical absorption at $662 \mathrm{~nm}$, using a cross section of $1.7 \times 10^{-17} \mathrm{~cm}^{2}$ molecule ${ }^{-1}$. Product branching ratios were measured with a quadrupole mass spectrometer.

(c) Rate coefficients $k$ were obtained from the first-order $\mathrm{NO}_{3}$ radical decays in the presence of excess $\mathrm{ClO}$ radicals and $\mathrm{O}_{3}$. Rate coefficients $k_{2}$ were obtained from the decays of $\mathrm{ClO}$ radicals in the presence of excess $\mathrm{NO}_{3}$ radicals, with $\mathrm{ClOO}$ radicals formed in channel (1) reforming $\mathrm{ClO}$ radicals by the reactions $\mathrm{ClOO} \rightarrow \mathrm{Cl}+\mathrm{O}_{2}$ and $\mathrm{Cl}+\mathrm{NO}_{3} \rightarrow \mathrm{ClO}+\mathrm{NO}_{2}$. This study (Kukui et al., 1994) supersedes the earlier study of Becker et al. (1991) from the same laboratory.

\section{Preferred Values}

$k=4.6 \times 10^{-13} \mathrm{~cm}^{3}$ molecule $\mathrm{e}^{-1} \mathrm{~s}^{-1}$, independent of temperature over the range $210-360 \mathrm{~K}$.

$k_{2}=1.2 \times 10^{-13} \mathrm{~cm}^{3}$ molecule ${ }^{-1} \mathrm{~s}^{-1}$ at $298 \mathrm{~K}$.

\section{Reliability}

$\Delta \log k= \pm 0.2$ at $298 \mathrm{~K}$.

$\Delta \log k_{2}= \pm 0.3$ at $298 \mathrm{~K}$.

$\Delta(E / R)= \pm 400 \mathrm{~K}$.

\section{Comments on Preferred Values}

The preferred $298 \mathrm{~K}$ value is based on the results of Kukui et al. (1994) which are in agreement with the data of Cox et al. (1984, 1987) and Biggs et al. (1991). The results of Cox et al. (1987) are consistent with those of Biggs et al. (1991) who reported that the rate coefficient is independent of temperature over the range $210 \mathrm{~K}$ to $353 \mathrm{~K}$. The two direct measurements of the branching ratio $k_{2} / k$, of $0.20 \pm 0.10$ at $297 \mathrm{~K}$ (Biggs et al., 1991) and $0.32 \pm 0.1$ at $300 \mathrm{~K}$ (Kukui et al., 1994), are in 
agreement that channel (1) dominates, and the preferred value of $k_{2}$ is based on the results of these two studies (Biggs et al., 1991; Kukui et al., 1994). From a study of the OClO- $\mathrm{NO}_{3}$ system, Friedl et al. (1992) conclude that at $220 \mathrm{~K}$ and $298 \mathrm{~K}$ the major reaction channel is channel (1), in agreement with the conclusions of Cox et al. (1987), Biggs et al. (1991) and Kukui et al. (1994).

\section{References}

Becker, E., Wille, U., Rahman, M. M., and Schindler, R. N.: Ber. Bunsenges. Phys. Chem., 95, 1173, 1991.

Biggs, P., Harwood, M. H., Parr, A. D., and Wayne, R. P.: J. Phys. Chem., 95, 7746, 1991.

Cox, R. A., Barton, R. A., Ljungstrøm, E., and Stocker, D. W.: Chem. Phys. Lett., 108, 228, 1984.

Cox, R. A., Fowles, M., Moulton, D., and Wayne, R. P.: J. Phys. Chem., 91, 3361, 1987.

Friedl, R. R., Sander, S. P., and Yung, Y. L : J. Phys. Chem., 96, 7490, 1992.

Kukui, A., Jungkamp, T. P. W., and Schindler, R. N.: Ber. Bunsenges. Phys. Chem., 98, 1619, 1994. 
III.A2.49

$$
\begin{aligned}
\mathrm{ClO}+\mathrm{ClO} & \rightarrow \mathrm{Cl}_{2}+\mathrm{O}_{2} \\
& \rightarrow \mathrm{Cl}+\mathrm{ClOO} \\
& \rightarrow \mathrm{Cl}+\mathrm{OClO}
\end{aligned}
$$

$\Delta H^{\circ}(1)=-203.2 \mathrm{~kJ} \mathrm{~mol}^{-1}$

$\Delta H^{\circ}(2)=15.6 \mathrm{~kJ} \mathrm{~mol}^{-1}$

$\Delta H^{\circ}(2)=12.7 \mathrm{~kJ} \mathrm{~mol}^{-1}$

Rate coefficient data $\left(k=k_{1}+k_{2}+k_{3}\right)$

\begin{tabular}{llll}
\hline$k / \mathrm{cm}^{3}$ molecule & Temp./K & Reference & Technique/Comments \\
\hline Absolute Rate Coefficients & & & \\
$k_{1}=1.01 \times 10^{-12} \exp [-(1590 \pm 100) / T]$ & $260-390$ & Nickolaisen et al., 1994 & (a) \\
$k_{2}=2.98 \times 10^{-11} \exp [-(2450 \pm 330) / T]$ & $260-390$ & & \\
$k_{3}=3.50 \times 10^{-13} \exp [-(1370 \pm 150) / T]$ & $260-390$ & & \\
& & & \\
Branching Ratios & 298 & Horowitz et al., 1994 & \\
$k_{1} / k=0.39 \pm 0.06$ & 298 & & \\
$k_{2} / k=0.41 \pm 0.06$ & 298 & & \\
$k_{3} / k=0.20 \pm 0.03$ & $285-331$ & & \\
$k_{3} / k_{2}=0.27 \exp [(220 \pm 100) / T]$ & & & \\
\hline
\end{tabular}

\section{Comments}

(a) Flash photolysis-long pathlength UV absorption technique. $\mathrm{Cl}_{2}-\mathrm{Cl}_{2} \mathrm{O}$ mixtures were photolyzed at wavelengths longer than $300 \mathrm{~nm}$. The UV absorption of $\mathrm{ClO}$ and $\mathrm{OClO}$ were monitored with an optical multichannel analyzer. The reaction was studied over a wide range of temperature, pressure, and initial reactant stoichiometry.

(a) $\mathrm{Cl}_{2}$-sensitized continuous photolysis of $\mathrm{Cl}_{2}-\mathrm{O}_{3}$ mixtures in excess $\mathrm{O}_{2}$. Decay of $\mathrm{O}_{3}$ and formation of $\mathrm{OClO}$ monitored by UV absorption.

\section{Preferred Values}

$k_{1}=4.8 \times 10^{-15} \mathrm{~cm}^{3}$ molecule $\mathrm{e}^{-1} \mathrm{~s}^{-1}$ at $298 \mathrm{~K}$.

$k_{2}=8.0 \times 10^{-15} \mathrm{~cm}^{3}$ molecule ${ }^{-1} \mathrm{~s}^{-1}$ at $298 \mathrm{~K}$.

$k_{3}=3.5 \times 10^{-15} \mathrm{~cm}^{3}$ molecule $\mathrm{s}^{-1} \mathrm{~s}^{-1}$ at $298 \mathrm{~K}$.

$k_{1}=1.0 \times 10^{-12} \exp (-1590 / T) \mathrm{cm}^{3}$ molecule ${ }^{-1} \mathrm{~s}^{-1}$ over the temperature range $260-390 \mathrm{~K}$.

$k_{2}=3.0 \times 10^{-11} \exp (-2450 / T) \mathrm{cm}^{3}$ molecule $\mathrm{e}^{-1} \mathrm{~s}^{-1}$ over the temperature range 260-390 $\mathrm{K}$.

$k_{3}=3.5 \times 10^{-13} \exp (-1370 / T) \mathrm{cm}^{3}$ molecule ${ }^{-1} \mathrm{~s}^{-1}$ over the temperature range $260-390 \mathrm{~K}$.

\section{Reliability}

$\Delta \log k_{1}=\Delta \log k_{2}=\Delta \log k_{3}= \pm 0.2$ at $298 \mathrm{~K}$.

$\Delta\left(E_{1} / R\right)=\Delta\left(E_{3} / R\right)= \pm 300 \mathrm{~K}$.

$\Delta\left(E_{2} / R\right)= \pm 500 \mathrm{~K}$.

\section{Comments on Preferred Values}

The $\mathrm{ClO}+\mathrm{ClO}$ reaction exhibits both bimolecular and termolecular reaction channels. The termolecular reaction, which leads to the formation of the $\mathrm{ClOOCl}$ dimer, dominates at high pressure ( $>0.013$ bar at $298 \mathrm{~K}$ ), but is not kinetically important at 
temperatures above $\sim 283 \mathrm{~K}$ because of the instability of the dimer with respect to the reverse decomposition. The recommended values for the individual reaction channels are those from the study of Nickolaisen et al. (1994). This study, using a flash photolysis-long pathlength UV absorption technique, is the most comprehensive study of this system, covering a wide range of temperature, initial reactant stoichiometry and pressure. These results (Nickolaisen et al., 1994) are preferred over the results of earlier studies of the total bimolecular rate coefficient at low pressures by Clyne and co-workers (1975) as discussed in the reviews of Watson $(1977,1980)$, and those of other studies reported by Cox and Derwent (1979), Hayman et al. (1986), Simon et al. (1990) and Horowitz et al. (1993).

The room temperature branching ratios from the study of Nickolaisen et al. (1994) are $k_{1}: k_{2}: k_{3}=0.29: 0.50: 0.21$. Horowitz et al. (1994) in their study of the temperature dependence of the channel branching ratios report slightly different values of $k_{1}: k_{2}: k_{3}=0.39: 0.41: 0.20$ at $298 \mathrm{~K}$ and observed distinctly non-Arrhenius behavior for $k$ over the temperature range $285 \mathrm{~K}$ to $331 \mathrm{~K}$. Their study (Horowitz et al., 1994) was carried out in excess $\mathrm{O}_{2}$, where the quantum yield for $\mathrm{O}_{3}$-photosensitized decomposition (which reflects $\mathrm{Cl}$ atom generation in this reaction) was consistently lower than in excess $\mathrm{N}_{2}$. The mechanistic explanation for this observation and for the apparent non-Arrhenius behavior remains obscure. The bath gas effect on $\Phi\left(-\mathrm{O}_{3}\right)$ can be accounted for by the observed difference in the branching ratios in the presence of $\mathrm{O}_{2}$ and $\mathrm{N}_{2}$, suggesting that $\mathrm{O}_{2}$ is not involved in the $\mathrm{ClO}+\mathrm{ClO}$ reaction simply as a third-body quencher.

\section{References}

Cox, R. A. and Derwent, R. G.: J. Chem. Soc. Faraday Trans., 1, 75, 1635, 1979.

Clyne, M. A. A., McKenney, D. J., and Watson, R. T.: J. Chem. Soc. Faraday Trans., 1, 71, 322, 1975.

Hayman, G. D., Davies, J. M., and Cox, R. A.: Geophys. Res. Lett., 13, 1347, 1986.

Horowitz, A., Bauer, D., Crowley, J. N., and Moortgat, G. K.: Geophys. Res. Lett., 20, 1423, 1993.

Horowitz, A., Crowley, J. N., and Moortgat, G. K.: J. Phys. Chem., 98, 11 924, 1994.

Nickolaisen, S. L., Friedl, R. R., and Sander, S. P.: J. Phys. Chem., 98, 155, 1994.

Simon, F. G., Schneider, W., Moortgat, G. K., and Burrows, J. P.: J. Photochem. Photobiol. A, 55, 1, 1990.

Watson, R. T. : J. Phys. Chem. Ref. Data, 6, 871, 1977.

Watson, R. T.: Proceedings of the NATO Advanced Study Institute on Atmospheric Ozone, Report FAA-EE-80-20, FAA, Washington, DC, 1980. 


\section{III.A2.50}

$\mathrm{ClO}+\mathrm{ClO}+\mathrm{M} \rightarrow \mathrm{Cl}_{2} \mathrm{O}_{2}+\mathrm{M}$

$\Delta H^{\circ}=-75.7 \mathrm{~kJ} \mathrm{~mol}^{-1}$

\section{Low-pressure rate coefficients}

\section{Rate coefficient data}

\begin{tabular}{lllc}
\hline$k_{0} / \mathrm{cm}^{3}$ molecule $^{-1} \mathrm{~s}^{-1}$ & Temp./K & Reference & Technique/Comments \\
\hline Absolute Rate Coefficients & & & \\
$5.0 \times 10^{-32}\left[\mathrm{O}_{2}\right]$ & 298 & Johnston et al., 1969 & MM (a) \\
$2.0 \times 10^{-32}[\mathrm{Ar}]$ & 298 & Walker, 1972 & DF-UVA (b) \\
$1.1 \times 10^{-32}\left[\mathrm{O}_{2}\right]$ & 300 & Basco and Hunt, 1979 & FP-UVA (c) \\
$3.0 \times 10^{-32}\left[\mathrm{~N}_{2}\right]$ & 298 & Cox et al., 1979 & MM (d) \\
$6.0 \times 10^{-32}(T / 300)^{-2.1}\left[\mathrm{O}_{2}\right]$ & $268-338$ & Hayman et al., 1986 & MM (e) \\
$(1.8 \pm 0.5) \times 10^{-32}(T / 300)^{-3.6}\left[\mathrm{~N}_{2}\right]$ & $194-247$ & Sander et al., 1989 & FP-UVA (f) \\
$(1.64 \pm 0.9) \times 10^{-32}(T / 300)^{-4.4}\left[\mathrm{~N}_{2}\right]$ & $200-263$ & Trolier et al., 1990 & FP-UVA (g) \\
$(1.32 \pm 0.08) \times 10^{-32}(T / 300)^{-4.4}\left[\mathrm{O}_{2}\right]$ & $200-263$ & & \\
$1.22 \times 10^{-33} \mathrm{exp}[(833 \pm 34) / T]\left[\mathrm{N}_{2}\right]$ & $195-390$ & Nickolaisen et al., 1994 & FP-UVA (h) \\
$(1.96 \pm 0.24) \times 10^{-32}\left[\mathrm{~N}_{2}\right]$ & 300 & & \\
$(1.24 \pm 0.09) \times 10^{-32}\left[\mathrm{O}_{2}\right]$ & 300 & & \\
$(2.5 \pm 0.4) \times 10^{-32}\left[\mathrm{~N}_{2}\right]$ & 300 & Bloss, 1999 & FP-UVA (i) \\
$1.7 \times 10^{-32}\left[\mathrm{~N}_{2}\right]$ & 300 & Stark, 1999 & PLP-UVA (j) \\
$1.1 \times 10^{-31}\left[\mathrm{~N}_{2}\right]$ & 200 & & \\
$(1.59 \pm 0.60) \times 10^{-32}(T / 300)^{-4.5}\left[\mathrm{~N}_{2}\right]$ & $183-245$ & Bloss et al. 2001 & FP-UVA (k) \\
\hline
\end{tabular}

\section{Comments}

(a) Photolysis of $\mathrm{Cl}_{2}-\mathrm{O}_{2}$ mixtures in the pressure range $0.07-1$ bar.

(b) Pressure range 1.3-10 mbar.

(c) Pressure range 70-930 mbar.

(d) Photolysis of $\mathrm{Cl}_{2}-\mathrm{O}_{2}$ mixtures at 50-400 mbar.

(e) Measurements in $\mathrm{Cl}_{2}-\mathrm{O}_{2}$ mixtures in the ratio 2:3, pressure range 7-30 mbar.

(f) $\mathrm{ClO}$ radicals generated from $\mathrm{Cl}_{2}-\mathrm{Cl}_{2} \mathrm{O}$ or $\mathrm{Cl}_{2}-\mathrm{O}_{3}$ mixtures with concentrations of bath gases $\mathrm{N}_{2}, \mathrm{Ar}$ or $\mathrm{O}_{2}$ in the range of $10^{18}$ molecule $\mathrm{cm}^{-3}$ to $3 \times 10^{-19}$ molecule $\mathrm{cm}^{-3}$. Falloff extrapolations to $k_{0}$ and $k_{\infty}$ used a value of $F_{c}=0.6$.

(g) $\mathrm{ClO}$ radicals generated from $\mathrm{Cl}_{2}-\mathrm{O}_{3}$ mixtures in the presence of 33 mbar to 800 mbar of $\mathrm{He}, \mathrm{N}_{2}, \mathrm{O}_{2}$ or $\mathrm{SF}_{6}, \mathrm{ClO}$ radicals and $\mathrm{Cl}_{2} \mathrm{O}_{2}$ monitored by long-path $\mathrm{UV}$ absorption. Falloff curves extrapolated with $F_{c}=0.6$.

(h) Pulsed laser photolysis of $\mathrm{Cl}_{2}$ at $\lambda>300 \mathrm{~nm}$ in the presence of $\mathrm{Cl}_{2} \mathrm{O}$. ClO radicals generated by the reaction $\mathrm{Cl}+\mathrm{Cl}_{2} \mathrm{O} \rightarrow \mathrm{ClO}+\mathrm{Cl}_{2}$ and monitored by $\mathrm{UV}$ absorption spectroscopy using either a photomultiplier for detection at $275.5 \mathrm{~nm}$ or an optical multichannel analyzer for detection over the wavelength range $270 \mathrm{~nm}$ to $280 \mathrm{~nm}$. Meaurements at 20-600 mbar. From a third-law analysis, a value of $\Delta H^{\circ}=-(75.7 \pm 0.9) \mathrm{kJ} \mathrm{mol}^{-1}$ was derived. Third-body efficiencies for the bath gases $\mathrm{He}, \mathrm{Ar}, \mathrm{CF}_{4}, \mathrm{SF}_{6}$ and $\mathrm{Cl}_{2}$ were also determined.

(i) $\mathrm{ClO}$ radicals generated by flash photolysis of $\mathrm{Cl}_{2}-\mathrm{Cl}_{2} \mathrm{O}-\mathrm{N}_{2}$ mixtures and detected by $\mathrm{UV}$ absorption. The bath gas pressure was varied between 0.25 bar and 1 bar. Falloff extrapolation used $F_{c}=0.6$. Small discrepancies between the various studies were attributed to the slightly different absorption cross sections used. 
(j) $\mathrm{ClO}$ radicals generated by pulsed laser photolysis of $\mathrm{Cl}_{2} \mathrm{O}$ between 0.1 bar and 1000 bar pressure of He and $\mathrm{N}_{2}$. The observed pressure dependences differ from conventional falloff expressions, suggesting overlapping contributions from the energy transfer and radical-complex mechanism, as well as diffusion control at the highest pressures. The cited rate coefficients correspond to a representation of the falloff curve at pressures below 1 bar using $F_{c}=0.6$.

(k) See comment (i). Pressure range 30-930 mbar. Falloff extrapolation with $F_{c}=0.6$ and $k_{\infty}=(1.36 \pm 0.2) \times 10^{-12}$ $(T / 300)^{-3.09} \mathrm{~cm}^{3}$ molecule $\mathrm{s}^{-1}$.

\section{Preferred Values}

$k_{0}=2.0 \times 10^{-32}(T / 300)^{-4}\left[\mathrm{~N}_{2}\right] \mathrm{cm}^{3}$ molecule ${ }^{-1} \mathrm{~s}^{-1}$ over the temperature range $190-390 \mathrm{~K}$.

\section{Reliability}

$\Delta \log k_{0}= \pm 0.1$ at $298 \mathrm{~K}$.

$\Delta n= \pm 1.5$.

\section{Comments on Preferred Values}

The preferred values are based on the studies of Trolier et al. (1999) and Bloss et al. (2001) accounting for some falloff, see coments on high-pressure rate coefficients.

\section{High-pressure rate coefficients}

\section{Rate coefficient data}

\begin{tabular}{llll}
\hline$k_{\infty} / \mathrm{cm}^{3}$ molecule & Temp./K & Reference & Technique/Comments \\
\hline Absolute Rate Coefficients & & & \\
$(6 \pm 2) \times 10^{-12}$ & $194-247$ & Sander et al., 1989 & FP-UVA (a) \\
$(4.8 \pm 1.3) \times 10^{-12}$ & $200-263$ & Trolier et al., 1990 & FP-UVA (b) \\
$(6 \pm 2) \times 10^{-12}$ & $195-390$ & Nickolaisen et al., 1994 & FP-UVA (c) \\
$(5 \pm 3) \times 10^{-12}$ & 300 & Bloss, 1999 & FP-UVA (d) \\
$4.5 \times 10^{-12}$ & 300 & Stark, 1999 & PLP-UVA (e) \\
$7 \times 10^{-12}$ & 200 & & \\
$(1.36 \pm 0.22) \times 10^{-12}(T / 300)^{-3.09}$ & $183-245$ & Bloss et al., 2001 & FP-UVA (f) \\
\hline
\end{tabular}

\section{Comments}

(a) See comment (a) for $k_{0}$.

(b) See comment (g) for $k_{0}$.

(c) See comment (h) for $k_{0}$. The $k_{\infty}$ value was obtained from falloff data measured below $250 \mathrm{~K}$.

(d) See comment (i) for $k_{0}$.

(e) See comment (j) for $k_{0}$. The cited rate coefficients are given for the energy-transfer mechanism only, such that the falloff curves below 1 bar are fitted. Above 1 bar pressure additional contributions from the radical-complex mechanism become increasingly important such that maximum values of $k$ of $4.5 \times 10^{-12} \mathrm{~cm}^{3}$ molecule $\mathrm{s}^{-1}$ at $300 \mathrm{~K}$ and $8 \times 10^{-12} \mathrm{~cm}^{3}$ molecule ${ }^{-1} \mathrm{~s}^{-1}$ at $200 \mathrm{~K}$ are reached near $200 \mathrm{bar}$, before they decrease because of diffusional control.

(f) See comment (i) and (k) for $k_{0}$. 


\section{Preferred Values}

$k_{\infty}=1.0 \times 10^{-11} \mathrm{~cm}^{3}$ molecule $\mathrm{e}^{-1} \mathrm{~s}^{-1}$, independent of temperature over the range 190-300 K.

\section{Reliability}

$\Delta \log k_{\infty}= \pm 0.3$ over the temperature range $190 \mathrm{~K}$ to $300 \mathrm{~K}$.

$\Delta n= \pm 1$.

\section{Comments on Preferred Values}

It is difficult to provide a reasonable representation of $k_{0}, k_{\infty}$ and $F_{c}$, because there is evidence that this reaction is governed by a superposition of the energy transfer and the radical-complex mechanism. The pressure dependence at $P>1$ bar looks anomalous (Stark, 1999). Likewise, the absolute value and the temperature coefficient of $k_{0}$ appear unusual. Neglecting these aspects, one may use the representation given by Bloss et al. (2001) with $F_{c}=0.6$ and $k_{0}$ and $k_{\infty}$ as given in the table. We here choose a different representation with $F_{c}=0.45$ and the preferred values given above which represent the data equally well at $P<1$ bar. However, we keep in mind that the mechanistic complications of this system ask for different treatments. Difficulties in the theoretical analysis of the rate coefficients were also encountered by Bloss et al. (2001), Golden (2003) and Zhu and Lin (2003).

\section{References}

Basco, N. and Hunt, J. K.: Int. J. Chem. Kinet., 11, 649, 1979.

Bloss, W.: Ph.D. Thesis, University of Cambridge, Cambridge, UK, 1999.

Bloss, W. J., Nickolaisen, S. L., Salawitch, R. J., Friedl, R. R., and Sander, S. P.: J. Phys. Chem. A, 105, 11226, 2001.

Cox, R. A., Derwent, R. G., Eggleton, A. E. J., and Reid, H. J.: J. Chem. Soc. Faraday Trans., 1, 75, 1648, 1979.

Golden, D. M.: Int. J. Kinet., 35, 206, 2003.

Hayman, G. D., Davies, J. M., and Cox, R. A.: Geophys. Res. Lett., 13, 1347, 1986.

Johnston, H. S., Morris, E. D., and Van de Bogaerde, J.: J. Am. Chem. Soc., 91, 7712, 1969.

Nickolaisen, S. L., Friedl, R. R., and Sander, S. P.: J. Phys. Chem., 98, 155, 1994.

Sander, S. P., Friedl, R. R., and Yung, Y. L.: Science, 245, 1095, 1989.

Stark, H.: Ph.D. Thesis, University of Göttingen, Göttingen, Germany, 1999.

Trolier, M., Mauldin III, R. L., and Ravishankara, A. R.: J. Phys. Chem., 94, 4896, 1990.

Walker, R. W.: Ph.D. Thesis, University of London, London, UK, 1972.

Zhu, R. S. and Lin, M. C.: J. Chem. Phys., 118, 3094, 2003. 
III.A2.51

$$
\mathrm{Cl}_{2} \mathrm{O}_{2}+\mathrm{M} \rightarrow \mathrm{ClO}+\mathrm{ClO}+\mathrm{M}
$$

$\Delta H^{\circ}=75.7 \mathrm{~kJ} \mathrm{~mol}^{-1}$

Low-pressure rate coefficients

Rate coefficient data

\begin{tabular}{llll}
\hline$k_{0} / \mathrm{s}^{-1}$ & Temp./K & Reference & Technique/Comments \\
\hline Absolute Rate Coefficients & & & \\
$9.81 \times 10^{-7} \exp [-(7980 \pm 320) / T]\left[\mathrm{N}_{2}\right]$ & $260-310$ & Nickolaisen et al., 1994 & FP-UVA (a) \\
$2.30 \times 10^{-18}\left[\mathrm{~N}_{2}\right]$ & 298 & & \\
\hline
\end{tabular}

\section{Comments}

(a) Photolysis of $\mathrm{Cl}_{2}$ at $\lambda>300 \mathrm{~nm}$ in the presence of $\mathrm{Cl}_{2} \mathrm{O}$. $\mathrm{ClO}$ radicals were monitored with an optical multichannel analyzer at $270 \mathrm{~nm}$ to $280 \mathrm{~nm}$. The pressure range used was 33 mbar to 400 mbar. Dissociation rate coefficients and equilibrium constants determined from analysis of two stages of $\mathrm{ClO}$ decay. From a third-law analysis, a value of $\Delta H^{\circ}=(75.7 \pm 0.9) \mathrm{kJ} \mathrm{mol}^{-1}$ was derived. A value of the equilibrium constant $K_{c}=(1.24 \pm 0.18) \times 10^{-27}$ $\exp (8820 / T) \mathrm{cm}^{3}$ molecule ${ }^{-1}$ was obtained in good agreement with a determination by Cox and Hayman (1988).

\section{Preferred Values}

$k_{0}=2.3 \times 10^{-18}\left[\mathrm{~N}_{2}\right] \mathrm{s}^{-1}$ at $298 \mathrm{~K}$.

$k_{0}=3.7 \times 10^{-7} \exp (-7690 / T)\left[\mathrm{N}_{2}\right] \mathrm{s}^{-1}$ over the temperature range $260-310 \mathrm{~K}$.

\section{Reliability}

$\Delta \log k_{0}= \pm 0.3$ at $298 \mathrm{~K}$.

$\Delta E / R= \pm 900 \mathrm{~K}$.

\section{Comments on Preferred Values}

The preferred values are based on the preferred values for the reverse reaction and the equilibrium constant from Nickolaisen et al. (1994) which agrees very well with the results of Cox and Hayman (1988).

\section{High-pressure rate coefficients}

\section{Rate coefficient data}

\begin{tabular}{lllc}
\hline$k_{\infty} / \mathrm{s}^{-1}$ & Temp./K & Reference & Technique/Comments \\
\hline Absolute Rate Coefficients & & & \\
$4.8 \times 10^{15} \exp (-8820 / T)$ & $260-310$ & Nickolaisen et al., 1994 & FP-UVA (a) \\
$6.7 \times 10^{2}$ & 298 & & \\
\hline
\end{tabular}

\section{Comments}

(a) See comment (a) for $k_{0}$. Falloff curve constructed with $F_{c}=0.6$. 


\section{Preferred Values}

$k_{\infty}=1.1 \times 10^{3} \mathrm{~s}^{-1}$ at $298 \mathrm{~K}$.

$k_{\infty}=7.9 \times 10^{15} \exp (-8820 / T) \mathrm{s}^{-1}$ over the temperature range $260-310 \mathrm{~K}$.

\section{Reliability}

$\Delta \log k_{\infty}= \pm 0.3$ at $298 \mathrm{~K}$.

$\Delta(E / R)= \pm 500 \mathrm{~K}$.

\section{Comments on Preferred Values}

The preferred values are based on the preferred values for the reverse reaction and the equilibrium constant from Nickolaisen et al. (1994). Falloff curves are constructed with $F_{c}=0.45$ like for the reverse reaction. One should keep in mind, however, that only data at $P<1$ bar are represented. There is evidence that the reaction is governed by a superposition of the energy transfer and the radical-complex mechanism such that the chosen simple representation of the falloff curve does not apply rigorously.

\section{References}

Cox, R. A. and Hayman, G. D.: Nature, 332, 796, 1988.

Nickolaisen, S. L., Friedl, R. R., and Sander, S. P.: J. Phys. Chem., 98, 155, 1994. 
III.A2.52

$$
\mathrm{ClO}+\mathrm{OClO}+\mathrm{M} \rightarrow \mathrm{Cl}_{2} \mathrm{O}_{3}+\mathrm{M}
$$

$\Delta H^{\circ}=-43.2 \mathrm{~kJ} \mathrm{~mol}^{-1}$

\section{Low-pressure rate coefficients}

\section{Rate coefficient data}

\begin{tabular}{lllc}
\hline$k_{0} / \mathrm{cm}^{3}$ molecule ${ }^{-1} \mathrm{~s}^{-1}$ & Temp./K & Reference & Technique/Comments \\
\hline Absolute Rate Coefficients & & & \\
$2.8 \times 10^{-31}\left[\mathrm{~N}_{2}\right]$ & 226 & Parr et al., 1990 & MM-UVA (a) \\
$(6.2 \pm 1.0) \times 10^{-32}(T / 300)^{-4.7}\left[\mathrm{~N}_{2}\right]$ & $200-260$ & Burkholder et al., 1993 & PLP-UVA (b) \\
\hline
\end{tabular}

\section{Comments}

(a) Experiments carried out with $\mathrm{Cl}_{2}-\mathrm{OClO}-\mathrm{N}_{2}$ mixtures in the pressure range 6.4-39 mbar. ClO monitored at $277.2 \mathrm{~nm}$. The reaction was apparently close to the low pressure limit.

(b) Pulsed laser photolysis of mixtures of $\mathrm{N}_{2} \mathrm{O}-\mathrm{Cl}_{2}-\mathrm{OClO}-\mathrm{He}$ or $\mathrm{CF}_{2} \mathrm{Cl}_{2}-\mathrm{OClO}-\mathrm{N}_{2}$ at $193 \mathrm{~nm}$. From the first mixture, rate data were obtained while from the second mixture equilibrium constants and the absorption spectra of $\mathrm{Cl}_{2} \mathrm{O}_{3}$ between $220 \mathrm{~nm}$ and $320 \mathrm{~nm}$ were derived. From a second-law analysis of the data, together with those of Hayman and Cox (1989), $\Delta H^{\circ}=-(46.4 \pm 5.1) \mathrm{kJ} \mathrm{mol}^{-1}$ and $\Delta S^{\circ}=-(88.7 \pm 18.9) \mathrm{J} \mathrm{mol}^{-1} \mathrm{~K}^{-1}$ were derived. The kinetic data were obtained from a fit of the falloff curves between 33 mbar and 333 mbar total pressure using $F_{c}=0.6$.

\section{Preferred Values}

$k_{0}=6.2 \times 10^{-32}(T / 300)^{-4.7}\left[\mathrm{~N}_{2}\right] \mathrm{cm}^{3}$ molecule ${ }^{-1} \mathrm{~s}^{-1}$ over the temperature range 200-300 $\mathrm{K}$.

\section{Reliability}

$\Delta \log k_{0}= \pm 0.3$ at $298 \mathrm{~K}$.

$\Delta n= \pm 1$.

\section{Comments on Preferred Values}

The values of the extensive study of Burkholder et al. (1993) are adopted here. At $226 \mathrm{~K}$ the rate coefficient of Parr et al. (1990) is in reasonable agreement with our preferred value (and therefore with the data of Burkholder et al., 1993). Abinitio calculations from Clark and Francisco (1997) predict the more stable structure of $\mathrm{Cl}_{2} \mathrm{O}_{3}$ to be $\mathrm{ClOCl}(\mathrm{O}) \mathrm{O}$ and result in a value of the enthalpy of the recombination reaction of $-45.6 \mathrm{~kJ} \mathrm{~mol}^{-1}$.

\section{High-pressure rate coefficients}

\section{Rate coefficient data}

\begin{tabular}{lclc}
\hline$k_{\infty} / \mathrm{cm}^{3}$ molecule ${ }^{-1} \mathrm{~s}^{-1}$ & Temp./K & Reference & Technique/Comments \\
\hline $\begin{array}{l}\text { Absolute Rate Coefficients } \\
(2.4 \pm 1.2) \times 10^{-11}\end{array}$ & $200-260$ & Burkholder et al., 1993 & (a) \\
\hline
\end{tabular}

\section{Comments}

(a) See comment (b) for $k_{0}$. 
R. Atkinson et al.: Evaluated kinetic and photochemical data for atmospheric chemistry

\section{Preferred Values}

$k_{\infty}=2.4 \times 10^{-11} \mathrm{~cm}^{3}$ molecule ${ }^{-1} \mathrm{~s}^{-1}$ over the temperature range $200-300 \mathrm{~K}$.

\section{Reliability}

$\Delta \log k_{\infty}= \pm 0.3$ over the temperature range $200-300 \mathrm{~K}$.

$\Delta n= \pm 1$.

\section{Comments on Preferred Values}

The preferred values are from Burkholder et al. (1993). The falloff extrapolation was done with $F_{c}=0.6$.

\section{References}

Burkholder, J. B., Mauldin III, R. L., Yokelson, R. J., Solomon, S., and Ravishankara, A. R.: J. Phys. Chem., 97, 7597, 1993. Clark, J. and Francisco, J. S.: J. Phys. Chem. A, 101, 7145, 1997.

Hayman, G. D. and Cox, R. A.: Chem. Phys. Lett., 155, 1, 1989.

Parr, A. D., Wayne, R. P., Hayman, G. D., Jenkin, M. E., and Cox, R. A.: Geophys. Res. Lett., 17, 2357, 1990. 
III.A2.53

$$
\mathrm{Cl}_{2} \mathrm{O}_{3}+\mathrm{M} \rightarrow \mathrm{ClO}+\mathrm{OClO}+\mathrm{M}
$$

$\Delta H^{\circ}=43.2 \mathrm{~kJ} \mathrm{~mol}^{-1}$

\section{Low-pressure rate coefficients}

\section{Rate coefficient data}

No direct measurements are available.

\section{Preferred Values}

$k_{0}=1.4 \times 10^{-10} \exp (-3810 / T)\left[\mathrm{N}_{2}\right] \mathrm{s}^{-1}$ over the temperature range $200-300 \mathrm{~K}$.

Reliability

$\Delta \log k_{0}= \pm 0.5$ at $240 \mathrm{~K}$.

$\Delta E / R= \pm 500 \mathrm{~K}$.

Comments on Preferred Values

The preferred values are from the preferred values for the reverse reaction $k_{0}=6.2 \times 10^{-32}(T / 300)^{-4.7}$ $\left[\mathrm{N}_{2}\right] \mathrm{cm}^{3}$ molecule ${ }^{-1} \mathrm{~s}^{-1}$, which were based on the measurements by Parr et al. (1990) and Burkholder et al. (1993), and the equilibrium constant $K_{c}=9.7 \times 10^{-24} \exp (4940 / T) \mathrm{cm}^{3}$ molecule ${ }^{-1}$ from Burkholder et al. (1993) and Hayman and Cox (1989).

\section{High-pressure rate coefficients}

\section{Rate coefficient data}

No direct measurements are available.

\section{Preferred Values}

$k_{\infty}=2.5 \times 10^{12} \exp (-4940 / T)\left[\mathrm{N}_{2}\right] \mathrm{s}^{-1}$ over the temperature range $200-300 \mathrm{~K}$.

\section{Reliability}

$\Delta \log k_{\infty}= \pm 0.5$ at $240 \mathrm{~K}$.

$\Delta E / R= \pm 500 \mathrm{~K}$.

\section{Comments on Preferred Values}

See comments on Preferred Values for $k_{0}$. Based on $k_{\infty}$ for the reverse reaction of $k_{\infty}=2.4 \times 10^{-11} \mathrm{~cm}^{3} \mathrm{molecule}^{-1} \mathrm{~s}^{-1}$. Falloff curves constructed with $F_{c}=0.6$.

\section{References}

Burkholder, J. B., Mauldin III, R. L., Yokelson, R. J., Solomon, S., and Ravishankara, A. R.: J. Phys. Chem., 97, 7597, 1993. Hayman, G. D. and Cox, R. A.: Chem. Phys. Lett., 155, 1, 1989.

Parr, A. D., Wayne, R. P., Hayman, G. D., Jenkin, M. E., and Cox, R. A.: Geophys. Res. Lett., 17, 2357, 1990. 


\section{III.A2.54}

$$
\mathrm{OClO}+\mathrm{O}_{3} \rightarrow \mathrm{ClO}_{3}+\mathrm{O}_{2}
$$

$\Delta H^{\circ}=-20 \mathrm{~kJ} \mathrm{~mol}^{-1}$

\section{Rate coefficient data}

\begin{tabular}{lllc}
\hline$k / \mathrm{cm}^{3}$ molecule ${ }^{-1} \mathrm{~s}^{-1}$ & Temp./K & Reference & Technique/Comments \\
\hline Absolute Rate Coefficients & & & \\
$(1.20 \pm 0.15) \times 10^{-19}$ & 298 & Birks et al., 1977 & (a) \\
$2.3 \times 10^{-12} \exp [-(4730 \pm 630) / T]$ & $262-298$ & Wongdontri-Stuper et al., 1979 & PLP-UVA (b) \\
$3.0 \times 10^{-19}$ & 298 & & \\
\hline
\end{tabular}

\section{Comments}

(a) Static system, rate coefficient determined by monitoring the loss of $\mathrm{O}_{3}$ in excess $\mathrm{OClO}$ and also loss of $\mathrm{OClO}$ in excess $\mathrm{O}_{3}$. Both species were measured by $\mathrm{UVA} ; \mathrm{O}_{3}$ at $254 \mathrm{~nm}$ and $\mathrm{OClO}$ at $366 \mathrm{~nm}$.

(b) The decay of $\mathrm{OClO}$ in excess $\mathrm{O}_{3}$ was monitored by UVA at $400 \mathrm{~nm}$. The reaction rate was also determined by the pulsed photolysis of $\mathrm{Cl}_{2}-\mathrm{O}_{2}$ mixtures at $366 \mathrm{~nm}$ to produce $\mathrm{OClO}$, followed by monitoring $\mathrm{OClO}$ decay.

\section{Preferred Values}

$k=3.0 \times 10^{-19} \mathrm{~cm}^{3}$ molecule $\mathrm{e}^{-1} \mathrm{~s}^{-1}$ at $298 \mathrm{~K}$.

$k=2.1 \times 10^{-12} \exp (-4700 / T) \mathrm{cm}^{3}$ molecule $\mathrm{e}^{-1} \mathrm{~s}^{-1}$ over the temperature range $260-300 \mathrm{~K}$.

\section{Reliability}

$\Delta \log k= \pm 0.4$ at $298 \mathrm{~K}$.

$\Delta(E / R)= \pm 1000 \mathrm{~K}$.

\section{Comments on Preferred Values}

The preferred values are based on the results reported in the study of Wongdontri-Stuper et al. (1979). Within the indicated uncertainty limits, the preferred values encompass the lower room temperature value reported by Birks et al. (1977).

\section{References}

Birks, J. W., Shoemaker, B., Leck, T. J., Borders, R. A., and Hart, L. J.: J. Chem. Phys., 66, 4591, 1977.

Wongdontri-Stuper, W., Jayanty, R. K. M., Simonaitis, R., and Heicklen, J.: J. Photochem., 10, 163, 1979. 
III.A2.55

$$
\mathrm{OClO}+\mathrm{NO} \rightarrow \mathrm{ClO}+\mathrm{NO}_{2}
$$

$\Delta H^{\circ}=-50.0 \mathrm{~kJ} \mathrm{~mol}^{-1}$

\section{Rate coefficient data}

\begin{tabular}{lllc}
\hline$k / \mathrm{cm}^{3}$ molecule ${ }^{-1} \mathrm{~s}^{-1}$ & Temp./K & Reference & Technique/Comments \\
\hline Absolute Rate Coefficients & & & \\
$(3.4 \pm 0.5) \times 10^{-13}$ & 298 & Bemand et al., 1973 & DF-MS \\
$1.04 \times 10^{-13} \exp [(347 \pm 58) / T]$ & $220-367$ & Li et al., 2002 & DF-MS \\
$(3.55 \pm 0.30) \times 10^{-13}$ & 298 & & \\
\hline
\end{tabular}

\section{Preferred Values}

$k=3.6 \times 10^{-13} \mathrm{~cm}^{3}$ molecule $\mathrm{e}^{-1} \mathrm{~s}^{-1}$ at $298 \mathrm{~K}$.

$k=1.1 \times 10^{-13} \exp (350 / T) \mathrm{cm}^{3}$ molecule $\mathrm{s}^{-1} \mathrm{~s}^{-1}$ over the temperature range $220-370 \mathrm{~K}$.

\section{Reliability}

$\Delta \log k= \pm 0.15$ at $298 \mathrm{~K}$.

$\Delta(E / R)= \pm 200 \mathrm{~K}$.

\section{Comments on Preferred Values}

The two available studies of this reaction (Bemand et al., 1973; Li et al., 2002), both using the same method, show good agreement at the common temperature, $298 \mathrm{~K}$, and the recommendation at this temperature is the average result. The recommended temperature dependence is provided by the study of Li et al. (2002), with a slight correction to the pre-exponential factor to match the preferred value at $298 \mathrm{~K}$.

\section{References}

Bemand, P. P., Clyne, M. A. A., and Watson, R. T.: J. Chem. Soc. Faraday Trans., 1, 69, 1356, 1973.

Li, Z., Wuebbles, D., and Pylawka, N. J.: Chem. Lett., 354, 491, 2002. 
III.A2.56

$$
\mathrm{OClO}+\mathrm{NO}_{3} \rightarrow \text { products }
$$

\section{Rate coefficient data}

\begin{tabular}{lllc}
\hline$k / \mathrm{cm}^{3}$ molecule $\mathrm{s}^{-1}$ & Temp./K & Reference & Technique/Comments \\
\hline Absolute Rate Coefficients & & & \\
$<1 \times 10^{-15}$ & 300 & Biggs et al., 1991 & DF-UV \\
$2 \times 10^{-14}$ & 298 & Friedl et al., 1992 & (a) \\
$2 \times 10^{-14}$ & 220 & & \\
$<6 \times 10^{-17}$ & $298-300$ & Boyd et al., 1996 & (b) \\
\hline
\end{tabular}

\section{Comments}

(a) The experiments were carried out in a long-path absorption flow reactor. $\mathrm{NO}_{3}$ radicals were generated by the reaction of $\mathrm{F}$ atoms with $\mathrm{HNO}_{3}$ or of $\mathrm{Cl}$ atoms with $\mathrm{ClONO}_{2}$. The products were analysed by IR and $\mathrm{UV}$ absorption measurements. Rate constant at $298 \mathrm{~K}$ derived by numerical simulation of $\mathrm{NO}_{3}$, OClO and $\mathrm{ClO}$ profiles, and assuming $\mathrm{NO}_{2}+\mathrm{O}_{2}+\mathrm{ClO}$ are products. At $220 \mathrm{~K}$ and 5.3 mbar He, formation of chlorylnitrate $\left(\mathrm{O}_{2} \mathrm{ClONO}_{2}\right)$ in a termolecular reaction channel was observed, with an apparent rate constant of $2 \times 10^{-14} \mathrm{~cm}^{3}$ molecule ${ }^{-1} \mathrm{~s}^{-1}$. At this temperature the rate constant for the bimolecular channel was derived to be $2 \times 10^{-15} \mathrm{~cm}^{3}$ molecule $\mathrm{e}^{-1} \mathrm{~s}^{-1}$.

(b) Room temperature studies at low pressure in discharge stopped flow (typically $10.7 \mathrm{mbar}$ ), slow flow (typically 8 mbar) and discharge flow ( $2.7 \mathrm{mbar}$ ) experiments. Detection of both $\mathrm{NO}_{3}$ and $\mathrm{OClO}$ was achieved using absorption spectroscopy. The slow flow experiments are comparable to those of Friedl et al. (1992).

\section{Preferred Values}

No recommendation is given.

\section{Comments on Preferred Values}

The available results of the studies of this reaction are very divergent. In their later study, Boyd et al. (1996) were unable to interpret their observations, obtained in three different set ups, in terms of a gas-phase reaction between $\mathrm{NO}_{3}$ and $\mathrm{OClO}$, and suggest that heterogeneous processes play an important role in their study, and potentially therefore also in the similar study of Friedl et al. (1992). Further work is clearly needed to resolve these discrepancies, and until this is available no recommendation is given, other than to note that the reaction is slow.

\section{References}

Biggs, P., Harwood, M. H., Parr, A. D., and Wayne, R. P.: J. Phys. Chem., 95, 7746, 1991. Boyd, A. A., Marston, G., and Wayne, R. P.: J. Phys. Chem., 100, 130, 1996. Friedl, R. R., Sander, S. P., and Yung, Y. L.: J. Phys. Chem., 96, 7490, 1992. 
III.A2.57

$$
\mathrm{Cl}_{2} \mathrm{O}_{2}+\mathrm{O}_{3} \rightarrow \mathrm{ClO}+\mathrm{ClOO}+\mathrm{O}_{2}
$$

$\Delta H^{\circ}=-71.2 \mathrm{~kJ} \mathrm{~mol}^{-1}$

\section{Rate coefficient data}

\begin{tabular}{lclc}
\hline$k / \mathrm{cm}^{3}$ molecule ${ }^{-1} \mathrm{~s}^{-1}$ & Temp./K & Reference & Technique/Comments \\
\hline $\begin{array}{l}\text { Absolute Rate Coefficients } \\
<1 \times 10^{-19}\end{array}$ & $195-217$ & DeMore and Tschuikow-Roux, 1990 & (a) \\
\hline
\end{tabular}

\section{Comments}

(a) Photolysis $(\lambda>300 \mathrm{~nm})$ of $\mathrm{Cl}_{2}-\mathrm{O}_{3}$ or $\mathrm{Cl}_{2}-\mathrm{Cl}_{2} \mathrm{O}$ mixtures, both in the gas phase and in the cryogenic solvents $\mathrm{CF}_{4}, \mathrm{CO}_{2}$ and $\mathrm{N}_{2} \mathrm{O}$. The quantum yield of $\mathrm{O}_{3}$ loss was measured.

\section{Preferred Values}

$k<1 \times 10^{-19} \mathrm{~cm}^{3}$ molecule $\mathrm{e}^{-1} \mathrm{~s}^{-1}$ at $200 \mathrm{~K}$.

\section{Comments on Preferred Values}

The recommended upper limit to the rate coefficient is that determined by DeMore and Tschuikow-Roux (1990) from measurements of the quantum yield of $\mathrm{O}_{3}$ loss in the photolysis of $\mathrm{Cl}_{2}-\mathrm{O}_{3}$ mixtures at $\lambda>300 \mathrm{~nm}$. The experiments were very sensitive to this reaction. Reaction at a rate greater than this upper limit would have had a marked effect on the quantum yield of ozone loss and also would have resulted in a dependence of the quantum yield on the ozone concentration; however, neither effect was observed (DeMore and Tschuikow-Roux, 1990). These measurements refer to a temperature of about $200 \mathrm{~K}$; the value of this rate coefficient at higher temperatures would be of no atmospheric significance because of the thermal decomposition of the $\mathrm{Cl}_{2} \mathrm{O}_{2}$ dimer.

\section{References}

DeMore, W. B. and Tschuikow-Roux, E.: J. Phys. Chem., 94, 5856, 1990. 


\section{Appendix 3: $\mathrm{BrO}_{\mathrm{x}}$ Reactions}

III.A3.58

$$
\mathrm{O}+\mathrm{HOBr} \rightarrow \mathrm{HO}+\mathrm{BrO}
$$

$\Delta H^{\circ} \leq-36 \mathrm{~kJ} \mathrm{~mol}^{-1}$

\section{Rate coefficient data}

\begin{tabular}{lllc}
\hline$k / \mathrm{cm}^{3}$ molecule ${ }^{-1} \mathrm{~s}^{-1}$ & Temp./K & Reference & Technique/Comments \\
\hline Absolute Rate Coefficients & & & \\
$(2.5 \pm 0.4) \times 10^{-11}$ & 298 & Monks et al., 1993 & DF-MS \\
$1.4 \times 10^{-10} \exp [-(430 \pm 260) / T]$ & $233-423$ & Nesbitt et al., 1995 & DF-MS \\
$(2.5 \pm 0.6) \times 10^{-11}$ & 298 & & \\
$(3.1 \pm 0.2) \times 10^{-11}$ & 300 & Kukui et al., 1996 & DF-MS \\
\hline
\end{tabular}

\section{Preferred Values}

$k=2.8 \times 10^{-11} \mathrm{~cm}^{3}$ molecule ${ }^{-1} \mathrm{~s}^{-1}$ at $298 \mathrm{~K}$.

$k=1.2 \times 10^{-10} \exp (-430 / T) \mathrm{cm}^{3}$ molecule $\mathrm{s}^{-1} \mathrm{~s}^{-1}$ over the temperature range $230-430 \mathrm{~K}$.

\section{Reliability}

$\Delta \log k= \pm 0.2$ at $298 \mathrm{~K}$.

$\Delta(E / R)= \pm 300 \mathrm{~K}$.

\section{Comments on Preferred Values}

The preferred rate coefficient at $298 \mathrm{~K}$ is the mean of the values of Nesbitt et al. (1995) and Kukui et al. (1996) and the temperature dependence is that of Nesbitt et al. (1995) with the $A$-factor adjusted to yield the preferred rate coefficient at $298 \mathrm{~K}$. Note that the rate coefficient for this reaction is almost a factor of 200 greater than that for the corresponding reaction of $\mathrm{O}\left({ }^{3} \mathrm{P}\right)$ atoms with $\mathrm{HOCl}$ (this evaluation).

\section{References}

Kukui, A., Kirchner, U., Benter, T., and Schindler, R. N.: Ber. Bunsenges. Phys. Chem., 100, 455, 1996.

Monks, P. S., Nesbitt, F. L., Scanlon, M., and Stief, L. J.: J. Phys. Chem., 97, 11 699, 1993.

Nesbitt, F. L., Monks, P. S., Payne, W. A., Stief, L. J., and Toumi, R.: Geophys. Res. Lett., 22, 827, 1995. 
III.A3.59

$$
\mathrm{O}+\mathrm{BrO} \rightarrow \mathbf{O}_{2}+\mathbf{B r}
$$

$\Delta H^{\circ}=-257 \mathrm{~kJ} \mathrm{~mol}^{-1}$

\section{Rate coefficient data}

\begin{tabular}{lllc}
\hline$k / \mathrm{cm}^{3}$ molecule ${ }^{-1} \mathrm{~s}^{-1}$ & Temp./K & Reference & Technique/Comments \\
\hline Absolute Rate Coefficients & & & \\
$\left(2.5_{-1.5}^{+2.5}\right) \times 10^{-11}$ & 298 & Clyne et al., 1976 & DF-RF (a) \\
$1.9 \times 10^{-11} \exp [(230 \pm 150) / T]$ & $231-328$ & Thorn et al., 1995 & PLP-A/RF (b) \\
$(4.1 \pm 0.6) \times 10^{-11}$ & 298 & & \\
\hline
\end{tabular}

\section{Comments}

(a) Measurements of $\mathrm{O}$ atom consumption rates and $\mathrm{Br}$ atom production rates in the $\mathrm{O}+\mathrm{Br}_{2}$ reaction were interpreted to give an estimate of $k\left(\mathrm{O}+\mathrm{BrO} \rightarrow \mathrm{O}_{2}+\mathrm{Br}\right)$.

(b) Pulsed laser flash photolysis system with detection of $\mathrm{BrO}$ radicals by long path absorption and of $\mathrm{O}\left({ }^{3} \mathrm{P}\right)$ atoms by resonance fluorescence.

\section{Preferred Values}

$k=4.1 \times 10^{-11} \mathrm{~cm}^{3}$ molecule ${ }^{-1} \mathrm{~s}^{-1}$ at $298 \mathrm{~K}$.

$k=1.9 \times 10^{-11} \exp (230 / T) \mathrm{cm}^{3}$ molecule $\mathrm{s}^{-1} \mathrm{~s}^{-1}$ over the temperature range $230-330 \mathrm{~K}$.

\section{Reliability}

$\Delta \log k= \pm 0.2$ at $298 \mathrm{~K}$.

$\Delta(E / R)= \pm 150 \mathrm{~K}$.

\section{Comments on Preferred Values}

The preferred value is based on the direct study of Thorn et al. (1995) in which the decay of $\mathrm{O}\left({ }^{3} \mathrm{P}\right)$ in the presence of excess $\mathrm{BrO}$ was monitored. Clyne et al. (1976) derived an indirect estimate of the room temperature value which was approximately $40 \%$ lower than the preferred value given above.

\section{References}

Clyne, M. A. A., Monkhouse, P. B., and Townsend, L. W.: Int. J. Chem. Kinet., 8, 425, 1976.

Thorn, R. P., Cronkhite, J. M., Nicovich, J. M., and Wine, P. H.: J. Chem. Phys., 102, 4131, 1995. 
III.A3.60

$$
\mathrm{O}+\mathrm{BrONO}_{2} \rightarrow \text { products }
$$

\section{Rate coefficient data}

\begin{tabular}{lllc}
\hline$k / \mathrm{cm}^{3}$ molecule ${ }^{-1} \mathrm{~s}^{-1}$ & Temp./K & Reference & Technique/Comments \\
\hline Absolute Rate Coefficients & & & \\
$1.91 \times 10^{-11} \exp [(215 \pm 30) / T]$ & $227-339$ & Soller et al., 2001 & LPF-RF (a) \\
$3.93 \times 10^{-11}$ & 298 & & \\
\hline
\end{tabular}

\section{Comments}

(a) Measurements of $\mathrm{O}\left({ }^{3} \mathrm{P}\right)$ atom consumption rates under pseudo-first-order conditions with $\mathrm{BrONO}_{2}$ in large excess.

\section{Preferred Values}

$k=3.9 \times 10^{-11} \mathrm{~cm}^{3}$ molecule ${ }^{-1} \mathrm{~s}^{-1}$ at $298 \mathrm{~K}$.

$k=1.9 \times 10^{-11} \exp (215 / T) \mathrm{cm}^{3}$ molecule $\mathrm{s}^{-1}$ over the temperature range $220-340 \mathrm{~K}$.

\section{Reliability}

$\Delta \log k= \pm 0.15$ at $298 \mathrm{~K}$.

$\Delta(E / R)= \pm 100 \mathrm{~K}$.

\section{Comments on Preferred Values}

The preferred value is based on the study of Soller et al., (2001) in which the decay of $\mathrm{O}\left({ }^{3} \mathrm{P}\right)$ in the presence of excess $\mathrm{BrONO}_{2}$ was monitored. Burkholder (2000) has studied the $\mathrm{O}\left({ }^{3} \mathrm{P}\right)+\mathrm{BrONO}_{2}$ reaction using pulsed laser photolysis with long-path transient absorption detection of $\mathrm{NO}_{3}$. The $\mathrm{NO}_{3}$ yield was found to be $>0.85$, suggesting that the primary product channel is $\mathrm{BrO}+\mathrm{NO}_{3}$.

\section{References}

Burkholder, J. B.: J. Phys. Chem. A., 104, 6733, 2000.

Soller, R., Nicovich, J. M. and Wine, P. H.: J. Phys. Chem. A., 105, 1416, 2001. 
III.A3.61

$$
\mathrm{Br}+\mathrm{HO}_{2} \rightarrow \mathrm{HBr}+\mathrm{O}_{2}
$$

$\Delta H^{\circ}=-162.8 \mathrm{~kJ} \mathrm{~mol}^{-1}$

\section{Rate coefficient data}

\begin{tabular}{lllc}
\hline$k / \mathrm{cm}^{3}$ molecule ${ }^{-1} \mathrm{~s}^{-1}$ & Temp./K & Reference & Technique/Comments \\
\hline Absolute Rate Coefficients & & & \\
$1.4 \times 10^{-11} \exp [-(590 \pm 140) / T]$ & $260-390$ & Toohey et al., 1987 & DF-LMR/RF (a) \\
$(2.0 \pm 0.3) \times 10^{-12}$ & 298 & & \\
$(1.5 \pm 0.2) \times 10^{-12}$ & 298 & Laverdet et al., 1990 & DF-EPR (b) \\
$4.9 \times 10^{-12} \exp [-(310 \pm 40) / T]$ & $230-355$ & Bedjanian et al., 2001 & DF-MS (c) \\
$(1.71 \pm 0.20) \times 10^{-12}$ & 297 & & \\
\hline
\end{tabular}

\section{Comments}

(a) $\mathrm{Br}$ atoms generated either directly by discharge of $\mathrm{Br}_{2}$, or from the addition of diluted $\mathrm{Br}_{2}$ to an excess of $\mathrm{O}\left({ }^{3} \mathrm{P}\right)$ atoms. $\mathrm{HO}_{2}$ radicals were generated by the $\mathrm{F}+\mathrm{H}_{2} \mathrm{O}_{2}$ reaction. $\mathrm{HO}_{2}$ radicals and $\mathrm{Br}$ atoms were monitored by laser magnetic resonance and resonance fluorescence, respectively. $k$ was determined from pseudo-first order decay of $\mathrm{HO}_{2}$ in the presence of excess Br.

(b) $\mathrm{Br}$ atoms generated either directly by discharge of $\mathrm{Br}_{2}$, or from the $\mathrm{Cl}+\mathrm{CH}_{2}=\mathrm{CHBr}$ reaction. $\mathrm{HO}_{2}$ radicals were generated from the reaction of $\mathrm{Cl}$ with $\mathrm{CH}_{3} \mathrm{OH}$ in the presence of $\mathrm{O}_{2} . k$ was determined from pseudo-first order decay of $\mathrm{HO}_{2}$ in the presence of excess $\mathrm{Br}$. A reinterpretation of previous indirect measurements conducted in the same laboratory (Poulet et al., 1984) is also given. This yielded revised values of $k$ in the range $(1.0-2.2) \times 10^{-11} \mathrm{~cm}^{3}$ molecule ${ }^{-1} \mathrm{~s}^{-1}$.

(c) $\mathrm{Br}$ atoms generated either directly by discharge of $\mathrm{Br}_{2}$, or from the $\mathrm{H}+\mathrm{Br}_{2}$ or $\mathrm{Cl}+\mathrm{Br}_{2}$ reactions. $\mathrm{HO}_{2}$ radicals were generated by the $\mathrm{F}+\mathrm{H}_{2} \mathrm{O}_{2}$ reaction. $k$ was determined from pseudo-first order decay of $\mathrm{HO}_{2}$ in the presence of excess $\mathrm{Br}$.

\section{Preferred Values}

$k=1.7 \times 10^{-12} \mathrm{~cm}^{3}$ molecule $\mathrm{e}^{-1} \mathrm{~s}^{-1}$ at $298 \mathrm{~K}$.

$k=7.7 \times 10^{-12} \exp (-450 / T) \mathrm{cm}^{3}$ molecule ${ }^{-1} \mathrm{~s}^{-1}$ over the temperature range 230-390 $\mathrm{K}$.

\section{Reliability}

$\Delta \log k= \pm 0.2$ at $298 \mathrm{~K}$.

$\Delta(E / R)= \pm 200 \mathrm{~K}$.

\section{Comments on Preferred Values}

The preferred value at $298 \mathrm{~K}$ is the mean of the results of Toohey et al. (1987), Laverdet et al. (1990) and Bedjanian et al. (2001), which are all in acceptable agreement. The preferred Arrhenius expression is based on the mean of the $E / R$ values from the temperature dependence studies of Toohey et al. (1987) and Bedjanian et al. (2001) combined with a pre-exponential factor adjusted to give the preferred value of $k$ at $298 \mathrm{~K}$. The uncertainty in the preferred value of $E / R$ reflects the fact that the values reported by Toohey et al. (1987) and Bedjanian et al. (2001) differ by almost a factor of two. The observed kinetics are consistent with the mechanism proceeding via direct hydrogen atom abstraction to yield $\mathrm{HBr}$, as also indicated by theoretical studies of the reaction (Sumathi and Peyerimhoff, 1999). 


\section{References}

Bedjanian, Y., Riffault, V., Le Bras, G., and Poulet, G.: J. Phys. Chem. A, 105, 573, 2001.

Laverdet, G., Le Bras, G., Mellouki, A., and Poulet, G.: Chem. Phys. Lett., 172, 430, 1990.

Poulet, G., Laverdet, G., and Le Bras, G.: J. Chem. Phys., 80, 1922, 1984.

Sumathi, R. and Peyerimhoff, S. D.: Phys. Chem. Chem. Phys., 1, 3973, 1999.

Toohey, D. W., Brune, W. H., and Anderson, J. G.: J. Phys. Chem., 91, 1215, 1987. 
III.A3.62

$$
\begin{aligned}
\mathrm{Br}+\mathrm{H}_{2} \mathrm{O}_{2} & \rightarrow \mathrm{HBr}+\mathrm{HO}_{2} \\
& \rightarrow \mathrm{HOBr}+\mathrm{HO}
\end{aligned}
$$

$\Delta H^{\circ}(1)=2.8 \mathrm{~kJ} \mathrm{~mol}^{-1}$

$\Delta H^{\circ}(2) \leq 6 \mathrm{~kJ} \mathrm{~mol}^{-1}$

\begin{tabular}{|c|c|c|c|}
\hline$k / \mathrm{cm}^{3}$ molecule $^{-1} \mathrm{~s}^{-1}$ & Temp./K & Reference & Technique/Comments \\
\hline \multicolumn{4}{|c|}{ Absolute Rate Coefficients } \\
\hline$<1.5 \times 10^{-15}$ & 298 & Leu, 1980 & DF-MS \\
\hline$<3.0 \times 10^{-15}$ & 417 & & \\
\hline$<2.0 \times 10^{-15}$ & $\sim 298$ & Posy et al., 1981 & DF-MS \\
\hline$<5 \times 10^{-16}$ & 298 & Toohey et al., 1987 & DF-RF (a) \\
\hline$<5 \times 10^{-16}$ & 378 & & \\
\hline
\end{tabular}

Rate coefficient data $\left(k=k_{1}+k_{2}\right)$

\section{Comments}

(a) Decays of $\mathrm{Br}$ radicals were monitored by the presence of excess $\mathrm{H}_{2} \mathrm{O}_{2}$. Measurement of $\mathrm{HO}_{2}$ and $\mathrm{HO}$ radical products by LMR allowed upper limits of $5 \times 10^{-16} \mathrm{~cm}^{3}$ molecule $\mathrm{s}^{-1} \mathrm{~s}^{-1}$ to be derived for both channel (1) and channel (2).

\section{Preferred Values}

$k<5 \times 10^{-16} \mathrm{~cm}^{3}$ molecule $\mathrm{e}^{-1} \mathrm{~s}^{-1}$ at $298 \mathrm{~K}$.

\section{Comments on Preferred Values}

The upper limit to the preferred value is based on the data of Toohey et al. (1987) who also obtained the same upper limit at $378 \mathrm{~K}$. The upper limits to the rate constant of Toohey et al. (1987) are consistent with the previous higher upper limits of Leu (1980) and Posey et al. (1981).

\section{References}

Leu, M.-T.: Chem. Phys. Lett., 69, 37, 1980.

Posey, J., Sherwell, J., and Kaufman, M.: Chem. Phys. Lett., 77, 476, 1981.

Toohey, D. W., Brune, W. H., and Anderson, J. G.: J. Phys. Chem., 91, 1215, 1987. 


\section{III.A3.63}

$$
\mathrm{Br}+\mathrm{O}_{3} \rightarrow \mathrm{BrO}+\mathrm{O}_{2}
$$

$\Delta H^{\circ}=-135 \mathrm{~kJ} \mathrm{~mol}^{-1}$

\section{Rate coefficient data}

\begin{tabular}{lllc}
\hline$k / \mathrm{cm}^{3}$ molecule ${ }^{-1} \mathrm{~s}^{-1}$ & Temp./K & Reference & Technique/Comments \\
\hline $\begin{array}{l}\text { Absolute Rate Coefficients } \\
(1.2 \pm 0.2) \times 10^{-12}\end{array}$ & 298 & Clyne and Watson, 1975 & DF-MS \\
$3.34 \times 10^{-11} \exp [-(978 \pm 36) / T]$ & $224-422$ & Leu and DeMore, 1977 & DF-MS \\
$(1.16 \pm 0.16) \times 10^{-12}$ & 298 & & \\
$7.74 \times 10^{-12} \exp [-(603 \pm 16) / T]$ & $200-360$ & Michael et al., 1978 & FP-RF \\
$(1.01 \pm 0.18) \times 10^{-12}$ & 298 & & \\
$9.45 \times 10^{-12} \exp [-(659 \pm 64) / T]$ & $234-360$ & Michael and Payne, 1979 & DF-RF \\
$(1.12 \pm 0.07) \times 10^{-12}$ & 298 & & \\
$3.28 \times 10^{-11} \exp [-(944 \pm 30) / T]$ & $248-418$ & Toohey et al., 1988 & DF-RF \\
$1.42 \pm 0.03) \times 10^{-12}$ & 298 & & \\
$1.50 \times 10^{-11} \exp [-(775 \pm 30) / T]$ & $195-392$ & Nicovich et al., 1990 & PLP-RF \\
$(1.11 \pm 0.07) \times 10^{-12}$ & 298 & & \\
$(1.2 \pm 0.1) \times 10^{-12}$ & 298 & Ninomiya et al., 2000 & PLP-CRDS (a) \\
\hline
\end{tabular}

\section{Comments}

(a) $\mathrm{BrO}$ formation was monitored by cavity ring down spectroscopy at $338.5 \mathrm{~nm}$. The background signal was monitored at $338.1 \mathrm{~nm}$.

\section{Preferred Values}

$k=1.2 \times 10^{-12} \mathrm{~cm}^{3}$ molecule $\mathrm{e}^{-1} \mathrm{~s}^{-1}$ at $298 \mathrm{~K}$.

$k=1.7 \times 10^{-11} \exp (-800 / T) \mathrm{cm}^{3}$ molecule ${ }^{-1} \mathrm{~s}^{-1}$ over the temperature range $190-430 \mathrm{~K}$.

\section{Reliability}

$\Delta \log k= \pm 0.08$ at $298 \mathrm{~K}$.

$\Delta(E / R)= \pm 200 \mathrm{~K}$.

\section{Comments on Preferred Values}

The recommended Arrhenius expression is based on a fit to the results of the temperature dependence of Clyne and Watson (1975), Leu and DeMore (1977), Michael et al. (1978), Michael and Payne (1979), Toohey et al. (1988), Nicovich et al. (1990) and the room temperature data of Ninomiya et al. (2000).

\section{References}

Clyne, M. A. A. and Watson, R. T.: J. Chem. Soc. Faraday Trans., 1, 71, 336, 1975.

Leu, M. T. and DeMore, W. B.: Chem. Phys. Lett., 48, 317, 1977.

Michael, J. V., Lee, J. H., Payne, W. A., and Stief, L. J.:. Chem. Phys., 68, 4093, 1978.

Michael, J. V. and Payne, W. A.: Int. J. Chem. Kinet., 11, 799, 1979.

Nicovich, J. M., Kreutter, K. D., and Wine, P. H.: Int. J. Chem. Kinet., 22, 399, 1990.

Nimomiya, Y., Hashimoto, S., Kawasaki, M., and Wallington, T. J.: Int. J. Chem. Kinet., 32, 125, 2000.

Toohey, D. W., Brune, W. H., and Anderson, J. G.: Int. J. Chem. Kinet., 20, 131, 1988. 
III.A3.64

$$
\mathrm{Br}+\mathrm{NO}_{2}+\mathrm{M} \rightarrow \mathrm{BrONO}+\mathrm{M}
$$

$\Delta H^{\circ}=-81 \mathrm{~kJ} \mathrm{~mol}^{-1}$

\section{Low-pressure rate coefficients}

\section{Rate coefficient data}

\begin{tabular}{lllc}
\hline$k_{0} / \mathrm{cm}^{3}$ molecule ${ }^{-1} \mathrm{~s}^{-1}$ & Temp./K & Reference & Technique/Comments \\
\hline Absolute Rate Coefficients & & & \\
$(3.7 \pm 0.7) \times 10^{-31}[\mathrm{He}]$ & 298 & Mellouki et al., 1989 & DF-EPR/MS (a) \\
$(2.75 \pm 0.55) \times 10^{-31}[\mathrm{He}]$ & 298 & Kreutter et al., 1991 & PLP-RF (b) \\
$4.24 \times 10^{-31}(T / 300)^{-2.4}\left[\mathrm{~N}_{2}\right]$ & $259-346$ & & \\
\hline
\end{tabular}

\section{Comments}

(a) Pressure range 0.8-2.8 mbar.

(b) Pressure range 16.7-933 mbar; measurements in the bath gases $\mathrm{He}, \mathrm{Ar}, \mathrm{H}_{2}, \mathrm{~N}_{2}, \mathrm{CO}_{2}, \mathrm{CF}_{4}$ and $\mathrm{SF}_{6}$. Falloff curves were analyzed with $F_{c}=0.59$ at $259 \mathrm{~K}, 0.55$ at $298 \mathrm{~K}$, and 0.50 at $346 \mathrm{~K}$.

\section{Preferred Values}

$k_{0}=4.2 \times 10^{-31}(T / 300)^{-2.4}\left[\mathrm{~N}_{2}\right] \mathrm{cm}^{3}$ molecule ${ }^{-1} \mathrm{~s}^{-1}$ over the temperature range $250-350 \mathrm{~K}$.

\section{Reliability}

$\Delta \log k_{0}= \pm 0.3$ at $298 \mathrm{~K}$.

$\Delta n= \pm 1$.

\section{Comments on Preferred Values}

The preferred values are based on the results of the study of Kreutter et al. (1991). The falloff curves are represented with $F_{c}=0.55$. Broske and Zabel (1998) as well as Orlando and Burkholder (2000) identified BrONO to be the major product of the reaction and reevaluated the thermochemistry data from Kreutter et al. (1991).

\section{High-pressure rate coefficients}

\section{Rate coefficient data}

\begin{tabular}{lclc}
\hline$k_{\infty} / \mathrm{cm}^{3}$ molecule ${ }^{-1} \mathrm{~s}^{-1}$ & Temp./K & Reference & Technique/Comments \\
\hline $\begin{array}{l}\text { Absolute Rate Coefficients } \\
2.66 \times 10^{-1}\end{array}$ & $259-346$ & Kreutter et al., 1991 & PLP-RF (a) \\
\hline
\end{tabular}

\section{Comments}

(a) See comment (b) for $k_{0}$.

\section{Preferred Values}

$k_{\infty}=2.7 \times 10^{-11} \mathrm{~cm}^{3}$ molecule $\mathrm{e}^{-1} \mathrm{~s}^{-1}$, independent of temperature over the range $250-350 \mathrm{~K}$. 


\section{Reliability}

$\Delta \log k_{\infty}= \pm 0.4$ over the range $250-350 \mathrm{~K}$.

$\Delta n= \pm 1$.

\section{Comments on Preferred Values}

See comments on $k_{0}$. There is only a single determination of $k_{\infty}$, but the measured falloff curve appears well behaved with rate coefficients close to those of the reactions $\mathrm{I}+\mathrm{NO}+\mathrm{M}$ and $\mathrm{I}+\mathrm{NO}_{2}+\mathrm{M}$.

\section{References}

Broske, R. and Zabel, F.: J. Phys. Chem. A, 102, 8626, 1998.

Kreutter, K. D., Nicovich, J. M., and Wine, P. H.: J. Phys. Chem., 95, 4020, 1991.

Mellouki, A., Laverdet, G., Jourdain, J. L., and Poulet, G.: Int. J. Chem. Kinet., 21, 1161, 1989.

Orlando, J. J. and Burkholder, J. B.: J. Phys. Chem. A, 104, 2048, 2000. 
III.A3.65

$$
\mathrm{Br}+\mathrm{OClO} \rightarrow \mathrm{BrO}+\mathrm{ClO}
$$

$\Delta H^{\circ}=15 \mathrm{~kJ} \mathrm{~mol}^{-1}$

\section{Rate coefficient data}

\begin{tabular}{lllc}
\hline$k / \mathrm{cm}^{3}$ molecule ${ }^{-1} \mathrm{~s}^{-1}$ & Temp./K & Reference & Technique/Comments \\
\hline Absolute Rate Coefficients & & & \\
$4.2 \times 10^{-13}$ & 298 & Clyne and Watson, 1977 & DF-MS (a) \\
$2.5 \times 10^{-11} \exp (-1336 / T)$ & $267-423$ & Toohey, 1988 & DF-RF (b) \\
$(2.82 \pm 0.03) \times 10^{-13}$ & 299 & & \\
\hline
\end{tabular}

\section{Comments}

(a) MS detection of $\mathrm{OClO}$ in an excess of $\mathrm{Br}$ atoms. The observed decays were first-order, but numerical modeling was used to correct for the effects of the reverse reaction.

(b) The measured rate coeficients $\left(\mathrm{cm}^{3}\right.$ molecule $\mathrm{e}^{-1} \mathrm{~s}^{-1}$ units) were: $267 \mathrm{~K},(1.70 \pm 0.03) \times 10^{-13} ; 294 \mathrm{~K},(2.63 \pm 0.04) \times 10^{-13}$; $299 \mathrm{~K},(2.82 \pm 0.03) \times 10^{-13}$; $325 \mathrm{~K},(4.03 \pm 0.07) \times 10^{-13}$; $351 \mathrm{~K},(5.45 \pm 0.22) \times 10^{-13} ; 385 \mathrm{~K},(7.88 \pm 0.24) \times 10^{-13}$; and $423 \mathrm{~K},(1.06 \pm 0.04) \times 10^{-12}$. A unit-weighted least-squares fit of these data to the Arrhenius expression results in $k=2.5 \times 10^{-11} \exp (-1336 / T) \mathrm{cm}^{3}$ molecule $\mathrm{s}^{-1} \mathrm{~s}^{-1}$ over the temperature range $267-423 \mathrm{~K}$.

\section{Preferred Values}

$k=3.5 \times 10^{-13} \mathrm{~cm}^{3}$ molecule $\mathrm{e}^{-1} \mathrm{~s}^{-1}$ at $298 \mathrm{~K}$.

$k=2.7 \times 10^{-11} \exp (-1300 / T) \mathrm{cm}^{3}$ molecule ${ }^{-1} \mathrm{~s}^{-1}$ over the temperature range $260-430 \mathrm{~K}$.

\section{Reliability}

$\Delta \log k= \pm 0.3$ at $298 \mathrm{~K}$.

$\Delta(E / R)= \pm 300 \mathrm{~K}$.

\section{Comments on Preferred Values}

The preferred value at $298 \mathrm{~K}$ is the mean of the values reported by Clyne and Watson (1977) and Toohey (1988). In the former study (Clyne and Watson, 1977) corrections were made for the effects of the reverse reaction, which was not done in the earlier study by Clyne and Coxon (1967) and which is therefore not used in this evaluation. The temperature dependence of $k$ obtained by Toohey (1988) is accepted, but with substantial uncertainty limits in the absence of confirmatory studies, and is combined with the preferred value of $k$ at $298 \mathrm{~K}$ to obtain the preferred Arrhenius expression.

\section{References}

Clyne, M. A. A. and Coxon, J. A.: Proc. Roy. Soc. London A, 298, 424, 1967.

Clyne, M. A. A. and Watson, R. T.: J. Chem. Soc. Faraday Trans., 1, 73, 1169, 1977.

Toohey, D. W.: Kinetic and Mechanistic Studies of Reactions of Bromine and Chlorine Species Important in the Earth's Stratosphere, Ph.D. Thesis, Harvard University, Cambridge, MA, 1988. 
III.A3.66

$$
\mathrm{Br}+\mathrm{Cl}_{2} \mathrm{O} \rightarrow \mathrm{BrCl}+\mathrm{ClO}
$$

$\Delta H^{\circ}=-72.8 \mathrm{~kJ} \mathrm{~mol}^{-1}$

\section{Rate coefficient data}

\begin{tabular}{lllc}
\hline$k / \mathrm{cm}^{3}$ molecule ${ }^{-1} \mathrm{~s}^{-1}$ & Temp./K & Reference & Technique/Comments \\
\hline Absolute Rate Coefficients & & & \\
$2.1 \times 10^{-11} \exp [-(520 \pm 260) / T]$ & $220-298$ & Sander and Friedl, 1989 & FP-AS (a) \\
$(3.79 \pm 0.38) \times 10^{-12}$ & 298 & & DF-RF \\
$2.1 \times 10^{-11} \exp [-(435 \pm 30) / T]$ & $233-402$ & Stevens and Anderson, 1992 & \\
$(4.8 \pm 0.2) \times 10^{-12}$ & 298 & & \\
\hline
\end{tabular}

\section{Comments}

(a) Flash photolysis $(\lambda>300 \mathrm{~nm})$ of $\mathrm{Br}_{2}$ in the presence of an excess of $\mathrm{Cl}_{2} \mathrm{O}$ at 130 mbar pressure of Ar. ClO radical concentrations were monitored by long-path UV absorption at $275.2 \mathrm{~nm}$.

\section{Preferred Values}

$k=4.3 \times 10^{-12} \mathrm{~cm}^{3}$ molecule $\mathrm{e}^{-1} \mathrm{~s}^{-1}$ at $298 \mathrm{~K}$.

$k=2.1 \times 10^{-11} \exp (-470 / T) \mathrm{cm}^{3}$ molecule ${ }^{-1} \mathrm{~s}^{-1}$ over the temperature range $220-410 \mathrm{~K}$.

\section{Reliability}

$\Delta \log k= \pm 0.1$ at $298 \mathrm{~K}$.

$\Delta(E / R)= \pm 200 \mathrm{~K}$.

\section{Comments on Preferred Values}

The studies of Sander and Friedl (1989) and Stevens and Anderson (1992), which used totally different techniques, are in excellent agreement. The preferred values are based on the results of these two studies (Sander and Friedl, 1989; Stevens and Anderson, 1992). The significantly lower value (by a factor of 4) reported earlier by Basco and Dogra (1971) is not used in the evaluation. In the same study, Basco and Dogra (1971) reported a value for $k\left(\mathrm{Cl}+\mathrm{Cl}_{2} \mathrm{O}\right)$ more than two orders of magnitude less than that recommended in the present evaluation, suggesting errors in their method of determining the $\mathrm{ClO}$ radical concentration which was used to monitor the progress of the reaction.

\section{References}

Basco, N. and Dogra, S. K.: Proc. Roy. Soc. London, A323, 401, 1971.

Sander, S. P. and Friedl, R. R.: J. Phys. Chem., 93, 4764, 1989.

Stevens, P. S. and Anderson, J. G.: J. Phys. Chem., 96, 1708, 1992. 
III.A3.67

$$
\mathrm{Br}+\mathrm{Cl}_{2} \mathrm{O}_{2} \rightarrow \mathrm{BrCl}+\mathrm{ClOO}
$$

$\Delta H^{\circ}=-127.4 \mathrm{~kJ} \mathrm{~mol}^{-1}$

\section{Rate coefficient data}

\begin{tabular}{lllc}
\hline$k / \mathrm{cm}^{3}$ molecule ${ }^{-1} \mathrm{~s}^{-1}$ & Temp./K & Reference & Technique/Comments \\
\hline Absolute Rate Coefficients & & & \\
$5.88 \times 10^{-12} \exp [-(173 \pm 20) / T]$ & $223-298$ & Ingham et al., 2005 & DF-MS (a) \\
$(3.3 \pm 0.4) \times 10^{-12}$ & 298 & & \\
\hline
\end{tabular}

\section{Comments}

(a) $k$ was determined from pseudo-first order decay of $\mathrm{Cl}_{2} \mathrm{O}_{2}$ in the presence of an excess of $\mathrm{Br}$ atoms. [Br] was determined after titration to $\mathrm{BrCl}$, following reaction with $\mathrm{Cl}_{2} \mathrm{O}$ or $\mathrm{NOCl}$.

\section{Preferred Values}

$k=3.3 \times 10^{-12} \mathrm{~cm}^{3}$ molecule $\mathrm{s}^{-1} \mathrm{~s}^{-1}$ at $298 \mathrm{~K}$.

$k=5.9 \times 10^{-12} \exp (-170 / T) \mathrm{cm}^{3}$ molecule ${ }^{-1} \mathrm{~s}^{-1}$ over the range $220-300 \mathrm{~K}$.

\section{Reliability}

$\Delta \log k= \pm 0.3$ at $298 \mathrm{~K}$.

$\Delta(E / R)= \pm 200 \mathrm{~K}$.

\section{Comments on Preferred Values}

The preferred values are based on the study of Ingham et al. (2005), which is the only published determination of the reaction. Ingham et al. (2005) observed $\mathrm{BrCl}$ as a reaction product, providing evidence for the likely product channel $(\mathrm{BrCl}+$ $\mathrm{ClOO}$ ), and were able to rule out the alternative formation of $\mathrm{ClOBr}$ and $\mathrm{ClO}$ from a failure to detect $\mathrm{ClOBr}$, but the value is reasonable.

\section{References}

Ingham, T., Sander, S. P. and Friedl, R. R.: Faraday Discuss., 130, 89, 2005. 


\section{III.A3.68}

$$
\mathrm{HO}+\mathrm{HBr} \rightarrow \mathrm{H}_{2} \mathrm{O}+\mathrm{Br}
$$

$\Delta H^{\circ}=-130.9 \mathrm{~kJ} \mathrm{~mol}^{-1}$

\section{Rate coefficient data}

\begin{tabular}{lllc}
\hline$k / \mathrm{cm}^{3}$ molecule ${ }^{-1} \mathrm{~s}^{-1}$ & Temp./K & Reference & Technique/Comments \\
\hline Absolute Rate Coefficients & & & \\
$(5.1 \pm 1.0) \times 10^{-12}$ & 295 & Takacs and Glass, 1973 & DF-EPR (a) \\
$(1.19 \pm 0.14) \times 10^{-11}$ & $249-416$ & Ravishankara et al., 1979 & PLP-RF \\
$(6.01 \pm 0.32) \times 10^{-12}$ & 300 & Husain et al., 1981 & FP-RF \\
$(9.2 \pm 0.7) \times 10^{-12}$ & $\sim 298$ & Jourdain et al., 1981 & DF-EPR \\
$(1.12 \pm 0.045) \times 10^{-11}$ & $298 \pm 4$ & Cannon et al., 1984 & FP-LIF \\
$(1.1 \pm 0.1) \times 10^{-11}$ & 298 & Ravishankara et al., 1985 & PLP-RF/LIF \\
$(2.97 \pm 0.46) \times 10^{-11}$ & 170 & Sims et al., 1994 & PLP-LIF (b,c) \\
$(1.16 \pm 0.04) \times 10^{-11}$ & 295 & & \\
$(8 \pm 1) \times 10^{-12}$ & 173 & Atkinson et al., 1997 & FP-LIF (b,d) \\
$(1.5 \pm 0.4) \times 10^{-11}$ & 194 & & \\
$(1.0 \pm 0.3) \times 10^{-11}$ & 194 & & \\
$(1.3 \pm 0.2) \times 10^{-11}$ & 222 & & \\
$(1.1 \pm 0.1) \times 10^{-11}$ & 242 & & DF-MS (e) \\
$5.5 \times 10^{-12}$ exp[(204 \pm 45$\left.) / T\right]$ & $230-360$ & Bedjanian et al., 1999 & \\
$(1.11 \pm 0.12) \times 10^{-11}$ & 298 & & FP-LIF (b,f,g) \\
$(9.36 \pm 2.74) \times 10^{-12}$ & 185 & Jaramillo amd Smith, 2001; & \\
$(1.01 \pm 0.15) \times 10^{-11}$ & 224 & Jaramillo et al., 2002 & \\
\hline
\end{tabular}

\section{Comments}

(a) Rate coefficient obtained from a numerical simulation of 4 reactions.

(b) Expansion of gas through a Laval nozzle to provide a collimated flow of cold gas at a uniform temperature, density and velocity.

(c) Experiments were carried out over the temperature range 23-295 K, with the measured rate coefficient decreasing with increasing temperature from $(1.07 \pm 0.04) \times 10^{-10} \mathrm{~cm}^{3}$ molecule $\mathrm{s}^{-1}$ at $23 \mathrm{~K}$ to $(1.16 \pm 0.04) \times 10^{-11} \mathrm{~cm}^{3} \mathrm{molecule}^{-1} \mathrm{~s}^{-1}$ at $295 \mathrm{~K}$. Combined with the rate coefficients of Ravishankara et al. (1979) the temperature-dependent expression $k=(1.26 \pm 0.24) \times 10^{-11}(T / 298)^{-(0.86 \pm 0.10)} \mathrm{cm}^{3}$ molecule $\mathrm{s}^{-1}$ was derived.

(d) Rate coefficients were measured over the temperature range $76-242 \mathrm{~K}$, with the rate coefficient decreasing from $(3.0 \pm 0.5) \times 10^{-11} \mathrm{~cm}^{3}$ molecule $\mathrm{s}^{-1} \mathrm{~s}^{-1}$ at $92 \mathrm{~K}$ and $(2.9 \pm 0.9) \times 10^{-11} \mathrm{~cm}^{3}$ molecule $\mathrm{s}^{-1} \mathrm{~s}^{-1}$ at $76 \mathrm{~K}$ to $(1.1 \pm 0.1) \times 10^{-11} \mathrm{~cm}^{3}$ molecule $\mathrm{e}^{-1} \mathrm{~s}^{-1}$ at $242 \mathrm{~K}$. Above $150 \mathrm{~K}$ the rate coefficient was independent of temperature, within the experimental uncertainties.

(e) The cited Arrhenius expression is obtained from a un-weighted least-squares analysis of the measured rate coefficients. The cited uncertainty is one least-squares standard deviation.

(f) Rate coefficients were obtained over the temperature range $120-224 \mathrm{~K}$ for $\mathrm{HO}+\mathrm{HBr}, \mathrm{DO}+\mathrm{HBr}, \mathrm{HO}+\mathrm{DBr}$ and $\mathrm{DO}+\mathrm{DBr}$ (Jaramillo and Smith, 2001), and over the temperature range 48-224 K for $\mathrm{HO}+\mathrm{HBr}$ (Jaramillo et al., 2002).

(g) The rate coefficients reported by Jaramillo and Smith (2001) have been re-evaluated by Mullen and Smith (2005), and the revised values are cited in the table. Mullen and Smith (2005) measured rate coefficients for $\mathrm{HO}+\mathrm{HBr}$ (and $\mathrm{HO}+$ $\mathrm{DBr}, \mathrm{DO}+\mathrm{HBr}$ and $\mathrm{DO}+\mathrm{DBr}$ ) at 53,83 and $135 \mathrm{~K}$ using a pulsed Laval nozzle with LIF detection of HO and DO radicals. A fit of the data of Ravishankara et al. (1979), Sims et al. (1994), Atkinson et al. (1997), Bedjanian et al. 
(1999), Jaramillo and Smith (2001) [using the rate coefficients as re-evaluated by Mullen and Smith (2005)], Jaramillo et al. (2002) [rate coefficients at 48 and $97 \mathrm{~K}$ ] and Mullen and Smith (2005) for $\mathrm{HO}+\mathrm{HBr}$ resulted in $k=1.06 \times 10^{-11}$ $(T / 298)^{-(0.90 \pm 0.11)} \mathrm{cm}^{3}$ molecule ${ }^{-1} \mathrm{~s}^{-1}$ over the temperature range 23-360 K.

\section{Preferred Values}

$k=6.7 \times 10^{-12} \exp (155 / T) \mathrm{cm}^{3}$ molecule $\mathrm{e}^{-1} \mathrm{~s}^{-1}$ over the temperature range $180-370 \mathrm{~K}$.

$k=1.1 \times 10^{-11} \mathrm{~cm}^{3}$ molecule ${ }^{-1} \mathrm{~s}^{-1}$ at $298 \mathrm{~K}$.

\section{Reliability}

$\Delta \log k= \pm 0.10$ at $298 \mathrm{~K}$. $\Delta(E / R)= \pm 200 \mathrm{~K}$.

\section{Comments on Preferred Values}

The studies of Sims et al. (1994), Atkinson et al. (1997), Jaramillo and Smith (2001), Jaramillo et al. (2002) and Mullen and Smith (2005), carried out using expansions through a Laval nozzle to achieve temperatures down to $23 \mathrm{~K}$, show reaction rate coefficients which increase with decreasing temperature, as does the 230-360 K study of Bedjanian et al. (1999). There is, however, a significant amount of scatter in the low temperature $(<250 \mathrm{~K})$ rate coefficients obtained by Sims et al. (1994), Atkinson et al. (1997), Jaramillo and Smith (2001) [as revised by Mullen and Smith, 2005], Jaramillo et al. (2002) and Mullen and Smith (2005). The preferred values are obtained from aleast-squares analysis of the 230-369 K rate coefficients of Ravishankara et al. (1979), Ravishankara et al. (1985) and Bedjanian et al. (1999). The preferred values are in good agreement with the room temperature rate coefficients of Jourdain et al. (1981) and Cannon et al. (1984), and are consistent with the $<250 \mathrm{~K}$ rate data of Sims et al. (1994), Atkinson et al. (1997), Jaramillo and Smith (2001), Jaramillo et al. (2002) and Mullen and Smith (2005). Accordingly, the preferred rate expression is judged to be applicable down to $\sim 180 \mathrm{~K}$.

\section{References}

Atkinson, D. B., Jaramillo, V. I., and Smith, M. A.: J. Phys. Chem. A, 101, 3356, 1997.

Bedjanian, Y., Riffault, V., Le Bras, G., and Poulet, G.: J. Photochem. Photobiol. A. Chem., 128, 15, 1999.

Cannon, B. D., Robertshaw, J. S., Smith, I. W. M., and Williams, M. D.: Chem. Phys. Lett., 105, 380, 1984.

Husain, D., Plane, J. M. C., and Slater, N. K. H.: J. Chem. Soc. Faraday Trans., 2 77, 1949, 1981.

Jaramillo, V. I. and Smith, M. A.: J. Phys. Chem. A, 105, 5854, 2001.

Jaramillo, V. I., Gougeon, S., Le Picard, S. D., Canosa, A., Smith, M. A., and Rowe, B. R.: Int. J. Chem. Kinet., 34, 339, 2002.

Jourdain, J. L., Le Bras, G., and Combourieu, J.: Chem. Phys. Lett., 78, 483, 1981.

Mullen, C. and Smith, M. A.: J. Phys. Chem. A 109, 3893, 2005.

Ravishankara, A. R., Wine, P. H., and Langford, A. O.: Chem. Phys. Lett., 63, 479, 1979.

Ravishankara, A. R., Wine, P. H., and Wells, J. R.: J. Chem. Phys., 83, 447, 1985.

Sims, I. R., Smith, I. W. M., Clary, D. C., Bocherel, P., and Rowe, B. R.: J. Chem. Phys., 101, 1748, 1994.

Takacs, G. A. and Glass, G. P.: J. Phys. Chem., 77, 1060, 1973. 


\section{III.A3.69}

$$
\mathrm{HO}+\mathrm{Br}_{2} \rightarrow \mathrm{HOBr}+\mathrm{Br}
$$

$\Delta H^{\circ} \geq-12 \mathrm{~kJ} \mathrm{~mol}^{-1}$

\section{Rate coefficient data}

\begin{tabular}{lllc}
\hline$k / \mathrm{cm}^{3}$ molecule ${ }^{-1} \mathrm{~s}^{-1}$ & Temp./K & Reference & Technique/Comments \\
\hline $\begin{array}{l}\text { Absolute Rate Coefficients } \\
(4.2 \pm 0.7) \times 10^{-11}\end{array}$ & $298 \pm 2$ & Poulet et al., 1983 & \\
$(5.28 \pm 0.63) \times 10^{-11}$ & $298 \pm 3$ & Loewenstein and Anderson, 1984 & DF-LIF/EPR \\
$(2.8 \pm 1.2) \times 10^{-11}$ & $262-303$ & Boodaghians et al., 1987 & DF-RF \\
$(3.4 \pm 1.2) \times 10^{-11}$ & 293 & & \\
$1.98 \times 10^{-11} \exp [(238 \pm 70) / T]$ & $235-357$ & Gilles et al., 1999 \\
$(4.80 \pm 0.70) \times 10^{-11}$ & 298 & & PLP-LIF \\
$1.8 \times 10^{-11} \exp [(235 \pm 50) / T]$ & $230-360$ & Bedjanian et al., 1999 & \\
$3.96 \times 10^{-11}$ & 298 & & DF-MS \\
& & & \\
\hline
\end{tabular}

\section{Comments}

(a) A least-squares fit of the measured rate coefficients results in $k=5.8 \times 10^{-10} \exp [-(866 \pm 1107) / T] \mathrm{cm}^{3}$ molecule ${ }^{-1} \mathrm{~s}^{-1}$, consistent with a temperature-independent rate coefficient over the small temperature range studied.

\section{Preferred Values}

$k=4.5 \times 10^{-11} \mathrm{~cm}^{3}$ molecule ${ }^{-1} \mathrm{~s}^{-1}$ at $298 \mathrm{~K}$.

$k=2.0 \times 10^{-11} \exp (240 / T) \mathrm{cm}^{3}$ molecule ${ }^{-1} \mathrm{~s}^{-1}$ over the temperature range $230-360 \mathrm{~K}$.

\section{Reliability}

$\Delta \log k= \pm 0.10$ at $298 \mathrm{~K}$.

$\Delta(E / R)= \pm 150 \mathrm{~K}$.

\section{Comments on Preferred Values}

The rate coefficient is reasonably well determined at room temperature, and the recommended value is the mean of those reported by Poulet et al. (1983), Loewenstein and Anderson (1984), Gilles et al. (1999) and Bedjanian et al. (1999). The rate coefficients of Boodaghians et al. (1987) have large uncertainties and are consistent with a zero temperature dependence over the range 262-303 K. Gilles et al. (1999) and Bedjanian et al. (1999) measured a small negative temperature dependence over the significantly wider temperature range of 230-360 K. Accordingly, the temperature dependence of Gilles et al. (1999) and Bedjanian et al. (1999) is preferred, and the pre-exponential factor, $A$, is adjusted to fit the preferred $298 \mathrm{~K}$ rate coefficient. Poulet et al. (1983), Loewenstein and Anderson (1984) and Bedjanian et al. (1999) determined that the products are $\mathrm{Br}+\mathrm{HOBr}$, with the alternative reaction pathway leading to $\mathrm{HBr}+\mathrm{BrO}$ accounting for $<1 \%$ of the overall reaction at $298 \mathrm{~K}$ (Loewenstein and Anderson, 1984).

\section{References}

Bedjanian, Y., Le Bras, G., and Poulet, G.: Int. J. Chem. Kinet., 31, 698, 1999.

Boodaghians, R. B., Hall, I. W., and Wayne, R. P.: J. Chem. Soc. Faraday Trans., 2, 83, 529, 1987.

Gilles, M. K., Burkholder, J. B., and Ravishankara, A. R.: Int. J. Chem. Kinet., 31, 417, 1999.

Loewenstein, L. M. and Anderson, J. G.: J. Phys. Chem., 88, 6277, 1984.

Poulet, G., Laverdet, G., and Le Bras, G.: Chem. Phys. Lett., 94, 129, 1983. 
III.A3.70

$$
\begin{aligned}
\mathrm{HO}+\mathrm{BrO} & \rightarrow \mathrm{HO}_{2}+\mathrm{Br} \\
& \rightarrow \mathrm{HBr}+\mathrm{O}_{2}
\end{aligned}
$$

$\Delta H^{\circ}(1)=-30 \mathrm{~kJ} \mathrm{~mol}^{-1}$

$\Delta H^{\circ}(2)=-193 \mathrm{~kJ} \mathrm{~mol}^{-1}$

Rate coefficient data $\left(k=k_{1}+k_{2}\right)$

\begin{tabular}{lllc}
\hline$k / \mathrm{cm}^{3}$ molecule $\mathrm{s}^{-1}$ & Temp./K & Reference & Technique/Comments \\
\hline Absolute Rate Coefficients & & & \\
$(7.5 \pm 4.2) \times 10^{-11}$ & 300 & Bogan et al., 1996 & DF-MS (a) \\
$(4.5 \pm 1.8) \times 10^{-11}$ & $298 \pm 3$ & Gilles et al., 2001 & DF (b) \\
$1.65 \times 10^{-11} \exp [(250 \pm 50) / T]$ & $230-355$ & Bedjanian et al., 2001 & DF-MS (c) \\
$(3.6 \pm 0.9) \times 10^{-11}$ & 300 & & $(\mathrm{~d})$ \\
$(3.9 \pm 1.0) \times 10^{-11}$ & 298 & & $(\mathrm{e})$ \\
$(3.85 \pm 0.70) \times 10^{-11}$ & 299 & & $(\mathrm{f})$ \\
Branching ratios & & & \\
$k_{2} / k \leq 0.03$ & 298 & Bedjanian et al., 2001 & DF-MS (g) \\
\hline
\end{tabular}

\section{Comments}

(a) $\mathrm{BrO}$ radicals generated by passing a $\mathrm{O}_{2}-\mathrm{Br}_{2}-\mathrm{He}$ mixture through a microwave discharge. $\mathrm{HO}$ radicals generated by the reaction of $\mathrm{F}$ atoms (generated in a second microwave discharge) with $\mathrm{H}_{2} \mathrm{O}$. BrO radical concentrations were obtained by titration with $\mathrm{NO}$ and measurement of the resulting $\mathrm{NO}_{2}$ by MS. HO radical concentrations were obtained by titration with $\mathrm{Br}_{2}$ and measurement of the depletion of $\mathrm{Br}_{2}$ by MS. The rate coefficient was derived from modelling using a chemical mechanism involving 18 reactions.

(b) $\mathrm{BrO}$ radicals generated from $\mathrm{Br}+\mathrm{O}_{3}$ reaction (following discharge of $\mathrm{Br}_{2}$ ). HO radicals generated from pulsed $248 \mathrm{~nm}$ laser photolysis of $\mathrm{O}_{3}$ in the presence of $\mathrm{H}_{2} \mathrm{O}$. $\mathrm{BrO}$ and $\mathrm{HO}$ were measured by $\mathrm{UV}$ absorption and LIF, respectively. Experiments carried out under pseudo-first order conditions with $\mathrm{HO}$ in excess.

(c) $\mathrm{BrO}$ generated from either $\mathrm{O}\left({ }^{3} \mathrm{P}\right)+\mathrm{Br}_{2}$ (following discharge of $\mathrm{O}_{2}$ ), or from $\mathrm{Br}+\mathrm{O}_{3}$ (following discharge of $\mathrm{Br}_{2}$ ). $\mathrm{Br}$ was also generated by $\mathrm{F}+\mathrm{HBr}$ (following discharge of $\mathrm{F}_{2}$ ) for mechanistic studies. $\mathrm{HO}$ was generated from either $\mathrm{H}+\mathrm{NO}_{2}$ (following discharge of $\mathrm{H}_{2}$ or $\mathrm{F}+\mathrm{H}_{2}$ ), or $\mathrm{F}+\mathrm{H}_{2} \mathrm{O}$ (following discharge of $\mathrm{F}_{2}$ ). $\mathrm{BrO}$ and $\mathrm{HO}$ concentrations were measured directly at their parent peaks. Experiments carried out under pseudo-first order conditions with $\mathrm{HO}$ in excess. $k$ also determined relative to $k\left(\mathrm{HO}+\mathrm{Br}_{2}\right)$ in a separate series of experiments. Results of the two methods are in good agreement and the reported rate coefficient is based on the combined dataset.

(d) $\mathrm{HO}$ generated by $\mathrm{H}+\mathrm{NO}_{2}$.

(e) $\mathrm{HO}$ generated by $\mathrm{F}+\mathrm{H}_{2} \mathrm{O}$.

(f) Relative rate measurement.

(g) Based on detection of $\mathrm{HBr}$.

\section{Preferred Values}

$k=4.1 \times 10^{-11} \mathrm{~cm}^{3}$ molecule $\mathrm{e}^{-1} \mathrm{~s}^{-1}$ at $298 \mathrm{~K}$.

$k=1.8 \times 10^{-11} \exp (250 / T) \mathrm{cm}^{3}$ molecule $\mathrm{e}^{-1} \mathrm{~s}^{-1}$ over the temperature range $230-350 \mathrm{~K}$. 


\section{Reliability}

$\Delta \log k= \pm 0.3$ at $298 \mathrm{~K}$.

$\Delta(E / R)= \pm 300 \mathrm{~K}$.

\section{Comments on Preferred Values}

The preferred value at $298 \mathrm{~K}$ is based on the room temperature data of Gilles et al. (2001) and Bedjanian et al. (2001). The previous study of Bogan et al. (1996) is also consistent with this recommendation. The preferred Arrhenius expression is based on the $E / R$ value from the temperature dependence study of Bedjanian et al. (2001) combined with a pre-exponential factor adjusted to give the preferred value of $k$ at $298 \mathrm{~K}$. The results of Bedjanian et al. (2001) are consistent with channel (a) being the dominant, if not sole, pathway. This conclusion is supported by the theoretical study of Sumathi and Peyerimhoff (1999).

\section{References}

Bedjanian, Y., Riffault, V., Le Bras, G., and Poulet, G.: J. Phys. Chem. A, 105, 6154, 2001.

Bogan, D. J., Thorn, R. P., Nesbitt, F. L., and Stief, L. J.: J. Phys. Chem., 100, 14 383, 1996.

Gilles, M. K., McCabe, D. C., Burkholder, J. B., and Ravishankara, A. R.: J. Phys. Chem. A, 105, 5849, 2001.

Sumathi, R. and Peyerimhoff, S. D.: Phys. Chem. Chem. Phys., 1, 3973, 1999. 


\section{III.A3.71}

$$
\mathrm{Br}+\mathrm{NO}_{3} \rightarrow \mathrm{BrO}+\mathrm{NO}_{2}
$$

$\Delta H^{\circ}=-33 \mathrm{~kJ} \mathrm{~mol}^{-1}$

\section{Rate coefficient data}

\begin{tabular}{lllc}
\hline $\mathrm{k} / \mathrm{cm}^{3}$ molecule & & Technique/Comments \\
\hline $\begin{array}{l}\text { Absolute Rate Coefficients } \\
(1.6 \pm 0.7) \times 10^{-11}\end{array}$ & 298 & Mellouki et al., 1989 & DF-EPR (a) \\
\hline
\end{tabular}

\section{Comments}

(a) The decays of $\mathrm{Br}$ atoms in excess concentrations of the $\mathrm{NO}_{3}$ radical were monitored by EPR. Numerical simulations of the decays were carried out with a mechanism consisting of five reactions.

\section{Preferred Values}

$k=1.6 \times 10^{-11} \mathrm{~cm}^{3}$ molecule $\mathrm{e}^{-1} \mathrm{~s}^{-1}$ at $298 \mathrm{~K}$.

\section{Reliability}

$\Delta \log k= \pm 0.3$ at $298 \mathrm{~K}$.

\section{Comments on Preferred Values}

The preferred value is based on the sole study of Mellouki et al. (1989).

\section{References}

Mellouki, A., Poulet, G., Le Bras, G., Singer, R., Burrows, J. P., and Moortgat, G. K.: J. Phys. Chem., 93, 8017, 1989. 
III.A3.72

$$
\begin{aligned}
\mathrm{BrO}+\mathrm{NO}_{3} & \rightarrow \mathrm{BrOO}+\mathrm{NO}_{2} \\
& \rightarrow \mathrm{OBrO}+\mathrm{NO}_{2}
\end{aligned}
$$

$\Delta H^{\circ}(1)=-52 \mathrm{~kJ} \mathrm{~mol}^{-1}$

$\Delta H^{\circ}(2)=3.5 \mathrm{~kJ} \mathrm{~mol}^{-1}$

\begin{tabular}{|c|c|c|c|}
\hline$k / \mathrm{cm}^{3}$ molecule ${ }^{-1} \mathrm{~s}^{-1}$ & Temp./K & Reference & Technique/Comments \\
\hline $\begin{array}{l}\text { Absolute Rate Coefficients } \\
(0.3-3.0) \times 10^{-12}\end{array}$ & 298 & Mellouki et al., 1989 & DF-EPR (a) \\
\hline
\end{tabular}

Rate coefficient data

\section{Comments}

(a) The decays of $\mathrm{Br}$ atoms and $\mathrm{BrO}$ radicals were monitored by EPR. Numerical simulations of the results were carried out with a mechanism consisting of five reactions.

\section{Preferred Values}

$k=1.0 \times 10^{-12} \mathrm{~cm}^{3}$ molecule ${ }^{-1} \mathrm{~s}^{-1}$ at $298 \mathrm{~K}$.

\section{Reliability}

$\Delta \log k= \pm 0.5$ at $298 \mathrm{~K}$.

\section{Comments on Preferred Values}

The preferred value is based on the room temperature results of Mellouki et al. (1989). This study (Mellouki et al., 1989), using the discharge flow-EPR technique, is the only experimental study of this reaction to date. The preferred value is the geometric mean of the upper and lower limits (Mellouki et al.,1989), which are encompassed within the stated uncertainty factor. The $\mathrm{Br}-\mathrm{O}_{2}$ bond is very weak and the bond energy has been estimated by Blake et al. (1970) to be $4 \mathrm{~kJ} \mathrm{~mol}^{-1}$. The product $\mathrm{BrOO}$ will therefore quickly decompose to yield $\mathrm{Br}+\mathrm{O}_{2}$. There is no evidence for the second channel producing $\mathrm{OBrO}$, which is slightly endothermic.

\section{References}

Blake, J. A., Browne, R. J., and Burns, G.: J. Chem. Phys., 53, 3320, 1970.

Mellouki, A., Poulet, G., Le Bras, G., Singer, R., Burrows, J. P., and Moortgat, G. K.: J. Phys. Chem., 93, 8017, 1989. 
III.A3.73

$$
\mathrm{NO}_{3}+\mathrm{HBr} \rightarrow \mathrm{HNO}_{3}+\mathrm{Br}
$$

$\Delta H^{\circ}=-60.6 \mathrm{~kJ} \mathrm{~mol}^{-1}$

\section{Rate coefficient data}

\begin{tabular}{lllc}
\hline$k / \mathrm{cm}^{3}$ molecule ${ }^{-1} \mathrm{~s}^{-1}$ & Temp./K & Reference & Technique/Comments \\
\hline $\begin{array}{l}\text { Absolute Rate Coefficients } \\
\leq 1 \times 10^{-16}\end{array}$ & 298 & Mellouki et al., 1989 & DF-EPR (a) \\
$(1.3 \pm 1.1) \times 10^{-16}$ & 298 & Canosa-Mas et al., 1989 & DF-A (b) \\
\hline
\end{tabular}

\section{Comments}

(a) The rate coefficient was derived from fitting the measured data to a complex mechanism.

(b) Discharge flow system with multipath absorption of $\mathrm{NO}_{3}$. The rate coefficient was derived from fitting the measured data to a complex mechanism.

\section{Preferred Values}

$k<1 \times 10^{-16} \mathrm{~cm}^{3}$ molecule ${ }^{-1} \mathrm{~s}^{-1}$ at $298 \mathrm{~K}$.

\section{Comments on Preferred Values}

The preferred value is the upper limit reported by Mellouki et al. (1989) in a study using the discharge flow-EPR technique. Canosa-Mas et al. (1989) reported a rate coefficient derived from fitting their data to a complex mechanism which, within the stated uncertainty limits, is consistent with the upper limit to the rate coefficient reported by Mellouki et al. (1989).

\section{References}

Canosa-Mas, C. E., Smith, S. J., Toby, S., and Wayne, R. P.: J. Chem. Soc. Faraday Trans., 2, 85, 709, 1989.

Mellouki, A., Poulet, G., Le Bras, G., Singer, R., Burrows, J. P., and Moortgat, G. K.: J. Phys. Chem., 93, 8017, 1989. 
III.A3.74

$$
\begin{aligned}
\mathrm{BrO}+\mathrm{HO}_{2} & \rightarrow \mathrm{HOBr}+\mathrm{O}_{2} \\
& \rightarrow \mathrm{HBr}+\mathrm{O}_{3}
\end{aligned}
$$

$\Delta H^{\circ}(1) \geq-190 \mathrm{~kJ} \mathrm{~mol}^{-1}$

$\Delta H^{\circ}(2)=-28 \mathrm{~kJ} \mathrm{~mol}^{-1}$

Rate coefficient data $\left(k=k_{1}+k_{2}\right)$

\begin{tabular}{lllc}
\hline $\mathrm{k} / \mathrm{cm}^{3}$ molecule $\mathrm{s}^{-1} \mathrm{~s}^{-1}$ & Temp./K & Reference & Technique/Comments \\
\hline $\begin{array}{l}\text { Absolute Rate Coefficients } \\
(3.4 \pm 1.0) \times 10^{-11}\end{array}$ & 300 & Bridier et al., 1993 & FP-UVA (a) \\
$4.77 \times 10^{-12} \exp [(580 \pm 100) / T]$ & $233-344$ & Larichev et al., 1995 & DF-MS (b) \\
$(3.4 \pm 0.6) \times 10^{-11}$ & 303 & & \\
$2.5 \times 10^{-12} \exp [(520 \pm 80) / T]$ & $210-298$ & Elrod et al., 1996 & DF-MS (c) \\
$(1.4 \pm 0.3) \times 10^{-11}$ & 298 & & \\
$3.13 \times 10^{-12} \exp [(536 \pm 206) / T]$ & $233-348$ & Li et al., 1997 & DF-MS (d) \\
$(1.73 \pm 0.61) \times 10^{-11}$ & 298 & & $(\mathrm{e})$ \\
$(2.05 \pm 0.64) \times 10^{-11}$ & 298 & & $(\mathrm{f})$ \\
$(2.0 \pm 0.6) \times 10^{-11}$ & 298 & Cronkhite et al., 1998 & PLP-IR/UVA (g) \\
$9.4 \times 10^{-12} \exp [(345 \pm 60) / T]$ & $230-360$ & Bedjanian et al., 2001 & DF-MS (h) \\
$(3.1 \pm 0.8) \times 10^{-11}$ & 298 & & \\
$(2.35 \pm 0.82) \times 10^{-11}$ & 298 & Bloss et al., 2002 & FP-UVA (a) \\
\hline
\end{tabular}

\section{Comments}

(a) Photolysis of $\mathrm{Br}_{2}-\mathrm{O}_{3}-\mathrm{Cl}_{2}-\mathrm{CH}_{3} \mathrm{OH}-\mathrm{O}_{2}-\mathrm{He}$ mixtures. $\mathrm{HO}_{2}$ and $\mathrm{BrO}$ radical concentrations were monitored by UV absorption spectroscopy under conditions where the $\mathrm{HO}_{2}$ radical and $\mathrm{BrO}$ radical concentrations were of a similar magnitude.

(b) $\mathrm{BrO}$ radicals were generated by the $\mathrm{O}\left({ }^{3} \mathrm{P}\right)+\mathrm{Br}_{2}$ reaction, and their concentrations were monitored by $\mathrm{MS}$ in an excess of $\mathrm{HO}_{2}$ radicals. A preliminary report of this study was noted in Poulet et al. (1992).

(c) Turbulent flow system at $130 \mathrm{mbar}$ total pressure. Reactant and product species were monitored by CIMS. BrO radicals were produced by the $\mathrm{O}\left({ }^{3} \mathrm{P}\right)+\mathrm{Br}_{2}$ reaction and $\mathrm{HO}_{2}$ radicals by the $\mathrm{H}+\mathrm{O}_{2}+\mathrm{M}$ reaction. $k$ was determined by monitoring the $\mathrm{BrO}$ radical concentrations in an excess of $\mathrm{HO}_{2}$.

(d) $\mathrm{BrO}$ and $\mathrm{HO}_{2}$ were monitored by MS. BrO radicals were produced by the $\mathrm{Br}+\mathrm{O}_{3}$ or $\mathrm{O}\left({ }^{3} \mathrm{P}\right)+\mathrm{Br}_{2}$ reactions and $\mathrm{HO}_{2}$ radicals by the $\mathrm{F}+\mathrm{H}_{2} \mathrm{O}_{2}$ or $\mathrm{Cl}+\mathrm{CH}_{3} \mathrm{OH}$ reactions. Experiments were carried out under conditions of both $[\mathrm{BrO}] \gg\left[\mathrm{HO}_{2}\right]$ and $\left[\mathrm{HO}_{2}\right] \gg[\mathrm{BrO}]$. A similar temperature dependence of $k$ was observed in each case, but values of $k$ determined with excess $\mathrm{BrO}$ were systematically $\sim 20 \%$ to $25 \%$ higher than those in excess $\mathrm{HO}_{2}$.

(e) $\mathrm{HO}_{2}$ in excess.

(f) $\mathrm{BrO}$ in excess.

(g) Photolysis of $\mathrm{Cl}_{2}-\mathrm{CH}_{3} \mathrm{OH}-\mathrm{O}_{2}-\mathrm{Br}_{2}-\mathrm{O}_{3}-\mathrm{N}_{2}$ mixtures. $\mathrm{HO}_{2}$ and $\mathrm{BrO}$ radical concentrations were monitored simultaneously by infrared tunable diode laser absorption spectroscopy and UV absorption spectroscopy, respectively. Rate coefficients $k$ were determined with $\left[\mathrm{HO}_{2}\right] \gg[\mathrm{BrO}]$.

(h) $\mathrm{BrO}$ radicals were produced by the $\mathrm{Br}+\mathrm{O}_{3}$ or $\mathrm{O}\left({ }^{3} \mathrm{P}\right)+\mathrm{Br}_{2}$ reactions and $\mathrm{HO}_{2}$ radicals by the $\mathrm{F}+\mathrm{H}_{2} \mathrm{O}_{2}$ reaction. Experiments were carried out under conditions of both $[\mathrm{BrO}] \gg\left[\mathrm{HO}_{2}\right]$ and $\left[\mathrm{HO}_{2}\right] \gg[\mathrm{BrO}]$. No systematic difference in the determined values of $k$ was observed. Consistent values of $k$, measured relative to $k\left(\mathrm{Br}+\mathrm{HO}_{2}\right)$, were also reported. 


\section{Preferred Values}

$k=2.4 \times 10^{-11} \mathrm{~cm}^{3}$ molecule ${ }^{-1} \mathrm{~s}^{-1}$ at $298 \mathrm{~K}$.

$k=4.5 \times 10^{-12} \exp (500 / T) \mathrm{cm}^{3}$ molecule $\mathrm{e}^{-1} \mathrm{~s}^{-1}$ over the temperature range $210-360 \mathrm{~K}$.

\section{Reliability}

$\Delta \log k= \pm 0.3$ at $298 \mathrm{~K}$.

$\Delta(E / R)= \pm 200 \mathrm{~K}$.

\section{Comments on Preferred Values}

Disregarding the early study of Cox and Sheppard (1982) which gave a very low value for $k$, the reported rate coefficients at $298 \mathrm{~K}$ cover a range of just over a factor of two. This is despite the use of very similar techniques in some of the studies. The temperature dependence of $k$ has generally provided values of $E / R$ which are in good agreement, although that from the most recent temperature dependence study of Bedjanian et al. (2001) is substantially lower than three previous determinations.

The preferred value at $298 \mathrm{~K}$ is the mean of the rate coefficients of Bridier et al. (1993), Larichev et al. (1995), Elrod et al. (1996), Li et al. (1997), Cronkhite et al. (1998), Bedjanian et al. (2001) and Bloss et al. (2002) with substantial uncertainty limits. The preferred Arrhenius expression for $k$ is obtained by taking the mean of the $E / R$ values from the studies of Larichev et al. (1995), Elrod et al. (1996), Li et al. (1997) and Bedjanian et al. (2001), and combining it with a pre-exponential factor adjusted to give the preferred value of $k$ at $298 \mathrm{~K}$. The uncertainty in the preferred $E / R$ value has been increased to encompass the recent result of Bedjanian et al. (2001).

Several studies (Larichev et al., 1995; Elrod et al., 1996; Li et al., 1997; Bedjanian et al., 2001) have shown that the major product is HOBr. Larichev et al. (1995) and Bedjanian et al. (2001) were unable to obtain evidence for $\mathrm{O}_{3}$ formation in their mass spectrometric studies of the reaction and set upper limits for the branching ratio of $k_{2} / k<0.015$ and $<0.004$, respectively. From a study of the reverse reaction at above room temperature, Mellouki et al. (1994) have determined, by extrapolation, that the yield of $\mathrm{HBr}+\mathrm{O}_{3}$ is negligible $(<0.01 \%)$ down to $200 \mathrm{~K}$. Furthermore, $k$ appears to be independent of pressure over the range covered by the studies to date of 1 mbar to 1 bar (Bridier et al., 1993; Larichev et al., 1995; Elrod et al., 1996; Li et al., 1997; Cronkhite et al., 2002) and there is no evidence for stable adduct formation. Thus all of the available data suggeststhat channel (1) is the sole pathway over the temperature range of the preferred values. This is supported by two recent theoretical studies (Guha and Francisco, 1992; Kaltsoyannis and Rowley, 2002) which conclude that the contribution of channel (2) is essentially zero.

\section{References}

Bedjanian, Y., Riffault, V, and Poulet, G.: J. Phys. Chem. A, 105, 3167, 2001.

Bloss, W. J., Rowley, D. M., Cox, R. A., and Jones, R. L..: Phys. Chem. Chem. Phys., 4, 3639, 2002.

Bridier, I., Veyret, B., and Lesclaux, R.: Chem. Phys. Lett., 201, 563, 1993.

Cox, R. A. and Sheppard, D. W.: J. Chem. Soc. Faraday Trans., 2, 78, 1383, 1982.

Cronkhite, J. M., Stickel, R. E., Nicovich, J. M., and Wine, P. H.: J. Phys. Chem. A, 102, 6651, 1998.

Elrod, M. J., Meads, R. F., Lipson, J. B., Seeley, J. V., and Molina, M. J.: J. Phys. Chem., 100, 5808, 1996.

Guha, S. and Franciso, J. S.: J. Phys. Chem. A, 103, 8000, 1999.

Kaltsoyannis, N. and Rowley, D. M.: Phys. Chem. Chem. Phys., 4, 419, 2002.

Larichev, M., Maguin, F., Le Bras, G., and Poulet, D.: J. Phys. Chem., 99, 15 911, 1995.

Li, Z., Friedl, R. R., and Sander, S. P.: J. Chem. Soc. Faraday Trans., 93, 2683, 1997.

Mellouki, A., Talukdar, R. K., and Howard, C. J.: J. Geophys. Res., 99, 22 949, 1994.

Poulet, G., Pirre, M., Maguin, F., Ramarosen, R., and Le Bras, G.: Geophys. Res. Lett., 19, 2305, 1992. 
III.A3.75

$$
\begin{aligned}
\mathrm{BrO}+\mathrm{O}_{3} & \rightarrow \mathrm{Br}+2 \mathrm{O}_{2} \\
& \rightarrow \mathrm{OBrO}+\mathrm{O}_{2}
\end{aligned}
$$

$\Delta H^{\circ}(1)=-151 \mathrm{~kJ} \mathrm{~mol}^{-1}$

$\Delta H^{\circ}(2)=-99 \mathrm{~kJ} \mathrm{~mol}^{-1}$

Rate coefficient data $\left(k=k_{1}+k_{2}\right)$

\begin{tabular}{lllc}
\hline$k / \mathrm{cm}^{3}$ molecule $\mathrm{s}^{-1}$ & Temp./K & Reference & Technique/Comments \\
\hline Absolute Rate Coefficients & & & \\
$\sim 10^{-17}$ & $318-343$ & Rattigan et al., 1995 & P-AS (a) \\
$k_{2}=7 \times 10^{-14} \exp [-(3100 \pm 350) / T]$ & $318-343$ & & \\
$k_{2}=2.1 \times 10^{-18}$ & $298^{*}$ & & \\
$<(2.1 \pm 0.7) \times 10^{-17}$ & 298 & Rowley et al., 1996 & FP-AS (b) \\
$k_{2}=(1.66 \pm 0.11) \times 10^{-18}$ & 298 & & \\
\hline
\end{tabular}

\section{Comments}

(a) Photolysis of $\mathrm{Br}_{2}-\mathrm{O}_{3}$ mixtures at $380 \mathrm{~nm}$ to $480 \mathrm{~nm}$ in $\mathrm{N}_{2}$ or $\mathrm{O}_{3}$ bath gas at total pressures in the range 16 mbar to 1 bar. Time-resolved UV absorption spectroscopy was used to monitor the concentrations of $\mathrm{O}_{3}, \mathrm{Br}_{2}$ and $\mathrm{BrO}$ radicals before, during, and after irradiation. $\mathrm{OBrO}$ was also detected in absorption in the wavelength range $400 \mathrm{~nm}$ to $600 \mathrm{~nm}$.

(b) Flash photolysis-longpath UV absorption technique. $\mathrm{BrO}$ radicals were produced by photolysis at $\sim 400 \mathrm{~nm}$ of $\mathrm{Br}_{2}$ in an excess of $\mathrm{O}_{3}$. Time-resolved UV/visible absorption spectra of $\mathrm{BrO}$ were recorded over the range $234 \mathrm{~nm}$ to $367 \mathrm{~nm}$ and of $\mathrm{OBrO}$ over the range $425 \mathrm{~nm}$ to $558 \mathrm{~nm}$. The $\mathrm{BrO}$ decay was largely due to the $\mathrm{BrO}+\mathrm{BrO}$ reaction but deviations from second-order behavior were observed at high $\mathrm{O}_{3}$ concentrations, and attributed to the $\mathrm{BrO}+\mathrm{O}_{3}$ reaction. The upper limit was derived from an analysis of the $[\mathrm{BrO}]$ temporal profiles at high $\mathrm{O}_{3}$ concentrations.

\section{Preferred Values}

$k<2 \times 10^{-17} \mathrm{~cm}^{3}$ molecule ${ }^{-1} \mathrm{~s}^{-1}$ at $298 \mathrm{~K}$.

\section{Comments on Preferred Values}

The two most recent studies of Rattigan et al. (1995) and Rowley et al. (1996) are in good agreement and set a lower upper limit to the rate coefficient for this reaction than did previous studies (Sander and Watson, 1981; Mauldin et al., 1993). The preferred upper limit to $k$ at $298 \mathrm{~K}$ is therefore based on the results reported by Rattigan et al. (1995) and Rowley et al. (1996).

Previously, the reaction of $\mathrm{BrO}$ with $\mathrm{O}_{3}$ had been assumed to occur exclusively by channel (1), but the positive identification of $\mathrm{OBrO}$ as a reaction product indicates that channel (2) is likely to be significant. The existing determinations of $k_{2}$ are in good agreement (Rattigan et al., 1995; Rowley et al., 1996) but involve significant uncertainties. Further studies are necessary before a branching ratio can be recommended.

\section{References}

Mauldin III, R. L., Wahner, A., and Ravishankara, A. R.: J. Phys. Chem., 97, 7585, 1993.

Rattigan. O. V., Cox, R. A., and Jones, R. L.: J. Chem. Soc. Faraday Trans., 91, 4189, 1995.

Rowley, D. M., Harwood, M. H., Freshwater, R. A., and Jones, R. L.: J. Phys. Chem., 100, 3020, 1996

Sander, S. P. and Watson, R. T.: J. Phys. Chem., 85, 4000, 1981. 
III.A3.76

$$
\mathrm{BrO}+\mathrm{NO} \rightarrow \mathrm{Br}+\mathrm{NO}_{2}
$$

$\Delta H^{\circ}=-65 \mathrm{~kJ} \mathrm{~mol}^{-1}$

\section{Rate coefficient data}

\begin{tabular}{lllc}
\hline$k / \mathrm{cm}^{3}$ molecule ${ }^{-1} \mathrm{~s}^{-1}$ & Temp./K & Reference & Technique/Comments \\
\hline Absolute Rate Coefficients & & & \\
$(2.2 \pm 0.4) \times 10^{-11}$ & 298 & Clyne and Watson, 1975 & DF-MS (a) \\
$7.11 \times 10^{-12} \exp [(296 \pm 10) / T]$ & $230-425$ & Leu, 1979 & DF-MS (a) \\
$(1.89 \pm 0.16) \times 10^{-11}$ & 298 & & \\
$1.28 \times 10^{-11} \exp [(181 \pm 46) / T]$ & $224-398$ & Watson et al., 1979 & FP-UVA (b) \\
$(2.15 \pm 0.25) \times 10^{-11}$ & 298 & & \\
$(2.15 \pm 0.18) \times 10^{-11}$ & 298 & Ray and Watson, 1981 & DF-MS (a) \\
\hline
\end{tabular}

\section{Comments}

(a) $\mathrm{BrO}$ radicals were produced by the $\mathrm{O}+\mathrm{Br}_{2}$ reaction and monitored by MS in an excess of NO.

(b) $\mathrm{BrO}$ radicals were produced by the flash photolysis of $\mathrm{Br}_{2}-\mathrm{O}_{2}$ mixtures in the presence of an excess of $\mathrm{NO}$. BrO radical concentrations were monitored by UV absorption at $339 \mathrm{~nm}$. $k$ was observed to be independent of pressure over the range 130 mbar to 930 mbar of $\mathrm{He}$ or $\mathrm{N}_{2}$.

\section{Preferred Values}

$k=2.1 \times 10^{-11} \mathrm{~cm}^{3}$ molecule $\mathrm{s}^{-1} \mathrm{~s}^{-1}$ at $298 \mathrm{~K}$.

$k=8.7 \times 10^{-12} \exp (260 / T) \mathrm{cm}^{3}$ molecule $\mathrm{s}^{-1} \mathrm{~s}^{-1}$ over the temperature range $220-430 \mathrm{~K}$.

\section{Reliability}

$\Delta \log k= \pm 0.1$ at $298 \mathrm{~K}$.

$\Delta(E / R)= \pm 100 \mathrm{~K}$.

\section{Comments on Preferred Values}

The results of the three low pressure mass spectrometric studies of Clyne and Watson (1975), Leu (1979) and Ray and Watson (1981) and the high pressure UV absorption study of Watson et al. (1979), all of which used pseudo-first order conditions, are in excellent agreement at $298 \mathrm{~K}$ and are considered to be more reliable than the earlier low pressure UV absorption study of Clyne and Cruse (1970). The results of the two temperature dependence studies (Leu, 1979; Watson et al., 1979) are in good agreement. The preferred Arrhenius expression is derived from a least-squares fit to all the data of Clyne and Watson (1975), Leu (1979), Watson et al. (1979) and Ray and Watson (1981). By combining the data reported in the high pressure UV absorption study (Watson et al., 1979) with those from the mass spectrometric studies (Clyne and Watson, 1975; Leu, 1979; Ray and Watson, 1981), this reaction does not exhibit any observable pressure dependence between 1 mbar and 1 bar total pressure. The temperature dependencies of the rate coefficients for the analogous $\mathrm{ClO}$ and $\mathrm{HO}_{2}$ reactions are also negative and similar in magnitude.

\section{References}

Clyne, M. A. A. and Cruse, H. W.: Trans. Faraday Soc., 66, 2227, 1970.

Clyne, M. A. A. and Watson, R. T.: J. Chem. Soc. Faraday Trans., 1, 71, 336, 1975.

Leu, M.-T.: Chem. Phys. Lett., 61, 275, 1979. 
Ray, G. W. and Watson, R. T.: J. Phys. Chem., 85, 2955,1981.

Watson, R. T., Sander, S. P., and Yung, Y. L.: J. Phys. Chem., 83, 2936, 1979. 
III.A3.77

$$
\mathrm{BrO}+\mathrm{NO}_{2}+\mathrm{M} \rightarrow \mathrm{BrONO}_{2}+\mathrm{M}
$$

$\Delta H^{\circ}=-106 \mathrm{~kJ} \mathrm{~mol}^{-1}$

\section{Low-pressure rate coefficients}

\section{Rate coefficient data}

\begin{tabular}{lllc}
\hline$k_{0} / \mathrm{cm}^{3}$ molecule ${ }^{-1} \mathrm{~s}^{-1}$ & Temp./K & Reference & Technique/Comments \\
\hline $\begin{array}{l}\text { Absolute Rate Coefficients } \\
(5.0 \pm 1.0) \times 10^{-31}\left[\mathrm{~N}_{2}\right]\end{array}$ & 298 & Sander et al., 1981 & DF-MS/FP-UVA (a) \\
$(4.2 \pm 0.8) \times 10^{-31}(T / 300)^{-2.0}\left[\mathrm{O}_{2}\right]$ & $263-343$ & Danis et al., 1990 & PLP-MS (b) \\
$5.4 \times 10^{-31}(T / 298)^{-3.2}\left[\mathrm{~N}_{2}\right]$ & $248-346$ & Thorn et al., 1993 & PLP-UVA (c) \\
\hline
\end{tabular}

\section{Comments}

(a) DF-MS study over the pressure range 1.3-8 mbar, and FP-UVA study from 57-933 mbar. In the DF-MS study, BrO radicals were produced by the reaction $\mathrm{Br}+\mathrm{O}_{3} \rightarrow \mathrm{BrO}+\mathrm{O}_{2}$, and in the FP-UVA study $\mathrm{BrO}$ radicals were formed by the reaction of $\mathrm{O}\left({ }^{3} \mathrm{P}\right)$ atoms (from the photolysis of $\mathrm{O}_{2}$ ) with $\mathrm{Br}_{2}$. A major portion of the falloff curve was observed and analyzed with a fitted value of $F_{c}=0.4$ at $298 \mathrm{~K}$.

(b) $\mathrm{BrO}$ radicals were produced by the photolysis of $\mathrm{O}_{3}$ at $248 \mathrm{~nm}$ in the presence of $\mathrm{Br}_{2}$. Rate coefficients were measured at total pressures below 16 mbar. Falloff curves were extrapolated using $F_{c}=\exp (-T / 325)$.

(c) $\mathrm{BrO}$ radicals were generated by the photolysis of $\mathrm{Br}_{2}-\mathrm{NO}_{2}-\mathrm{N}_{2}$ mixtures at $351 \mathrm{~nm}$, and were monitored by long-path $(550 \mathrm{~cm})$ absorption at $338.3 \mathrm{~nm}$. The total pressure was varied over the range 21-1060 mbar. The data were analyzed with $F_{c}=\exp (-T / 327)$, based on the fitted value of $F_{c}=0.4$ of Sander et al. (1981). If a value of $F_{c}=0.6$ is used, a rate coefficient of $k_{0}=5.2 \times 10^{-31}(T / 300)^{-3.2}\left[\mathrm{~N}_{2}\right] \mathrm{cm}^{3}$ molecule $\mathrm{e}^{-1} \mathrm{~s}^{-1}$ is obtained.

\section{Preferred Values}

$k_{0}=4.7 \times 10^{-31}(T / 300)^{-3.1}\left[\mathrm{~N}_{2}\right] \mathrm{cm}^{3}$ molecule ${ }^{-1} \mathrm{~s}^{-1}$ over the temperature range $240-350 \mathrm{~K}$.

\section{Reliability}

$\Delta \log k_{0}= \pm 0.1$ at $298 \mathrm{~K}$.

$\Delta n= \pm 1$.

\section{Comments on Preferred Values}

The preferred values are based on the data of Sander et al. (1981), Danis et al. (1990) and Thorn et al. (1993) employing $F_{c}$ $=0.4$. The reverse dissociation reaction $\mathrm{BrONO}_{2}+\mathrm{M} \rightarrow \mathrm{BrO}+\mathrm{NO}_{2}+\mathrm{M}$ was measured by Orlando and Tyndall (1996) over the temperature range $320-340 \mathrm{~K}$ and at pressures of 133-1330 mbar. Their rate data were combined with the present preferred values for the reverse reaction leading to $\Delta H^{\circ}=-118 \mathrm{~kJ} \mathrm{~mol}^{-1}$. Ab initio calculations of the bond strength have also been reported by Rayez and Destriau (1993) and Parthiban and Lee (1998).

\section{High-pressure rate coefficients}


Rate coefficient data

\begin{tabular}{lllc}
\hline$k_{\infty} / \mathrm{cm}^{3}$ molecule ${ }^{-1} \mathrm{~s}^{-1}$ & Temp./K & Reference & Technique/Comments \\
\hline Absolute Rate Coefficients & & & \\
$(2.0 \pm 0.5) \times 10^{-11}$ & 298 & Sander et al., 1981 & DF-MS/FP-UVA (a) \\
$1.4 \times 10^{-11}(T / 300)^{-1.2}$ & $248-346$ & Thorn et al., 1993 & PLP-UVA (b) \\
\hline
\end{tabular}

\section{Comments}

(a) See comment (a) for $k_{0}$. Extrapolation of falloff curve with a fitted value of $F_{c}=0.4$.

(a) See comment (c) for $k_{0}$. Evaluated with $F_{c}=\exp (-T / 327) . \quad$ If $F_{c}=0.6$ is employed, $k_{\infty}=6.9 \times 10^{-12}$ $(T / 300)^{-2.9} \mathrm{~cm}^{3}$ molecule ${ }^{-1} \mathrm{~s}^{-1}$ is fitted.

\section{Preferred Values}

$k_{\infty}=1.8 \times 10^{-11} \mathrm{~cm}^{3}$ molecule $\mathrm{e}^{-1} \mathrm{~s}^{-1}$ independent of temperature over the range $240-350 \mathrm{~K}$.

\section{Reliability}

$\Delta \log k_{\infty}= \pm 0.1$ at $298 \mathrm{~K}$.

$\Delta n= \pm 1$.

\section{Comments on Preferred Values}

The preferred values are based on the data of Thorn et al. (1993) which are in good agreement with the data of Sander et al. (1981) at $298 \mathrm{~K}$. A temperature-independent $F_{c}=0.4$ is used for representing the falloff curve which leads to the given practically temperature-independent $k_{\infty}$.

\section{References}

Danis, R., Caralp, F., Masanet, J., and Lesclaux, R.: Chem. Phys. Lett., 167, 450, 1990.

Orlando, J. J. and Tyndall, G. S.: J. Phys. Chem., 100, 19398, 1996.

Parthiban, S. and Lee, T. J.: J. Chem. Phys., 109, 525, 1998.

Rayez, M. T. and Destriau, M.: Chem. Phys. Lett., 206, 278, 1993.

Sander, S. P., Ray, G. W., and Watson, R. T.: J. Phys. Chem., 85, 199. 1981.

Thorn, R. P., Daykin, E. P., and Wine, P. H.: Int. J. Chem. Kinet., 25, 521, 1993. 
III.A3.78

$\begin{array}{ll}\mathrm{BrO}+\mathrm{ClO} & \rightarrow \mathrm{Br}+\mathrm{OClO} \\ & \rightarrow \mathrm{Br}+\mathrm{ClOO} \\ & \rightarrow \mathrm{BrCl}+\mathrm{O}_{2} \\ \mathrm{BrO}+\mathrm{ClO}+\mathrm{M} & \rightarrow \mathrm{Cl}+\mathrm{OBrO} \\ & \rightarrow \mathrm{BrOOCl}+\mathrm{M}\end{array}$
$\Delta H^{\circ}(1)=-14 \mathrm{~kJ} \mathrm{~mol}^{-1}$
$\Delta H^{\circ}(2)=-12 \mathrm{~kJ} \mathrm{~mol}^{-1}$
$\Delta H^{\circ}(3)=-207 \mathrm{~kJ} \mathrm{~mol}^{-1}$
$\Delta H^{\circ}(4)=52 \mathrm{~kJ} \mathrm{~mol}^{-1}$

Rate coefficient data $\left(k=k_{1}+k_{2}+k_{3}+k_{4}+k_{5}\right)$

\begin{tabular}{|c|c|c|c|}
\hline $\mathrm{k} / \mathrm{cm}^{3}$ molecule $^{-1} \mathrm{~s}^{-1}$ & Temp./K & Reference & Technique/Comments \\
\hline \multicolumn{4}{|l|}{ Absolute Rate Coefficients } \\
\hline $6.1 \times 10^{-12} \exp [(240 \pm 60) / T]$ & $220-400$ & Sander and Friedl, 1988 & FP-UVA (a) \\
\hline$(1.29 \pm 0.18) \times 10^{-11}$ & 298 & & \\
\hline $4.7 \times 10^{-12} \exp [(320 \pm 60) / T]$ & $220-400$ & Friedl and Sander, 1988 & DF-MS (b) \\
\hline$(1.29 \pm 0.19) \times 10^{-11}$ & 298 & & \\
\hline $2.59 \times 10^{-12} \exp [(445 \pm 84) / T]$ & $234-406$ & Turnipseed et al., 1991 & DF-MS (c) \\
\hline$(1.08 \pm 0.20) \times 10^{-11}$ & 304 & & \\
\hline$k_{1}=6.7 \times 10^{-13} \exp [(622 \pm 94) / T]$ & $234-406$ & & \\
\hline$k_{2}=2.1 \times 10^{-12} \exp [(258 \pm 56) / T]$ & 234-406 & & \\
\hline$k_{3}=1.9 \times 10^{-13} \exp [(513 \pm 86) / T]$ & $234-406$ & & \\
\hline \multicolumn{4}{|l|}{ Branching Ratios } \\
\hline$k_{1} / k=0.68 \pm 0.10$ & 220 & Sander and Friedl, 1988 & (a) \\
\hline$k_{1} / k=0.59 \pm 0.10$ & 298 & & \\
\hline$k_{1} / k=0.55 \pm 0.07$ & 220 & Friedl and Sander, 1988 & (b) \\
\hline$k_{1} / k=0.48 \pm 0.07$ & 298 & & \\
\hline$k_{1} / k=0.44 \pm 0.07$ & 400 & & \\
\hline$k_{2} / k=0.39 \pm 0.10$ & 220 & Friedl and Sander, 1988 & (b) \\
\hline$k_{2} / k=0.40 \pm 0.10$ & 298 & & \\
\hline$k_{2} / k=0.44 \pm 0.10$ & 400 & & \\
\hline$k_{3} / k=0.06 \pm 0.03$ & 220 & Friedl and Sander, 1988 & (b) \\
\hline$k_{3} / k=0.08 \pm 0.03$ & 298 & & \\
\hline$k_{3} / k=0.08 \pm 0.03$ & 400 & & \\
\hline$k_{1} / k=0.51 \pm 0.09$ & 250 & Turnipseed et al., 1991 & (c) \\
\hline$k_{1} / k=0.48 \pm 0.07$ & 304 & & \\
\hline$k_{1} / k=0.39 \pm 0.07$ & 406 & & \\
\hline$\left(k_{2}+k_{3}\right) / k=0.46 \pm 0.7$ & 250 & Turnipseed et al., 1991 & (c) \\
\hline$\left(k_{2}+k_{3}\right) / k=0.55 \pm 0.9$ & 304 & & \\
\hline$\left(k_{2}+k_{3}\right) / k=0.61 \pm 0.11$ & 406 & & \\
\hline$k_{3} / k=0.10 \pm 0.02$ & 250 & Turnipseed et al., 1991 & (c) \\
\hline$k_{3} / k=0.09 \pm 0.02$ & 304 & & \\
\hline$k_{3} / k=0.09 \pm 0.02$ & 406 & & \\
\hline$k_{1} / k=0.53 \pm 0.05$ & 295 & Bloss, 1999 & (d) \\
\hline$k_{4} / k<0.02$ & 295 & & \\
\hline
\end{tabular}




\section{Comments}

(a) $\mathrm{BrO}, \mathrm{ClO}$ and $\mathrm{OClO}$ were detected using the temperature-dependent absorption cross sections measured in the same study. $\mathrm{BrO}$ radical decays were monitored with $[\mathrm{ClO}]>[\mathrm{BrO}]$. Measurement of the rate coefficient ratio $k_{1} / k$ was based on $\Delta[\mathrm{OClO}] / \Delta[\mathrm{BrO}]$ as a function of time.

(b) $\mathrm{BrO}, \mathrm{ClO}, \mathrm{OClO}$ and $\mathrm{BrCl}$ were detected. $\mathrm{BrO}$ radical decays were measured in excess $\mathrm{ClO}$. The branching ratios were based on the yields of $\mathrm{OClO}, \mathrm{Cl}$ (after conversion to $\mathrm{BrCl}$ ) and $\mathrm{BrCl}$ compared to the amounts of $\mathrm{BrO}$ and $\mathrm{ClO}$ reacted.

(c) Dischage flow system with $\mathrm{MS}$ detection of $\mathrm{BrO}, \mathrm{ClO}, \mathrm{OClO}$ and $\mathrm{BrCl}$. $\mathrm{BrO}$ radical decays were monitored by the presence of a 10- to 60-fold excess of $\mathrm{ClO}$ radicals. Branching ratios were based on the yields of $\mathrm{OClO}, \mathrm{ClO}$ and $\mathrm{BrCl}$ in the presence of the $\mathrm{Cl}$ atom scavengers $\mathrm{HBr}$ and $\mathrm{C}_{2} \mathrm{H}_{3} \mathrm{Br}$.

(d) Flash photolysis system with UV absorption detection (using a charge coupled detector) of $\mathrm{BrO}, \mathrm{ClO}, \mathrm{OClO}$ and $\mathrm{OBrO}$ using differential absorption spectroscopy. The branching ratio $k_{4} / k$ was based on the absence of characteristic $\mathrm{OBrO}$ absorption in the region $400 \mathrm{~nm}$ to $500 \mathrm{~nm}$ during the $\mathrm{BrO}$ and $\mathrm{ClO}$ decays.

\section{Preferred Values}

$k_{1}=6.8 \times 10^{-12} \mathrm{~cm}^{3}$ molecule ${ }^{-1} \mathrm{~s}^{-1}$ at $298 \mathrm{~K}$.

$k_{2}=6.1 \times 10^{-12} \mathrm{~cm}^{3}$ molecule ${ }^{-1} \mathrm{~s}^{-1}$ at $298 \mathrm{~K}$.

$k_{3}=1.0 \times 10^{-12} \mathrm{~cm}^{3}$ molecule ${ }^{-1} \mathrm{~s}^{-1}$ at $298 \mathrm{~K}$.

$k_{1}=1.6 \times 10^{-12} \exp (430 / T) \mathrm{cm}^{3}$ molecule ${ }^{-1} \mathrm{~s}^{-1}$ over the temperature range $220-400 \mathrm{~K}$.

$k_{2}=2.9 \times 10^{-12} \exp (220 / T) \mathrm{cm}^{3}$ molecule ${ }^{-1} \mathrm{~s}^{-1}$ over the temperature range $220-400 \mathrm{~K}$.

$k_{3}=5.8 \times 10^{-13} \exp (170 / T) \mathrm{cm}^{3}$ molecule ${ }^{-1} \mathrm{~s}^{-1}$ over the temperature range $220-400 \mathrm{~K}$.

\section{Reliability}

$\Delta \log k_{1}=\Delta \log k_{2}=\Delta \log k_{3}= \pm 0.1$ at $298 \mathrm{~K}$.

$\Delta\left(E_{1} / R\right)=\Delta\left(E_{2} / R\right)=\Delta\left(E_{3} / R\right)= \pm 200 \mathrm{~K}$.

\section{Comments on Preferred Values}

The database for this reaction is now extensive. Friedl and Sander (1989), using a discharge flow-mass spectrometry system, measured the overall rate coefficient over the temperature range $220-400 \mathrm{~K}$ and also over this temperature range determined directly the branching ratios for the reaction channels producing $\mathrm{BrCl}$ and $\mathrm{OClO}$. In a separate study, the same authors (Sander and Friedl, 1989), using flash photolysis-ultraviolet absorption techniques, measured the overall rate coefficient over the temperature range $220-400 \mathrm{~K}$ and pressure range $67 \mathrm{mbar}$ to $1000 \mathrm{mbar}$, and also determined the branching ratio for OClO production at $220 \mathrm{~K}$ and $298 \mathrm{~K}$. The results by these two independent techniques (Friedl and Sander, 1989; Sander and Friedl, 1989) are in excellent agreement, with the overall rate coefficient showing a negative temperature dependence. The study of Turnipseed et al. (1991) also resulted in a comprehensive set of rate coefficient and branching ratio data. The overall rate coefficients from these three studies (Friedl and Sander, 1989; Sander and Friedl, 1989; Turnipseed et al., 1991) are in good agreement at room temperature (within 20\%) and are in excellent agreement at stratospheric temperatures. Toohey and Anderson (1988), using discharge flow-resonance fluorescence/LMR techniques, reported room temperature values of the overall rate coefficient and the branching ratio for $\mathrm{OClO}$ production. They also found evidence for the direct production of $\mathrm{BrCl}$ in a vibrationally excited $\pi$ state (Toohey and Anderson, 1988). Poulet et al. (1990), using discharge flow-mass spectrometry techniques, reported room temperature values of the overall rate coefficient and branching ratios for $\mathrm{OClO}$ and $\mathrm{BrCl}$ production. Clyne and Watson (1977) also studied this reaction using a discharge flow-MS system.

The results of the studies of Toohey and Anderson (1988), Sander and Friedl (1989), Friedl and Sander 1989), Poulet et al. (1990), Turnipseed et al. (1991) and Bloss (1999) are in reasonably good agreement. The rate coefficients of Hills et al. (1988), using a discharge flow-mass spectrometry technique, were independent of temperature over the range $241 \mathrm{~K}$ to $308 \mathrm{~K}$ and the room temperature rate coefficient was substantially lower than the average value from the above-mentioned studies (Friedl and Sander, 1989; Sander and Friedl, 1989; Turnipseed et al., 1991; Toohey and Anderson, 1988; Poulet et al., 1990). Hills et al. (1988) also reported no $\mathrm{BrCl}$ formation. In the flash photolysis study of Basco and Dogra (1971) a different interpretation of the reaction mechanism was used; the reported rate coefficients were low and are not used in the evaluation of the rate coefficient for this reaction. 
The recommended Arrhenius expressions for the individual reaction channels are taken from the studies of Friedl and Sander (1989) and Turnipseed et al. (1991), which contain the most comprehensive sets of rate coefficient and branching ratio data. Both of these studies (Sander and Friedl, 1989; Turnipseed et al., 1991), as well as that of Sander and Friedl (1989), show that $\mathrm{OClO}$ production by channel (1) becomes dominant at very low temperature. Both studies show an $\sim 8 \%$ yield of $\mathrm{BrCl}$ by channel (3). The recommended expressions are consistent with the body of data from all studies except those of Hills et al. (1988) and Basco and Dogra (1971). Quantum mechanical calculations of the transition state configurations and energy minima on the P.E. surface for this reaction confirm the mechanism involving a $\mathrm{BrOOCl}$ peroxide intermediate (Papayannis et al., 2001). However there is no experimental evidence for a pressure dependence, as expected if this intermediate was formed as a stable product in channel (5).

\section{References}

Basco, N. and Dogra, S. K.: Proc. Roy. Soc. London, A, 323, 417, 1971.

Bloss, W.: Ph.D. Thesis, University of Cambridge, Cambridge, UK, 1999.

Clyne, M. A. A. and Watson, R. T.: J. Chem. Soc. Faraday Trans., 1, 73, 1169, 1977.

Friedl , R. R. and Sander, S. P.: J. Phys. Chem., 93, 4756, 1989.

Hills, A. J., Cicerone, R. J., Calvert, J. G., and Birks, J. W.: J. Phys. Chem., 92, 1853, 1988.

Papayannis, D. K., Cosmas, A. M., and Melissas, V. S.: J. Phys. Chem. A, 105, 2209, 2001.

Poulet, G., Lancar, I. T., Laverdet, G., and Le Bras, G.: J. Phys. Chem., 94, 278, 1990.

Sander, S. P. and Friedl, R. R.: J. Phys. Chem., 93, 4764, 1989.

Toohey, D. W. and Anderson, J. G.: J. Phys. Chem., 92, 1705, 1988.

Turnipseed, A. A., Birks, J. W., and Calvert, J. G.: J. Phys. Chem., 95, 4356, 1991. 
III.A3.79

$\begin{array}{ll}\mathrm{BrO}+\mathrm{BrO} & \rightarrow 2 \mathrm{Br}+\mathrm{O}_{2} \\ & \rightarrow \mathrm{Br}_{2}+\mathrm{O}_{2} \\ \mathrm{BrO}+\mathrm{BrO}+\mathrm{M} & \rightarrow \mathrm{Br}_{2} \mathrm{OBB}_{2}+\mathrm{M}\end{array}$

$\begin{aligned} \Delta H^{\circ}(1) & =-16 \mathrm{~kJ} \mathrm{~mol}^{-1} \\ \Delta H^{\circ}(2) & =-209 \mathrm{~kJ} \mathrm{~mol}^{-1} \\ \Delta H^{\circ}(3) & =24 \mathrm{~kJ} \mathrm{~mol}^{-1} \\ \Delta H^{\circ}(4) & =-59 \mathrm{~kJ} \mathrm{~mol}^{-1}\end{aligned}$

Rate coefficient data $\left(k=k_{1}+k_{2}+k_{3}+k_{4}\right)$

\begin{tabular}{lllc}
\hline$k / \mathrm{cm}^{3}$ molecule ${ }^{-1} \mathrm{~s}^{-1}$ & Temp./K & Reference & Technique/Comments \\
\hline Absolute Rate Coefficients & & & \\
$(3.17 \pm 0.67) \times 10^{-12}$ & 298 & Clyne and Watson, 1975 & DF-MS \\
$9.58 \times 10^{-13} \exp [(255 \pm 195) / T]$ & $223-388$ & Sander and Watson, 1981 & (a) \\
$(2.17 \pm 0.68) \times 10^{-12}$ & 298 & & \\
$(3.2 \pm 0.5) \times 10^{-12}$ & 298 & Lancar et al., 1991 & (b) \\
$k_{2}=(4.7 \pm 1.5) \times 10^{-13}$ & 298 & & \\
$(2.75 \pm 0.57) \times 10^{-12}$ & 298 & Mauldin et al., 1993 & (c) \\
$k_{2}=(4.45 \pm 0.82) \times 10^{-13}$ & 298 & & \\
$k_{1}=(2.49 \pm 0.42) \times 10^{-12}$ & 298 & Rowley et al.,1996 & (d) \\
$k_{2}=(4.69 \pm 0.68) \times 10^{-13}$ & 298 & & \\
$(2.8 \pm 0.5) \times 10^{-12}$ & 298 & Laszlo et al., 1997 & (e) \\
$1.70 \times 10^{-12} \exp [(215 \pm 50) / T]$ & $204-388$ & Gilles et al., 1997 & (f) \\
$(3.51 \pm 0.35) \times 10^{-12}$ & 298 & & (g) \\
$k_{1}=5.31 \times 10^{-12} \exp [-(211 \pm 59) / T]$ & $250-298$ & Harwood et al., 1998 & \\
$k_{2}=1.13 \times 10^{-14} \exp [(983 \pm 111) / T]$ & $250-298$ & & \\
$k_{4}=(8.2 \pm 1.1) \times 10^{-32}[\mathrm{M}]$ & 222 & & \\
& & & (a) \\
Branching Ratios & & & (c) \\
$k_{1} / k=0.84 \pm 0.03$ & 298 & Sander and Watson, 1981 & (d) \\
$k_{1} / k=0.84 \pm 0.01$ & 298 & Mauldin et al., 1993 & \\
$k_{1} / k=0.68 \pm 0.05$ & 220 & & \\
$k_{1} / k=0.85 \pm 0.02$ & 298 & Rowley et al., 1996 &
\end{tabular}

\section{Comments}

(a) Flash photolysis study with absorption spectroscopic detection of $\mathrm{BrO}$ radicals using the 7-0 band of the A-X system at $339 \mathrm{~nm}$, for which a cross section of $(1.14 \pm 0.14) \times 10^{-17} \mathrm{~cm}^{2}$ molecule ${ }^{-1}$ was measured. The total pressure was $65 \mathrm{mbar}$ to 789 mbar of $\mathrm{N}_{2}$. The branching ratio was determined from measurements with and without excess $\mathrm{O}_{3}$ present, using two methods which gave the same result.

(b) Discharge flow-mass spectrometry study, in which rate coefficients were determined from measurements with and without excess $\mathrm{O}_{3}$ present. The rate coefficient $k_{2}$ was obtained from $\mathrm{BrO}$ radical decays and $\mathrm{Br}_{2}$ formation.

(c) Flash photolysis-long path absorption technique. Measurements were made at $298 \mathrm{~K}$ and $220 \mathrm{~K}$ over a pressure range of $100 \mathrm{mbar}$ to $800 \mathrm{mbar}$ of $\mathrm{He}, \mathrm{N}_{2}$ and $\mathrm{SF}_{6}$. The overall rate coefficient was found to be independent of pressure at $298 \mathrm{~K}$, but at $220 \mathrm{~K}$ to increase from $2.0 \times 10^{-12} \mathrm{~cm}^{3}$ molecule ${ }^{-1} \mathrm{~s}^{-1}$ at $133 \mathrm{mbar}$ to $3.1 \times 10^{-12} \mathrm{~cm}^{3}$ molecule ${ }^{-1} \mathrm{~s}^{-1}$ at $530 \mathrm{mbar}$. The branching ratio was found to be independent of pressure at $298 \mathrm{~K}$ and $220 \mathrm{~K}$. An additional transient absorption feature was observed at $220 \mathrm{~K}$ and was tentatively attributed to $\mathrm{Br}_{2} \mathrm{O}_{2}$. $\mathrm{BrO}$ concentrations were determined using the absorption cross sections of Wahner et al. (1988); the cross section at $338.5 \mathrm{~nm}$ was $1.71 \times 10^{-17} \mathrm{~cm}^{2}$ molecule ${ }^{-1}$ at $298 \mathrm{~K}$ and 
$2.21 \times 10^{-17} \mathrm{~cm}^{2}$ molecule ${ }^{-1}$ at $220 \mathrm{~K}(0.2 \mathrm{~nm}$ resolution). The following expressions were recommended for atmospheric modeling: $k_{1}=4.0 \times 10^{-12} \exp (-190 / T) \mathrm{cm}^{3}$ molecule $\mathrm{s}^{-1} \mathrm{~s}^{-1}$ and $k_{2}=4.2 \times 10^{-14} \exp (660 / T) \mathrm{cm}^{3} \mathrm{molecule}^{-1} \mathrm{~s}^{-1}$.

(d) Flash photolysis-UV absorption technique, with detection of $\mathrm{BrO}$ radicals using time-resolved $\mathrm{CCD}$ detection in the A-X system at $400 \mathrm{~nm}$ to $470 \mathrm{~nm}$. BrO radical concentrations were determined using the absorption cross sections of Wahner et al. (1988) compensated for the change in resolution. Rate coefficients were obtained from measurements with and without excess $\mathrm{O}_{3}$ present. $\mathrm{OBrO}$ was observed in the presence of high concentrations of $\mathrm{O}_{3}$, apparently due to the $\mathrm{BrO}+\mathrm{O}_{3}$ reaction and not to channel (3). The total pressure was 1000 mbar.

(e) Pulsed laser photolysis of $\mathrm{N}_{2} \mathrm{O}-\mathrm{Br}_{2}-\mathrm{N}_{2}$ mixtures, with absorption spectroscopic detection of $\mathrm{BrO}$ radicals. An absorption cross section of $(1.41 \pm 0.15) \times 10^{-17} \mathrm{~cm}^{2}$ molecule ${ }^{-1}$ at $338.5 \mathrm{~nm}$ was measured.

(f) Pulsed laser photolysis of $\mathrm{N}_{2} \mathrm{O}-\mathrm{Br}_{2}-\mathrm{N}_{2}$ mixtures, with absorption spectroscopic detection of $\mathrm{BrO}$ radicals. An absorption cross section of $1.63 \times 10^{-17} \mathrm{~cm}^{2}$ molecule ${ }^{-1}$ at $338.5 \mathrm{~nm}(0.5 \mathrm{~nm}$ resolution) was measured at $298 \mathrm{~K}$. A similar temperature dependence of the absorption cross section as observed by Wahner et al. (1988) was obtained.

(g) Flash photolysis-absorption spectroscopy technique with detection of $\mathrm{BrO}$ radicals using time-resolved CCD detection in the A-X system at $400 \mathrm{~nm}$ to $470 \mathrm{~nm}$. BrO concentrations were determined using the absorption cross sections of Wahner et al. (1988) compensated for change in resolution and for temperature dependence. Rate coefficients were obtained from measurements with and without excess $\mathrm{O}_{3}$ present. The total pressure was in the range 130 mbar to 1 bar. In the presence of $\mathrm{O}_{3}$ and below $250 \mathrm{~K}$, departure from second-order kinetics for $\mathrm{BrO}$ and a transient absorption attributed to $\mathrm{Br}_{2} \mathrm{O}_{2}$ was observed. The overall rate coefficient was pressure dependent in this temperature regime and the results were analyzed to yield a value for the rate coefficient for dimer formation [channel (4)] at $222 \mathrm{~K}$. The formation of the dimer apparently replaced the bimolecular channels at low temperature, and the expressions for $k_{1}$ and $k_{2}$ only apply to temperatures $>250 \mathrm{~K}$.

\section{Preferred Values}

$k_{1}=2.7 \times 10^{-12} \mathrm{~cm}^{3}$ molecule ${ }^{-1} \mathrm{~s}^{-1}$, independent of temperature over the range $250-390 \mathrm{~K}$.

$k_{2}=4.8 \times 10^{-13} \mathrm{~cm}^{3}$ molecule $\mathrm{s}^{-1} \mathrm{~s}^{-1}$ at $298 \mathrm{~K}$.

$k=3.2 \times 10^{-12} \mathrm{~cm}^{3}$ molecule $\mathrm{s}^{-1} \mathrm{~s}^{-1}$ at $298 \mathrm{~K}$.

$k_{2}=2.9 \times 10^{-14} \exp (840 / T) \mathrm{cm}^{3}$ molecule ${ }^{-1} \mathrm{~s}^{-1}$ over the temperature range $250-390 \mathrm{~K}$.

$k=1.6 \times 10^{-12} \exp (210 / T) \mathrm{cm}^{3}$ molecule $\mathrm{s}^{-1} \mathrm{~s}^{-1}$ over the temperature range $200-390 \mathrm{~K}$.

\section{Reliability}

$\Delta \log k_{1}=\Delta \log k_{2}= \pm 0.1$ at $298 \mathrm{~K}$.

$\Delta\left(E_{1} / R\right)=\Delta\left(E_{2} / R\right)= \pm 200 \mathrm{~K}$.

\section{Comments on Preferred Values}

The total rate coefficient for the $\mathrm{BrO}+\mathrm{BrO}$ reaction has been studied by a variety of techniques, including discharge flowmass spectrometry and flash photolysis-ultraviolet absorption spectroscopy. The results from the latter technique depend on the value used for the absorption cross section of $\mathrm{BrO}$ at the monitoring wavelength, usually $338.5 \mathrm{~nm}$ (the (7-0) band of the $\mathrm{A} \leftarrow \mathrm{X}$ transition). The absorption cross section of $\mathrm{BrO}$ was remeasured by Gilles et al. (1997) with the values obtained being given by the expression $\sigma(\mathrm{BrO})=\left[3.29-\left(5.58 \times 10^{-3}\right) T\right] \times 10^{-17} \mathrm{~cm}^{2}$ molecule ${ }^{-1}$ at $338.5 \mathrm{~nm}$. At a comparable resolution this expression gives values of $\sigma(\mathrm{BrO}) \sim 10 \%$ larger than those of Wahner et al. (1988) and employed by most of the earlier studies. When this difference is taken into account, the $298 \mathrm{~K}$ rate coefficients from the flash photolysis-absorption spectroscopy studies are in excellent agreement with the discharge flow studies (to within 10\%), except for the study of Turnipseed et al. (1990). The mean $298 \mathrm{~K}$ rate coefficient is $3.2 \times 10^{-12} \mathrm{~cm}^{3}$ molecule $\mathrm{e}^{-1} \mathrm{~s}^{-1}$ independent of pressure.

The branching ratio between the bimolecular channels has been measured directly in the studies cited (Clyne and Watson, 1975; Mauldin et al., 1993; Rowley et al., 1996) and by Turnipseed et al. (1990) and indirectly by Jaffe and Mainquist (1980) from $258 \mathrm{~K}$ to $333 \mathrm{~K}$, Cox et al. (1982) from $278 \mathrm{~K}$ to $348 \mathrm{~K}$, and by Rattigan et al. (1995) at $298 \mathrm{~K}$. All studies are in agreement that $k_{1} / k=0.85 \pm 0.03$ at $298 \mathrm{~K}$ and that the termolecular channel increases in importance with decreasing temperature. Recent ab initio calculations ( $\mathrm{Li}$ and Jeong, 2001) have confirmed the existence of stable $\mathrm{Br}_{2} \mathrm{O}_{2}$ isomers and the endothermicity of channel (3) forming OBrO. 
The temperature dependence is complicated by a pressure dependence of the rate coefficients at low temperatures $(<250 \mathrm{~K})$, as observed by Mauldin et al. (1993) and Harwood et al. (1998). The rate coefficients at $<250 \mathrm{~K}$ increase with pressure, which Harwood et al. (1998) associated with the formation of an unstable $\mathrm{Br}_{2} \mathrm{O}_{2}$ dimer which was observed spectroscopically by both Mauldin et al. (1993) and Harwood et al. (1998). The study of Gilles et al. (1997), which covers the largest temperature range and was conducted at low total pressures, shows a small negative temperature dependence for the overall rate coefficient. The preferred values are based on the above $298 \mathrm{~K}$ rate coefficient of $k=3.2 \times 10^{-12} \mathrm{~cm}^{3}$ molecule $^{-1} \mathrm{~s}^{-1}$ and an $(E / R)=-210 \mathrm{~K}$, resulting in $k=1.6 \times 10^{-12} \exp (210 / T) \mathrm{cm}^{3}$ molecule ${ }^{-1} \mathrm{~s}^{-1}$. The recommended channel-specific rate coefficients are based on the values of $k_{1} / k=0.85$ at $298 \mathrm{~K}$ and $k_{1} / k=0.68$ at $220 \mathrm{~K}$.

\section{References}

Clyne, M. A. A. and Watson, R. T.: J. Chem. Soc. Faraday Trans., 1, 71, 336, 1975.

Cox, R. A., Sheppard, D. W., and Stevens, M. P.: J. Photochem., 19, 189, 1982.

Gilles, M. K., Turnipseed, A. A., Burkholder, J. B., Ravishankara, A. R., and Solomon, S.: J. Phys. Chem. A, 101, 5526, 1997.

Harwood, M. H., Rowley, D. M., Cox, R. A., and Jones, R. L.: J. Phys. Chem. A, 102, 1790, 1998.

Jaffe, S. and Mainquist, W. K.: J. Phys. Chem., 84, 3277, 1980.

Lancar, I. T., Laverdet, G., Le Bras, G., and Poulet, G.: Int. J. Chem. Kinet., 23, 37, 1991.

Laszlo, B., Huie, R. E., Kurylo, M. J., and Miziolek, A. W.: J. Geophys. Res., 102, 1523, 1997.

Li, Z. and Jeong, G-R.: Chem. Phys. Lett., 340, 194, 2001.

Mauldin III, R. L., Wahner, A., and Ravishankara, A. R.: J. Phys. Chem., 97, 7585, 1993.

Rattigan, O. V., Cox, R. A., and Jones, R. L.: J. Chem. Soc. Faraday Trans., 91, 4189, 1995.

Rowley, D. M., Harwood, M. H., Freshwater, R. A., and Jones, R. L.: J. Phys. Chem., 100, 3020, 1996.

Sander, S. P. and Watson, R. T.: J. Phys. Chem., 85, 4000, 1981.

Turnipseed, A. A., Birks, J. W., and Calvert, J. G.: J. Phys. Chem., 94, 7477, 1990.

Wahner, A., Ravishankara, A. R., Sander, S. P., and Friedl, R. R.: Chem. Phys. Lett., 152, 507, 1988. 
Appendix 4: $\mathrm{IO}_{\mathrm{x}}$ Reactions

III.A4.80

$$
\mathbf{O}+\mathbf{I}_{2} \rightarrow \mathbf{I O}+\mathbf{I}
$$

$\Delta H^{\circ}=-89 \mathrm{~kJ} \mathrm{~mol}^{-1}$

\section{Rate coefficient data}

\begin{tabular}{|c|c|c|c|}
\hline$k / \mathrm{cm}^{3}$ molecule $^{-1} \mathrm{~s}^{-1}$ & Temp./K & Reference & Technique/Comments \\
\hline $\begin{array}{l}\text { Absolute Rate Coefficients } \\
(1.38 \pm 0.44) \times 10^{-10}\end{array}$ & 298 & Ray and Watson, 1981 & DF-MS (a) \\
\hline$(1.4 \pm 0.4) \times 10^{-10}$ & 298 & Laszo et al., 1995 & PLP-AS (b) \\
\hline$(1.3 \pm 0.15) \times 10^{-10}$ & 295 & Hölscher et al., 1998 & PLP-LIF (c) \\
\hline$(1.2 \pm 0.1) \times 10^{-10}$ & 298 & Tucceri et al., 2005 & PLP-RF (d) \\
\hline
\end{tabular}

\section{Comments}

(a) MS detection of $\mathrm{I}_{2}$ in a large excess of $\mathrm{O}\left({ }^{3} \mathrm{P}\right)$ atoms. The $\mathrm{O}\left({ }^{3} \mathrm{P}\right)$ atom concentrations were determined by titration with $\mathrm{NO}_{2}$. The total pressure was $\sim 2.6$ mbar.

(b) $\mathrm{O}\left({ }^{3} \mathrm{P}\right)$ atoms were produced by pulsed laser photolysis of $\mathrm{N}_{2} \mathrm{O}$ at $193 \mathrm{~nm}$ in the presence of $\mathrm{I}_{2}$, at total pressures of $\sim 260$ mbar of $\mathrm{N}_{2}$. The $\mathrm{I}_{2}$ concentrations used were comparable to those of $\mathrm{O}\left({ }^{3} \mathrm{P}\right)$ atoms. The $\mathrm{I}_{2}$ and IO radical concentrations were monitored simultaneously by absorption spectroscopy at $530 \mathrm{~nm}$ and at $340 \mathrm{~nm}$ to $435 \mathrm{~nm}$, respectively, and values of $k$ were derived by modeling the $\mathrm{I}_{2}$ and IO radical time-concentration profiles.

(c) $\mathrm{O}\left({ }^{3} \mathrm{P}\right)$ atoms were produced by pulsed laser photolysis of $\mathrm{N}_{2} \mathrm{O}$ at $193 \mathrm{~nm}$ in the presence of an excess of $\mathrm{I}_{2}$, at total pressures of 40 mbar of $\mathrm{N}_{3}$. IO radical concentrations were monitored by LIF at $445.05 \mathrm{~nm}$.

(d) $\mathrm{O}\left({ }^{3} \mathrm{P}\right)$ atoms were produced by pulsed laser photolysis of $\mathrm{NO}_{2}$ at $351 \mathrm{~nm}$ in the presence of an excess of $\mathrm{I}_{2}$, which was monitored in situ at $500 \mathrm{~nm}$. Total pressures of 80 or $266 \mathrm{mbar}$ of $\mathrm{He}$ or $80 \mathrm{mbar} \mathrm{N}_{2}$ were used. The I atom product was monitored by RF.

\section{Preferred Values}

$k=1.25 \times 10^{-10} \mathrm{~cm}^{3}$ molecule ${ }^{-1} \mathrm{~s}^{-1}$ at $298 \mathrm{~K}$.

\section{Reliability}

$\Delta \log k= \pm 0.1$ at $298 \mathrm{~K}$.

\section{Comments on Preferred Values}

The recommended rate coefficient is based on the data of Hölscher et al. (1998) and Tucceri et al. (2005), both of whom employed sufficiently sensitive detection schemes that the IO self reaction was unimportant, and a simple exponential behaviour of IO and I was therefore observed. Note that the recommended value is within the large errors limits presented by Ray and Watson (1981) and Laszlo et al. (1995). The rate coefficient is large, approaching the gas kinetic collisional value and suggesting a near zero temperature dependence for $k$. This is in accord with the molecular beam study of the reaction by Parrish and Herschbach (1973). 


\section{References}

Hölscher, D., Fockenberg, C., and Zellner, R.: Ber. Bunsenges. Phys. Chem., 102, 716, 1998.

Laszlo, B., Kurylo, M. J., and Huie, R. E.: J. Phys. Chem., 99, 11 701, 1995.

Parrish, D. D. and Herschbach, D. R.: J. Am. Chem. Soc., 95, 6133, 1973.

Ray, G. W. and Watson, R. T.: J. Phys. Chem., 85, 2955, 1981.

Tucceri, M. E., Dillon, T. J., and Crowley, J. N.: Phys. Chem. Chem. Phys., 7, 1657, 2005. 


\section{III.A4.81}

$$
\mathrm{O}+\mathrm{IO} \rightarrow \mathrm{IO}_{2}+\mathrm{I}
$$

$\Delta H^{\circ}=-258 \mathrm{~kJ} \mathrm{~mol}^{-1}$

\section{Rate coefficient data}

\begin{tabular}{llll}
\hline$k / \mathrm{cm}^{3}$ molecule ${ }^{-1} \mathrm{~s}^{-1}$ & Temp./K & Reference & Technique/Comments \\
\hline Absolute Rate Coefficients & & & \\
$(1.2 \pm 0.5) \times 10^{-10}$ & 298 & Laszo et al., 1995 & PLP-AS (a) \\
$(1.5 \pm 0.7) \times 10^{-10}$ & 298 & Payne et al., 1998 & DF-MS (b) \\
$(1.35 \pm 0.15) \times 10^{-10}$ & 296 & Canosa-Mas et al., 1999 & DF-RF (c) \\
\hline
\end{tabular}

\section{Comments}

(a) $\mathrm{O}\left({ }^{3} \mathrm{P}\right)$ atoms were produced by pulsed laser photolysis of $\mathrm{N}_{2} \mathrm{O}$ at $193 \mathrm{~nm}$ in the presence of $\mathrm{I}_{2}$, at total pressures of $\sim 260$ mbar of $\mathrm{N}_{2}$. The $\mathrm{I}_{2}$ concentrations used were comparable to those of $\mathrm{O}\left({ }^{3} \mathrm{P}\right)$ atoms. The $\mathrm{I}_{2}$ and $\mathrm{IO}$ radical concentrations were monitored simultaneously by absorption spectroscopy at $530 \mathrm{~nm}$ and at $340 \mathrm{~nm}$ to $435 \mathrm{~nm}$, respectively, and values of $k$ were derived by modeling the $\mathrm{I}_{2}$ and $\mathrm{IO}$ radical time-concentration profiles.

(b) IO radical concentrations were monitored by MS in the presence of a large excess of $\mathrm{O}\left({ }^{3} \mathrm{P}\right)$ atoms. The total pressure was $\sim 1.3$ mbar of He.

(c) IO radical concentrations in the presence of a large excess of $\mathrm{O}\left({ }^{3} \mathrm{P}\right)$ atoms were monitored by conversion to I atoms by reaction with excess NO; the I atoms were observed by RF at $170-200 \mathrm{~nm}$. The total pressure was $\sim 2.5 \mathrm{mbar}$ of He.

\section{Preferred Values}

$k=1.4 \times 10^{-10} \mathrm{~cm}^{3}$ molecule $\mathrm{e}^{-1} \mathrm{~s}^{-1}$ at $298 \mathrm{~K}$.

\section{Reliability}

$\Delta \log k= \pm 0.2$ at $298 \mathrm{~K}$.

\section{Comments on Preferred Values}

Prior to the three studies cited in the table (Laszlo et al., 1995; Payne et al., 1998; Canosa-Mas et al., 1999) only estimates of the rate coefficient for this reaction were available. The preferred value is the mean of the rate coefficients obtained by Laszlo et al. (1995), Payne et al. (1998) and Canosa-Mas et al. (1999), which are in good agreement and were obtained using quite different experimental techniques. The value of the rate coefficient is large, approaching the gas kinetic collisional value and suggesting a near zero temperature dependence of $k$.

\section{References}

Canosa-Mas, C. E., Flugge, M. L., Shah, D., Vipond, A., and Wayne, R. P.: J. Atmos. Chem., 34, 153, 1999.

Laszlo, B., Kurylo, M. J., and Huie, R. E.: J. Phys. Chem., 99, 11701, 1995.

Payne, W. A., Thorn Jr., R. P., Nesbitt, F. L., and Stief, L. J.: J. Phys. Chem. A, 102, 6247, 1998. 


\section{III.A4.82}

$$
\mathbf{I}+\mathbf{H O}_{2} \rightarrow \mathbf{H I}+\mathbf{O}_{2}
$$

$\Delta H^{\circ}=-94.9 \mathrm{~kJ} \mathrm{~mol}^{-1}$

\section{Rate coefficient data}

\begin{tabular}{lllc}
\hline$k / \mathrm{cm}^{3}$ molecule ${ }^{-1} \mathrm{~s}^{-1}$ & Temp./K & Reference & Technique/Comments \\
\hline Absolute Rate Coefficients & & & \\
$1.47 \times 10^{-11} \exp [-(1090 \pm 130) / T]$ & $283-353$ & Jenkin et al., 1990 & PF-EPR, \\
$(3.8 \pm 1.0) \times 10^{-13}$ & 298 & & MMS-UVA (a) \\
\hline
\end{tabular}

\section{Comments}

(a) Two experimental methods were used. The first technique involved a discharge flow system with EPR detection of I atoms (directly) and of $\mathrm{HO}_{2}$ radicals after conversion to $\mathrm{HO}$ radicals (by reaction with $\mathrm{NO}$ ). The first-order decays of $\mathrm{HO}_{2}$ radicals in excess I atoms were measured, resulting in a rate coefficient of $k=(3.1 \pm 1.2) \times 10^{-13} \mathrm{~cm}^{3} \mathrm{molecule}^{-1} \mathrm{~s}^{-1}$ at $298 \mathrm{~K}$. The second technique, which provided the temperature dependence, employed the molecular modulation method with UV absorption detection of $\mathrm{HO}_{2}$ radicals, and with the I atom concentration being determined from the observed modulation of the $\mathrm{I}_{2}$ absorption at $500 \mathrm{~nm}$. Excess I atoms were employed, and the $\mathrm{HO}_{2}$ radical self-reaction competed with the $\mathrm{I}+\mathrm{HO}_{2}$ reaction. The best analysis gave $k=(4.17 \pm 0.4) \times 10^{-13} \mathrm{~cm}^{3}$ molecule ${ }^{-1} \mathrm{~s}^{-1}$ at $298 \mathrm{~K}$. The Arrhenius expression was obtained from the mean of the discharge flow and molecular modulation determinations at $298 \mathrm{~K}$ and the $E / R$ obtained from a least-squares fit to the temperature-dependent data.

\section{Preferred Values}

$k=3.8 \times 10^{-13} \mathrm{~cm}^{3}$ molecule $\mathrm{e}^{-1} \mathrm{~s}^{-1}$ at $298 \mathrm{~K}$.

$k=1.5 \times 10^{-11} \exp (-1090 / T) \mathrm{cm}^{3}$ molecule ${ }^{-1} \mathrm{~s}^{-1}$ over the temperature range $280-360 \mathrm{~K}$.

\section{Reliability}

$\Delta \log k= \pm 0.3$ at $298 \mathrm{~K}$.

$\Delta(E / R)= \pm 500 \mathrm{~K}$.

\section{Comments on Preferred Values}

The preferred values are based on the two experimental studies reported by Jenkin et al. (1990) which are the only reported measurements for this reaction. The values of the rate coefficient at $298 \mathrm{~K}$ from the two studies agree quite well, although both studies exhibited significant experimental error. The Arrhenius expression suggested by Jenkin et al. (1990) is accepted for the temperature dependence.

\section{References}

Jenkin, M. E., Cox, R. A., Mellouki, A., Le Bras, G., and Poulet, G.: J. Phys. Chem., 94, 2927, 1990. 
III.A4.83

$$
\mathbf{I}+\mathbf{O}_{3} \rightarrow \mathbf{I O}+\mathbf{O}_{2}
$$

$\Delta H^{\circ}=-134 \mathrm{~kJ} \mathrm{~mol}^{-1}$

\section{Rate coefficient data}

\begin{tabular}{lllc}
\hline$k / \mathrm{cm}^{3}$ molecule $\mathrm{s}^{-1}$ & Temp./K & Reference & Technique/Comments \\
\hline Absolute Rate Coefficients & & & \\
$(9.6 \pm 3.0) \times 10^{-13}$ & 303 & Jenkin and Cox, 1985 & MM-AS (a) \\
$(9.5 \pm 1.5) \times 10^{-13}$ & 298 & Sander, 1986 & FP-AS (b) \\
$2.3 \times 10^{-11} \exp [-(886 \pm 15) / T]$ & $231-337$ & Buben et al., 1990 & DF-RF (c) \\
$(1.2 \pm 0.1) \times 10^{-12}$ & 298 & & \\
$2.3 \times 10^{-11} \exp [-(860 \pm 100) / T]$ & $240-370$ & Turnipseed et al., 1995 & PLP-LIF (d) \\
$(1.38 \pm 0.08) \times 10^{-12}$ & 298 & & \\
$1.6 \times 10^{-11} \exp [-(750 \pm 194) / T]$ & $243-295$ & Hölscher et al., 1998 & PLP-LIF (d) \\
$(1.2 \pm 0.1) \times 10^{-12}$ & 295 & & \\
$(1.28 \pm 0.06) \times 10^{-12}$ & 298 & Tucceri et al., 2005 & PLP-RF (c) \\
\hline
\end{tabular}

\section{Comments}

(a) Modulated photolysis of $\mathrm{I}_{2}-\mathrm{O}_{3}$ mixtures at $570 \mathrm{~nm}$ and a total pressure of 34 mbar. IO radicals were monitored by absorption at $426.9 \mathrm{~nm}$.

(b) Detection of IO in absorption at $427.2 \mathrm{~nm}$. A non-linear dependence of the pseudo first-order decay constant on the $\mathrm{O}_{3}$ concentration was observed.

(c) Direct detection of I atom reactant in excess $\mathrm{O}_{3}$.

(d) Detection of IO product by LIF.

\section{Preferred Values}

$k=1.3 \times 10^{-12} \mathrm{~cm}^{3}$ molecule $\mathrm{e}^{-1} \mathrm{~s}^{-1}$ at $298 \mathrm{~K}$.

$k=2.1 \times 10^{-11} \exp (-830 / T) \mathrm{cm}^{3}$ molecule ${ }^{-1} \mathrm{~s}^{-1}$ over the temperature range $230-370 \mathrm{~K}$.

\section{Reliability}

$\Delta \log k= \pm 0.05$ at $298 \mathrm{~K}$.

$\Delta(E / R)= \pm 150 \mathrm{~K}$.

Comments on Preferred Values

The most recent studies of this reaction (Buben et al., 1990,; Turnipseed et al., 1995; Hölscher et al., 1998; Tucceri et al., 2005) are in excellent agreement and indicate somewhat higher rate coefficients than those obtained previously. A weighted average value of $(1.28 \pm 0.08) \times 10^{-12} \mathrm{~cm}^{3}$ molecule $\mathrm{e}^{-1} \mathrm{~s}^{-1}$ is derived from these four studies, and provides the basis of the recommendation.

The preferred Arrhenius expression for $k$ is obtained by combining the mean of the values of $E / R$ from the studies of Buben et al. (1990), Turnipseed et al. (1995) and Hölscher et al. (1998) with a pre-exponential factor adjusted to give the preferred value of $k$ at $298 \mathrm{~K}$. 


\section{References}

Buben, S. N., Larin, I. K., Messineva, N. A., and Trofimova, E. M.: Khim. Fiz., 9, 116, 1990.

Hölscher, D., Fockenberg, C., and Zellner, R.: Ber. Bunsenges. Phys. Chem., 102, 716, 1998.

Jenkin, M. E. and Cox, R. A.: J. Phys. Chem., 89, 192, 1985.

Sander, S. P.: J. Phys. Chem., 90, 2194, 1986.

Tucceri, M. E., Dillon, T. J., and Crowley, J. N.: Phys. Chem. Chem. Phys, 7, 1657, 2005.

Turnipseed, A. A., Gilles, M. K., Burkholder, J. B., and Ravishankara, A. R.: Chem. Phys. Lett., $242,427,1995$. 


\section{III.A4.84}

$$
\mathrm{I}+\mathrm{NO}+\mathrm{M} \rightarrow \mathrm{INO}+\mathrm{M}
$$

$\Delta H^{\circ}=-75.7 \mathrm{~kJ} \mathrm{~mol}^{-1}$

\section{Low-pressure rate coefficients}

\section{Rate coefficient data}

\begin{tabular}{llll}
\hline$k_{0} / \mathrm{cm}^{3}$ molecule ${ }^{-1} \mathrm{~s}^{-1}$ & Temp./K & Reference & Technique/Comments \\
\hline Absolute Rate Coefficients & & & \\
$(6.0 \pm 2.5) \times 10^{-33}(T / 300)^{-1.0}[\mathrm{He}]$ & $320-450$ & van den Bergh and Troe, 1976 & PLP-UVA (a) \\
$(1.6 \pm 0.5) \times 10^{-32}\left[\mathrm{~N}_{2}\right]$ & 330 & van den Bergh et al., 1977 & PLP-UVA (b) \\
$(9.5 \pm 3.0) \times 10^{-33}[\mathrm{Ar}]$ & 330 & & \\
$(1.05 \pm 0.30) \times 10^{-32}[\mathrm{Ar}]$ & 298 & & \\
$(1.03 \pm 0.06) \times 10^{-32}(T / 300)^{-1.1}[\mathrm{He}]$ & $298-328$ & Basco and Hunt, 1978 & FP (c) \\
\hline
\end{tabular}

\section{Comments}

(a) Photolysis of $\mathrm{I}_{2}$ at $694 \mathrm{~nm}$ in the presence of $\mathrm{NO}$ and He. The pressure of $\mathrm{He}$ was varied between 1 and 200 bar. $\mathrm{I}_{2}$ and INO spectra were observed.

(b) As in comment (a). The rate coefficient for $\mathrm{M}=\mathrm{Ar}$ at $298 \mathrm{~K}$ was calculated from the measured rate coefficient at $330 \mathrm{~K}$ and the temperature dependence reported by van den Bergh and Troe (1976).

(c) Photolysis of $\mathrm{I}_{2}$ in the presence of $\mathrm{NO}$ and Ar.

\section{Preferred Values}

$k_{0}=1.8 \times 10^{-32}(T / 300)^{-1.0}\left[\mathrm{~N}_{2}\right] \mathrm{cm}^{3}$ molecule ${ }^{-1} \mathrm{~s}^{-1}$ over the temperature range 290-450 K.

\section{Reliability}

$\Delta \log k_{0}= \pm 0.1$ at $298 \mathrm{~K}$.

$\Delta n= \pm 0.5 \mathrm{~K}$.

\section{Comments on Preferred Values}

The preferred values are based on the rate coefficients for $\mathrm{M}=\mathrm{Ar}$ determined by van den Bergh et al. (1976) and Basco and Hunt (1978) which agree remarkably well. 


\section{High-pressure rate coefficients}

\section{Rate coefficient data}

\begin{tabular}{lccc}
\hline$k_{\infty} / \mathrm{cm}^{3}$ molecule ${ }^{-1} \mathrm{~s}^{-1}$ & Temp./K & Reference & Technique/Comments \\
\hline $\begin{array}{l}\text { Absolute Rate Coefficients } \\
\geq 1.7 \times 10^{-11}\end{array}$ & 330 & van den Bergh and Troe, 1976 & PLP-UVA (a) \\
\hline
\end{tabular}

\section{Comments}

(a) As for comment (a) for $k_{0}$. Based on a falloff extrapolation with $F_{c}=0.6$.

\section{Preferred Values}

$k_{\infty}=1.7 \times 10^{-11} \mathrm{~cm}^{3}$ molecule ${ }^{-1} \mathrm{~s}^{-1}$ over the temperature range $300-400 \mathrm{~K}$.

Reliability

$\Delta \log k_{\infty}= \pm 0.5$ over the temperature range $300-400 \mathrm{~K}$.

$\Delta n= \pm 1$.

\section{Comments on Preferred Values}

The preferred values are based on the only measurement by van den Bergh and Troe (1976), extrapolated by using a value of $F_{c}=0.6$.

\section{References}

Basco, N. and Hunt, J. E.: Int. J. Chem. Kinet., 10, 733, 1978.

van den Bergh, H. and Troe, J.: J. Chem. Phys., 64, 736, 1976.

van den Bergh, H., Benoit-Guyot, N., and Troe, J.: Int. J. Chem. Kinet., 9, 223, 1977. 
III.A4.85

$$
\mathrm{I}+\mathrm{NO}_{2}+\mathrm{M} \rightarrow \mathrm{INO}_{2}+\mathrm{M}
$$

$\Delta H^{\circ}=-79.8 \mathrm{~kJ} \mathrm{~mol}^{-1}$

\section{Low-pressure rate coefficients}

\section{Rate coefficient data}

\begin{tabular}{lllc}
\hline$k_{0} / \mathrm{cm}^{3}$ molecule ${ }^{-1} \mathrm{~s}^{-1}$ & Temp./K & Reference & Technique/Comments \\
\hline Absolute Rate Coefficients & & & \\
$1.5 \times 10^{-31}(\mathrm{~T} / 300)^{-1.0}[\mathrm{He}]$ & $320-450$ & van den Bergh and Troe, 1976 & PLP-UVA (a) \\
$1.62 \times 10^{-31}[\mathrm{He}]$ & 330 & van den Bergh et al., 1977 & PLP-UVA (b) \\
$2.6 \times 10^{-31}\left[\mathrm{~N}_{2}\right]$ & 330 & & \\
$(9.5 \pm 3.5) \times 10^{-32}[\mathrm{He}]$ & 298 & Mellouki et al., 1989 & DF-EPR (c) \\
$3.1 \times 10^{-31}\left[\mathrm{~N}_{2}\right]$ & 298 & Buben et al., 1990 & FP-RF (d) \\
\hline
\end{tabular}

\section{Comments}

(a) Derived from the $\mathrm{NO}_{2}$ catalyzed recombination of I atoms, with I atoms being produced by photolysis of $\mathrm{I}_{2}$ at $694 \mathrm{~nm}$. The falloff curve was measured from 1-200 bar of He, and only a short extrapolation to $k_{0}$ was required.

(b) As in comment (a). The efficiencies of 26 bath gases were studied.

(c) Measurements performed over the pressure range 0.8 to 2.9 mbar.

(d) I atoms generated by photolysis of $\mathrm{CH}_{3} \mathrm{I}$ in a flow system with $\mathrm{NO}_{2}-\mathrm{N}_{2}$ mixtures. The bath gases $\mathrm{N}_{2}, \mathrm{O}_{2}, \mathrm{Ar}$ and He were studied at total pressures between 0.7 and 13 mbar.

\section{Preferred Values}

$k_{0}=3.0 \times 10^{-31}(T / 300)^{-1.0}\left[\mathrm{~N}_{2}\right] \mathrm{cm}^{3}$ molecule ${ }^{-1} \mathrm{~s}^{-1}$ over the temperature range $290-450 \mathrm{~K}$.

\section{Reliability}

$\Delta \log k_{0}= \pm 0.2$ at $298 \mathrm{~K}$.

$\Delta n= \pm 1 \mathrm{~K}$.

\section{Comments on Preferred Values}

The preferred values are based on the results of the studies of van den Bergh and Troe (1976), van den Bergh et al. (1977) and Buben et al. (1990). The data of Mellouki et al. (1989) for $\mathrm{M}=\mathrm{He}$ are also consistent with these data. Falloff extrapolations are made with a fitted value of $F_{C}=0.63$ from van den Bergh and Troe (1976). 


\section{High-pressure rate coefficients}

\section{Rate coefficient data}

\begin{tabular}{lccc}
\hline$k_{\infty} / \mathrm{cm}^{3}$ molecule ${ }^{-1} \mathrm{~s}^{-1}$ & Temp./K & Reference & Technique/Comments \\
\hline $\begin{array}{l}\text { Absolute Rate Coefficients } \\
6.6 \times 10^{-11}\end{array}$ & $320-350$ & van den Bergh and Troe, 1976 & PLP-UVA (a) \\
\hline
\end{tabular}

\section{Comments}

(a) See comment (a) for $k_{0}$. Extrapolation of the falloff curve towards the high pressure limit uses a fitted value of $F_{c}=0.63$.

\section{Preferred Values}

$k_{\infty}=6.6 \times 10^{-11} \mathrm{~cm}^{3}$ molecule $\mathrm{e}^{-1} \mathrm{~s}^{-1}$, independent of temperature over the range $290-450 \mathrm{~K}$.

Reliability

$\Delta \log k_{\infty}= \pm 0.3$ over the temperature range $300-400 \mathrm{~K}$.

Comments on Preferred Values

The preferred values are based on the results of the study of van den Bergh and Troe (1976). Falloff curves are represented with $F_{c}=0.63$.

\section{References}

Buben, S. N., Larin, I. K., Messineva, N. A., and Trofimova, E. M.: Kinet. Catal., 31, 854, 1990; original pages 973-977, 1990.

Mellouki, A., Laverdet, G., Jourdain, J. L., and Poulet, G.: Int. J. Chem. Kinet., 21, 1161, 1989.

van den Bergh, H. and Troe, J.: J. Chem. Phys., 64, 736, 1976.

van den Bergh, H., Benoit-Guyot, N., and Troe, J.: Int. J. Chem. Kinet., 9, 223, 1977. 
III.A4.86

$$
\mathrm{I}+\mathrm{NO}_{3} \rightarrow \mathrm{IO}+\mathrm{NO}_{2}
$$

$\Delta H^{\circ}=-31.4 \mathrm{~kJ} \mathrm{~mol}^{-1}$

\section{Rate coefficient data}

\begin{tabular}{lllc}
\hline $\mathrm{k} / \mathrm{cm}^{3}$ molecule ${ }^{-1} \mathrm{~s}^{-1}$ & Temp./K & Reference & Technique/Comments \\
\hline $\begin{array}{l}\text { Absolute Rate Coefficients } \\
(4.5 \pm 1.9) \times 10^{-10}\end{array}$ & 298 & Chambers et al., 1992 & DF-RF (a) \\
\hline
\end{tabular}

\section{Comments}

(a) Discharge flow system with resonance fluorescence detection of I atoms in the presence of excess $\mathrm{NO}_{3}$ radicals. $\mathrm{NO}_{3}$ radicals and $\mathrm{I}$ atoms were produced by the $\mathrm{F}+\mathrm{HNO}_{3}$ and $\mathrm{O}+\mathrm{I}_{2}$ reactions, respectively. $\mathrm{NO}_{3}$ radical concentrations were measured by visible absorption spectroscopy. Corrections of up to $33 \%$ were applied to compensate for diffusion effects.

\section{Preferred Values}

No recommendation.

\section{Comments on Preferred Values}

The only reported measurement of this rate constant was made using the discharge flow technique at room temperature (Chambers et al., 1992). Difficulties were encountered due to wall reactions, and the pseudo first-order plots exhibited pronounced curvature at contact times longer than $3 \mathrm{~ms}$. In their study of $\mathrm{HI}+\mathrm{NO}_{3}$, Lancar et al. (1991) stated that they failed to observe a reaction between I atoms and $\mathrm{NO}_{3}$ radicals, but gave no details or an upper limit. In view of these uncertainties, no recommendation is made for the rate coefficient at this time.

\section{References}

Chambers, R. M., Heard, A. C., and Wayne, R. P.: J. Phys. Chem., 96, 3321, 1992.

Lancar, I. T., Mellouki, A., and Poulet, G.: Chem. Phys. Lett., 177, 554, 1991. 


\section{III.A4.87}

$$
\mathrm{I}_{2}+\mathrm{NO}_{3} \rightarrow \mathrm{I}+\mathrm{IONO}_{2}
$$

$\Delta H^{\circ}=-10 \mathrm{~kJ} \mathrm{~mol}^{-1}$

Rate coefficient data

\begin{tabular}{|c|c|c|c|}
\hline$k / \mathrm{cm}^{3}$ molecule $^{-1} \mathrm{~s}^{-1}$ & Temp./K & Reference & Technique/Comments \\
\hline $\begin{array}{l}\text { Absolute Rate Coefficients } \\
(1.5 \pm 0.5) \times 10^{-12}\end{array}$ & $292-423$ & Chambers et al., 1992 & DF (a) \\
\hline
\end{tabular}

\section{Comments}

(a) Laser induced fluorescence detection of $\mathrm{I}_{2}$ and visible absorption spectroscopic measurement of $\mathrm{NO}_{3} \cdot \mathrm{NO}_{3}$ radicals were produced by the $\mathrm{F}+\mathrm{HNO}_{3}$ reaction. Pseudo first-order conditions were used, with $\mathrm{NO}_{3}$ concentrations in excess over $\mathrm{I}_{2}$. Experiments were performed to substantiate that $\mathrm{I}_{2}$ loss was due to reaction with $\mathrm{NO}_{3}$ radicals, and small corrections were made to compensate for diffusion effects; the overall error takes into account the uncertainties in the $\mathrm{NO}_{3}$ radical concentrations $( \pm 26 \%)$.

\section{Preferred Values}

$k=1.5 \times 10^{-12} \mathrm{~cm}^{3}$ molecule ${ }^{-1} \mathrm{~s}^{-1}$ at $298 \mathrm{~K}$.

\section{Reliability}

$\Delta \log k= \pm 0.5$ at $298 \mathrm{~K}$.

\section{Comments on Preferred Values}

There is only one reported measurement of this rate constant (Chambers et al., 1992) and the products of the reaction were not determined. Chambers et al. (1992) argue that product channels giving $\mathrm{I}+\mathrm{IO}+\mathrm{NO}_{2}, \mathrm{I}+\mathrm{O}_{2}+\mathrm{INO}$ or $\mathrm{IO}+\mathrm{INO}_{2}$ are all endothermic and propose formation of $\mathrm{I}+\mathrm{IONO}_{2}$.

Several values of the bond dissociation energy, $\mathrm{D}_{0}\left(\mathrm{IO}-\mathrm{NO}_{2}\right)$ have been reported: Rayez and Destriau (1993) calculated $132 \mathrm{kJmol}^{-1}$, somewhat higher than the value reported by Allan and Plane (2002) of $95 \mathrm{kJmol}^{-1}$. Recent calculations of Papayannis and Kosmas $(2004,2005)$ return values of close to $130 \mathrm{kJmol}^{-1}$, whereas an analysis of rate data for IO $+\mathrm{NO}_{2}$ has led to a best value of $\approx 150 \mathrm{kJmol}^{-1}$ (Golden, 2006). Based on formation enthalpies (IUPAC, 2006) of IO (116 kJmol $\left.{ }^{-1}\right), \mathrm{NO}_{2}$ $\left(33 \mathrm{kJmol}^{-1}\right), \mathrm{I}_{2}\left(62 \mathrm{kJmol}^{-1}\right)$ and I $\left(107 \mathrm{kJmol}^{-1}\right)$ the title reaction becomes exothermic for values of $\mathrm{D}_{0}\left(\mathrm{IO}-\mathrm{NO}_{2}\right)$ which are greater than $\approx 120 \mathrm{kJmol}^{-1}$ as most of the calculations above indicate is the case. The value for the reaction enthalpy quoted above is estimated using $\mathrm{D}_{0}\left(\mathrm{IO}-\mathrm{NO}_{2}\right)=130 \mathrm{kJmol}^{-1}$ yielding an enthalpy of formation of $\mathrm{IONO}_{2}$ of $29 \mathrm{kJmol}^{-1}$. The error limits for $k$ have been expanded to take into account that only one data set is available, and products were not observed.

\section{References}

Allan, B. J. and Plane, J. M. C.: J. Phys. Chem. A., 106, 8634, 2002.

Chambers, R. M., Heard, A. C., and Wayne, R. P.: J. Phys. Chem., 96, 3321, 1992.

Golden, D. M.: J. Phys. Chem.A 110, 2940, 2006.

IUPAC: http://www.iupac-kinetic.ch.cam.ac.uk/. 2006.

Papayannis, D. and Kosmas, A.: Chem. Phys. Lett. 398, 75, 2004.

Papayannis, D. and Kosmas, A.: Chem. Phys. 315, 251, 2005.

Rayez, M. T. and Destriau, M.: Chem. Phys. Lett., 206, 278, 1993. 
III.A4.88

$$
\mathrm{HO}+\mathrm{HI} \rightarrow \mathrm{H}_{2} \mathrm{O}+\mathrm{I}
$$

$\Delta H^{\circ}=-198.8 \mathrm{~kJ} \mathrm{~mol}^{-1}$

\section{Rate coefficient data}

\begin{tabular}{llll}
\hline$k / \mathrm{cm}^{3}$ molecule & & Technique/Comments \\
\hline Absolute Rate Coefficients & Temp./K & Reference & \\
$(1.3 \pm 0.5) \times 10^{-11}$ & & & DF-EPR \\
$(2.7 \pm 0.2) \times 10^{-11}$ & 295 & Takacs and Glass, 1973 & PLP-RF \\
$(3.3 \pm 0.2) \times 10^{-11}$ & 298 & Mac Leod et al., 1990 & DF-EPR \\
$\left(7.0_{-0.4}^{+1.9}\right) \times 10^{-11}(T / 298)^{-(1.5 \pm 0.5)}$ & 298 & Lancar et al., 1991 & PLP-RF \\
$\left(6.5_{-0.4}^{+2}\right) \times 10^{-11}$ & $246-353$ & Campuzano-Jost and Crowley, 1999 & \\
\hline
\end{tabular}

\section{Preferred Values}

$k=7.0 \times 10^{-11} \mathrm{~cm}^{3}$ molecule $\mathrm{e}^{-1} \mathrm{~s}^{-1}$ at $298 \mathrm{~K}$.

$k=1.6 \times 10^{-11} \exp (440 / T) \mathrm{cm}^{3}$ molecule $\mathrm{e}^{-1} \mathrm{~s}^{-1}$ over the temperature range $240-360 \mathrm{~K}$.

\section{Reliability}

$\Delta \log k= \pm 0.3$ at $298 \mathrm{~K}$.

$\Delta(E / R)= \pm 400 \mathrm{~K}$.

\section{Comments on Preferred Values}

The preferred values are based on the most recent and extensive study of Campuzano-Jost and Crowley (1999), in which, although the $\mathrm{HI}$ concentrations in the reaction cell were not monitored directly during the experiments, care was taken to remove potential impurities in the $\mathrm{HI}$ and a number of $\mathrm{HO}$ radical precursors were investigated before choosing $\mathrm{H}_{2} \mathrm{O}_{2}$ photolysis at $248 \mathrm{~nm}$ as the optimum. Additionally, two analyses using ion chromatography showed that the HI concentrations in the reaction cell were within $\sim 20 \%$ to $25 \%$ of those expected (Campuzano-Jost and Crowley, 1999). The lower room temperature rate coefficients obtained in the studies of Mac Leod et al. (1990) and Lancar et al. (1991), which are more than a factor of two higher than the earlier results of Takacs and Glass (1973), may have suffered from unrecognized losses of HI due to reactions with the HO radical precursors used and/or (in the study of Lancar et al., 1991) from generation of vibrationally-excited HO radicals (Campuzano-Jost and Crowley, 1999).

\section{References}

Campuzano-Jost, P. and Crowley, J. N.: J. Phys. Chem. A, 103, 2712, 1999.

Lancar, I. T., Mellouko, A., and Poulet, G.: Chem. Phys. Lett., 177, 554, 1991.

Mac Leod, H., Balestra, C., Jourdain, J. L., Laverdet, G., and Le Bras, G.: Int. J. Chem. Kinet., 22, 1167, 1990.

Takacs, G. A. and Glass, G. P.: J. Phys. Chem., 77, 1948, 1973. 


\section{III.A3.89}

$$
\mathrm{HO}+\mathrm{I}_{2} \rightarrow \mathrm{HOI}+\mathrm{I}
$$

$\Delta H^{\circ}=-62.5 \mathrm{~kJ} \mathrm{~mol}^{-1}$

\section{Rate coefficient data}

\begin{tabular}{lllc}
\hline$k / \mathrm{cm}^{3}$ molecule & Temp./K & Reference & Technique/Comments \\
\hline $\begin{array}{l}\text { Absolute Rate Coefficients } \\
\left(1.6_{-0.8}^{+1.6}\right) \times 10^{-10}\end{array}$ & 298 & Loewenstein and Anderson, 1985 & DF-RF \\
$(2.1 \pm 0.6) \times 10^{-10}$ & $240-348$ & Gilles et al., 1999 & PLP-LIF (a) \\
$\begin{array}{l}\text { Relative Rate Coefficients } \\
(2.3 \pm 0.3) \times 10^{-10}\end{array}$ & 294 & Jenkin et al., 1984 & \\
\hline
\end{tabular}

\section{Comments}

(a) From measurements of the rate coefficients at $240 \mathrm{~K}, 293-295 \mathrm{~K}$ and $348 \mathrm{~K}$, a least-squares analysis led to $k=1.97 \times 10^{-10}$ $\exp [(21 \pm 318) / T] \mathrm{cm}^{3}$ molecule ${ }^{-1} \mathrm{~s}^{-1}$. The temperature independent expression cited in the table is preferred (Gilles et al., 1999)

(b) Steady-state photolysis of $\mathrm{HONO}-\mathrm{I}_{2}$-ethene-air ( or $\mathrm{N}_{2}$ ) mixtures at 1 bar total pressure. A rate coefficient ratio $k\left(\mathrm{HO}+\mathrm{I}_{2}\right) / k(\mathrm{HO}+$ ethene $)=26.5 \pm 3.5$ was obtained from the rate of disappearance of ethene as a function of the $\mathrm{I}_{2}$ concentration. This rate coefficient ratio is placed on an absolute basis by use of a rate coefficient of $k(\mathrm{HO}+$ ethene $)=8.69 \times 10^{-12} \mathrm{~cm}^{3}$ molecule ${ }^{-1} \mathrm{~s}^{-1}$ at $294 \mathrm{~K}$ and 1 bar of air (Atkinson, 1997).

\section{Preferred Values}

$k=2.1 \times 10^{-10} \mathrm{~cm}^{3}$ molecule $\mathrm{e}^{-1} \mathrm{~s}^{-1}$, independent of temperature over the range $240-350 \mathrm{~K}$.

\section{Reliability}

$\Delta \log k= \pm 0.15$ at $298 \mathrm{~K}$.

$\Delta(E / R)= \pm 300 \mathrm{~K}$.

\section{Comments on Preferred Values}

The reported room temperature rate coefficients of Loewenstein and Anderson (1985), Jenkin et al. (1984) and Gilles et al. (1999) agree well, noting the large quoted error limits associated with the Loewenstein and Anderson (1985) data. The preferred values are based on the most recent and extensive study of Gilles et al. (1999). Loewenstein and Anderson (1985) determined that the exclusive products are HOI and I.

\section{References}

Atkinson, R.: J. Phys. Chem. Ref. Data, 26, 215, 1997.

Gilles, M. K., Burkholder, J. B., and Ravishankara, A. R.: Int. J. Chem. Kinet., 31, 417, 1999.

Jenkin, M. E., Clemitshaw, K. C., and Cox, R. A.: J. Chem. Soc. Faraday Trans., 2, 80, 1633, 1984.

Loewenstein, L. M. and Anderson, J. G.: J. Phys. Chem., 89, 5371, 1985. 
III.A4.90

$$
\mathrm{NO}_{3}+\mathrm{HI} \rightarrow \mathrm{HNO}_{3}+\mathrm{I}
$$

$\Delta H^{\circ}=-128.5 \mathrm{~kJ} \mathrm{~mol}^{-1}$

\section{Rate coefficient data}

\begin{tabular}{lllc}
\hline$k / \mathrm{cm}^{3}$ molecule $\mathrm{s}^{-1}$ & Temp./K & Reference & Technique/Comments \\
\hline Absolute Rate Coefficients & & & \\
$1.3 \times 10^{-12} \exp [-(1830 \pm 300) / T]$ & $298-373$ & Lancar et al., 1991 & DF-EPR/MS (a) \\
$(2.5 \pm 0.8) \times 10^{-15}$ & 298 & & \\
\hline
\end{tabular}

\section{Comments}

(a) $\mathrm{NO}_{3}$ radicals were generated by the reaction of $\mathrm{F}$ atoms with $\mathrm{HNO}_{3}$. The rate coefficient was determined by measuring the decay rate of $\mathrm{NO}_{3}$ radicals (by MS, correcting for the contribution of $\mathrm{HNO}_{3}$ to the $\mathrm{m} / \mathrm{z}=62$ ion signal) or by measuring the formation rate of I atoms (by EPR).

\section{Preferred Values}

No recommendation.

\section{Comments on Preferred Values}

Although the rate coefficients measured in the only study (Lancar et al., 1991) of this reaction from the decay of $\mathrm{NO}_{3}$ using MS and I atom production using EPR spectrometry were in agreement (Lancar et al., 1991), there is a serious potential for secondary chemistry occurring in the system leading to an overestimation of the rate coefficient for the elementary process. Lancar et al. (1991) reported that the reaction of $\mathrm{I}+\mathrm{NO}_{3} \rightarrow \mathrm{IO}+\mathrm{NO}_{2}$ does not occur, while Chambers et al. (1992) observed that the $\mathrm{I}+\mathrm{NO}_{3}$ reaction is rapid, with a measured rate coefficient of $k\left(\mathrm{I}+\mathrm{NO}_{3}\right)=4.5 \times 10^{-10} \mathrm{~cm}^{3}$ molecule $\mathrm{e}^{-1} \mathrm{~s}^{-1}$ at $298 \mathrm{~K}$, and that $\mathrm{I}$ atoms are regenerated from subsequent reactions of IO radicals. Until this uncertainty is resolved, no recommendation can be made.

\section{References}

Chambers, R. M., Heard, A. C., and Wayne, R. P.: J. Phys. Chem., 96, 3321, 1992.

Lancar, I. T., Mellouki, A., and Poulet, G.: Chem. Phys. Lett., 177, 554, 1991. 


\section{III.A4.91}

$$
\mathrm{IO}+\mathrm{HO}_{2} \rightarrow \mathrm{HOI}+\mathrm{O}_{2}
$$

$\Delta H^{\circ}=-200 \mathrm{~kJ} \mathrm{~mol}^{-1}$

\section{Rate coefficient data}

\begin{tabular}{lllc}
\hline$k / \mathrm{cm}^{3}$ molecule ${ }^{-1} \mathrm{~s}^{-1}$ & Temp./K & Reference & Technique/Comments \\
\hline Absolute Rate Coefficients & & & \\
$(6.4 \pm 0.7) \times 10^{-11}$ & 298 & Jenkin et al., 1991 & MM (a) \\
$(1.03 \pm 0.13) \times 10^{-10}$ & 298 & Maguin et al., 1992 & DF-MS (b) \\
$9.3 \times 10^{-12} \exp [(680 \pm 110) / T]$ & $274-373$ & Cronkhite et al., 1999 & FP-UVA/IR (c) \\
$(9.7 \pm 2.9) \times 10^{-11}$ & 298 & & \\
$(7.1 \pm 1.6) \times 10^{-11}$ & 296 & Canosa-Mas et al., 1999 & DF-RF (d) \\
$2.2 \times 10^{-11} \exp [(400 \pm 80) / T]$ & $273-353$ & Knight and Crowley, 2001 & DF-MS (e) \\
$(8.9 \pm 0.9) \times 10^{-11}$ & 298 & & $(\mathrm{f})$ \\
$(8.00 \pm 0.15) \times 10^{-11}$ & 298 & & $(\mathrm{~g})$ \\
\hline
\end{tabular}

\section{Comments}

(a) Molecular modulation technique with UV absorption detection of $\mathrm{HO}_{2}$ radicals at $220 \mathrm{~nm}$ and visible absorption detection of IO radicals at $427 \mathrm{~nm}$. The radicals were produced by photolysis of $\mathrm{O}_{3}-\mathrm{CH}_{3} \mathrm{OH}-\mathrm{I}_{2}-\mathrm{O}_{2}$ mixtures at $254 \mathrm{~nm}$ with $\mathrm{HO}_{2}$ in excess over IO. The rate coefficient, $k$, was derived from a non-linear least-squares analysis of absorption wave-forms. The error limits do not include possible systematic errors.

(b) Discharge flow system with MS detection of $\mathrm{HO}_{2}$ and IO radicals and $\mathrm{HOI}$. IO and $\mathrm{HO}_{2}$ radicals were produced by the $\mathrm{O}\left({ }^{3} \mathrm{P}\right)+\mathrm{I}_{2}$ and $\mathrm{Cl}+\mathrm{CH}_{3} \mathrm{OH}+\mathrm{O}_{2}$, reactions, respectively. Pseudo first-order decays of IO radicals were measured in the presence of excess $\mathrm{HO}_{2}$. The cited value of $k$ is the average of 25 experiments. HOI was shown to be a major product. The uniqueness of the $\mathrm{HOI}+\mathrm{O}_{2}$ forming channel could not be established, although no evidence was found for $\mathrm{O}_{3}$ formation by the alternative $\mathrm{HI}+\mathrm{O}_{3}$ channel.

(c) Pulsed laser photolysis of $\mathrm{Cl}_{2}-\mathrm{CH}_{3} \mathrm{OH}-\mathrm{O}_{2}-\mathrm{I}_{2}-\mathrm{NO}_{2}-\mathrm{SF}_{6}-\mathrm{N}_{2}$ mixtures at $308 \mathrm{~nm}$ with simultaneous time-resolved detection of $\mathrm{HO}_{2}$ radicals (by infrared TDLS) and IO radicals (by visible absorption spectroscopy). $\mathrm{HO}_{2}$ radicals were generated by the reaction of $\mathrm{Cl}$ atoms (from photolysis of $\mathrm{Cl}_{2}$ ) with $\mathrm{CH}_{3} \mathrm{OH}$ in the presence of $\mathrm{O}_{2}$, and IO radicals were generated by the reaction of $\mathrm{O}\left({ }^{3} \mathrm{P}\right.$ ) atoms (from photolysis of $\mathrm{NO}_{2}$ ) with $\mathrm{I}_{2}$.

(d) IO generated from $\mathrm{O}\left({ }^{3} \mathrm{P}\right)+\mathrm{CF}_{3} \mathrm{I}$ (following discharge of $\mathrm{O}_{2}$ ). $\mathrm{HO}_{2}$ generated from $\mathrm{Cl}+\mathrm{CH}_{3} \mathrm{OH}$ in the presence of $\mathrm{O}_{2}$. IO and $\mathrm{HO}_{2}$ concentrations were monitored by titration to $\mathrm{I}$ and $\mathrm{HO}$ by the respective reactions with NO. Experiments carried out at $1.7-2$ Torr.

(e) IO generated from $\mathrm{O}\left({ }^{3} \mathrm{P}\right)+\mathrm{CF}_{3} \mathrm{I}$ or $\mathrm{O}\left({ }^{3} \mathrm{P}\right)+\mathrm{I}_{2}$ (following discharge of $\left.\mathrm{O}_{2}\right) . \mathrm{HO}_{2}$ generated from $\mathrm{Cl}+\mathrm{CH}_{3} \mathrm{OH}$ in the presence of $\mathrm{O}_{2}$. $\mathrm{IO}$ and $\mathrm{HO}_{2}$ concentrations were monitored directly at their parent peaks. Experiments carried out at 1.3-2.3 mbar.

(f) IO from $\mathrm{O}\left({ }^{3} \mathrm{P}\right)+\mathrm{CF}_{3} \mathrm{I}$.

(g) IO from $\mathrm{O}\left({ }^{3} \mathrm{P}\right)+\mathrm{I}_{2}$.

\section{Preferred Values}

$k=8.4 \times 10^{-11} \mathrm{~cm}^{3}$ molecule ${ }^{-1} \mathrm{~s}^{-1}$ at $298 \mathrm{~K}$.

$k=1.4 \times 10^{-11} \exp (540 / T) \mathrm{cm}^{3}$ molecule $\mathrm{e}^{-1} \mathrm{~s}^{-1}$ over the temperature range $270-380 \mathrm{~K}$. 


\section{Reliability}

$\Delta \log k= \pm 0.2$ at $298 \mathrm{~K}$.

$\Delta(E / R)= \pm 300 \mathrm{~K}$.

\section{Comments on Preferred Values}

The preferred value at $298 \mathrm{~K}$ is the average of the reported room temperature data (Jenkin et al., 1991; Maguin et al., 1992; Cronkhite et al., 1999; Canosa-Mas et al., 1999; Knight and Crowley, 2001). The preferred Arrhenius expression is based on the $E / R$ values from the temperature dependence studies of Cronkhite et al. (1999) and Knight and Crowley (2001), combined with a pre-exponential factor adjusted to give the preferred value of $k$ at $298 \mathrm{~K}$.

The studies of Maguin et al. (1992) and Knight and Crowley (2001) provide strong evidence that the formation of HOI and $\mathrm{O}_{2}$ is the dominant pathway. On the basis of current thermochemical data for the $\mathrm{IO}$ radical, the channel forming $\mathrm{HI}+\mathrm{O}_{3}$ is endothermic by $\sim 40 \mathrm{~kJ} \mathrm{~mol}^{-1}$, and a limit of $\leq 10 \%$ has been reported for this channel (Knight and Crowley, 2001), based on no detectable formation of $\mathrm{O}_{3}$. As pointed out by Knight and Crowley (2001), a channel forming $\mathrm{HO}+\mathrm{OIO}$ is exothermic by $12 \mathrm{~kJ} \mathrm{~mol}^{-1}$, but no firm evidence for this channel has been reported.

\section{References}

Canosa-Mas, C. E., Flugge, M. L., Shah, D., Vipond, A., and Wayne, R. P.: J. Atmos. Chem., 34, 153, 1999.

Cronkhite, J. M., Stickel, R. E., Nicovich, J. M., and Wine, P. H.: J. Phys. Chem. A, 103, 3228, 1999.

Jenkin, M. E., Cox, R. A., and Hayman, G. D.: Chem. Phys. Lett., 177, 272, 1991.

Knight, G. P. and Crowley, J. N.: Phys. Chem. Chem. Phys., 3, 393, 2001.

Maguin, F., Laverdet, G., Le Bras, G., and Poulet, G.: J. Phys. Chem., 96, 1775, 1992. 
III.A4.92

$$
\begin{aligned}
\mathrm{IO}+\mathrm{O}_{3} & \rightarrow \mathrm{I}+2 \mathrm{O}_{2} \\
& \rightarrow \mathrm{OIO}+\mathrm{O}_{2}
\end{aligned}
$$

$\Delta H^{\circ}=-151 \mathrm{~kJ} \mathrm{~mol}^{-1}$

\begin{tabular}{|c|c|c|c|}
\hline$k / \mathrm{cm}^{3}$ molecule $^{-1} \mathrm{~s}^{-1}$ & Temp./K & Reference & Technique/Comments \\
\hline \multicolumn{4}{|c|}{ Absolute Rate Coefficients } \\
\hline$k_{1}<1.2 \times 10^{-15}$ & 292 & Larin et al., 1999 & F-RF (a) \\
\hline$k_{2}<2.3 \times 10^{-16}$ & 323 & & \\
\hline
\end{tabular}

Rate coefficient data $\left(k=k_{1}+k_{2}\right)$

\section{Comments}

(a) I atoms were generated by photolysis of $\mathrm{CF}_{3} \mathrm{I}$ at $253.7 \mathrm{~nm}$ in a fast flow system using $\mathrm{He}$ as the carrier gas. Channel (1) was investigated by direct monitoring of I atom concentrations by resonance fluorescence and channel (2) was studied by monitoring the IO concentration by addition of $\mathrm{NO}$ and detection of the I atoms generated.

\section{Preferred Values}

$k_{1}<1 \times 10^{-15} \mathrm{~cm}^{3}$ molecule $\mathrm{e}^{-1} \mathrm{~s}^{-1}$ at $298 \mathrm{~K}$.

$k_{2}<2 \times 10^{-16} \mathrm{~cm}^{3}$ molecule $\mathrm{e}^{-1} \mathrm{~s}^{-1}$ at $298 \mathrm{~K}$.

\section{Comments on Preferred Values}

The only experimental study of the reaction (Larin et al., 1999) gives upper limits for the rate coefficients for the two channels which are substantially higher than the corresponding rate coefficients for the analogous reactions of FO, $\mathrm{ClO}$, and $\mathrm{BrO}$ radicals. It is likely that the rate coefficients are substantially smaller but the measured upper limits are provisionally accepted.

\section{References}

Larin, K., Nevozhai, D. V., Spasskii, A. I., Trofimova, E. F. M., and Turkin, L. E.: Kinet. Katal., 40, 487, 1999, Eng. Trans. p. 435. 
III.A4.93

$\begin{array}{ll}\mathbf{I O}+\mathbf{C l O} & \rightarrow \mathbf{I C l}+\mathbf{O}_{2} \\ & \rightarrow \mathrm{Cl}+\mathbf{I}+\mathbf{O}_{2} \\ & \rightarrow \mathrm{Cl}+\mathbf{O I O} \\ & \rightarrow \mathbf{I}+\mathbf{O C l O} \\ \mathrm{IO}+\mathrm{ClO}+\mathrm{M} & \rightarrow \mathrm{IOOCl}+\mathbf{M}\end{array}$

$\Delta H^{\circ}(1)=-200 \mathrm{~kJ} \mathrm{~mol}^{-1}$

$\Delta H^{\circ}(2)=10 \mathrm{~kJ} \mathrm{~mol}^{-1}$

$\Delta H^{\circ}(3)=-19 \mathrm{~kJ} \mathrm{~mol}^{-1}$

$\Delta H^{\circ}(4)=-15 \mathrm{~kJ} \mathrm{~mol}^{-1}$

Rate coefficient data $\left(k=k_{1}+k_{2}+k_{3}+k_{4}+k_{5}\right)$

\begin{tabular}{lllc}
\hline$k / \mathrm{cm}^{3}$ molecule ${ }^{-1} \mathrm{~s}^{-1}$ & Temp./K & Reference & Technique/Comments \\
\hline $\begin{array}{l}\text { Absolute Rate Coefficients } \\
(1.1 \pm 0.2) \times 10^{-11}\end{array}$ & 298 & Bedjanian et al., 1997 & DF-MS (a) \\
$5.1 \times 10^{-12} \exp [(280 \pm 80) / T]$ & $200-362$ & Turnipseed et al., 1997 & DF-PLP-LIF (b) \\
$(1.29 \pm 0.27) \times 10^{-11}$ & 298 & & \\
& & & \\
Branching Ratio & 298 & Bedjanian et al., 1997 & (c) \\
$k_{1} / k=0.20 \pm 0.02$ & 298 & & \\
$k_{2} / k=0.25 \pm 0.02$ & 298 & & \\
$k_{4} / k=0.55 \pm 0.03$ & 298 & Turnipseed et al., 1997 & (d) \\
$\left(k_{1}+k_{3}\right) / k=0.14 \pm 0.04$ & & & \\
\hline
\end{tabular}

\section{Comments}

(a) The rate coefficient $k$ was determined from the decay of $\mathrm{IO}$ radicals in the presence of excess $\mathrm{ClO}$ under pseudo-first order conditions. The total pressure was 1.3 mbar He. $k$ was measured in four different reaction mixtures using $\mathrm{CF}_{3} \mathrm{I}$ and $\mathrm{I}_{2}$ as sources of $\mathrm{IO}$ radicals, and $\mathrm{OClO}$ and $\mathrm{Cl}_{2} \mathrm{O}$ as sources of $\mathrm{ClO}$ radicals.

(b) Coupled DF-PLP system with LIF detection of IO radicals. IO radicals were photolytically generated in excess ClO, which was measured by UV absorption. The temporal profile of IO allowed accurate determination of $k$. I atoms were a major product, with a yield of $0.8 \pm 0.2$ at $298 \mathrm{~K}$. Total pressure was $6.6 \mathrm{mbar}$ to $21 \mathrm{mbar}$ of $\mathrm{N}_{2}-\mathrm{He}$. The quoted errors include estimates of systematic errors.

(c) Quantitative detection of reaction products $\mathrm{OClO}, \mathrm{Cl}$ and $\mathrm{ICl}$, using both absolute and relative rate approaches to determine the branching ratios. The errors quoted are two least-squares standard deviations.

(d) Based on the ratio of the overall bimolecular rate coefficient determined from the first-order decay of IO in excess $\mathrm{ClO}$ (giving $k_{1}+k_{3}$ ) with $4 \times 10^{15}$ molecule $\mathrm{cm}^{-3}$ of $\mathrm{O}_{3}$ present, to the total rate coefficient $k$ determined in a similar manner with no excess $\mathrm{O}_{3}$ present. At $223 \mathrm{~K}$ the yield of I atoms was $0.78 \pm 0.25$, suggesting that the $\mathrm{I}$ atom yield does not vary significantly with temperature over the range $223 \mathrm{~K}$ to $298 \mathrm{~K}$.

\section{Preferred Values}

$k=1.2 \times 10^{-11} \mathrm{~cm}^{3}$ molecule ${ }^{-1} \mathrm{~s}^{-1}$ at $298 \mathrm{~K}$.

$k=4.7 \times 10^{-12} \exp (280 / T) \mathrm{cm}^{3}$ molecule $\mathrm{e}^{-1} \mathrm{~s}^{-1}$ over the temperature range $200-370 \mathrm{~K}$.

$k_{1} / k=0.20$ at $298 \mathrm{~K}$.

$k_{2} / k=0.25$ at $298 \mathrm{~K}$.

$k_{4} / k=0.55$ at $298 \mathrm{~K}$. 


\section{Reliability}

$\Delta \log k= \pm 0.1$ at $298 \mathrm{~K}$.

$\Delta(E / R)= \pm 100 \mathrm{~K}$.

$\Delta\left(k_{1} / k\right)=0.10$ at $298 \mathrm{~K}$.

$\Delta\left(k_{2} / k\right)=0.10$ at $298 \mathrm{~K}$.

$\Delta\left(k_{4} / k\right)=0.10$ at $298 \mathrm{~K}$.

\section{Comments on Preferred Values}

The two experimental studies of Bedjanian et al. (1997) and Turnipseed et al. (1997), which used different techniques, give overall rate coefficients $k$ which are in excellent agreement at $298 \mathrm{~K}$. The recommended value is a simple mean of the two results (Bedjanian et al., 1997; Turnipseed et al., 1997). The temperature dependence from Turnipseed et al. (1997) is consistent with those observed for other exothermic $\mathrm{XO}+\mathrm{YO}$ reactions and is accepted for the recommendation.

The quantitative information from the two studies (Bedjanian et al., 1997; Turnipseed et al., 1997) concerning the product channels is consistent within the cited uncertainties, with the discharge flow study of Bedjanian et al. (1997) giving more detailed data and being used for the recommendation. The overall rate coefficient is accounted for by Reactions (1)+(2)+(4) and it is concluded that Reaction (3) is negligible. Provisionally, the branching ratios at $298 \mathrm{~K}$ can be applied to stratospheric temperatures since the I atom yield exhibits no significant temperature dependence (Turnipseed et al., 1997). There is no experimental evidence for a pressure dependence, as expected if the $\mathrm{IOOCl}$ intermediate was formed as a stable product in channel (5).

\section{References}

Bedjanian, Y., Le Bras, G., and Poulet, G.: J. Phys. Chem. A, 101, 4088, 1997.

Turnipseed, A. A., Gilles, M. K., Burkholder, J. B., and Ravishankara, A. R.: J. Phys. Chem. A, 101, 5517, 1997. 
III.A4.94

$\begin{array}{ll}\mathbf{I O}+\mathrm{BrO} & \rightarrow \mathrm{IBr}+\mathrm{O}_{2} \\ & \rightarrow \mathrm{Br}+\mathrm{I}+\mathrm{O}_{2} \\ & \rightarrow \mathrm{Br}+\mathrm{OIO} \\ \mathrm{IO}+\mathrm{BrO}+\mathrm{M} & \rightarrow \mathrm{I}+\mathrm{OBrO} \\ & \rightarrow \mathrm{IOOBr}+\mathrm{M}\end{array}$

$\Delta H^{\circ}(1)=-195 \mathrm{~kJ} \mathrm{~mol}^{-1}$

$\Delta H^{\circ}(2)=-17 \mathrm{~kJ} \mathrm{~mol}^{-1}$

$\Delta H^{\circ}(3)=-47 \mathrm{~kJ} \mathrm{~mol}^{-1}$

$\Delta H^{\circ}(4)=23 \mathrm{~kJ} \mathrm{~mol}^{-1}$

Rate coefficient data $\left(k=k_{1}+k_{2}+k_{3}+k_{4}+k_{5}\right)$

\begin{tabular}{lllc}
\hline$k / \mathrm{cm}^{3}$ molecule ${ }^{-1} \mathrm{~s}^{-1}$ & Temp./K & Reference & Technique/Comments \\
\hline Absolute Rate Coefficients & & & \\
$(6.9 \pm 2.7) \times 10^{-11}$ & 298 & Laszlo et al., 1997 & PLP-AS (a) \\
$k_{1}+k_{3}=2.5 \times 10^{-11} \exp [(260 \pm 100) / T]$ & $204-388$ & Gilles et al., 1997 & PLP-LIF (b) \\
$k_{1}+k_{3}=6.0 \times 10^{-11}$ & 298 & & \\
$(8.5 \pm 1.5) \times 10^{-11}$ & 298 & Bedjanian et al., 1998 & DF-MS (c) \\
$k_{1}+k_{3}=(7.5 \pm 1.0) \times 10^{-11}$ & 298 & & \\
$6.7 \times 10^{-12} \exp [(760 \pm 30) / T]$ & $210-333$ & Rowley et al., 2001 & PLP-AS (d) \\
$(8.5 \pm 1.4) \times 10^{-11}$ & 295 & & \\
& & & \\
Branching Ratios & & & \\
$\left(k_{2}+k_{4}\right) / k<0.35$ & 298 & Gilles et al., 1997 & (b) \\
$k_{1} / k<0.05$ & 298 & Bedjanian et al., 1998 & (e) \\
$k_{2} / k<0.3$ & 298 & & \\
$k_{3} / k=0.65-1.0$ & 298 & & \\
$k_{4} / k<0.2$ & 298 & & \\
$\left(k_{2}+k_{4}\right) / k<0.3$ & 298 & & (f) \\
$k_{1} / k<0.2$ & 298 & Rowley et al., 2001 & \\
$k_{4} / k<0.15$ & 298 & & \\
\hline
\end{tabular}

\section{Comments}

(a) IO and BrO radicals were monitored at $427.2 \mathrm{~nm}$ and $338.5 \mathrm{~nm}$, respectively, using resolutions of $0.3 \mathrm{~nm}$ and $0.6 \mathrm{~nm}$ and cross sections of $2.8 \times 10^{-17} \mathrm{~cm}^{2}$ molecule ${ }^{-1}$ and $1.4 \times 10^{-17} \mathrm{~cm}^{2}$ molecule ${ }^{-1}$, respectively. The rate coefficient $k$ was determined by a numerical fit to complex kinetic decay curves. The total pressure was 260 mbar.

(b) IO radicals were detected by LIF. Pseudo-first order decays of IO radicals were measured in the presence of excess $\mathrm{BrO}$ and $\mathrm{O}_{3}$. The reported rate coefficient applies only to the non-I-atom producing channels. An upper limit of 0.35 is suggested for the fraction of the overall reaction yielding I atoms at $298 \mathrm{~K}$. Total pressure was 8 mbar to 20 mbar.

(c) IO radical decays were monitored by the presence of excess $\mathrm{BrO}$ and $\mathrm{O}_{3}$ to obtain the rate coefficient for the total non-Iatom forming channels. The total rate coeficient was obtained from simulations of the $\mathrm{BrO}$, IO and IBr profiles. The total pressure was 1 mbar.

(d) Pulsed laser photolysis with absorption spectroscopic detection of $\mathrm{BrO}$ and $\mathrm{IO}$ radicals using a time-resolved charge coupled detector (CCD) in the A-X systems at $300 \mathrm{~nm}$ to $350 \mathrm{~nm}$ and $400 \mathrm{~nm}$ to $470 \mathrm{~nm}$, respectively. The IO radical cross section at $427.2 \mathrm{~nm}$ was measured to be $(1.9 \pm 0.17) \times 10^{-17} \mathrm{~cm}^{2}$ molecule ${ }^{-1}(1.13 \mathrm{~nm}$ resolution) and the BrO radical differential cross sections were based on those measured by Wahner et al. (1988), but increased in magnitude by $9 \%$ as recommended by Gilles et al. (1997) and adjusted for a resolution of $1.13 \mathrm{~nm}$. The rate coefficient $k$ was determined by numerical simulation of $\mathrm{IO}$ decays in excess $\mathrm{BrO}_{2}$. The total pressure was 100 mbar to 1 bar. 
(e) Several experiments under varying conditions in the discharge flow system were used to establish the branching ratios. The major channel produces $\mathrm{Br}+\mathrm{OIO}$ with a branching ratio in the range given. Only upper limits were obtained for I atom and $\mathrm{IBr}$ formation.

(f) Based on the upper limits to the formation of the products $\mathrm{IBr}$ and $\mathrm{OBrO}$, as measured by absorption spectroscopy. OIO was shown to be the major product.

\section{Preferred Values}

$k=8.5 \times 10^{-11} \mathrm{~cm}^{3}$ molecule ${ }^{-1} \mathrm{~s}^{-1}$ at $298 \mathrm{~K}$.

$k=1.5 \times 10^{-11} \exp (510 / T) \mathrm{cm}^{3}$ molecule $\mathrm{s}^{-1} \mathrm{~s}^{-1}$ over the temperature range $200-390 \mathrm{~K}$.

$k_{3} / k=0.80$ at $298 \mathrm{~K}$.

Reliability

$\Delta \log k= \pm 0.1$ at $298 \mathrm{~K}$.

$\Delta(E / R)= \pm 350 \mathrm{~K}$.

$\Delta\left(k_{3} / k\right)=0.15$ at $298 \mathrm{~K}$.

\section{Comments on Preferred Values}

The kinetic studies of this reaction by Laszlo et al. (1997), Gilles et al. (1997), Bedjanian et al. (1998) and Rowley et al. (2001) are in remarkedly good agreement considering the experimental difficulties. Both Gilles et al. (1997) and Bedjanian et al. (1998) observed first-order kinetics for IO radical decays in excess BrO to obtain the rate coefficient for non-I-atom producing channels, $\left(k_{1}+k_{3}\right)=(6.8 \pm 0.8) \times 10^{-11} \mathrm{~cm}^{3}$ molecule ${ }^{-1} \mathrm{~s}^{-1}$.

The overall rate coefficients measured by Bedjanian et al. (1998) and Rowley et al. (2001) which were measured under complex kinetic conditions, are nevertheless in excellent agreement, giving $k=(8.5 \pm 1.2) \times 10^{-11} \mathrm{~cm}^{3}$ molecule $\mathrm{s}^{-1}$. These measurements give a value of $\left(k_{1}+k_{3}\right) / k=0.80 \pm 0.15$ which lies in the middle of the range suggested by Bedjanian et al. (1998) for the branching ratio $k_{3} / k$. Considering that the IBr measurements of Bedjanian et al. (1998) give $k_{1} / k<0.05$, we recommend that $k_{3} / k=0.80$ and that the total rate coefficient is that determined by Bedjanian et al. (1998) and Rowley et al. (2001) at $298 \mathrm{~K}$. The rate coefficient measurement of Laszlo et al. (1997) is less precise but agrees within the experimental error limits with the recommendation.

The two studies of the temperature dependence (Gilles et al., 1997; Rowley et al., 2001) both show a negative activation energy for this radical + radical reaction. Although the temperature dependence of Gilles et al. (1997) is derived from measurements of $k_{1}+k_{3}$ over a wider temperature range, their result may not reflect the temperature dependence of the overall reaction if the branching ratio changes with temperature. The recommended temperature dependence is the simple mean of the two determinations of Gilles et al. (1997) and Rowley et al. (2001) with the pre-exponential factor, $A$, being adjusted to fit the preferred $298 \mathrm{~K}$ rate coefficient. The data do not allow a precise recommendation for the remaining branching between channels (1), (2) and (4). However, $\mathrm{OBrO}$ formation is not favorable on thermochemical grounds. There is no experimental evidence for a pressure dependence, as expected if the $\mathrm{IOOCl}$ intermediate was formed as a stable product in channel (5).

\section{References}

Bedjanian, Y., Le Bras, G., and Poulet, G.: J. Phys. Chem. A, 102, 10501, 1998.

Gilles, M. K., Turnipseed, A. A., Burkholder, J. B., Ravishankara, A. R., and Solomon, S.: J. Phys. Chem. A, 101, 5526, 1997.

Laszlo, B., Huie, R. E., Kurylo, M. J., and Miziolek, A. W.: J. Geophys. Res., 102, 1523, 1997.

Rowley, D. M., Bloss, W. J., Cox, R. A., and Jones, R. L.: J. Phys. Chem. A, 105, 7885, 2001.

Wahner, A., Ravishankara, A. R., Sander, S. P., and Friedl, R. R.: Chem. Phys. Lett., 152, 507, 1988. 
III.A4.95

$$
\begin{array}{ll}
\mathrm{IO}+\mathrm{IO} & \rightarrow \mathrm{I}_{2}+\mathrm{O}_{2} \\
& \rightarrow \mathbf{I}+\mathrm{O}_{2} \\
\mathrm{IO}+\mathrm{IO}+\mathrm{M} & \rightarrow \mathrm{I}+\mathbf{O I O} \\
& \rightarrow \mathrm{I}_{2} \mathrm{O}_{2}+\mathrm{M}
\end{array}
$$

$\Delta H^{\circ}(1)=-170 \mathrm{~kJ} \mathrm{~mol}^{-1}$

$\Delta H^{\circ}(2)=-18 \mathrm{~kJ} \mathrm{~mol}^{-1}$

$\Delta H^{\circ}(3)=-48 \mathrm{~kJ} \mathrm{~mol}^{-1}$

Rate coefficient data $\left(k=k_{1}+k_{2}+k_{3}+k_{4}\right)$

\begin{tabular}{lllc}
\hline$k / \mathrm{cm}^{3}$ molecule ${ }^{-1} \mathrm{~s}^{-1}$ & Temp./K & Reference & Technique/Comments \\
\hline $\begin{array}{l}\text { Absolute Rate Coefficients } \\
(8.0 \pm 1.8) \times 10^{-11}\end{array}$ & 298 & Laszlo et al., 1995 & PLP-UVA (a) \\
$(9.9 \pm 1.5) \times 10^{-11}$ & $250-320$ & Harwood et al., 1997 & PLP-UVA (b) \\
$(1.0 \pm 0.3) \times 10^{-10}$ & 295 & Atkinson et al., 1999 & PLP-CRDS (c) \\
$(9.3 \pm 1.0) \times 10^{-11}$ & 295 & Ingham et al., 2000 & PLP-UVA (d) \\
$4.54 \times 10^{-11} \exp [(182 \pm 122) / T]$ & $250-320$ & Bloss et al., 2001 & PLP-UVA (e) \\
$(8.2 \pm 1.0) \times 10^{-11}$ & 298 & & \\
$(9.3 \pm 1.0) \times 10^{-11}$ & 296 & Vipond, 2002 & DF-RF (f) \\
& & & \\
Branching Ratios & & & FP-UVA (g) \\
$k_{1} / k<0.05$ & 298 & Sander, 1986 & \\
$\left(k_{2}+0.5 k_{3}\right) / k=0.45$ at $28 \mathrm{mbar}$ & 298 & & (a) \\
$\left(k_{2}+0.5 k_{3}\right) / k=0.18$ at $870 \mathrm{mbar}$ & 298 & & (h) \\
$k_{1} / k<0.05$ & 298 & Laszo et al., 1995 & \\
$\left(0.5 k_{3}+k_{4}\right) / k=0.78$ at 1 bar & 298 & Harwood et al., 1977 & (i) \\
$k_{1} / k<0.30$ & 298 & & \\
$k_{1} / k<0.05$ & 298 & Bloss et al., 2001 & \\
$k_{2} / k=0.11 \pm 0.04$ & 298 & & (f) \\
$k_{3} / k=0.38 \pm 0.08$ & 298 & & \\
$k_{4} / k=0.46 \pm 0.06$ & 298 & & \\
$k_{2} / k=0.56 \pm 0.20$ & 296 & Vipond, 2002 & \\
\hline
\end{tabular}

\section{Comments}

(a) Pulsed laser photolysis with detection of IO radicals by absorption spectroscopy using the 4-0 band of the A-X system at $427.2 \mathrm{~nm}$, for which a cross section of $(2.8 \pm 0.5) \times 10^{-17} \mathrm{~cm}^{2}$ molecule ${ }^{-1}$ was measured. The total pressure was $78 \mathrm{mbar}$ to 789 mbar of $\mathrm{N}_{2}$. No prompt $\mathrm{I}_{2}$ formation from IO decay was observed.

(b) Pulsed laser photolysis with detection of IO radicals by absorption spectroscopy using the 4-0 band of the A-X system at $427.2 \mathrm{~nm}$, for which a temperature-independent cross section of $(3.6 \pm 0.5) \times 10^{-17} \mathrm{~cm}^{2}$ molecule ${ }^{-1}$ was measured. The total pressure was 78 mbar to 789 mbar of $\mathrm{N}_{2}$. No statistically significant temperature dependence of either $k$ or $\sigma$ was observed over the temperature range studied.

(c) Pulsed laser photolysis with detection of IO radicals by cavity ring-down spectroscopy using the 2-0 bandhead of the A-X system at $445.02 \mathrm{~nm}$, for which an absorption cross section of $(7.3 \pm 0.7) \times 10^{-17} \mathrm{~cm}^{2}$ molecule ${ }^{-1}$ was used. This was determined relative to $\sigma=(3.6 \pm 0.7) \times 10^{-17} \mathrm{~cm}^{2}$ molecule ${ }^{-1}$ measured by Harwood et al. (1997). The total pressure was 12.4 mbar to 40.2 mbar of Ar.

(d) Pulsed laser photolysis $(248 \mathrm{~nm})$ of $\mathrm{O}_{3}-\mathrm{I}_{2}$ mixtures, with detection of IO radicals by time-resolved absorption spectroscopy at $427.2 \mathrm{~nm}$. A cross section of $(3.6 \pm 0.5) \times 10^{-17} \mathrm{~cm}^{2}$ molecule ${ }^{-1}$ was used to determine $k$. The total pressure was 78 mbar $\mathrm{N}_{2}$. OIO product detected by absorption spectroscopy. 
(e) Pulsed laser photolysis with detection of IO radicals by absorption spectroscopy using time-resolved charge-coupled detection (CCD) in the A-X system at $400 \mathrm{~nm}$ to $470 \mathrm{~nm}$. The cross section at $427.2 \mathrm{~nm}$ was measured to be $(1.9 \pm 0.17) \times 10^{-17} \mathrm{~cm}^{2}$ molecule ${ }^{-1}(1.13 \mathrm{~nm}$ resolution). The differential cross section used to determine [IO] decreased by $\sim 45 \%$ on increasing the temperature from $220 \mathrm{~K}$ to $335 \mathrm{~K}$. The total pressure was 130 mbar to 1 bar of $\mathrm{N}_{2}$.

(f) Discharge flow system with RF detection of I atoms after titration of IO radicals with NO. The total pressure was 2.5 mbar of He. Branching ratio $k_{2} / k$ from analysis of I atom measurements in the absence of NO.

(g) Flash photolysis system with detection by absorption spectroscopy. The pressure dependence of the branching ratio to produce I atoms was based on the pressure dependence of $k$ in the presence of excess $\mathrm{O}_{3}$.

(h) Based on $\mathrm{I}_{2}$ formation at short reaction times, and on comparison of rate coefficients measured in the presence and absence of $\mathrm{O}_{3}$, with $k$ (presence of $\left.\mathrm{O}_{3}\right) / k\left(\right.$ absence of $\left.\mathrm{O}_{3}\right)=0.73$ at 1 bar.

(i) Based on product absorptions due to $\mathrm{I}_{2}$, OIO and an unknown broad-band absorption at $\lambda \leq 400 \mathrm{~nm}$ assigned to $\mathrm{I}_{2} \mathrm{O}_{2}$. The value of $\sigma(\mathrm{OIO})$ used was based on the branching ratio for the reaction $\mathrm{IO}+\mathrm{BrO} \rightarrow \mathrm{Br}+\mathrm{OIO}$ determined by Bedjanian et al. (1998).

\section{Preferred Values}

$k=9.9 \times 10^{-11} \mathrm{~cm}^{3}$ molecule $\mathrm{e}^{-1} \mathrm{~s}^{-1}$ at $298 \mathrm{~K}$.

$k=5.4 \times 10^{-11} \exp (180 / T) \mathrm{cm}^{3}$ molecule $\mathrm{s}^{-1} \mathrm{~s}^{-1}$ over the temperature range $250-320 \mathrm{~K}$.

$k_{1} / k<0.05$ at $298 \mathrm{~K}$.

$k_{3} / k=0.38$ at $298 \mathrm{~K}$ and 1 bar.

\section{Reliability}

$\Delta \log k= \pm 0.1$ at $298 \mathrm{~K}$.

$\Delta(E / R)= \pm 200 \mathrm{~K}$.

$\Delta\left(k_{3} / k\right)= \pm 0.1$ at $298 \mathrm{~K}$ and 1 bar.

\section{Comments on Preferred Values}

The recently reported (Laszlo et al., 1995; Harwood et al., 1997; Atkinson et al., 1999; Ingham et al., 2000; Bloss et al., 2001; Vipond et al., 2002) values of $k$ show good agreement for the overall rate coefficient at room temperature, which is higher than previously reported by Sander (1986), Jenkin and Cox (1985) and Barnes et al. (1991) (who used a discharge flow technique). When the different values of the absorption cross sections are taken into account, there is excellent agreement in the values of $k / \sigma(427 \mathrm{~nm})$ obtained by Laszlo et al. (1995), Harwood et al. (1997), Bloss et al. (2001) and Ingham et al. (2000). Using a value of $\sigma(\mathrm{IO})=3.6 \times 10^{-17} \mathrm{~cm}^{3}$ molecule ${ }^{-1}$ at $427 \mathrm{~nm}$ from the IUPAC evaluation (see data sheet on IO photolysis), and the mean value of $k / \sigma(427 \mathrm{~nm})=2.75 \times 10^{6} \mathrm{~cm} \mathrm{~s}^{-1}$ from these studies, gives the preferred value at $298 \mathrm{~K}$ of $k=9.9 \times 10^{-11} \mathrm{~cm}^{3}$ molecule $\mathrm{e}^{-1} \mathrm{~s}^{-1}$. The results of Vipond et al. (2002) and Atkinson et al. (1999) are consistent with this value.

All studies agree that the overall rate coefficient in the absence of excess $\mathrm{O}_{3}$ is independent of pressure over the range $1 \mathrm{mbar}$ to 1 bar. The fraction of the IO+IO reaction leading to I atom production from studies at higher pressures (Harwood et al., 1997; Atkinson et al., 1999; Sander, 1986) appears to be $\sim 20 \%$ to $30 \%$, with $\left(k_{2}+0.5 k_{3}\right) / k \sim 0.2-0.3$ consistent with the quantum yield for $\mathrm{I}_{2}$-photosensitized decomposition of $\mathrm{O}_{3}$ (Jenkin et al., 1985). However, Jenkin and Cox (1985) and Sander (1986) observed a falloff in $k$ with decreasing pressure in the presence of excess $\mathrm{O}_{3}$, i.e., when the $\mathrm{I}$ atom products are recycled to form IO, suggesting that the fractional I atom yield increases as pressure decreases. This is consistent with the higher branching ratio $k_{2} / k$ reported by Vipond et al. (2002). Bloss et al. (2001) observed OIO formation with a branching ratio of $k_{3} / k$ in the range 0.30 to 0.48 , based on an OIO absorption cross section of $\sigma(\mathrm{OIO})=1.07 \times 10^{-17} \mathrm{~cm}^{2}$ molecule ${ }^{-1}$ at $524 \mathrm{~nm}$ deduced from the OIO yield in the IO+BrO reaction (Bedjanian et al., 1998; Rowley et al., 2001).

All studies show that $\mathrm{I}_{2}$ formation is minor, with $k_{1} / k<0.05$ (Sander, 1986; Laszlo et al., 1995; Harwood et al., 1997; Bloss et al., 2001). Most authors have assumed that $\mathrm{I}_{2} \mathrm{O}_{2}$ is the other major product formed, although evidence for $\mathrm{I}_{2} \mathrm{O}_{2}$ formation is not unequivocal. Both Sander (1986) and Bloss et al. (2001) report products which absorb in the UV near $300 \mathrm{~nm}$ but no direct identification of the absorbing species has been reported.

Temperature-dependent rate coefficients have been reported by Sander (1986), Harwood et al. (1997) and Bloss et al. (2001). The high value of $E / R=-(1020 \pm 200) \mathrm{K}$ reported by Sander (1986) reflects the large temperature coefficient obtained for $\sigma$. 
When the much weaker changes in $\sigma$ are used (see data sheet on IO photolysis), the temperature dependence of $k$ disappears. On balance the results of Bloss et al. (2001), which take into account the changes in the yield of IO radicals from the $\mathrm{O}+\mathrm{CF}_{3} \mathrm{I}$ reaction used to calibrate the absorptions, are preferred. The temperature dependence of Bloss et al. (2001) is used and the pre-exponential factor, $A$, is adjusted to fit the preferred $298 \mathrm{~K}$ rate coefficient. The error reflects the possibility of a zero $E / R$.

\section{References}

Atkinson, D. B., Hudgens, J. W., and Orr-Ewing, A. J.: J. Phys. Chem. A, 103, 6173, 1999.

Barnes, I., Bastian, V., Becker, K. H., and Overath, R. D.: Int. J. Chem. Kinet., 23, 579, 1991.

Bedjanian, Y., Le Bras, G., and Poulet, G.: J. Phys. Chem. A, 102, 10 501, 1998.

Bloss, W. J., Rowley, D. M., Cox, R. A., and Jones, R. L.: J. Phys. Chem. A, 105, 7885, 2001.

Harwood, M. H., Burkholder, J. B., Hunter, M., Fox, R. W., and Ravishankara, A. R.: J. Phys. Chem. A, 101, 853, 1997.

Ingham, T., Cameron, M., and Crowley, J. N.: J. Phys. Chem. A, 104, 8001, 2000.

Jenkin, M. E. and Cox, R. A.: J. Phys. Chem., 89, 192, 1985.

Jenkin, M. E., Cox, R. A., and Candeland, D. E.: J. Atmos. Chem., 2, 359, 1985.

Laszlo, B., Kurylo, M. J., and Huie, R. E.: J. Phys. Chem., 99, 11 701, 1995.

Rowley, D. M., Bloss, W. J., Cox, R. A., and Jones, R. L.: J. Phys. Chem. A, 105, 7885, 2001.

Sander, S. P.: J. Phys. Chem., 90, 2194, 1986.

Vipond, A., Canosa-Mas, C. E., Flugge, M. L., Gray, D. J., Shallcross, D. E., Shah, D., and Wayne, R. P.: Phys. Chem. Chem. Phys., 4, 3648, 2002. 


\section{III.A4.96}

$$
\mathrm{IO}+\mathrm{NO} \rightarrow \mathrm{I}+\mathrm{NO}_{2}
$$

$\Delta H^{\circ}=-66 \mathrm{~kJ} \mathrm{~mol}^{-1}$

\section{Rate coefficient data}

\begin{tabular}{lllc}
\hline$k / \mathrm{cm}^{3}$ molecule ${ }^{-1} \mathrm{~s}^{-1}$ & Temp./K & Reference & Technique/Comments \\
\hline Absolute Rate Coefficients & 298 & Ray and Watson, 1981 & DF-MS (a) \\
$(1.67 \pm 0.16) \times 10^{-11}$ & 298 & Inoue et al., 1983 & PLP-LIF (b) \\
$(2.8 \pm 0.2) \times 10^{-11}$ & $242-359$ & Daykin and Wine, 1990 & PLP-AS (c) \\
$6.9 \times 10^{-12} \exp [(328 \pm 71) / T]$ & & \\
$(2.17 \pm 0.22) \times 10^{-11}$ & 298 & & PLP-LIF (d) \\
$1.02 \times 10^{-11} \exp [(185 \pm 70) / T]$ & $237-346$ & Turnipseed et al., 1995 & \\
$(1.92 \pm 0.07) \times 10^{-11}$ & 298 & & PLP-AS (e) \\
$(1.9 \pm 0.5) \times 10^{-11}$ & 295 & Atkinson et al., 1999 & DF-MS (f) \\
$8.3 \times 10^{-12} \exp [(269 \pm 85) / T]$ & $273-353$ & Knight and Crowley, 2001 & \\
$(2.17 \pm 0.20) \times 10^{-11}$ & 298 & & PLP-LIF (g) \\
$4.3 \times 10^{-12} \exp [(397 \pm 65) / T]$ & $233-346$ & Hölscher and Zellner, 2002 & \\
$(1.68 \pm 0.11) \times 10^{-11}$ & 296 & & PLP-LIF (h) \\
$(1.82 \pm 0.10) \times 10^{-11}$ & 294 & Dillon and Heard, 2003 & \\
Relative Rate Coefficients & & & \\
$7.2 \times 10^{-12} \exp [(330 \pm 160) / T]$ & $293-366$ & Buben et al., 1996 & DF-RF (i) \\
$2.18 \times 10^{-11}$ & 298 & & \\
\hline
\end{tabular}

\section{Comments}

(a) IO radicals were produced by the reaction $\mathrm{I}^{+} \mathrm{O}_{3}$ and monitored by MS in an excess of NO. Pressure varied between 1.33 and $2.8 \mathrm{mbar} \mathrm{He}$.

(b) IO formed from laser photolysis of $\mathrm{HI}-\mathrm{N}_{2} \mathrm{O}$ at $193 \mathrm{~nm}$, or $\mathrm{HI}-\mathrm{O}_{3}$ at $248 \mathrm{~nm}$. Total pressure was $1.33 \mathrm{mbar}$ He.

(c) Pulsed laser photolysis of $\mathrm{NO}_{2}-\mathrm{I}_{2}$ mixtures at $351 \mathrm{~nm}$. IO radical concentrations were monitored by longpath absorption spectroscopy in an excess of NO. $k$ was found to be independent of pressure over the range 50 mbar to 260 mbar of $\mathrm{N}_{2}$.

(d) Pulsed laser photolysis of $\mathrm{N}_{2} \mathrm{O}-\mathrm{I}_{2}$ mixtures at $193 \mathrm{~nm}$. IO radical concentrations were monitored by LIF in an excess of NO. $k$ was found to be independent of pressure over the range $6.5 \mathrm{mbar}$ to $130 \mathrm{mbar}$ of $\mathrm{N}_{2}$.

(e) Pulsed laser photolysis of $\mathrm{N}_{2} \mathrm{O}-\mathrm{CF}_{3} \mathrm{I}-\mathrm{NO}-\mathrm{Ar}$ mixtures at $193 \mathrm{~nm}$. IO radicals were monitored by cavity ring-down spectroscopy at $445.04 \mathrm{~nm}$. $k$ was found to be independent of pressure over the range $12.5 \mathrm{mbar}$ to $40 \mathrm{mbar}$ of Ar.

(f) IO radicals made by $\mathrm{O}+\mathrm{I}_{2}$ and detected by MS.

(g) IO made by laser photolysis of $\mathrm{N}_{2} \mathrm{O}-\mathrm{CF}_{3} \mathrm{I}$ at $193 \mathrm{~nm}$. Pressure varied between 13 and 130 mbar synthetic air.

(h) IO made by laser photolysis of $\mathrm{N}_{2} \mathrm{O}-\mathrm{CF}_{3} \mathrm{I}$ at $193 \mathrm{~nm}$. Pressure varied between 88 and 173 mbar $\mathrm{N}_{2}$ or synthetic air.

(i) IO made in photolysis of $\mathrm{CH}_{3} \mathrm{I}-\mathrm{O}_{2}-\mathrm{O}_{3}$ mixtures. Steady state $\mathrm{I}$ atom signals were monitored by resonance fluorescence and shown to depend on the relative concentration of $\mathrm{O}_{3}$ and $\mathrm{NO}$, and the relative rate coefficients for $\mathrm{I}+\mathrm{O}_{3}$ and IO+NO, i.e. $k / k\left(\mathrm{I}+\mathrm{O}_{3}\right)$ was derived. The expression for $k(\mathrm{~T})$ was derived using the temperature dependent, recommended value for $k\left(\mathrm{I}+\mathrm{O}_{3}\right)$ (IUPAC, current evaluation). 


\section{Preferred Values}

$k=1.95 \times 10^{-11} \mathrm{~cm}^{3}$ molecule $\mathrm{e}^{-1} \mathrm{~s}^{-1}$ at $298 \mathrm{~K}$.

$k=7.15 \times 10^{-12} \exp (300 / T) \mathrm{cm}^{3}$ molecule ${ }^{-1} \mathrm{~s}^{-1}$ over the temperature range $240-370 \mathrm{~K}$.

\section{Reliability}

$\Delta \log k= \pm 0.15$ at $298 \mathrm{~K}$.

$\Delta(E / R)= \pm 100 \mathrm{~K}$.

\section{Comments on Preferred Values}

Most of the available rate coefficient data for this reaction (Ray and Watson, 1981; Inoue et al., 1983; Daykin and Wine, 1990; Turnipseed et al., 1995; Buben et al., 1996; Atkinson et al., 1999; Knight and Crowley, 2001; Hölscher and Zellner, 2002; Dillon and Heard, 2003) are in good agreement, only the result of Inoue et al. (1983) is anomalously high. The preferred value of $k=1.95 \times 10^{-11} \mathrm{~cm}^{3}$ molecule ${ }^{-1} \mathrm{~s}^{-1}$ at $298 \mathrm{~K}$ is the mean of all other values.

The preferred expression for $k(\mathrm{~T})$ is obtained by taking the mean of the values of $E / R$ of Daykin and Wine (1990), Turnipseed et al. (1995), Knight and Crowley (2001), Hölscher and Zellner (2002) and Buben et al. (1996) and combining it with a pre-exponential factor adjusted to give the preferred value of $k$ at $298 \mathrm{~K}$.

\section{References}

Atkinson, D. B., Hudgens, J. W., and Orr-Ewing, A. J.: J. Phys. Chem. A, 103, 6173, 1999.

Buben, S. N., Larin, I. K., Messineva, N. A., and Trofimova, E. M.: Khim. Fiz., 15, 116, 1996, available in English as: Chem. Phys. Reports, 15, 745, 1996.

Daykin, E. P. and Wine, P. H.: J. Phys. Chem., 94, 4528, 1990.

Dillon, T. J. and Heard, D. E.: J. Photochem. Photobiol. A. Chem., 157, 223, 2003.

Hölscher, D. and Zellner, R.: Phys. Chem. Chem. Phys., 4, 1839, 2002.

Inoue, G., Suzuki, M., and Washida, N.: J. Chem. Phys., 79, 4730, 1983.

IUPAC: http://www.iupac-kinetic.ch.cam.ac.uk/, 2003.

Knight, G. P. and Crowley, J. N.: Phys. Chem. Chem. Phys., 3, 393, 2001.

Ray, G. W. and Watson, R. T.: J. Phys. Chem., 85, 2955, 1981.

Turnipseed, A. A., Gilles, M. K., Burkholder, J. B., and Ravishankara, A. R. : Chem. Phys. Lett., 242, 427, 1995. 


\section{III.A4.97}

$\mathrm{IO}+\mathrm{NO}_{2}+\mathrm{M} \rightarrow \mathrm{IONO}_{2}+\mathrm{M}$

$\Delta H^{\circ}=-79 \mathrm{~kJ} \mathrm{~mol}^{-1}$

\section{Low-pressure rate coefficients}

\section{Rate coefficient data}

\begin{tabular}{lllc}
\hline$k_{0} / \mathrm{cm}^{3}$ molecule & & Technique/Comments \\
\hline Absolute Rate Coefficients & Temp./K & Reference & \\
$(4.3 \pm 2.0) \times 10^{-31}\left[\mathrm{~N}_{2}\right]$ & & & \\
$7.7 \times 10^{-31}(T / 300)^{-5.0}\left[\mathrm{~N}_{2}\right]$ & 277 & Jenkin and Cox, 1985 & MM-A (a) \\
$(3.6 \pm 1.0) \times 10^{-31}[\mathrm{He}]$ & $254-354$ & Daykin and Wine, 1990 & PLP-A (b) \\
$(7.9 \pm 2.2) \times 10^{-31}\left[\mathrm{~N}_{2}\right]$ & 298 & Manguin et al., 1992 & DF-MS (c) \\
$(1.80 \pm 0.07) \times 10^{-31}(T / 300)^{-2.6}\left[\mathrm{O}_{2}\right]$ & 298 & & \\
$4.1 \times 10^{-31}(T / 298)^{-6.3}\left[\mathrm{~N}_{2}\right]$ & $290-350$ & Larin et al., 1998 & FR-F (d) \\
$1.3 \times 10^{-30}(T / 300)^{-4.5}\left[\mathrm{~N}_{2}\right]$ & $238-298$ & Hölscher and Zellner, 2002 & PLP-LIF (e) \\
\hline
\end{tabular}

\section{Comments}

(a) Photolysis of $\mathrm{I}_{2}$ in the presence of $\mathrm{O}_{3}$ producing $\mathrm{IO}$ radicals monitored by absorption at $427 \mathrm{~nm}$ in the presence of an excess of $\mathrm{NO}_{2}$. The total pressure was varied over the range $47-537 \mathrm{mbar}$ of $\mathrm{N}_{2}$. The falloff curve was analyzed using $F_{c}=0.4$ by analogy to the $\mathrm{BrO}+\mathrm{NO}_{2}+\mathrm{M}$ reaction. A small correction was made for a second-order component to the IO radical kinetics at higher pressures.

(b) IO radicals generated by pulsed laser photolysis of $\mathrm{I}_{2}-\mathrm{NO}_{2}-\mathrm{N}_{2}$ mixtures at $351 \mathrm{~nm}$; IO radicals monitored by absorption at $427 \mathrm{~nm}$. Pressure range 53-1000 mbar. The data were extrapolated to the low- and high-pressure rate coefficients using $F_{c}=0.4$.

(c) IO radicals and $\mathrm{IONO}_{2}$ detected by MS. IO radicals were generated by the reaction $\mathrm{O}+\mathrm{I}_{2} \rightarrow \mathrm{IO}+\mathrm{I}$. The pressure range was 1.6-2.8 mbar of $\mathrm{He}$. Using a relative third-body efficiency of $\mathrm{N}_{2}$ and $\mathrm{He}$ for the analogous $\mathrm{BrO}+\mathrm{NO}_{2}+\mathrm{M}$ (ratio $\left.k_{0}\left(\mathrm{~N}_{2}\right) / k_{0}(\mathrm{He})=2.2\right)$ from Sander et al. (1981), the value reported above was derived.

(d) I atoms generated by photolysis of a flow of $\mathrm{CH}_{3} \mathrm{I}$ at $254 \mathrm{~nm}$; IO radicals formed by the reaction $\mathrm{I}^{+} \mathrm{O}_{3} \rightarrow \mathrm{IO}+\mathrm{O}_{2}$. Pressure range 1.3-8 mbar of $\mathrm{O}_{2}$. Assuming a ratio of $\beta_{c}\left(\mathrm{~N}_{2}\right) / \beta_{c}\left(\mathrm{O}_{2}\right)=1.4$, the expression $k_{0}=2.50 \times 10^{-31}(T / 300)^{-2.6}\left[\mathrm{~N}_{2}\right]$ $\mathrm{cm}^{3}$ molecule $\mathrm{s}^{-1} \mathrm{~s}^{-1}$ over the temperature range $290 \mathrm{~K}$ to $350 \mathrm{~K}$ was derived.

(e) Laser flash photolysis of mixtures of $\mathrm{O}_{3}, \mathrm{CF}_{3} \mathrm{I}$ and $\mathrm{NO}_{2}$ in air with pulsed LIF detection of IO. Pressure range 50 400 mbar. Evaluation of the falloff curve with $F_{c}=0.6$. Rate coefficients about $20 \%$ below those from Daykin and Wine (1990).

(f) Laser flash photolysis of $\mathrm{NO}_{2}$ in the presence of $\mathrm{CF}_{3} \mathrm{I}$ and $\mathrm{N}_{2}$ with LIF detection of IO. Falloff extrapolation with $F_{c}=0.57$ obtained from RRKM theory. Rate coefficients about $20 \%$ above data from Daykin and Wine (1990). Preliminary results by Blitz et al. (2000) are cited which are close to the cited results.

\section{Preferred Values}

$k=7.7 \times 10^{-31}(T / 300)^{-5}\left[\mathrm{~N}_{2}\right] \mathrm{cm}^{3}$ molecule $\mathrm{e}^{-1} \mathrm{~s}^{-1}$ over the temperature range 250-360 $\mathrm{K}$.

\section{Reliability}

$\Delta \log k_{0}= \pm 0.3$ at $298 \mathrm{~K}$.

$\Delta n= \pm 2$. 


\section{Comments on Preferred Values}

The preferred values for $k_{0}$ are an average of the data of Daykin and Wine (1990), the value of Maguin et al. (1992) derived with the given ratio of efficiencies for $\mathrm{N}_{2}$ and $\mathrm{He}$, the data from Hölscher and Zellner (2002), extrapolated with $F_{c}=0.4$ instead of 0.6, and the data from Allan and Plane (2002). The measurements of Larin et al. (1998) are a factor of 4 lower than the preferred values.

\section{High-pressure rate coefficients}

\section{Rate coefficient data}

\begin{tabular}{lllc}
\hline$k_{\infty} / \mathrm{cm}^{3}$ molecule ${ }^{-1} \mathrm{~s}^{-1}$ & Temp./K & Reference & Technique/Comments \\
\hline Absolute Rate Coefficients & & & \\
$(1.6 \pm 0.6) \times 10^{-11}$ & 277 & Jenkin and Cox, 1985 & MM-A (a) \\
$1.55 \times 10^{-11}$ & $254-354$ & Daykin and Wine, 1990 & PLP-A (b) \\
$1.0 \times 10^{-11}$ & $238-298$ & Hölscher and Zellner, 2002 & PLP-LIF (c) \\
$6.5 \times 10^{-12}(T / 300)^{-1.3}$ & $216-474$ & Allan and Plane, 2002 & PLP-LIF (d) \\
\hline
\end{tabular}

\section{Comments}

(a) See comment (a) for $k_{0}$. The rate coefficient $k_{\infty}$ was obtained from a fit of the falloff curve using $F_{c}=0.4$.

(b) See comment (b) for $k_{0}$.

(c) See comment (e) for $k_{0}$.

(d) See comment (f) for $k_{0}$.

\section{Preferred Values}

$k_{\infty}=1.6 \times 10^{-11} \mathrm{~cm}^{3}$ molecule $\mathrm{e}^{-1} \mathrm{~s}^{-1}$, independent of temperature over the range $250-360 \mathrm{~K}$.

\section{Reliability}

$\Delta \log k_{\infty}= \pm 0.3$ at $250-360 \mathrm{~K}$.

$\Delta n= \pm 1$.

\section{Comments on Preferred Values}

The preferred values for $k_{\infty}$ are based on the data of Daykin and Wine (1990). Falloff extrapolations are made with $F_{c}=0.4$, independent of temperature over the range 250 to $360 \mathrm{~K}$. If extrapolated with this $F_{c}$ instead of $F_{c} \approx 0.6$, the measurements by Hölscher and Zellner (2002) and Allan and Plane (2002) are consistent with the preferred $k_{\infty}$.

\section{References}

Allan, B. J. and Plane, J. M. C.: J. Phys. Chem. A, 106, 8634, 2002.

Blitz, M. A., Dillon, T. J., and Heard, D. E.: 16th Int. Symp. on Gas Kinetics, Cambridge, UK, 2000.

Daykin, E. P. and Wine, P. H.: J. Phys. Chem., 94, 4528, 1990.

Hölscher, D. and Zellner, R.: Phys. Chem. Chem. Phys., 4, 1839, 2002.

Jenkin, M. E. and Cox, R. A.: J. Phys. Chem., 89, 192, 1985.

Larin, I. K., Nevozhai, D. V., Sapasskii, A. I., and Trofimova, E. M.: Kinet. Catal., 39, 666. 1998.

Maguin, F., Laverdet, G., Le Bras, G., and Poulet, G.: J. Phys. Chem., 96, 1775, 1992.

Sander, S. P., Ray, G. W., and Watson, R. T.: J. Phys. Chem., 85, 199, 1981. 
R. Atkinson et al.: Evaluated kinetic and photochemical data for atmospheric chemistry

\section{III.A4.98}

$$
\mathrm{IONO}_{2}+\mathrm{M} \rightarrow \mathrm{IO}+\mathrm{NO}_{2}+\mathrm{M}
$$

$\Delta H^{\circ}=79 \mathrm{~kJ} \mathrm{~mol}^{-1}$

\section{Falloff range}

No direct measurements are available.

\section{Preferred Values}

$k(1$ bar of air $)=1.1 \times 10^{15} \exp (-12060 / T) \mathrm{s}^{-1}$ over the temperature range $240-305 \mathrm{~K}$.

$k(1$ bar of air $)=2.9 \times 10^{-3} \mathrm{~s}^{-1}$ at $298 \mathrm{~K}$.

\section{Reliability}

$\Delta \log k= \pm 1$ at $300 \mathrm{~K}$.

$\Delta(E / R)= \pm 500 \mathrm{~K}$.

\section{Comments on Preferred Values}

The expression was obtained by Allan and Plane (2002) by inverting an RRKM fit of rate coefficient measurements of the reverse reaction. Measurements of $\mathrm{IO}$ profiles at $473 \mathrm{~K}$ and 300 Torr indicated the presence of $\mathrm{IONO}_{2}$ dissociation which is consistent with the proposed rate expression.

\section{References}

Allan, B. J. and Plane, J. M. C.: J. Phys. Chem. A, 106, 8634, 2002. 


\section{III.A4.99}

$$
\mathrm{INO}+\mathrm{INO} \rightarrow \mathrm{I}_{2}+\mathbf{2 N O}
$$

$\Delta H^{\circ}=0.3 \mathrm{~kJ} \mathrm{~mol}^{-1}$

\section{Rate coefficient data}

\begin{tabular}{lllc}
\hline$k / \mathrm{cm}^{3}$ molecule ${ }^{-1} \mathrm{~s}^{-1}$ & Temp./K & Reference & Technique/Comments \\
\hline Absolute Rate Coefficients & & & \\
$8.4 \times 10^{-11} \exp (-2620 / T)$ & $320-450$ & van den Bergh and Troe, 1976 & PLP-UVA \\
$1.3 \times 10^{-14}$ & $298^{*}$ & & \\
$2.9 \times 10^{-12} \exp (-1320 / T)$ & $298-328$ & Basco and Hunt, 1978 & FP-UVA \\
$3.4 \times 10^{-14}$ & 298 & & \\
\hline
\end{tabular}

\section{Preferred Values}

$k=1.3 \times 10^{-14} \mathrm{~cm}^{3}$ molecule ${ }^{-1} \mathrm{~s}^{-1}$ at $298 \mathrm{~K}$.

$k=8.4 \times 10^{-11} \exp (-2620 / T) \mathrm{cm}^{3}$ molecule $\mathrm{e}^{-1} \mathrm{~s}^{-1}$ over the temperature range $300-450 \mathrm{~K}$.

\section{Reliability}

$\Delta \log k= \pm 0.4$ at $298 \mathrm{~K}$.

$\Delta(E / R)= \pm 600 \mathrm{~K}$.

\section{Comments on Preferred Values}

The results from the study of van den Bergh and Troe (1976) are preferred over those from Basco and Hunt (1978) because of a much wider range of conditions studied.

\section{References}

Basco, N. and Hunt, J. E.: Int. J. Chem. Kinet., 10, 733, 1978.

van den Bergh, H. and Troe, J.: J. Chem. Phys., 64, 736, 1976. 
III.A4.100

$$
\mathrm{INO}_{2}+\mathrm{INO}_{2} \rightarrow \mathrm{I}_{2}+\mathbf{2 N O}
$$

$\Delta H^{\circ}=8.4 \mathrm{kj} \mathrm{mol}^{-1}$

\section{Rate coefficient data}

\begin{tabular}{lllc}
\hline$k / \mathrm{cm}^{3}$ molecule $\mathrm{s}^{-1}$ & Temp./K & Reference & Technique/Comments \\
\hline $\begin{array}{l}\text { Absolute Rate Coefficients } \\
1.7 \times 10^{-14}\end{array}$ & 350 & van den Bergh and Troe, 1976 & PLP-UVA \\
$4.7 \times 10^{-13} \exp (-1670 \pm 340 / T)$ & $277-345$ & Gawler et al., 2003 & FP-UVA \\
\hline
\end{tabular}

\section{Preferred Values}

$k=1.7 \times 10^{-15} \mathrm{~cm}^{3}$ molecule ${ }^{-1} \mathrm{~s}^{-1}$ at $298 \mathrm{~K}$.

$k=4.7 \times 10^{-13} \exp (-1670 / T) \mathrm{cm}^{3}$ molecule $\mathrm{e}^{-1} \mathrm{~s}^{-1}$ over the temperature range $270-350 \mathrm{~K}$.

\section{Reliability}

$\Delta \log k= \pm 0.7$ at $298 \mathrm{~K}$.

$\Delta(E / R)= \pm 1000 \mathrm{~K}$.

\section{Comments on Preferred Values}

The preferred values are based on the new measurements of Gawler et al. (2003). The measured rate constant at a single temperature of $350 \mathrm{~K}$ from van den Bergh and Troe (1976) is higher by a factor of 4, but uncertainties in both studies are large.

\section{References}

Gawler, K. S., Boakes, G., and Rowley, D. M.: Phys. Chem. Chem. Phys., 5, 3632, 2003.

van den Bergh, H. and Troe, J.: Chem. Phys., 64, 736, 1976. 
III.A4.101

$$
\mathrm{OIO}+\mathrm{NO} \rightarrow \mathrm{IO}+\mathrm{NO}_{2}
$$

$\Delta H^{\circ}=-17.9 \mathrm{~kJ} \mathrm{~mol}^{-1}$

\section{Rate coefficient data}

\begin{tabular}{lllc}
\hline$k / \mathrm{cm}^{3}$ molecule ${ }^{-1} \mathrm{~s}^{-1}$ & Temp./K & Reference & Technique/Comments \\
\hline Absolute Rate Coefficients & & & \\
$7.6 \times 10^{-13} \exp [(607 \pm 128) / T]$ & $235-320$ & Plane et al., 2006 & PLP-CRDS (a) \\
$(6.0 \pm 1.1) \times 10^{-12}$ & 298 & & \\
\hline
\end{tabular}

\section{Comments}

(a) OIO formed in self-reaction of IO, was produced by $193 \mathrm{~nm}$ photolysis of $\mathrm{N}_{2} \mathrm{O}$ in the presence of $\mathrm{CF}_{3} \mathrm{I}$. The rate coefficient $k$ was determined from the decay of OIO in the presence of excess NO. [OIO] measured by time resolved cavity ring-down spectroscopy (CRDS) at $567.808 \mathrm{~nm}$. $k$ was independent of pressure in the range $27-96$ mbar at $300 \mathrm{~K}$.

\section{Preferred Values}

$k=6.7 \times 10^{-12} \mathrm{~cm}^{3}$ molecule $\mathrm{e}^{-1} \mathrm{~s}^{-1}$ at $298 \mathrm{~K}$.

$k=1.1 \times 10^{-12} \exp (542 / T) \mathrm{cm}^{3}$ molecule ${ }^{-1} \mathrm{~s}^{-1}$ over the temperature range $240-320 \mathrm{~K}$.

\section{Reliability}

$\Delta \log k= \pm 0.3$ at $298 \mathrm{~K}$.

$\Delta(E / R)= \pm 250 \mathrm{~K}$.

\section{Comments on Preferred Values}

The single experimental study provides well defined rate constants over the given pressure and temperature range, despite the complex source chemistry for the OIO radical. The observed rate constants and their temperature and pressure dependence were well reproduced by quantum chemical and RRKM calcualtions using a potential surface with a weakly bound OIONO intermediate which dissociates into $\mathrm{IO}+\mathrm{NO}_{2}$ products. Even at 1 bar pressure significant formation of OIONO is not predicted to occur. The authors recommend the expression: $(1.1 \pm 0.4) \times 10^{-12} \exp [(542 \pm 130) / T]$ for $k\left(\mathrm{~cm}^{3}\right.$ molecule $\left.{ }^{-1} \mathrm{~s}^{-1}\right)$ at $1 \mathrm{bar}$, taking account of experimental uncertainties and the theoretical analysis, which is adopted for the preferred value for formation of $\mathrm{IO}+\mathrm{NO}_{2}$ all pressures.

\section{References}

Plane, J. M. C., Joseph, D. M., Allan, B. J., Ashworth, S. H. and Francisco, J. S.: J. Phys. Chem. 110, 93, 2006. 


\section{Appendix 5: Photochemical Reactions}

III.A5.102

$$
\mathbf{H C l}+\mathbf{h} v \rightarrow \text { products }
$$

Primary photochemical processes

\begin{tabular}{lll}
\hline Reaction & $\Delta H^{\circ} / \mathrm{kJ} \mathrm{mol}^{-1}$ & $\lambda_{\text {threshold }} / \mathrm{nm}$ \\
\hline $\mathrm{HCl}+\mathrm{h} \nu \rightarrow \mathrm{H}+\mathrm{Cl}$ & 432 & 277 \\
\hline
\end{tabular}

Preferred Values

Absorption cross sections for $\mathrm{HCl}$ at $298 \mathrm{~K}$

\begin{tabular}{llllll}
\hline$\lambda / \mathrm{nm}$ & $\begin{array}{l}10^{20} \sigma / \\
\mathrm{cm}^{2} \text { molecule }^{-1}\end{array}$ & $\lambda / \mathrm{nm}$ & $\begin{array}{l}10^{20} \sigma / \\
\mathrm{cm}^{2} \text { molecule }^{-1}\end{array}$ & $\begin{array}{l}\lambda / \mathrm{nm} \\
10^{20} \sigma / \\
\mathrm{cm}^{2} \mathrm{molecule}^{-1}\end{array}$ & $\begin{array}{l}13.8 \\
135\end{array}$ \\
137.5 & 123 & 162,5 & 273 & 190 & 5.96 \\
140 & 152 & 165 & 240 & 195 & 2.39 \\
142.5 & 205 & 167.5 & 199 & 200 & 0.903 \\
145 & 238 & 170 & 163 & 205 & 0.310 \\
147.5 & 279 & 172.5 & 136 & 210 & 0.101 \\
150 & 311 & 175 & 106 & 215 & 0.030 \\
152.5 & 334 & 177.5 & 79.6 & 220 & 0.010 \\
155 & 342 & 180 & 58.9 & 225 & 0.0034 \\
157.5 & 343 & 182.5 & 42.3 & 230 & \\
160 & 327 & 185 & 29.4 & & \\
\hline
\end{tabular}

\section{Comments on Preferred Values}

The preferred values of the absorption cross-sections at $298 \mathrm{~K}$ are those reported by Bahou et al. (2001) and Cheng et al. (2002). These are in good agreement with previous spectra from Nee et al. (1986) and Inn et al. (1975). The tabulated values of the cross sections are 2.5 or $5 \mathrm{~nm}$ averages of the $0.1 \mathrm{~nm}$ resolution data reported in Bahou et al. (2001), and evaluated by the NASA-JPL panel (Sander et al., 2006).

Photolysis is expected to occur with unit quantum efficiency, with some wavelength dependence in the branching ratio to ground and excited state $\mathrm{Cl}$ atoms. See Sander et al. (2006), and references therein for details.

\section{References}

Bahou, M., Chung, C. Y., Lee, Y. P., Cheng, B. M., Yung, Y. L. and Lee, L. C.: Astrophy. J. 559, 179-182, 2001.

Cheng, B. M., Chung, C. Y., Bahou, M., Lee, Y. P. and Lee, L. C.: J. Chem. Phys. 117, 4293-4298, 2002.

Inn, E. C. Y.: J. Atmos. Sci., 32, 2375, 1975.

Nee, J. B., Suto, M. and Lee, L. C.: J. Chem. Phys. 85, 719-724, 1986.

Sander, S. P., Finlayson-Pitts, B. J., Friedl, R. R., Golden, D. M., Huie, R. F., Keller-Rudek, H., R. E., Kolb, C. E., Kurylo, M. J., Molina, M. J., Moortgat, G. K., Orkin, V. L., Ravishankara, A. R. and Wine, P. H.: "Chemical Kinetics and Photochemical Data for Use in Atmospheric Studies, Evaluation Number 15," JPL Publication 06-2, Jet Propulsion Laboratory, Pasadena, 2006. 
III.A5.103

$\mathbf{H O C l}+\mathbf{h} v \rightarrow$ products

Primary photochemical processes

\begin{tabular}{lllll}
\hline Reaction & & $\Delta H^{\circ} / \mathrm{kJ} \mathrm{mol}^{-1}$ & $\lambda_{\text {threshold }} / \mathrm{nm}$ \\
\hline $\mathrm{HOCl}+\mathrm{h} v$ & $\rightarrow \mathrm{HO}+\mathrm{Cl}$ & $(1)$ & 239 & 500 \\
& $\rightarrow \mathrm{HCl}+\mathrm{O}\left({ }^{3} \mathrm{P}\right)$ & $(2)$ & 432 & 277 \\
\hline
\end{tabular}

\section{Preferred Values}

Absorption cross sections for $\mathrm{HOCl}$ at $298 \mathrm{~K}$

\begin{tabular}{|c|c|c|c|c|c|}
\hline$\lambda / \mathrm{nm}$ & $\begin{array}{l}10^{20} \sigma / \mathrm{cm}^{2} \\
\text { molecule }^{-1}\end{array}$ & $\lambda / \mathrm{nm}$ & $\begin{array}{l}10^{20} \sigma / \mathrm{cm}^{2} \\
\text { molecule }^{-1}\end{array}$ & $\lambda / \mathrm{nm}$ & $\begin{array}{l}10^{20} \sigma / \mathrm{cm}^{2} \\
\text { molecule }\end{array}$ \\
\hline 200 & 7.18 & 274 & 5.29 & 348 & 1.55 \\
\hline 202 & 6.39 & 276 & 4.94 & 350 & 1.43 \\
\hline 204 & 5.81 & 278 & 4.74 & 352 & 1.33 \\
\hline 206 & 5.46 & 280 & 4.64 & 354 & 1.24 \\
\hline 208 & 5.37 & 282 & 4.62 & 356 & 1.17 \\
\hline 210 & 5.54 & 284 & 4.68 & 358 & 1.11 \\
\hline 212 & 5.98 & 286 & 4.79 & 360 & 1.06 \\
\hline 214 & 6.68 & 288 & 4.95 & 362 & 1.02 \\
\hline 216 & 7.63 & 290 & 5.13 & 364 & 0.985 \\
\hline 218 & 8.81 & 292 & 5.33 & 366 & 0.951 \\
\hline 220 & 10.2 & 294 & 5.52 & 368 & 0.919 \\
\hline 222 & 11.6 & 296 & 5.71 & 370 & 0.888 \\
\hline 224 & 13.2 & 298 & 5.86 & 372 & 0.855 \\
\hline 226 & 14.7 & 300 & 5.99 & 374 & 0.822 \\
\hline 228 & 16.2 & 302 & 6.08 & 376 & 0.786 \\
\hline 230 & 17.5 & 304 & 6.12 & 378 & 0.748 \\
\hline 232 & 18.7 & 306 & 6.12 & 380 & 0.708 \\
\hline 234 & 19.6 & 308 & 6.07 & 382 & 0.667 \\
\hline 236 & 20.2 & 310 & 5.97 & 384 & 0.624 \\
\hline 238 & 20.5 & 312 & 5.84 & 386 & 0.580 \\
\hline 240 & 20.6 & 314 & 5.66 & 388 & 0.535 \\
\hline 242 & 20.3 & 316 & 5.45 & 390 & 0.491 \\
\hline 244 & 19.8 & 318 & 5.21 & 392 & 0.447 \\
\hline 246 & 19.0 & 320 & 4.95 & 394 & 0.405 \\
\hline 248 & 18.1 & 322 & 4.67 & 396 & 0.364 \\
\hline 250 & 17.0 & 324 & 4.38 & 398 & 0.325 \\
\hline 252 & 15.8 & 326 & 4.09 & 400 & 0.288 \\
\hline 254 & 14.6 & 328 & 3.79 & 402 & 0.254 \\
\hline 256 & 13.3 & 330 & 3.50 & 404 & 0.222 \\
\hline 258 & 12.1 & 332 & 3.21 & 406 & 0.194 \\
\hline 260 & 10.9 & 334 & 2.94 & 408 & 0.168 \\
\hline 262 & 9.73 & 336 & 2.68 & 410 & 0.144 \\
\hline 264 & 8.68 & 338 & 2.44 & 412 & 0.124 \\
\hline 266 & 7.75 & 340 & 2.22 & 414 & 0.105 \\
\hline 268 & 6.94 & 342 & 2.03 & 416 & 0.089 \\
\hline 270 & 6.25 & 344 & 1.84 & 418 & 0.075 \\
\hline 272 & 5.69 & 346 & 1.69 & 420 & 0.063 \\
\hline
\end{tabular}




\section{Quantum yield for HOCl photolysis at $298 \mathrm{~K}$}

$\Phi_{1}=1.0$ for $\lambda>200 \mathrm{~nm}$

\section{Comments on Preferred Values}

The preferred values of the absorption cross-sections at $298 \mathrm{~K}$ are the values calculated with the recent expression given by Barnes et al. (1998) based on their data from the laser induced fluorescence of HO and on the data of Burkholder (1993). In the Barnes et al. (1998) study a weak absorption centred at $\approx 370 \mathrm{~nm}$ that extends down to $500 \mathrm{~nm}$ is observed. The recommended values agree very well with the values reported by Knauth et al. (1979) and Jungkamp et al. (1995) at wavelengths between 250 and $350 \mathrm{~nm}$. Earlier results (Molina and Molina, 1978; Spence et al., 1980; Mishalanie et al., 1986) were erroneous due to spectral interference from $\mathrm{Cl}_{2} \mathrm{O}$ and $\mathrm{Cl}_{2}$.

The preferred quantum yield values are based on the results of Molina et al. (1980), Butler and Phillips (1983), Vogt and Schindler (1992), and Schindler et al. (1987). An upper limit of $\Phi_{2}<0.02$ was determined by Butler and Phillips (1983) at $308 \mathrm{~nm}$. Relative yields of $\mathrm{HO}\left({ }^{2} \Pi_{3 / 2}\right) / \mathrm{HO}\left({ }^{2} \Pi_{1 / 2}\right)$ were found to be 2.0 at $266 \mathrm{~nm}$ and 1.5 at $355 \mathrm{~nm}$ (Fujiwara and Ishiwata, 1998).

\section{References}

Barnes, R. J., Sinha, A., and Michelsen, H. A.: J. Phys. Chem. A, 102, 8855, 1998.

Burkholder, J. B.: J. Geophys. Res., 98, 2963, 1993.

Butler, P. J. D. and Phillips, L. F.: J. Phys. Chem., 87, 183, 1983.

Fujiwara, H. and Ishiwata, T.: J. Phys. Chem. A, 102, 3856, 1998.

Jungkamp, T. P. W., Kirchner, U., Schmidt, M., and Schindler, R. N.: J. Photochem. Photobiol. A 91, 1-6, 1995.

Knauth, H. D., Alberti, H., and Clausen, H.: J. Phys. Chem. 83, 1604-1612, 1979.

Mishalanie, E.A., Rutkowski, C. J., Hutte, R. S., and Birks, J. W.: J. Chem. Phys. 90, 5578-5584, 1986.

Molina, L. T., and Molina, M. J.: J. Phys. Chem. 82, 2410-2414, 1978.

Molina, M. J., Ishiwata, T. and Molina, L. T.: J. Phys. Chem. 84, 821, 1980.

Schindler, R. N., Liesner, M., Schmidt, S., Kirchner, U., and Benter, Th.: J. Photochem. Photobiol. A: Chem. 107, 9-19, 1987. Spence, J. W., Edney, E. O., and Hanst, P. L.: J. Air Pollut. Control Assoc. 30, 50-52 1980.

Vogt, R., and Schindler, R. N.: J. Photochem. Photobiol. A: Chem. 66, 133, 1992. 
III.A5.104

$$
\text { OClO }+\mathbf{h} v \rightarrow \text { products }
$$

Primary photochemical processes

\begin{tabular}{lllll}
\hline Reaction & & $\Delta H^{\circ} / \mathrm{kj} \mathrm{mol}^{-1}$ & $\lambda_{\text {threshold }} / \mathrm{nm}$ \\
\hline $\mathrm{OClO}+\mathrm{h} v$ & $\rightarrow \mathrm{ClO}+\mathrm{O}\left({ }^{3} \mathrm{P}\right)$ & $(1)$ & 255 & 470 \\
& $\rightarrow \mathrm{Cl}+\mathrm{O}_{2}$ & $(2)$ & 26 & 4540 \\
\hline
\end{tabular}

\section{Preferred Values}

Absorption cross sections of $\mathrm{OClO}$ at the band peaks at $204 \mathrm{~K}, 296 \mathrm{~K}$ and $378 \mathrm{~K}$

\begin{tabular}{|c|c|c|c|c|}
\hline Band & $\lambda / \mathrm{nm}$ & $\begin{array}{l}10^{20} \sigma / \mathrm{cm}^{2} \text { molecule }^{-1} \\
204 \mathrm{~K}\end{array}$ & $\begin{array}{l}10^{20} \sigma / \mathrm{cm}^{2} \text { molecule }^{-1} \\
296 \mathrm{~K}\end{array}$ & $\begin{array}{l}10^{20} \sigma / \mathrm{cm}^{2} \text { molecule }^{-1} \\
378 \mathrm{~K}\end{array}$ \\
\hline $\mathrm{a}(0)$ & 475.53 & & 13 & \\
\hline$a(1)$ & 461.15 & 17 & 17 & 16 \\
\hline$a(2)$ & 446.41 & 94 & 69 & 57 \\
\hline$a(3)$ & 432.81 & 220 & 166 & 134 \\
\hline$a(4)$ & 420.58 & 393 & 304 & 250 \\
\hline$a(5)$ & 408.83 & 578 & 479 & 378 \\
\hline$a(6)$ & 397.76 & 821 & 670 & 547 \\
\hline$a(7)$ & 387.37 & 1046 & 844 & 698 \\
\hline $\mathrm{a}(8)$ & 377.44 & 1212 & 992 & 808 \\
\hline $\mathrm{a}(9)$ & 368.30 & 1365 & 1136 & 920 \\
\hline $\mathrm{a}(10)$ & 359.73 & 1454 & 1219 & 984 \\
\hline $\mathrm{a}(11)$ & 351.30 & 1531 & 1275 & 989 \\
\hline $\mathrm{a}(12)$ & 343.44 & 1507 & 1230 & 938 \\
\hline $\mathrm{a}(13)$ & 336.08 & 1441 & 1139 & 864 \\
\hline$a(14)$ & 329.22 & 1243 & 974 & 746 \\
\hline $\mathrm{a}(15)$ & 322.78 & 1009 & 791 & 628 \\
\hline $\mathrm{a}(16)$ & 317.21 & 771 & 618 & 516 \\
\hline$a(17)$ & 311.53 & 542 & 435 & 390 \\
\hline $\mathrm{a}(18)$ & 305.99 & 393 & 312 & 291 \\
\hline $\mathrm{a}(19)$ & 300.87 & 256 & 219 & 216 \\
\hline $\mathrm{a}(20)$ & 296.42 & 190 & 160 & 167 \\
\hline $\mathrm{a}(21)$ & 291.77 & 138 & 114 & 130 \\
\hline $\mathrm{a}(22)$ & 287.80 & 105 & 86 & 105 \\
\hline $\mathrm{a}(23)$ & 283.51 & 89 & 72 & 90 \\
\hline $\mathrm{a}(24)$ & 279.647 & 73 & 60 & 79 \\
\hline$a(25)$ & 275.74 & 59 & 46 & \\
\hline$a(26)$ & 272.93 & 53 & 33 & \\
\hline
\end{tabular}

Quantum yield for OClO photolysis at $298 \mathrm{~K}$

$\Phi_{1}=1.0$ over the wavelength range $270-480 \mathrm{~nm}$.

$\Phi_{2}<0.04$ between 365 and $450 \mathrm{~nm}$. 


\section{Comments on Preferred Values}

The preferred values of the absorption cross-sections at the peak of the bands [a(0) to a(26)] at $204 \mathrm{~K}, 296 \mathrm{~K}$ and $378 \mathrm{~K}$ are the values reported by Wahner et al. (1987). The bands become appreciably sharper with decreasing temperature (Wahner et al., 1987). However, the integrated band intensities remain constant for all bands between $204 \mathrm{~K}$ and $296 \mathrm{~K}$, and therefore, the solar photolysis rate is not expected to have a significant temperature dependence. Spectra have been obtained over a different temperature range (213-293 K) at higher resolution and, using Fourier transform methods, with better wavelength accuracy by Kromminga et al. (2003). In wavelength regions where data overlap, these is generally good agreement in the cross section, though Kromminga et al. (2003) note some wavelength inconsistencies, presumably errors in the wavelength calibration by Wahner et al. (1987). For this reason, the Kromminga et al. data may be more suited for retrieval of OClO concentrations from high resolution absorption measurements. Photoabsorption measurements of OClO over the wavelength range of 125 to $470 \mathrm{~nm}$ at $298 \mathrm{~K}$ have been carried out by Hubinger and Nee (1994). Absorption cross-sections as a function of vibrational excitation are reported.

The recommended quantum yield of unity for O-atom production is based on results reported by Colussi (1990), and results of earlier studies discussed by Watson (1977). Vaida and coworkers $(1989,1990)$ reported the detection of $\mathrm{Cl}$ atoms by resonance-enhanced multiphoton ionization (REMPI) in the photoisomerization of $\mathrm{OClO}$ to $\mathrm{ClOO}$ followed by dissociation to $\mathrm{Cl}+\mathrm{O}_{2}$. Bishenden et al. (1991), using REMPI detection of $\mathrm{Cl}$ atoms, report that the quantum yield for $\mathrm{Cl}$ atom formation near $360 \mathrm{~nm}$ is $0.15 \pm 0.10$. In contrast, Lawrence et al. (1990) using a technique involving charge transfer excitation of Cl-Xe collision pairs as a sensitive probe of $\mathrm{Cl}$ atoms, determined that the quantum yield for $\mathrm{Cl}$ atom production in the $359-368 \mathrm{~nm}$ region is $<5 \times 10^{-4}$. In a molecular beam-photofragment study over the wavelength range 350-475 nm, Davis and Lee (1992) observed the dominant products to be $\mathrm{ClO}+\mathrm{O}$ and also observed $\mathrm{Cl}$ atom yields reaching a maximum of $3.9 \%$ near $404 \mathrm{~nm}$, decreasing to $<0.2 \%$ in the wavelength range $350-370 \mathrm{~nm}$, in qualitative agreement with the results of Lawrence et al. (1990). More recent experiments of Davis and Lee (1996) show that the quantum yield for $\mathrm{Cl}+\mathrm{O}_{2}$ production is $3.9 \pm 0.8 \%$ at $404 \mathrm{~nm}$, decreasing at longer and shorter wavelengths, and the branching ratio between the channels (1) and (2) depends on the OClO excited state vibrational mode. Delmdahl et al. (1998) observed nascent $\mathrm{Cl}$ atom formation between 360 and $450 \mathrm{~nm}$. A quantum yield less than $3.6 \%$ was determined between 365 and $450 \mathrm{~nm}$. Below $365 \mathrm{~nm} \mathrm{Cl}$ atom formation resulting from the photolysis of vibrationally excited $\mathrm{ClO}(v \geq 4)$ radicals was observed.

\section{References}

Bishenden, E., Haddock, J. and Donaldson, D. J.: J. Phys. Chem., 95, 2113, 1991.

Colussi, A. J.: J. Phys. Chem., 94, 8922, 1990.

Davis, H. F. and Lee, Y. T.: J. Phys. Chem., 96, 5681, 1992.

Davis, H. F. and Lee, Y. T.: J. Chem. Phys., 105, 8142, 1996.

Delmdahl, R. F., Ullrich, S., and Gericke, K.-H.: J. Phys. Chem. A, 102, 7680, 1998.

Hubinger, S. and Nee, J. B.: Chem. Phys., 181, 247, 1994.

Kromminga, H., Orphal, J., Spietz, P., Voigt, S. and Burrows, J. P.: J. Photchem. Photobiol. A 157, 149-160, 2003.

Lawrence, W. G., Clemitshaw, K. C. and Apkarian, V. A.: J. Geophys. Res., 95, 18591, 1990.

Ruehl, E., Jefferson, A. and Vaida, V.: J. Phys. Chem., 94, 2990, 1990.

Vaida, V., Solomon, S., Richard, E. C., Ruhl, E. and Jefferson, A.: Nature, 342, 405, 1989.

Wahner, A., Tyndall, G. S. and Ravishankara, A. R.: J. Phys. Chem., 91, 2734, 1987.

Watson, R. T.: J. Phys. Chem. Ref. Data, 6, 871, 1977. 
III.A5.105

$$
\mathbf{C l}_{2} \mathbf{O}+\mathbf{h} v \rightarrow \text { products }
$$

Primary photochemical processes

\begin{tabular}{lllll}
\hline Reaction & & $\Delta H^{\circ} / \mathrm{kJ} \mathrm{mol}^{-1}$ & $\lambda_{\text {threshold }} / \mathrm{nm}$ \\
\hline $\mathrm{Cl}_{2} \mathrm{O}+\mathrm{h} v$ & $\rightarrow \mathrm{Cl}+\mathrm{ClO}$ & $(1)$ & 142 & 840 \\
& $\rightarrow \mathrm{O}+\mathrm{Cl}_{2}$ & $(2)$ & 168 & 710 \\
& $\rightarrow \mathrm{O}+2 \mathrm{Cl}$ & $(3)$ & 410 & 292 \\
\hline
\end{tabular}

\section{Preferred Values}

Absorption cross sections of $\mathrm{Cl}_{2} \mathrm{O}$ at $298 \mathrm{~K}$.

\begin{tabular}{llllll}
\hline$\lambda / \mathrm{nm}$ & $\begin{array}{l}10^{20} \sigma / \mathrm{cm}^{2} \\
\text { molecule }^{-1}\end{array}$ & $\lambda / \mathrm{nm}$ & $\begin{array}{l}10^{20} \sigma / \mathrm{cm}^{2} \\
\text { molecule }\end{array}$ & $\lambda / \mathrm{nm}$ & $\begin{array}{l}10^{20} \sigma / \mathrm{cm}^{2} \\
\text { molecule }\end{array}$ \\
\hline 200 & 69.0 & 305 & 53.2 & 410 & 1.09 \\
205 & 43.5 & 310 & 39.3 & 415 & 1.18 \\
210 & 23.6 & 315 & 27.8 & 420 & 1.23 \\
215 & 12.8 & 320 & 19.0 & 425 & 1.23 \\
220 & 8.95 & 325 & 12.9 & 430 & 1.21 \\
225 & 12.7 & 330 & 8.70 & 435 & 1.15 \\
230 & 28.2 & 335 & 6.06 & 440 & 1.09 \\
235 & 57.6 & 340 & 3.86 & 445 & 0.959 \\
240 & 101 & 345 & 2.61 & 450 & 0.842 \\
245 & 150 & 350 & 1.77 & 455 & 0.730 \\
250 & 187 & 355 & 1.28 & 460 & 0.623 \\
255 & 199 & 360 & 0.862 & 465 & 0.531 \\
260 & 189 & 365 & 0.614 & 470 & 0.451 \\
265 & 168 & 370 & 0.478 & 475 & 0.377 \\
270 & 147 & 375 & 0.444 & 480 & 0.312 \\
275 & 133 & 380 & 0.453 & 485 & 0.277 \\
280 & 123 & 385 & 0.506 & 490 & 0.251 \\
285 & 113 & 390 & 0.587 & 495 & 0.231 \\
290 & 101 & 395 & 0.706 & 500 & 0.216 \\
295 & 85.6 & 400 & 0.832 & & \\
300 & 69.2 & 405 & 0.968 & & \\
\hline
\end{tabular}

Quantum Yields

$\phi(1)=1.0$ at $\lambda>300 \mathrm{~nm} ; \lambda<300 \mathrm{~nm}$ see comments

\section{Comments on Preferred Values}

The preferred values of the absorption cross sections at $298 \mathrm{~K}$ are the values reported by Knauth et al. (1979). The preferred values are in excellent agreement with the values reported by Molina and Molina (1978), except for the 330-400 nm range where the values in Molina and Molina (1978) are higher, and they are in reasonable agreement with the values reported by Johnsson et al. (1995) $\left(\sigma=186 \times 10^{-20} \mathrm{~cm}^{2}\right.$ molecule ${ }^{-1}$ at $\left.260 \mathrm{~nm}\right)$ and by Lin $(1976)\left(\sigma=183 \times 10^{-20} \mathrm{~cm}^{2} \mathrm{molecule}-1\right.$ at $260 \mathrm{~nm})$. Values for the 150-200 $\mathrm{nm}$ wavelength region have been reported by Nee (1991).

Photolysis proceeds predominantly by breaking of the $\mathrm{Cl}-\mathrm{O}$ bond to yield $\mathrm{Cl}+\mathrm{ClO}$. However, Sander and Friedl (1989) determined the quantum yield for formation of oxygen atoms from $\mathrm{Cl}_{2} \mathrm{O}$ photolysis to be $0.25 \pm 0.05$, the main products being $\mathrm{Cl}+\mathrm{ClO}$. In these experiments a broad-band photolysis source with a spectral distribution extending from the visible 
down to $180 \mathrm{~nm}$ was used, so that it was not possible to determine the wavelength dependence of the quantum yield. More recently, Nelson et al. (1994) have used photofragment translational energy spectroscopy in a molecular beam to study the photodecomposition of $\mathrm{Cl}_{2} \mathrm{O}$ at 308, 248 and $193 \mathrm{~nm}$. In all cases Reaction (1) occurs. At $308 \mathrm{~nm}$ the only channel is $\mathrm{Cl}+\mathrm{ClO}$; this is the major channel at $248 \mathrm{~nm}$ and a minor channel at $193 \mathrm{~nm}$. At $248 \mathrm{~nm}$ the $\mathrm{ClO}$ fragment dissociates spontaneously. At $193 \mathrm{~nm}$ a concerted dissociation pathway leads to the formation of $\mathrm{O}+\mathrm{Cl}_{2}$. Almost all of the primary $\mathrm{Cl}_{2} \mathrm{O}$ photoproducts dissociate. More recently, Nickolaisen et al. (1996) studied the pressure dependence of $\mathrm{Cl}_{2} \mathrm{O}$ photodissociation. The observed pressure dependence of $\mathrm{ClO}$ formation was explained assuming that, after $\mathrm{Cl}_{2} \mathrm{O}$ excitation at $\lambda>300 \mathrm{~nm}$, a rapid intersystem crossing between two metastable states operates. These states were assumed to undergo competitive dissociation to $\mathrm{Cl}+\mathrm{ClO}$ and collisional relaxation to the ground state. However, this interpretation appears to be in disagreement with lifetime estimates by Moore et al. (1997). A detailed investigation of the dynamics of the complicated photodissociation process using the photoimaging technique was reported by Tanaka et al. (1998).

\section{References}

Johnsson, K., Engdahl, A., and Nelander, B.: J. Phys. Chem., 99, 3965, 1995.

Knauth, H. D., Alberti, H., and Clausen, H.: J. Phys. Chem., 83, 1604, 1979.

Lin, C. L.: J. Chem. Eng. Data, 21, 411, 1976.

Molina, L. T. and Molina, M. J.: J. Phys. Chem., 82, 2410, 1978.

Moore, T. A., Okumura, M. and Minton, T. K.: J. Chem. Phys., 107, 3337, 1997.

Nee, J. B.: J. Quant. Spectrosc. Radiat. Transfer, 46, 55, 1991.

Nelson, C. M., Moore, T. A., Okumura, M. and Minton, T. K.: J. Chem. Phys., 100, 8055, 1994.

Nickolaisen, S. L., Miller, C. E., Sander, S. P., Hard, M. R., Williams, I. H. and Francisco, J. S.: J. Chem. Phys., 104, 2857, 1996.

Sander, S. P. and Friedl, R. R.: J. Phys. Chem., 93, 4764, 1989.

Tanaka, Y., Kawasaki, M., Matsumi, Y., Fujiwara, H., Ishiwata, T., Rogers, L. J., Dixon, R. N. and Ashfold, M. N. R.: J. Chem. Phys., 109, 1315, 1998. 
III.A5.106

$$
\mathbf{C l}_{2} \mathbf{O}_{2}+\mathbf{h} v \rightarrow \text { products }
$$

Primary photochemical processes

\begin{tabular}{lllll}
\hline Reaction & & $\Delta H^{\circ} / \mathrm{kJ} \mathrm{mol}^{-1}$ & $\lambda_{\text {threshold }} / \mathrm{nm}$ \\
\hline $\mathrm{Cl}_{2} \mathrm{O}_{2}+\mathrm{h} v$ & $\rightarrow \mathrm{ClO}+\mathrm{ClO}$ & $(1)$ & 76 & 1580 \\
& $\rightarrow \mathrm{Cl}+\mathrm{ClOO}$ & $(2)$ & 91 & 1310 \\
\hline
\end{tabular}

\section{Preferred Values}

Absorption cross sections of $\mathrm{Cl}_{2} \mathrm{O}_{2}$ at 200-250 K.

\begin{tabular}{llllllll}
\hline$\lambda / \mathrm{nm}$ & $\begin{array}{l}10^{20} \sigma / \mathrm{cm}^{2} \\
\text { molecule }^{-1}\end{array}$ & $\lambda / \mathrm{nm}$ & $\begin{array}{l}10^{20} \sigma / \mathrm{cm}^{2} \\
\text { molecule }\end{array}$ & $\lambda / \mathrm{nm}$ & $\begin{array}{l}10^{20} \sigma / \mathrm{cm}^{2} \\
\text { molecule }\end{array}$ & $\lambda / \mathrm{nm}$ & $\begin{array}{l}10^{20} \sigma / \mathrm{cm}^{2} \\
\text { molecule }^{-1}\end{array}$ \\
\hline 200 & 375 & 262 & 332 & 324 & 15.3 & 386 & 0.68 \\
202 & 343 & 264 & 299 & 326 & 13.8 & 388 & 0.62 \\
204 & 313 & 266 & 270 & 328 & 12.5 & 390 & 0.56 \\
206 & 285 & 268 & 245 & 330 & 11.3 & 392 & 0.50 \\
208 & 260 & 270 & 223 & 332 & 10.2 & 394 & 0.46 \\
210 & 238 & 272 & 204 & 334 & 9.2 & 396 & 0.41 \\
212 & 220 & 274 & 188 & 336 & 8.4 & 398 & 0.37 \\
214 & 206 & 276 & 171 & 338 & 7.6 & 400 & 0.34 \\
216 & 197 & 278 & 157 & 340 & 6.8 & 402 & 0.30 \\
218 & 194 & 280 & 143 & 342 & 6.2 & 404 & 0.28 \\
220 & 198 & 282 & 131 & 344 & 5.6 & 406 & 0.25 \\
222 & 211 & 284 & 119 & 346 & 5.1 & 408 & 0.23 \\
224 & 233 & 286 & 108 & 348 & 4.6 & 410 & 0.20 \\
226 & 265 & 288 & 97.2 & 350 & 4.1 & 412 & 0.18 \\
228 & 305 & 290 & 88.5 & 354 & 3.4 & 416 & 0.15 \\
232 & 407 & 294 & 71.5 & 356 & 3.1 & 418 & 0.14 \\
234 & 462 & 296 & 63.7 & 358 & 2.8 & 420 & 0.12 \\
236 & 515 & 298 & 56.9 & 360 & 2.5 & 422 & 0.11 \\
238 & 564 & 300 & 51.3 & 362 & 2.3 & 424 & 0.10 \\
240 & 602 & 302 & 46.0 & 364 & 2.1 & 426 & 0.09 \\
242 & 629 & 304 & 41.6 & 366 & 1.9 & 428 & 0.08 \\
244 & 640 & 306 & 37.7 & 368 & 1.7 & 430 & 0.07 \\
246 & 637 & 308 & 34.1 & 370 & 1.5 & 432 & 0.07 \\
248 & 619 & 310 & 30.8 & 372 & 1.4 & 434 & 0.06 \\
250 & 589 & 312 & 25.2 & 376 & 1.1 & 438 & 0.05 \\
254 & 505 & 316 & 22.8 & 378 & 1.0 & 440 & 0.05 \\
256 & 458 & 318 & 20.6 & 380 & 0.92 & 442 & 0.05 \\
258 & 413 & 320 & 18.7 & 382 & 0.83 & 444 & 0.04 \\
260 & 370 & 322 & 16.9 & 384 & 0.75 & 446 & 0.03 \\
& & & & & 448 & 0.03 \\
\hline & & & & & & \\
\hline
\end{tabular}

\section{Quantum yields for $\mathrm{Cl}_{2} \mathrm{O}_{2}$ photolysis}

$\Phi_{2}=1.0$ throughout the range $200-398 \mathrm{~nm}$. 


\section{Comments on Preferred Values}

Absorption cross sections for $\mathrm{Cl}_{2} \mathrm{O}_{2}$ have been published by Cox and Hayman (1988), DeMore and Tschuikow-Roux (1990), Burkholder et al. (1990) and Huder and DeMore (1995). A single wavelength value of the cross section at $210 \mathrm{~nm}$ (Bloss et al., 2001) of $(2.94 \pm 0.86) \times 10^{-18} \mathrm{~cm}^{3}$ molecule ${ }^{-1} \mathrm{~s}^{-1}$ is also available. Older spectra, (Basco and Hunt, 1979; Molina and Molina, 1987) were later shown to be heavily contaminated with other absorbers such as $\mathrm{Cl}_{2} \mathrm{O}_{3}$.

Whereas the spectra of Cox and Hayman (1988), DeMore and Tschuikow-Roux (1990), Burkholder et al. (1990) and Huder and DeMore $(1995)$ show reasonable agreement at wavelengths close to the maximum $(\approx 245 \mathrm{~nm})$ there are significant differences in cross sections at longer wavelengths, which are related to spectral subtraction of e.g. $\mathrm{Cl}_{2} \mathrm{O}, \mathrm{Cl}_{2}$ and $\mathrm{Cl}_{2} \mathrm{O}_{3}$. The spectrum of Burkholder et al. (1990) shows a weak but distinct enhancement in cross section between $\approx 260$ and 310 $\mathrm{nm}$ when compared to all other spectra. The data of Cox and Hayman (1988) are in good agreement with those of DeMore and Tschuikow-Roux (1990) at wavelengths out to $\approx 300 \mathrm{~nm}$. Beyond $320 \mathrm{~nm}$, the Cox and Hayman data are suggested to have an associated uncertainty of a factor of 2, and are too noisy to allow detailed comparison. Huder and DeMore (1995) have compared their data with the older dataset from the same laboratory using $\mathrm{Cl}_{2}-\mathrm{O}_{3}$ mixtures, and find good agreement in the relative shape of the spectrum. The monotonic change in the cross sections of Huder and DeMore (1995) at wavelengths greater than $\approx 270 \mathrm{~nm}$ is closely approximated by an exponential decay, and extrapolated data at $\lambda>310 \mathrm{~nm}$ are considered more reliable than the experimental data at these wavelengths. As Huder and DeMore (1995) appear to prefer their data to the older study from that group (DeMore and Tschuikow-Roux, 1990), the recommendation is based on the single study from 1995. The errors associated with the preferred cross sections at wavelengths greater than $280 \mathrm{~nm}$ may be substantial and further study of the $\mathrm{ClOOCl}$ spectrum is warranted.

Pulsed photolysis at isolated laser wavelengths have shown that the $\mathrm{Cl}$ atoms are formed with near unity quantum yield. Molina et al. (1990) determined $\phi_{2}=1.03 \pm 0.12$ at $308 \mathrm{~nm}$ using resonance fluorescence detection of Cl. Moore et al., (1999) determined $\phi_{2}=0.9 \pm 0.1$ and $\phi_{1}=0.1 \pm 0.1$ at 248 and $308 \mathrm{~nm}$ in a molecular beam experiment, and Plenge et al. (2004) determined $\phi_{2} \geq 0.9$ at $308 \mathrm{~nm}$, and $\phi_{1}<0.02$ or $\phi_{1}<0.1$ at 250 and at $308 \mathrm{~nm}$, respectively. These results are also in agreement with the interpretation of the steady-state photolysis experiments of Cox and Hayman (1988).

\section{References}

Basco, N., and Hunt, J. E.: Int. J. Chem. Kinet. 61, 649, 1979.

Bloss, W. J., Nickolaisen, S. L., Salawitch, R. J., Friedl, R. R., and Sander, S. P.: J. Phys. Chem. 105, 11226, 2001.

Burkholder, J. B., Orlando, J. J., and Howard, C. J.: J. Phys. Chem., 94, 687, 1990.

Cox, R. A., and Hayman, G. D.: Nature, 332, 796, 1988.

DeMore, W. B., and Tschuikow-Roux, E.: J. Phys. Chem., 94, 5856, 1990.

Huder, K., and DeMore, W. B.: J. Phys. Chem. 99, 3905, 1995.

Molina, L. T., and Molina, M. J.: J. Phys. Chem. 91, 433, 1987.

Molina, M. J., Colussi, A. J., Molina, L. T., Schindler, R. N., and Tso, T. L.: Chem. Phys. Lett., 173, 310, 1990.

Moore, T. A., Okumura, M., Seale, J. W., and Minton, T. K.: J. Phys. Chem. A, 103, 1691, 1999.

Plenge, J., Flesch, R., Kuhl, S., Vogel, B., Muller, R., Stroh, F., and Rhl, E.: J. Phys. Chem. A 108, 4859, 2004. 
III.A5.107

$$
\mathrm{Cl}_{2} \mathbf{O}_{3}+\mathbf{h} v \rightarrow \text { products }
$$

Primary photochemical processes

\begin{tabular}{lllll}
\hline Reaction & & $\Delta H^{\circ} / \mathrm{kJ} \mathrm{mol}^{-1}$ & $\lambda_{\text {threshold }} / \mathrm{nm}$ \\
\hline $\mathrm{Cl}_{2} \mathrm{O}_{3}+\mathrm{h} v$ & $\rightarrow \mathrm{ClO}+\mathrm{OClO}$ & $(1)$ & 44 & 2720 \\
& $\rightarrow \mathrm{Cl}+\mathrm{ClO}_{3}$ & $(2)$ & 201 & 595 \\
\hline
\end{tabular}

\section{Preferred Values}

Absorption cross sections for $\mathrm{Cl}_{2} \mathrm{O}_{3}$ at 200-260 K.

\begin{tabular}{llll}
\hline$\lambda / \mathrm{nm}$ & $10^{20} \sigma / \mathrm{cm}^{2}$ molecule & $\lambda / \mathrm{nm}$ & $10^{20} \sigma / \mathrm{cm}^{2}$ molecule $^{-1}$ \\
\hline 220 & 968 & 275 & 1376 \\
225 & 930 & 280 & 1136 \\
230 & 908 & 285 & 890 \\
235 & 883 & 290 & 642 \\
240 & 904 & 295 & 435 \\
245 & 989 & 300 & 288 \\
250 & 1154 & 305 & 176 \\
255 & 1352 & 310 & 107 \\
260 & 1512 & 315 & 56 \\
265 & 1594 & 320 & 36 \\
270 & 1544 & & \\
\hline
\end{tabular}

\section{Comments on Preferred Values}

The preferred values of the absorption cross sections are those reported by Burkholder et al. (1993). Green et al. (2003) report a spectrum that is similar in shape, with a value of $\sigma_{\max }$ which is $\approx 10 \%$ lower. There is no dependence on temperature over the range $200-260 \mathrm{~K}$. The cross sections of Hayman and Cox (1989) are approximately $20 \%$ larger than those of Burkholder et al. (1993) close to $\lambda_{\max }$ and a factor of three larger at $310 \mathrm{~nm}$. A similar enhancement in cross section at $\lambda>300 \mathrm{~nm}$ was observed by Harwood et al. (1995). The cross sections at $\lambda>290 \mathrm{~nm}$ are thus associated with substantial uncertainty.

The mechanism and quantum yield for photodissociation have not been determined.

\section{References}

Burkholder, J. B., Mauldin, R. L., Yokelson, R. J., Solomon, S. and Ravishankara, A. R : J. Phys. Chem., 97, 7597, 1993.

Green, T. J., Islam, M., Guest., P., Hickson, K., Canosa-Mas, C. E. and Wayne, R. P.: Phys. Chem. Chem. Phys. 4, 5409, 2003.

Harwood, M. H., Rowley, D. M., Freshwater, R. A., Cox, R. A. and Jones, R. L.: J. Chem. Soc. Faraday Trans., 91, 3027, 1995.

Hayman, G. D. and Cox, R. A.: Chem. Phys. Lett., 155, 1, 1989. 
III.A5.108

$$
\text { CINO }+\mathbf{h} v \rightarrow \text { products }
$$

\section{Primary photochemical processes}

\begin{tabular}{llll}
\hline Reaction & $\Delta H^{\circ} / \mathrm{kJ} \mathrm{mol}^{-1}$ & $\lambda_{\text {threshold }} / \mathrm{nm}$ \\
\hline $\mathrm{ClNO}+\mathrm{h} v$ & $\rightarrow \mathrm{Cl}+\mathrm{NO}$ & 160 & 750 \\
\hline
\end{tabular}

Preferred Values

Absorption cross sections for CINO at $298 \mathrm{~K}$.

\begin{tabular}{|c|c|c|c|c|c|c|c|}
\hline$\lambda / \mathrm{nm}$ & $\begin{array}{l}10^{20} \sigma / \mathrm{cm}^{2} \\
\text { molecule }^{-1}\end{array}$ & $\lambda / \mathrm{nm}$ & $\begin{array}{l}10^{20} \sigma / \mathrm{cm}^{2} \\
\text { molecule }^{-1}\end{array}$ & $\lambda / \mathrm{nm}$ & $\begin{array}{l}10^{20} \sigma / \mathrm{cm}^{2} \\
\text { molecule }^{-1}\end{array}$ & $\lambda / \mathrm{nm}$ & $\begin{array}{l}10^{20} \sigma / \mathrm{cm}^{2} \\
\text { molecule }^{-1}\end{array}$ \\
\hline 190 & 4320 & 246 & 45.2 & 302 & 10.3 & 370 & 11.0 \\
\hline 192 & 5340 & 248 & 37.7 & 304 & 10.5 & 375 & 9.95 \\
\hline 194 & 6150 & 250 & 31.7 & 306 & 10.8 & 380 & 8.86 \\
\hline 196 & 6480 & 252 & 27.4 & 308 & 11.1 & 385 & 7.82 \\
\hline 198 & 6310 & 254 & 23.7 & 310 & 11.5 & 390 & 6.86 \\
\hline 200 & 5860 & 256 & 21.3 & 312 & 11.9 & 395 & 5.97 \\
\hline 202 & 5250 & 258 & 19.0 & 314 & 12.2 & 400 & 5.13 \\
\hline 204 & 4540 & 260 & 17.5 & 316 & 12.5 & 405 & 4.40 \\
\hline 206 & 3840 & 262 & 16.5 & 318 & 13.0 & 410 & 3.83 \\
\hline 208 & 3210 & 264 & 15.3 & 320 & 13.4 & 415 & 3.38 \\
\hline 210 & 2630 & 266 & 14.4 & 322 & 13.6 & 420 & 2.89 \\
\hline 212 & 2180 & 268 & 13.6 & 324 & 14.0 & 425 & 2.45 \\
\hline 214 & 1760 & 270 & 12.9 & 326 & 14.3 & 430 & 2.21 \\
\hline 216 & 1400 & 272 & 12.3 & 328 & 14.6 & 435 & 2.20 \\
\hline 218 & 1110 & 274 & 11.8 & 330 & 14.7 & 440 & 2.20 \\
\hline 220 & 896 & 276 & 11.3 & 332 & 14.9 & 445 & 2.07 \\
\hline 222 & 707 & 278 & 10.7 & 334 & 15.1 & 450 & 1.87 \\
\hline 224 & 552 & 280 & 10.6 & 336 & 15.3 & 455 & 1.79 \\
\hline 226 & 436 & 282 & 10.2 & 338 & 15.3 & 460 & 1.95 \\
\hline 228 & 339 & 284 & 9.99 & 340 & 15.2 & 465 & 2.25 \\
\hline 230 & 266 & 286 & 9.84 & 342 & 15.3 & 470 & 2.50 \\
\hline 232 & 212 & 288 & 9.71 & 344 & 15.1 & 475 & 2.61 \\
\hline 234 & 164 & 290 & 9.64 & 346 & 15.1 & 480 & 2.53 \\
\hline 236 & 128 & 292 & 9.63 & 348 & 14.9 & 485 & 2.33 \\
\hline 238 & 101 & 294 & 9.69 & 350 & 14.5 & 490 & 2.07 \\
\hline 240 & 82.5 & 296 & 9.71 & 355 & 13.6 & 495 & 1.78 \\
\hline 242 & 67.2 & 298 & 9.89 & 360 & 12.9 & 500 & 1.50 \\
\hline 244 & 55.1 & 300 & 10.0 & 365 & 12.0 & & \\
\hline
\end{tabular}

\section{Quantum yields for CINO photolysis at $298 \mathrm{~K}$}

$\Phi=1.0$ over the entire wavelength range.

\section{Comments on Preferred Values}

The preferred values of the absorption cross sections at $298 \mathrm{~K}$ for the wavelength range 190-350 nm are the values reported by Tyndall et al. (1987) and for the longer wavelengths are the values reported by Roehl et al. (1992). Roehl et al. (1992) 
determined values over the wavelength range $350-650 \mathrm{~nm}$ and the temperature range 223-343 K. Earlier results are discussed by Sander et al. (2006). The preferred quantum yield values are taken from Calvert and Pitts (1966). Relative yields of the spin-orbit states of $\mathrm{Cl}\left({ }^{2} \Pi_{3 / 2}\right)$ and $\mathrm{Cl}\left({ }^{2} \Pi_{1 / 2}\right)$ have been measured by Felder and Morley (1994) and Skorokhodov et al. (1996).

\section{References}

Calvert, J. G. and Pitts Jr., J. N.: Photochemistry, John Wiley \& Sons Inc., New York, p. 230, 1966.

Felder, P. and Morley, G. P.: Chem. Phys., 185, 145, 1994.

Roehl, C. M., Orlando, J. J. and Calvert, J. G.: J. Photochem. Photobiol. A: Chem., 69, 1, 1992.

Sander, S. P., Finlayson-Pitts, B. J., Friedl, R. R., Golden, D. M., Huie, R. F., Keller-Rudek, H., R. E., Kolb, C. E., Kurylo, M. J., Molina, M. J., Moortgat, G. K., Orkin, V. L., Ravishankara, A. R. and Wine, P. H.: "Chemical Kinetics and Photochemical Data for Use in Atmospheric Studies, Evaluation Number 15," JPL Publication 06-2, Jet Propulsion Laboratory, Pasadena, 2006.

Skorokhodov, V., Sato, Y., Suto, K., Matsumi, Y. and Kawasaki, M.: J. Phys. Chem., 100, 12321, 1996.

Tyndall, G. S., Stedman, K. M., Schneider, W., Burrows, J. P. and Moortgat, G. K.: J. Photochem., 36, 133, 1987. 
III.A5.109

$$
\text { ClONO }+\mathbf{h} v \rightarrow \text { products }
$$

\section{Primary photochemical processes}

\begin{tabular}{|c|c|c|c|c|}
\hline Reaction & & & $\Delta H^{\circ} / \mathrm{kJ} \mathrm{mol}^{-1}$ & $\lambda_{\text {threshold }} / \mathrm{nm}$ \\
\hline $\mathrm{ClONO}+\mathrm{h} v$ & $\begin{array}{l}\rightarrow \mathrm{Cl}+\mathrm{NO}_{2} \\
\rightarrow \mathrm{ClO}+\mathrm{NO}\end{array}$ & $\begin{array}{l}\text { (1) } \\
(2)\end{array}$ & $\begin{array}{l}98 \\
136\end{array}$ & $\begin{array}{l}1220 \\
880\end{array}$ \\
\hline
\end{tabular}

\section{Preferred Values}

\section{Absorption cross sections for ClONO at $231 \mathrm{~K}$.}

\begin{tabular}{llll}
\hline$\lambda / \mathrm{nm}$ & $\begin{array}{l}10^{20} \sigma / \mathrm{cm}^{2} \\
\text { molecule }^{-1}\end{array}$ & $\lambda / \mathrm{nm}$ & $\begin{array}{l}10^{20} \sigma / \mathrm{cm}^{2} \\
\text { molecule }^{-1}\end{array}$ \\
\hline 235 & 215 & 320 & 80.3 \\
240 & 176 & 325 & 75.4 \\
245 & 137 & 330 & 58.7 \\
250 & 106 & 335 & 57.7 \\
255 & 65 & 340 & 43.7 \\
260 & 64 & 345 & 35.7 \\
265 & 69 & 350 & 26.9 \\
270 & 90 & 355 & 22.9 \\
275 & 110 & 360 & 16.1 \\
280 & 132 & 365 & 11.3 \\
285 & 144 & 370 & 9.0 \\
290 & 144 & 375 & 6.9 \\
295 & 142 & 380 & 4.1 \\
300 & 129 & 385 & 3.3 \\
305 & 114 & 390 & 2.2 \\
310 & 105 & 395 & 1.5 \\
315 & 98.1 & 400 & 0.6 \\
\hline
\end{tabular}

Comments on Preferred Values

The preferred values of the absorption cross sections at $231 \mathrm{~K}$ are the values reported by Molina and Molina (1977). Photolysis is expected to occur with unit quantum efficiency by breaking of the $\mathrm{Cl}-\mathrm{O}$ bond to yield $\mathrm{Cl}+\mathrm{NO}_{2}$.

\section{References}

Molina, L. T. and Molina, M. J.: Geophys. Res. Lett., 4, 83, 1977. 
III.A5.110

$$
\mathrm{ClNO}_{2}+\mathbf{h} v \rightarrow \text { products }
$$

\section{Primary photochemical processes}

\begin{tabular}{lllll}
\hline Reaction & & $\Delta H^{\circ} / \mathrm{kJ} \mathrm{mol}^{-1}$ & $\lambda_{\text {threshold }} / \mathrm{nm}$ \\
\hline $\mathrm{ClNO}_{2}+\mathrm{h} v$ & $\rightarrow \mathrm{Cl}+\mathrm{NO}_{2}$ & $(1)$ & 142 & 840 \\
& $\rightarrow \mathrm{ClNO}+\mathrm{O}\left({ }^{3} \mathrm{P}\right)$ & $(2)$ & 288 & 415 \\
\hline
\end{tabular}

\section{Preferred Values}

\section{Absorption cross sections for $\mathrm{ClNO}_{2}$ at $298 \mathrm{~K}$.}

\begin{tabular}{llll}
\hline$\lambda / \mathrm{nm}$ & $\begin{array}{l}10^{20} \sigma / \mathrm{cm}^{2} \\
\text { molecule }^{-1}\end{array}$ & $\lambda / \mathrm{nm}$ & $\begin{array}{l}10^{20} \sigma / \mathrm{cm}^{2} \\
\text { molecule }^{-1}\end{array}$ \\
\hline 210 & 320 & 300 & 14.9 \\
220 & 339 & 310 & 12.1 \\
230 & 226 & 320 & 8.87 \\
240 & 133 & 330 & 5.84 \\
250 & 90.6 & 340 & 3.54 \\
260 & 61.3 & 350 & 2.04 \\
270 & 35.3 & 360 & 1.15 \\
280 & 22.0 & 370 & 0.69 \\
290 & 17.3 & & \\
\hline
\end{tabular}

\section{Quantum yield for $\mathrm{CINO}_{2}$ photolysis}

$\Phi_{1}=1.0$

\section{Comments on Preferred Values}

The preferred values of the absorption cross sections are the values reported in the recent study of Ganske et al. (1992) between 210 and $370 \mathrm{nmm}$. They are in good agreement with the values reported by Nelson and Johnston (1981) over the same wavelength range, and with the data of Illies and Takacs (1976/77) between 210 and $300 \mathrm{~nm}$. Furlan et al. (2000) have measured the spectrum at high resolution and find weak structure superimposed on the continuum between $\sim 220$ and $270 \mathrm{~nm}$.

Nelson and Johnston (1981) determined that photolysis at $350 \mathrm{~nm}$ occurs with a quantum yield of unity (within experimental error) to produce $\mathrm{Cl}+\mathrm{NO}_{2}\left(\Phi_{1}=0.93 \pm 0.15\right)$. They also reported a negligible production of oxygen atoms $\left(\Phi_{2}<0.02\right)$. At 235 and $248 \mathrm{~nm}$, the product $\mathrm{NO}_{2}$ from reaction (1) is formed both in the electronic ground state and in excited electronic states (Miller and Johnston, 1993; Carter et al., 1999; Furlan et al., 2000).

\section{References}

Carter, R. T., Hallou, A. and Huber, J. R.: Chem. Phys. Lett., 310, 166, 1999.

Furlan, A, Haeberle, M. A. and Huber, R. J.: J. Phys. Chem. A, 104, 10392-10397, 2000.

Ganske, J. A., Berko, H. N. and Finlayson-Pitts, B. J.: J. Geophys. Res., 97, 7651, 1992.

Illies, A. J. and Takacs, G. A.: J. Photochem., 6, 35, 1976/77.

Miller, C. E. and Johnston, H. S.: J. Phys. Chem., 97, 9924, 1993.

Nelson, H. H. and Johnston, H. S.: J. Phys. Chem., 85, 3891, 1981. 
III.A5.111

$\mathrm{ClONO}_{2}+\mathbf{h} v \rightarrow$ products

Primary photochemical processes

\begin{tabular}{lllll}
\hline Reaction & & $\Delta H^{\circ} / \mathrm{kJ} \mathrm{mol}^{-1}$ & $\lambda_{\text {threshold }} / \mathrm{nm}$ \\
\hline $\mathrm{ClONO}_{2}+\mathrm{h} v$ & $\rightarrow \mathrm{ClO}+\mathrm{NO}_{2}$ & $(1)$ & 112 & 1065 \\
& $\rightarrow \mathrm{Cl}+\mathrm{NO}_{3}$ & $(2)$ & 163 & 735 \\
& $\rightarrow \mathrm{ClONO}+\mathrm{O}\left({ }^{3} \mathrm{P}\right)$ & $(3)$ & 282 & 425 \\
\hline
\end{tabular}

Preferred Values

Absorption cross sections for $\mathrm{ClONO}_{2}$ at 296 and $220 \mathrm{~K}$

\begin{tabular}{llllll}
\hline$\lambda / \mathrm{nm}$ & $\begin{array}{l}10^{20} \sigma / \mathrm{cm}^{2} \\
\text { molecule }\end{array}$ & $\begin{array}{l}10^{20} \sigma / \mathrm{cm}^{2} \\
\text { molecule }\end{array}$ & $\lambda / \mathrm{nm}$ & $\begin{array}{l}10^{20} \sigma / \mathrm{cm}^{2} \\
\text { molecule }\end{array}$ & $\begin{array}{l}10^{20} \sigma / \mathrm{cm}^{2} \\
\text { molecule }\end{array}$ \\
& $296 \mathrm{~K}$ & $220 \mathrm{~K}$ & & $296 \mathrm{~K}$ & $220 \mathrm{~K}$ \\
\hline 200 & 282 & 270 & 315 & 1.14 & \\
205 & 284 & & 320 & 0.831 & 0.578 \\
210 & 314 & 315 & 325 & 0.613 & \\
215 & 342 & & 330 & 0.466 & 0.329 \\
220 & 332 & 335 & 335 & 0.367 & \\
225 & 278 & & 340 & 0.302 & 0.230 \\
230 & 208 & 200 & 345 & 0.258 & \\
235 & 148 & & 350 & 0.229 & 0.186 \\
240 & 105 & 96.7 & 355 & 0.208 & \\
245 & 76.4 & & 360 & 0.200 & 0.169 \\
250 & 56.0 & 49.7 & 365 & 0.180 & \\
245 & 76.4 & & 360 & 0.200 & 0.169 \\
250 & 56.0 & 49.7 & 365 & 0.180 & \\
255 & 43.2 & & 370 & 0.159 & 0.136 \\
260 & 33.8 & 29.1 & 375 & 0.141 & \\
265 & 26.5 & & 380 & 0.121 & 0.104 \\
270 & 20.5 & 17.3 & 385 & 0.137 & \\
275 & 15.7 & & 390 & 0.091 & 0.077 \\
280 & 11.9 & 9.83 & 395 & 0.076 & \\
285 & 8.80 & & 400 & 0.064 & 0.052 \\
290 & 6.41 & 5.15 & 405 & 0.054 & \\
295 & 4.38 & & 410 & 0.044 & 0.034 \\
300 & 3.13 & 2.40 & 415 & 0.036 & \\
305 & 2.24 & & 420 & 0.032 & 0.023 \\
310 & 1.60 & 1.16 & 425 & 0.023 & \\
& & & 430 & 0.019 & 0.013 \\
\hline
\end{tabular}

\section{Quantum yields for $\mathrm{ClONO}_{2}$ photolysis}

$\Phi_{2}(\lambda<308 \mathrm{~nm})=0.6$

$\Phi_{2}(\lambda 308-364 \mathrm{~nm})=7.143 \times 10^{-3} \lambda(\mathrm{nm})-1.60$

$\Phi_{2}(\lambda>364 \mathrm{~nm})=1.0$ 


$$
\Phi_{1}(\lambda)=1-\Phi_{2}(\lambda)
$$

\section{Comments on Preferred Values}

The preferred values of the absorption cross sections are taken from Burkholder et al. (1994) who measurements covered the wavelength range 195-430 nm and the temperature range 220-296 K. They report (Burkholder et al., 1994) every $2 \mathrm{~nm}$, values of $\sigma$ at $296 \mathrm{~K}$ and values of the parameters $A_{1}$ and $A_{2}$ needed to compute the temperature dependence by the equation:

$\sigma(\lambda, T) / \sigma(\lambda, 296)=1+A_{1}(T-296)+A_{2}(T-296)^{2}$

In this data sheet, room temperature values at $5 \mathrm{~nm}$ intervals and values for $220 \mathrm{~K}$ at $10 \mathrm{~nm}$ intervals are given. These values are in good agreement with results of Molina and Molina (1979).

Photolysis quantum yields have been derived by observation of the radical fragments, $\mathrm{Cl}, \mathrm{ClO}, \mathrm{NO}_{3}$ and $\mathrm{O}\left({ }^{3} \mathrm{P}\right)$. The most recent studies (Ravishankara, 1995; Moore et al., 1995; Nelson et al., 1996; Nickolaisen et al., 1996; Tyndall et al., 1997; Goldfarb et al., 1997; Yokelsen et al., 1997; Zou et al., 2002) approach a general agreement of the wavelength dependence of the quantum yields $\Phi_{1}, \Phi_{2}$ and $\Phi_{3}$, and are considered more reliable than older investigations (Margitan, 1983; Knauth and Schindler, 1983; Chang et al., 1979). Despite generally good agreement, some discrepancies, in particular pressure dependences, such as observed in Nickolaisen et al. (1997) were not reproduced in Tyndall et al. (1997), Goldfarb et al. (1997) and Yokelsen et al. (1997) and remain unexplained. The preferred values are based on the results of Goldfarb et al. (1997) and Yokelsen et al. (1997), who have the most extensive dataset. The results obtained are $\Phi_{1}=0.60,0.40$ and 0.35 for $\lambda=222$, 248 and $308 \mathrm{~nm}$ respectively. $\Phi_{2}=0.40,0.60,0.65$ and 0.93 for $\lambda=222,248,308$ and $352.5 \mathrm{~nm}$, respectively. Oxygen atoms have been observed in several experiments, though they cannot be unambiguously assigned to channel (3) as some (or all) are formed by the decomposition of hot $\mathrm{NO}_{3}$ radicals formed when $\mathrm{ClONO}_{2}$ is photolysed at short wavelengths, e.g. Zou et al. (2002).

The preferred quantum yields follow recommendations of the JPL-NASA evaluation panel (Sander et al., 2006). There appears to be no significant change in $\Phi_{2}$ between 248 and $308 \mathrm{~nm}$ so that a wavelength independent quantum yield of 0.6 is appropriate. $\Phi_{2}$ increases with wavelength at the expense of $\Phi_{1}$ between 308 and $364 \mathrm{~nm}$, so that a wavelength dependence is given. Above $364 \mathrm{~nm} \Phi_{2}$ is close to unity, so that $\Phi_{1}$ becomes zero.

\section{References}

Burkholder, J. B., Talukdar, R. K., and Ravishankara, A. R.: Geophys. Res. Lett., 21, 585, 1994.

Burrows, J. P., Tyndall, G. S., and Moortgat, G. K.: J. Phys. Chem., 92, 4340, 1988.

Chang, J. S., Barker, J. R., Davenport, J. E., and Golden, D. M.: Chem. Phys. Lett., 60, 385, 1979.

Goldfarb, L., Schmoltner, A.-M., Gilles, M. K., Burkholder, J. B., and Ravishankara, A. R.: J. Phys. Chem. A, 101, 6658, 1997.

Knauth, H. D. and Schindler, R. N.: Z. Naturforsch., 38a, 393, 1983.

Margitan, J. J.: J. Phys. Chem., 87, 674, 1983.

Molina, L. T. and Molina, M. J.: J. Photochem., 11, 139, 1979.

Moore, T. A., Okumura, M. Tagawa, M., and Minton, T. K.: Faraday Discuss., 100, 295, 1995.

Nelson, C. M., Moore, T. A., Okumura, M., and Minton, T. K.: Chem. Phys., 207, 287, 1996.

Nickolaisen, S. L., Sander, S. P., and Friedl, R. R.: J. Phys. Chem., 100, 10 165, 1996.

Ravishankava, A. R.: Faraday Discuss., 100, 335, 1995.

Sander, S. P., Finlayson-Pitts, B. J., Friedl, R. R., Golden, D. M., Huie, R. F., Keller-Rudek, H., R. E., Kolb, C. E., Kurylo, M. J., Molina, M. J., Moortgat, G. K., Orkin, V. L., Ravishankara, A. R. and Wine, P. H.: "Chemical Kinetics and Photochemical Data for Use in Atmospheric Studies, Evaluation Number 15," JPL Publication 06-2, Jet Propulsion Laboratory, Pasadena, 2006.

Tyndall, G. S., Kegley-Owen, C. S., Orlando, J. J., and Calvert, J. G.: J. Chem. Soc. Faraday Trans., 93, 2675, 1997.

Yokelson, R. J.: Burkholder, J. B., Fox, R. W., and Ravishankara, A. R.: J. Phys. Chem. A, 101, 6667, 1997.

Zou, P., Park, B. A., Schmitz, B. A., Nguyen, T., North, S. W.: J. Phys. Chem. A 106, 1004-1010, 2002 
III.A5.112

$$
\mathbf{C l}_{2}+\mathbf{h} v \rightarrow \mathbf{C l}+\mathbf{C l}
$$

\section{Primary photochemical processes}

\begin{tabular}{llll}
\hline Reaction & $\Delta H^{\circ} / \mathrm{kJ} \mathrm{mol}^{-1}$ & $\lambda_{\text {threshold }} / \mathrm{nm}$ \\
\hline $\mathrm{Cl}_{2}+\mathrm{h} v$ & $\left.\rightarrow \mathrm{Cl}\left({ }^{2} \mathrm{P}_{3 / 2}\right)+\mathrm{Cl}^{2}{ }^{2} \mathrm{P}_{3 / 2}\right)$ & 242 & 495 \\
\hline
\end{tabular}

\section{Preferred Values}

\section{Absorption cross sections for $\mathrm{Cl}_{2}$ at $298 \mathrm{~K}$.}

\begin{tabular}{llll}
\hline$\lambda / \mathrm{nm}$ & $\begin{array}{l}10^{20} \sigma / \mathrm{cm}^{2} \\
\text { molecule }\end{array}$ & $\lambda / \mathrm{nm}$ & $\begin{array}{l}10^{20} \sigma / \mathrm{cm}^{2} \\
\text { molecule }\end{array}$ \\
\hline 260 & 0.20 & 370 & 8.4 \\
270 & 0.82 & 380 & 5.0 \\
280 & 2.6 & 390 & 2.9 \\
290 & 6.2 & 400 & 1.8 \\
300 & 11.9 & 410 & 1.3 \\
310 & 18.5 & 420 & 0.96 \\
320 & 23.7 & 430 & 0.73 \\
330 & 25.5 & 440 & 0.54 \\
340 & 23.5 & 450 & 0.38 \\
350 & 18.8 & 460 & 0.26 \\
360 & 13.2 & 370 & 0.16 \\
\hline
\end{tabular}

\section{Comments on Preferred Values}

The preferred values of the absorption cross sections at $298 \mathrm{~K}$ are the values reported by Maric et al. (1993), which are in excellent agreement with those of Ganske et al. (1992). There is good agreement with earlier studies which are cited in IUPAC (1992). Maric et al. (1993) fitted the data for the wavelength region 250-550 nm with the following semi-empirical expression:

$$
10^{20} \sigma / \mathrm{cm}^{2} \text { molecule }{ }^{-1}=\alpha^{0.5} \times 27.3 \exp \left\{-99.0 \alpha[\ln (329.5 / \lambda)]^{2}\right\}+\alpha^{0.5} \times 0.932 \exp \left\{-91.5 \alpha[\ln (406.5 / \lambda)]^{2}\right\}
$$

where $\alpha=\tanh (402.676 / T)$

This expression combines the semi-empirical function originally proposed by Johnston et al. (1984) with the temperature dependence expressions proposed by Sulzer and Wieland (1952). The photodissociation occurs with a quantum yield of unity.

\section{References}

Ganske, J. A., Berko, H. N., and Finlayson-Pitts, B. J.: J. Geophys. Res., 97, 7651, 1992.

IUPAC: Supplement IV, 1992 (see references in Introduction).

Johnston, H. S., Paige, M., and Yao, F.: J. Geophys. Res., 89, 11661, 1984.

Maric, D., Burrows, J. P., Meller, R., and Moortgat, G. K.: J. Photochem. Photobiol. A. Chem., 70, 205, 1993.

Sulzer, P. and Wieland, K.: Helv. Phys. Acta., 25, 653, 1952. 
III.A5.113

$$
\mathbf{H B r}+\mathbf{h} v \rightarrow \text { products }
$$

Primary photochemical processes

\begin{tabular}{llll}
\hline Reaction & $\Delta H^{\circ} / \mathrm{kJ} \mathrm{mol}^{-1}$ & $\lambda_{\text {threshold }} / \mathrm{nm}$ \\
\hline $\mathrm{HBr}+\mathrm{h} v$ & $\rightarrow \mathrm{H}+\mathrm{Br}$ & 366 & 327 \\
\hline
\end{tabular}

\section{Preferred Values}

Absorption cross sections of $\mathrm{HBr}$ at $298 \mathrm{~K}$.

\begin{tabular}{llll}
\hline$\lambda / \mathrm{nm}$ & $10^{20} \sigma / \mathrm{cm}^{2}$ molecule $^{-1}$ & $\lambda / \mathrm{nm}$ & $10^{20} \sigma / \mathrm{cm}^{2}$ molecule $^{-1}$ \\
\hline 170 & 254 & 215 & 39.0 \\
175 & 270 & 220 & 23.5 \\
180 & 265 & 225 & 14.2 \\
185 & 242 & 230 & 8.08 \\
190 & 204 & 235 & 4.43 \\
195 & 164 & 240 & 2.35 \\
200 & 122 & 250 & 0.661 \\
205 & 87.2 & 260 & 0.141 \\
210 & 59.1 & 270 & 0.020 \\
\hline
\end{tabular}

\section{Quantum yields for $\mathrm{HBr}$ photolysis}

$\Phi=1.0$

\section{Comments on Preferred Values}

The preferred cross section values are those determined by Huebert and Martin (1968) between 170 and $220 \mathrm{~nm}$, Goodeve and Taylor, (1935) between 220 and $240 \mathrm{~nm}$, (scaled by 0.95) and Okabe, 1977 (240-270 nm). The resultant spectrum is in good agreement with the cross section at $184.9 \mathrm{~nm}$ from Ravishankara (1979) and Barone et al. (1994). Other determinations of Romand (1949), Roxlo et al. (1980) and Nee et al. (1986) show, in some wavelength regions, substantial differences.

A primary quantum yield of unity was obtained with an $\mathrm{N}_{2} \mathrm{O}$ actinometer (Martin and Willard, 1964). The branching ratio for photolysis forming $\operatorname{Br}\left({ }^{2} \mathrm{P}_{1 / 2}\right)$ and $\operatorname{Br}\left({ }^{2} \mathrm{P}_{3 / 2}\right)$ was determined in Regan et al. (1999).

\section{References}

Barone, S. B., Turnipseed, A. A., Gierczak, T., and Ravishankara, A. R.: J. Phys. Chem. 98, 11969, 1994.

Goodeve, C. F. and Taylor, A. W. C.: Proc. Roy. Soc. A, 152, 221, 1935.

Huebert, B. J. and Martin, R. M.: J. Phys. Chem., 72, 3046, 1968.

Martin, R. M. and Willard, J. E.: J. Chem. Phys., 40, 2999, 1964.

Nee, J. B., Suto, M., Lee, L. C., J. Chem. Phys. 85, 4919, 1986.

Okabe, H.: J. Chem. Phys. 66, 2058, 1977.

Ravishankara, A. R., Wine, P. H. and Langford, A. O.: Chem. Phys. Lett. 63, 479, 1979.

Regan, P. M., Langford, S. R., Orr-Ewing, A. J., and Ashfold, M. N. R.: J. Chem. Phys., 110, 281, 1999.

Romand, J.: Ann. Phys. (Paris), 4, 527, 1949.

Roxlo, C., and Mandl, A.: J. Appl. Phys. 51, 2969, 1980. 
III.A5.114

$\mathrm{HOBr}+\mathbf{h} v \rightarrow$ products

Primary photochemical processes

\begin{tabular}{lllll}
\hline Reaction & & $\Delta H^{\circ} / \mathrm{kJ} \mathrm{mol}^{-1}$ & $\lambda_{\text {threshold }} / \mathrm{nm}$ \\
\hline $\mathrm{HOBr}+\mathrm{h} v$ & $\rightarrow \mathrm{HO}+\mathrm{Br}$ & $(1)$ & 207 & 578 \\
& $\rightarrow \mathrm{HBr}+\mathrm{O}\left({ }^{3} \mathrm{P}\right)$ & $(2)$ & 267 & 445 \\
& $\rightarrow \mathrm{BrO}+\mathrm{H}$ & $(3)$ & 394 & 304 \\
\hline
\end{tabular}

\section{Absorption cross section data}

\begin{tabular}{llc}
\hline Wavelength range/nm & Reference & Comments \\
\hline $240-410$ & Orlando and Burkholder, 1995 & (a) \\
$234-400$ & Benter et al., 1995 & (b) \\
$240-390$ & Deters et al., 1996 & (a) \\
$235-430$ & Rattigan et al, 1996 & (a) \\
$260-545$ & Ingham et al., 1998 & (c) \\
\hline
\end{tabular}

\section{Quantum yield data}

See Comments on Preferred Values.

\section{Comments}

(a) $\mathrm{HOBr}$ was generated by allowing a gas phase mixture of $\mathrm{Br}_{2} \mathrm{O}$ with $\mathrm{H}_{2} \mathrm{O}$ to reach equilibrium. Corrections were necessary to account for the $\mathrm{Br}_{2} \mathrm{O}$ and $\mathrm{Br}_{2}$ present in the mixture.

(b) $\mathrm{HOBr}$ generated in aqueous solution and flowed into an absorption cell.

(c) $\mathrm{HOBr}$ was generated by pulsed laser photolysis of flowing $\mathrm{H}_{2} \mathrm{O}_{2}-\mathrm{Br}_{2}$ mixtures in an absorption cell through which the analysing beam could be passed twice to give an absorption path length of $2.6 \mathrm{~m}$. Detection was achieved either by means of time-resolved photomutiplier measurements or by a diode array which could be gated from $0.06 \mathrm{~ms}$ to $5.06 \mathrm{~ms}$. The spectral resolutions for the two techniques were $2 \mathrm{~nm}$ and $1.2 \mathrm{~nm}$ respectively. 


\section{Preferred Values}

\section{Absorption cross sections of $\mathrm{HOBr}$ at $295 \mathrm{~K}$.}

\begin{tabular}{|c|c|c|c|}
\hline$\lambda / \mathrm{nm}$ & $\begin{array}{l}10^{20} \sigma / \mathrm{cm}^{2} \\
\text { molecule }\end{array}$ & $\lambda / \mathrm{nm}$ & $\begin{array}{l}10^{20} \sigma / \mathrm{cm}^{2} \\
\text { molecule }\end{array}$ \\
\hline 250 & 4.16 & 405 & 1.80 \\
\hline 255 & 6.93 & 410 & 1.36 \\
\hline 260 & 10.5 & 415 & 1.08 \\
\hline 265 & 14.6 & 420 & 0.967 \\
\hline 270 & 18.7 & 425 & 1.00 \\
\hline 275 & 22.1 & 430 & 1.15 \\
\hline 280 & 24.3 & 435 & 1.40 \\
\hline 285 & 25.0 & 440 & 1.68 \\
\hline 290 & 24.0 & 445 & 1.96 \\
\hline 295 & 21.0 & 450 & 2.18 \\
\hline 300 & 19.1 & 455 & 2.28 \\
\hline 305 & 16.2 & 460 & 2.28 \\
\hline 310 & 13.6 & 465 & 2.14 \\
\hline 315 & 11.8 & 470 & 1.91 \\
\hline 320 & 10.8 & 475 & 1.62 \\
\hline 325 & 10.5 & 480 & 1.30 \\
\hline 330 & 10.8 & 485 & 0.993 \\
\hline 335 & 11.3 & 490 & 0.723 \\
\hline 340 & 11.9 & 495 & 0.502 \\
\hline 350 & 12.3 & 500 & 0.334 \\
\hline 345 & 12.5 & 505 & 0.212 \\
\hline 355 & 12.2 & 510 & 0.129 \\
\hline 360 & 11.5 & 515 & 0.075 \\
\hline 365 & 10.5 & 520 & 0.042 \\
\hline 370 & 9.32 & 525 & 0.023 \\
\hline 375 & 8.00 & 530 & 0.012 \\
\hline 380 & 6.66 & 535 & 0.006 \\
\hline 385 & 5.38 & 540 & 0.003 \\
\hline 390 & 4.22 & 545 & 0.0001 \\
\hline 395 & 3.24 & & \\
\hline 400 & 2.43 & & \\
\hline
\end{tabular}

\section{Comments on Preferred Values}

There remain significant uncertainties in the values of the absorption cross sections despite a number of recent studies (Orlando and Burkholder, 1995; Benter et al., 1995; Deters et al., 1996; Rattigan et al., 1996; Ingham et al., 1998). However, the shape of the spectrum has been clarified. Orlando and Burkholder (1995), Benter et al. (1995) and Deters et al. (1996) observe two absorption bands between 200 and $400 \mathrm{~nm}$ with a rapid decline in the cross sections beyond $400 \mathrm{~nm}$. Rattigan et al. (1996) and Ingham et al. (1998) also observe these two bands but find another weak band with a maximum at $\sim 460 \mathrm{~nm}$ as predicted by theoretical calculations (Francisco et al., 1996; Minaev et al., 1999). Further evidence for the long wavelength band comes from a laser photolysis study of Barnes et al. (1994) who observed HO production from HOBr photolysis over the range $400-600 \mathrm{~nm}$. It now seems clear that the spectrum consists of three broad bands with maxima at $\sim 284 \mathrm{~nm}, \sim 351 \mathrm{~nm}$, and $\sim 457 \mathrm{~nm}$.

At the maximum of the short wavelength band the measured values of the cross sections differ by $\sim 20 \%$, whilst in the $350 \mathrm{~nm}$ region the differences become as much as a factor of three. It is likely that this scatter, and the difficulty in detecting the long wavelength band, are largely due to the presence of impurities such as $\mathrm{Br}_{2} \mathrm{O}$ and $\mathrm{Br}_{2}$, which absorb strongly in the same spectral region as $\mathrm{HOBr}$. 
In most of the studies (Orlando and Burkholder, 1995; Deters et al., 1996; Rattigan et al., 1996) HOBr was generated by reaction of $\mathrm{Br}_{2} \mathrm{O}$ with $\mathrm{H}_{2} \mathrm{O}$, leading to the production of equilibrium mixtures of $\mathrm{Br}_{2} \mathrm{O}, \mathrm{H}_{2} \mathrm{O}$ and $\mathrm{HOBr}$. Benter et al. (1995) achieved smaller $\left[\mathrm{Br}_{2} \mathrm{O}\right] /[\mathrm{HOBr}]$ ratios by generation and elution of $\mathrm{HOBr}$ from aqueous solution and Ingham et al. (1998) attempted to circumvent the problems of impurities by in situ generation of the $\mathrm{HOBr}$ using pulsed laser photolysis of $\mathrm{H}_{2} \mathrm{O}_{2}-$ $\mathrm{Br}_{2}$ mixtures, calibrating the cross sections relative to the better established cross sections of $\mathrm{Br}_{2}$. The study of Ingham et al. (1998) appears to have been the most successful in avoiding interference from impurities and their values are adopted as our preferred values. Their measurements (Ingham et al., 1998) only went down to $260 \mathrm{~nm}$ but they fitted their results to an expression consisting of the sum of three Gaussian terms and the range of our preferred values have been extended slightly using calculated values from this expression. Experimental values reported for $\lambda<250 \mathrm{~nm}$ are subject to large uncertainty and no recommendation is made.

HO quantum yields close to unity have been observed for photolysis of HOI and HOCl, and a similar value would be expected for HOBr. The only experimental study is that of Benter et al. (1995) who obtained a value of $>0.95$ at $363 \mathrm{~nm}$ but this value is dependent on the cross sections used. Confirmation of unit quantum yield is desirable.

Calculations of the atmospheric lifetime of HOBr by Ingham et al. (1998) using their own cross sections give values of $\sim 5 \mathrm{~min}$ in the lower stratosphere at a zenith angle of $40^{\circ}$ and $\sim 30 \mathrm{~min}$ at the surface at high zenith angles.

\section{References}

Barnes, R. J., Lock, M., Coleman, J., and Sinha, M.: J. Phys. Chem., 100, 817, 1994.

Benter, T., Feldman, Chr., Kirchner, U., Schmidt, M., Schmidt, S., and Schindler, R. N.: Ber. Bunsenges. Phys. Chem., 99, $1144,1995$.

Deters, B., Burrows, J. P., Himmelman, S., and Blindauer, C.: Ann. Geophys., 14, 468, 1996.

Francisco, J., Hand, M. R., and Williams, I. H.: J. Phys. Chem., 100, 457, 1996.

Ingham, T., Bauer, D., Landgraf, J., and Crowley, J. N.: J. Phys. Chem. A, 102, 3293, 1998.

Minaev, B. F.: J. Phys. Chem. A, 103, 7294, 1999.

Orlando, J. J. and Burkholder, J. B.: J. Phys. Chem., 99, 1143, 1995.

Rattigan, O. V., Lary, D. J., Jones, R. L., and Cox, R. A.: J. Geophys. Res., 101, 23021, 1996. 
III.A5.115

$$
\mathbf{B r O}+\mathbf{h} v \rightarrow \text { products }
$$

Primary photochemical processes

\begin{tabular}{lllll}
\hline Reaction & & $\Delta H^{\circ} / \mathrm{kJ} \mathrm{mol}^{-1}$ & $\lambda_{\text {threshold }} / \mathrm{nm}$ \\
\hline $\mathrm{BrO}+\mathrm{h} v$ & $\rightarrow \mathrm{Br}+\mathrm{O}\left({ }^{3} \mathrm{P}\right)$ & $(1)$ & 232 & 515 \\
& $\rightarrow \mathrm{Br}+\mathrm{O}\left({ }^{1} \mathrm{D}\right)$ & $(2)$ & 422 & 238 \\
\hline
\end{tabular}

\section{Absorption cross section data}

\begin{tabular}{llc}
\hline Wavelength range/nm & Reference & Comments \\
\hline $296-375$ & Cox et al., 1982 & (a) \\
$312-385$ & Wahner et al., 1988 & (b) \\
338.5 & Gilles et al., 1997 & (c) \\
\hline
\end{tabular}

\section{Quantum yield data}

No experimental data are available.

\section{Comments}

(a) $\mathrm{BrO}$ radicals were produced by square-wave modulated photolysis of $\mathrm{Br}_{2}-\mathrm{O}_{3}$ mixtures and detected in absorption at $0.22 \mathrm{~nm}$ resolution by molecular modulation spectroscopy using a multichannel analyser to collect the signal. The absolute cross section at $338.3 \mathrm{~nm}$ was determined by measuring the kinetics of $\mathrm{BrO}$ production and removal.

(b) $\mathrm{BrO}$ radicals were generated in a flowing $\mathrm{He}$ carrier gas by reacting $\mathrm{Br}$ atoms with $\mathrm{O}_{3}$ and passed into a $1 \mathrm{~m}$ long absorption cell coupled to a diode array spectrometer. Spectra were recorded at $298 \mathrm{~K}$ and $223 \mathrm{~K}$ with a resolution of $0.4 \mathrm{~nm}$. Absolute cross sections were determined at $338.5 \mathrm{~nm}$ at both temperatures by photolysis of $\mathrm{Br}-\mathrm{O}_{3}$ or $\mathrm{Br}-\mathrm{O}_{2}$ mixtures and monitoring the kinetics of the changes in $[\mathrm{BrO}]$.

(c) $\mathrm{BrO}$ radicals were produced by pulsed laser photolysis at $193 \mathrm{~nm}$ of $\mathrm{N}_{2} \mathrm{O}-\mathrm{Br}_{2}$ mixtures in an absorption cell of $87 \mathrm{~cm}$ path length, and detected in time resolved experiments by means of a monochromator-photomultiplier combination. Pulsed photolysis of $\mathrm{N}_{2} \mathrm{O}-\mathrm{O}_{2}$ mixtures, detecting $\mathrm{O}_{3}$ production by absorption at $253.7 \mathrm{~nm}$, was carried out in "back-to-back" experiments in the same system. The $\mathrm{BrO}$ absorption cross sections were thus determined relative to the $\mathrm{O}_{3}$ cross section at $253.7 \mathrm{~nm}$. The absorption cross section at the peak of the $(7,0)$ band was measured over the temperature range 204$388 \mathrm{~K}$. 


\section{Preferred Values}

\section{Absorption cross sections of $\mathrm{BrO}$ at $303 \mathrm{~K}$.}

\begin{tabular}{llll}
\hline$\lambda / \mathrm{nm}$ & $10^{20} \sigma / \mathrm{cm}^{2}$ molecule ${ }^{-1}$ & $\lambda / \mathrm{nm}$ & $10^{20} \sigma / \mathrm{cm}^{2}$ molecule $^{-1}$ \\
\hline $300-305$ & 200 & $340-345$ & 515 \\
$305-310$ & 259 & $345-350$ & 399 \\
$310-315$ & 454 & $350-355$ & 228 \\
$315-320$ & 391 & $355-360$ & 172 \\
$320-325$ & 600 & $360-365$ & 161 \\
$325-330$ & 753 & $365-370$ & 92 \\
$330-335$ & 628 & $370-375$ & 51 \\
$335-340$ & 589 & & \\
\hline
\end{tabular}

\section{Comments on Preferred Values}

The BrO radical has a banded absorption spectrum in the $290-380 \mathrm{~nm}$ range. The values of the absorption cross sections at the band peaks are dependent on temperature and spectral resolution. The band locations, vibrational level assignments, and the values of the absorption cross sections at several spectral resolutions, are reported in the paper by Wahner et al. (1988) which should be consulted for detailed information. The strongest absorption feature is the $(7,0)$ band at $338.5 \mathrm{~nm}$ for which the cross section at $0.5 \mathrm{~nm}$ resolution was determined to be $(1.48 \pm 0.14) \times 10^{-17} \mathrm{~cm}^{2}$ molecule ${ }^{-1}$ at $298 \mathrm{~K}$. More recently a study by Gilles et al. (1997) from the same laboratory gives a value of $1.63 \times 10^{-17} \mathrm{~cm}^{2}$ molecule ${ }^{-1}$. This latter value (Gilles et al., 1997) is preferred. In the same study, Gilles et al. (1997) investigated the temperature dependence of the absorption cross section at the peak of the $338.5 \mathrm{~nm}$ band over the range $204-388 \mathrm{~K}$ and found that it could be represented by the relationship $\sigma_{338} / 10^{-17} \mathrm{~cm}^{2}$ molecule ${ }^{-1}=3.29-\left(5.58 \times 10^{-3}\right) T$.

The preferred values given in the Table are the values of the cross section averaged over $5 \mathrm{~nm}$ intervals reported by Cox et al. (1982), which are in good agreement with those of Wahner et al. (1988) and Gilles et al. (1997). Cox et al. (1982) used their data to calculate a lifetime against solar photoexcitation of $30 \mathrm{~s}$ for a solar zenith angle of 30 degrees. Earlier studies are discussed in previous evaluations (CODATA, 1980, 1984) .

\section{References}

Cox, R. A., Sheppard, D. W., and Stevens, M. P.: J. Photochem., 19, 189, 1982.

CODATA: 1980 (see references in Introduction).

CODATA: Supplement II, 1984 (see references in Introduction).

Gilles, M. K., Turnipseed, A. A., Burkholder, J. B., Ravishankara, A. R., and Solomon, S.: J. Phys. Chem. A, 101, 5526, 1997.

Wahner, A., Ravishankara, A. R., Sander, S. P., and Friedl, R. R.: Chem. Phys. Lett., 152, 507, 1988. 
III.A5.116

$$
\mathrm{OBrO}+\mathbf{h} v \rightarrow \text { products }
$$

\section{Primary photochemical processes}

\begin{tabular}{lllll}
\hline Reaction & & & $\Delta H^{\circ} / \mathrm{kJ} \mathrm{mol}^{-1}$ & $\lambda_{\text {threshold }} / \mathrm{nm}$ \\
\hline $\mathrm{OBrO}+\mathrm{h} v$ & $\rightarrow \mathrm{Br}+\mathrm{O}_{2}$ & $(1)$ & -52 & - \\
& $\rightarrow \mathrm{BrO}+\mathrm{O}\left({ }^{3} \mathrm{P}\right)$ & $(2)$ & 205 & 584 \\
\hline
\end{tabular}

\section{Absorption cross section data}

\begin{tabular}{llc}
\hline Wavelength range/nm & Reference & Comments \\
\hline $400-600$ & Rattigan et al., 1994 & (a) \\
$385-645$ & Miller et al., 1997 & (b) \\
$390-630$ & Knight et al., 2000 & (c) \\
\hline
\end{tabular}

\section{Comments}

(a) Bromine-sensitized photodecomposition of ozone at $380 \mathrm{~nm}$ to $480 \mathrm{~nm}$. After subtraction of absorbances due to $\mathrm{O}_{3}$ and $\mathrm{Br}_{2}$, the residual spectrum consisted of absorption bands from $400 \mathrm{~nm}$ to $600 \mathrm{~nm}$ superimposed on a continuum, with a maximum absorption near $505 \mathrm{~nm}$. This spectrum was attributed to $\mathrm{OBrO}$ because of its strong resemblance to the $\mathrm{OClO}$ absorption spectrum. Because absolute amounts of $\mathrm{OBrO}$ were not determined, absolute absorption cross section values were not estimated. The spectral features show clear signs of broadening as $T$ was increased from $273 \mathrm{~K}$ to $339 \mathrm{~K}$, indicating temperature dependence of cross sections in the bands.

(b) Molecular bromine and products of an $\mathrm{O}_{2}-\mathrm{He}$ discharge flowed through an absorption cell at $250 \mathrm{~K}$. Strong $\mathrm{OBrO}$ signals were observed after pumping on the condensate collected on the cell walls. An experimental and theoretical analysis of the $C\left({ }^{2} A_{2}\right) \leftarrow X\left({ }^{2} B_{1}\right)$ absorption spectrum from $385 \mathrm{~nm}$ to $645 \mathrm{~nm}$ is presented, and a complete set of transition energies and assignments is given. Because absolute amounts of $\mathrm{OBrO}$ were not determined, absolute absorption cross section values were not derived.

(c) Products of a $\mathrm{Br}_{2}-\mathrm{O}_{2}-\mathrm{He}$ discharge flow were collected in a cold trap followed by evaporation at warmer temperatures. $\mathrm{OBrO}$ concentrations were determined by chemical titration with excess $\mathrm{NO}$ yielding $\mathrm{NO}_{2}+\mathrm{BrO}$, with quantitative measurement of the $\mathrm{NO}_{2}$ product by UV absorption. Quantitative values of absorption cross sections are reported over the wavelength range $400 \mathrm{~nm}$ to $560 \mathrm{~nm}$. During this study another UV absorber, assumed to be an unspecified bromine oxide $\mathrm{Br}_{\mathrm{x}} \mathrm{O}_{\mathrm{y}}$, was observed to originate from this $\mathrm{OBrO}$ source. 


\section{Preferred Values}

\section{Absorption cross sections of $\mathrm{OBrO}$ at $298 \mathrm{~K}$.}

\begin{tabular}{lllll}
\hline $\mathrm{n}$ & $\begin{array}{l}(\mathrm{n}, 0,0) \leftarrow(0,0,0) \\
\lambda / \mathrm{nm}\end{array}$ & $\begin{array}{l}(\mathrm{n}, 1,0) \leftarrow(0,0,0) \\
10^{17} \sigma / \mathrm{cm}^{2} \\
\text { molecule }^{-1}\end{array}$ & $\begin{array}{l}\lambda / \mathrm{nm} \\
10^{17} \sigma / \mathrm{cm}^{2} \\
\text { molecule }^{-1}\end{array}$ \\
\hline 0 & 630.4 & - & 622.0 & - \\
1 & 606.1 & - & 598.4 & - \\
2 & 583.8 & - & 576.8 & - \\
3 & 563.4 & 1.08 & 556.8 & 1.35 \\
4 & 544.4 & 1.45 & 538.5 & 1.74 \\
5 & 527.1 & 1.64 & 521.6 & 1.91 \\
6 & 510.7 & 1.77 & 505.5 & 1.96 \\
7 & 495.5 & 1.72 & 490.7 & 1.76 \\
8 & 481.2 & 1.67 & 476.9 & 1.51 \\
9 & 468.2 & 1.44 & 464.1 & 1.26 \\
10 & 455.8 & 1.21 & 452.2 & 0.96 \\
11 & 444.4 & 1.02 & 440.8 & 0.72 \\
12 & 433.7 & 0.79 & 430.4 & 0.49 \\
13 & 423.5 & 0.57 & 420.6 & 0.31 \\
14 & 414.1 & 0.40 & 411.0 & 0.22 \\
15 & 405.1 & 0.26 & 402.3 & 0.13 \\
16 & 396.4 & - & 394.0 & - \\
17 & 388.3 & - & - & - \\
\hline
\end{tabular}

\section{Comments on Preferred Values}

The preferred cross section values are taken from the study of Knight et al. (2000). This is the only study in which the concentration of $\mathrm{OBrO}$ was quantitatively determined, thereby allowing the derivation of absolute absorption cross section values. The uncertainty in these values is estimated to be $\pm 30 \%$. The transition assignments are those reported by Miller et al. (1997). No quantum yield data are available. However, the threshold for photodissociation to yield $\mathrm{BrO}+\mathrm{O}\left({ }^{3} \mathrm{P}\right)$ lies well beyond the wavelength of maximum absorption in the $C\left({ }^{2} A_{2}\right) \leftarrow X\left({ }^{2} B_{1}\right)$ envelope. By analogy with OClO efficient photodissociation via Reaction (2) is expected to occur at $\lambda<550 \mathrm{~nm}$. The possibility of dissociation via Reaction (1) at longer wavelengths cannot be ruled out, but its contribution is expected to be minor if the analogy with $\mathrm{OClO}$ is used.

\section{References}

Knight, G., Ravishankara, A. R., and Burkholder, J. B.: J. Phys. Chem. A, 104, 11121, 2000.

Miller, C. E., Nickolaisen, S. L., Francisco, J. S., and Sander, S. P.: J. Chem. Phys., 107, 2300, 1997.

Rattigan, O. V., Jones, R. L., and Cox, R. A.: Chem. Phys. Lett., 230, 121, 1994. 
III.A5.117

$$
\text { cis-BrONO }+\mathbf{h} v \rightarrow \text { products }
$$

Primary photochemical processes

\begin{tabular}{lllll}
\hline Reaction & & $\Delta H^{\circ} / \mathrm{kJ} \mathrm{mol}^{-1 *}$ & $\lambda_{\text {threshold }} / \mathrm{nm}$ \\
\hline $\mathrm{BrONO}+\mathrm{h} v$ & $\rightarrow \mathrm{Br}+\mathrm{NO}_{2}$ & $(1)$ & 68 & 1759 \\
$\mathrm{BrONO}+\mathrm{h} v$ & $\rightarrow \mathrm{BrO}+\mathrm{NO}$ & $(2)$ & 133 & 899 \\
\hline
\end{tabular}

${ }^{*} \Delta H_{298}^{\circ}(\mathrm{BrONO})=77 \mathrm{~kJ} \mathrm{~mol}^{-1}$ taken from Lee (1996).

\section{Preferred Values}

\section{Absorption cross sections for cis-BrONO at 228-296 K}

\begin{tabular}{llll}
\hline$\lambda / \mathrm{nm}$ & $\begin{array}{l}10^{20} \sigma / \mathrm{cm}^{2} \\
\text { molecule }\end{array}$ & $\lambda / \mathrm{nm}$ & $\begin{array}{l}10^{20} \sigma / \mathrm{cm}^{2} \\
\text { molecule }\end{array}$ \\
\hline 205 & 289 & 285 & 254 \\
210 & 687 & 290 & 293 \\
215 & 1172 & 295 & 341 \\
220 & 1940 & 300 & 377 \\
225 & 2588 & 305 & 396 \\
230 & 2620 & 310 & 413 \\
235 & 2022 & 315 & 411 \\
240 & 1240 & 320 & 406 \\
245 & 790 & 325 & 403 \\
250 & 514 & 330 & 387 \\
255 & 367 & 335 & 370 \\
260 & 273 & 340 & 332 \\
265 & 212 & 345 & 273 \\
270 & 192 & 350 & 233 \\
275 & 196 & 355 & 185 \\
280 & 223 & 360 & 138 \\
\hline
\end{tabular}

\section{Comments on Preferred Values}

The absorption spectrum of BrONO has been reported by Burkholder and Orlando (2000) who generated it (along with $\mathrm{BrNO}_{2}$ and $\mathrm{BrNO}$ ) photochemically. Following deconvolution of $\mathrm{BrNO}_{2}$ and $\mathrm{BrNO}$ absorption the $\mathrm{BrONO}$ cross sections were calculated relative to $\mathrm{BrNO}_{2}$ (Scheffler et al., 1997). Uncertainties of 36\% (200-210 nm), 25\% (210-250 nm) and 22\% $(\lambda>250 \mathrm{~nm})$ are reported. No change in the spectral shape was observed between 228 and $296 \mathrm{~K}$.

There are no experimental data on the primary photochemical processes for BrONO, both dissociation channels (1) and (2) are possible.

\section{References}

Burkholder, J. B. and Orlando, J. J.: Chem. Phys. Lett., 317, 603-608, 2000.

Lee, T. J.: J. Phys. Chem., 100, 19847-19852, 1996.

Scheffler, D., Grothe, H., Willner, A., Frenzel, A. and Zetzsch, C.: Inorg. Chem. 36, 335-338, 1997. 
III.A5.118

$$
\mathrm{BrNO}_{2}+\mathbf{h} v \rightarrow \text { products }
$$

\section{Primary photochemical processes}

\begin{tabular}{|c|c|c|c|c|}
\hline Reaction & & & $\Delta H^{\circ} / \mathrm{kJ} \mathrm{mol}^{-1 *}$ & $\lambda_{\text {threshold }} / \mathrm{nm}$ \\
\hline $\mathrm{BrNO}_{2}+\mathrm{h} v$ & $\rightarrow \mathrm{Br}+\mathrm{NO}_{2}$ & (1) & 94 & 1272 \\
\hline
\end{tabular}

${ }^{*} \Delta H^{\circ}{ }_{298}\left(\mathrm{BrNO}_{2}\right)=51 \mathrm{~kJ} \mathrm{~mol}^{-1}$ taken from Lee (1996).

\section{Preferred Values}

Absorption cross sections for $\mathrm{BrNO}_{2}$ at $296 \mathrm{~K}$

\begin{tabular}{llllll}
\hline$\lambda / \mathrm{nm}$ & $\begin{array}{l}10^{20} \sigma / \mathrm{cm}^{2} \\
\text { molecule }\end{array}$ & $\lambda / \mathrm{nm}$ & $\begin{array}{l}10^{20} \sigma / \mathrm{cm}^{2} \\
\text { molecule }^{-1}\end{array}$ & $\lambda / \mathrm{nm}$ & $\begin{array}{l}10^{20} \sigma / \mathrm{cm}^{2} \\
\text { molecule }^{-1}\end{array}$ \\
\hline 185 & 2048 & 275 & 116 & 365 & 19 \\
190 & 3601 & 280 & 88 & 370 & 17 \\
195 & 5013 & 285 & 63 & 375 & 18 \\
200 & 5386 & 290 & 44 & 380 & 17 \\
205 & 4499 & 295 & 30 & 385 & 17 \\
210 & 2521 & 300 & 20 & 390 & 16 \\
215 & 1170 & 305 & 15 & 395 & 15 \\
220 & 554 & 310 & 11 & 400 & 14 \\
225 & 373 & 315 & 11 & 405 & 14 \\
230 & 343 & 320 & 10 & 410 & 13 \\
235 & 362 & 325 & 12 & 415 & 12 \\
240 & 387 & 330 & 13 & 420 & 11 \\
245 & 390 & 335 & 14 & 425 & 10 \\
250 & 363 & 340 & 16 & 430 & 9 \\
255 & 310 & 345 & 15 & 435 & 8 \\
260 & 251 & 350 & 16 & 440 & 7 \\
265 & 197 & 355 & 16 & 445 & 7 \\
270 & 154 & 360 & 18 & 450 & 6 \\
\hline
\end{tabular}

\section{Comments on Preferred Values}

The absorption spectrum of $\mathrm{BrNO}_{2}$ samples (0.2-4 mbar, purity estimated as $\left.95 \%\right)$ have been reported by Scheffler et al. (1997). Burkholder and Orlando (2000) report a similar shaped $\mathrm{BrNO}_{2}$ spectrum in their photochemical study of BrONO formation.

There are no experimental data on the primary photochemical processes for $\mathrm{BrNO}_{2}$, though the major dissociation pathway is most likely to be formation of $\mathrm{Br}$ and $\mathrm{NO}_{2}$ as indicated, with a quantum yield of unity.

\section{References}

Burkholder, J. B. and Orlando, J. J.: Chem. Phys. Lett., 317, 603-608, 2000.

Lee, T. J.: J. Phys. Chem., 100, 19847-19852, 1996.

Scheffler, D., Grothe, H., Willner, A., Frenzel, A. and Zetzsch, C.: Inorg. Chem. 36, 335-338, 1997. 
III.A5.119

$\mathrm{BrONO}_{2}+\mathbf{h} v \rightarrow$ products

Primary photochemical processes

\begin{tabular}{lllll}
\hline Reaction & & $\Delta H^{\circ} / \mathrm{kJ} \mathrm{mol}^{-1}$ & $\lambda_{\text {threshold }} / \mathrm{nm}$ \\
\hline $\mathrm{BrONO}_{2}+\mathrm{h} v$ & $\rightarrow \mathrm{BrO}+\mathrm{NO}_{2}$ & $(1)$ & 106 & 1129 \\
& $\rightarrow \mathrm{Br}+\mathrm{NO}_{3}$ & $(2)$ & 139 & 861 \\
& $\rightarrow \mathrm{Br}+\mathrm{NO}+\mathrm{O}_{2}$ & $(3)$ & 155 & 772 \\
& $\rightarrow \mathrm{BrONO}+\mathrm{O}\left({ }^{3} \mathrm{P}\right)$ & $(4)$ & 305 & 392 \\
& $\rightarrow \mathrm{Br}+\mathrm{O}\left({ }^{3} \mathrm{P}\right)+\mathrm{NO}_{2}$ & $(5)$ & 347 & 345 \\
& $\rightarrow \mathrm{BrO}+\mathrm{NO}+\mathrm{O}\left({ }^{3} \mathrm{P}\right)$ & $(6)$ & 412 & 290 \\
& $\rightarrow \mathrm{BrONO}+\mathrm{O}\left({ }^{1} \mathrm{D}\right)$ & $(7)$ & 496 & 240 \\
\hline
\end{tabular}

Absorption cross section data

\begin{tabular}{llc}
\hline Wavelength range/nm & Reference & Comments \\
\hline $200-500$ & Burkholder et al., 1995 & (a) \\
$208-500$ & Deters et al., 1998 & (b) \\
\hline
\end{tabular}

\section{Quantum yield data}

\begin{tabular}{lclc}
\hline Measurement & Wavelength $/ \mathrm{nm}$ & Reference & Comments \\
\hline$\Phi_{2}=0.28 \pm 0.09$ & 248 & Harwood et al., 1998 & (c) \\
$\Phi_{2}=1.01 \pm 0.35$ & 308 & & \\
$\Phi_{2}=0.92 \pm 0.43$ & 325.5 & & \\
\hline
\end{tabular}

\section{Comments}

(a) Absorption spectra were measured at a resolution of $\sim 0.5 \mathrm{~nm}$ in a $100 \mathrm{~cm}$ path length cell, thermostatted to $\pm 1 \mathrm{~K}$. Relative cross sections were obtained at 298,250 , and $220 \mathrm{~K}$ and placed on an absolute basis by determinations of the absolute cross section at $330 \mathrm{~nm}$ at temperatures of $298 \mathrm{~K}, 273 \mathrm{~K}, 250 \mathrm{~K}$, and $235 \mathrm{~K}$. The concentrations of $\mathrm{BrONO}_{2}$ were determined by pressure measurements. Corrections were made to the absorption and concentration measurements for $\mathrm{Br}_{2}$ impurity. A number of other possible sample impurities were evaluated quantitatively and found to be negligible.

(b) Spectra were recorded at $0.23-0.46 \mathrm{~nm}$ resolution using a flowing system with a multipass absorption cell of $270 \mathrm{~cm}$ optical path length coupled to a spectrograph and multichannel analyser. $\mathrm{BrONO}_{2}$ concentrations were determined by photolysis of $\mathrm{BrONO}_{2}-\mathrm{Br}_{2}$ mixtures to completion, and measurement of the $\mathrm{Br}_{2}$ concentrations by optical absorption at wavelengths $>500 \mathrm{~nm}$. Absorption cross sections for $\mathrm{BrONO}_{2}$ were obtained at $298 \mathrm{~K}$ and $230 \mathrm{~K}$.

(c) Excimer laser photolysis at $248 \mathrm{~nm}, 308 \mathrm{~nm}$, and $325.5 \mathrm{~nm}$ of flowing mixtures of $\mathrm{BrONO}_{2}$ and $\mathrm{N}_{2}$ or $\mathrm{O}_{2}$. [ $\mathrm{NO}_{3}$ ] was monitored by time resolved diode laser absorption at $661.9 \mathrm{~nm}$. The laser fluence was calibrated by $\mathrm{N}_{2} \mathrm{O}_{5}$ photolysis and $\mathrm{BrONO}_{2}$ and $\mathrm{N}_{2} \mathrm{O}_{5}$ concentrations were determined by $\mathrm{UV}$ absorption. The measured quantum yields were pressure independent over the range 200-790 mbar. 
Preferred Values

Absorption cross sections of $\mathrm{BrONO}_{2}$ at $298 \mathrm{~K}$ and $230 \mathrm{~K}$.

\begin{tabular}{|c|c|c|c|c|c|}
\hline$\lambda / \mathrm{nm}$ & $\begin{array}{l}10^{20} \sigma / \mathrm{cm}^{2} \\
\text { molecule } \\
298 \mathrm{~K}\end{array}$ & $\begin{array}{l}10^{20} \sigma / \mathrm{cm}^{2} \\
\text { molecule } \\
230 \mathrm{~K}\end{array}$ & $\lambda / \mathrm{nm}$ & $\begin{array}{l}10^{20} \sigma / \mathrm{cm}^{2} \\
\text { molecule } \\
298 \mathrm{~K}\end{array}$ & $\begin{array}{l}10^{20} \sigma / \mathrm{cm}^{2} \\
\text { molecule } \\
230 \mathrm{~K}\end{array}$ \\
\hline 200 & 680 & 553 & 355 & 6.52 & 6.62 \\
\hline 205 & 520 & 447 & 360 & 5.99 & 6.07 \\
\hline 210 & 361 & 345 & 365 & 5.43 & 5.51 \\
\hline 215 & 292 & 294 & 370 & 4.89 & 4.94 \\
\hline 220 & 256 & 265 & 375 & 4.35 & 4.40 \\
\hline 225 & 230 & 241 & 380 & 3.85 & 3.84 \\
\hline 230 & 205 & 215 & 385 & 3.37 & 3.34 \\
\hline 235 & 175 & 182 & 390 & 2.97 & 2.91 \\
\hline 240 & 140 & 143 & 395 & 2.59 & 2.52 \\
\hline 245 & 106 & 106 & 400 & 2.28 & 2.21 \\
\hline 250 & 79.7 & 77.2 & 405 & 2.01 & 1.96 \\
\hline 255 & 60.0 & 57.0 & 410 & 1.81 & 1.76 \\
\hline 260 & 47.1 & 44.0 & 415 & 1.65 & 1.63 \\
\hline 265 & 38.9 & 36.1 & 420 & 1.50 & 1.51 \\
\hline 270 & 33.8 & 31.3 & 425 & 1.38 & 1.43 \\
\hline 275 & 30.5 & 28.3 & 430 & 1.29 & 1.36 \\
\hline 280 & 27.9 & 26.2 & 435 & 1.20 & 1.29 \\
\hline 285 & 25.6 & 24.3 & 440 & 1.11 & 1.20 \\
\hline 290 & 23.2 & 22.5 & 445 & 1.03 & 1.12 \\
\hline 295 & 20.8 & 20.6 & 450 & 0.928 & 1.01 \\
\hline 300 & 18.6 & 18.8 & 455 & 0.831 & 0.893 \\
\hline 305 & 16.5 & 17.0 & 460 & 0.742 & 0.785 \\
\hline 310 & 14.5 & 15.2 & 465 & 0.652 & 0.664 \\
\hline 315 & 12.7 & 13.4 & 470 & 0.566 & 0.492 \\
\hline 320 & 11.3 & 11.8 & 475 & 0.461 & 0.431 \\
\hline 325 & 10.2 & 10.4 & 480 & 0.392 & 0.329 \\
\hline 330 & 9.32 & 9.50 & 485 & 0.397 & 0.240 \\
\hline 335 & 8.62 & 8.79 & 490 & 0.249 & 0.167 \\
\hline 340 & 8.06 & 8.18 & 495 & 0.207 & 0.105 \\
\hline 345 & 7.57 & 7.66 & 500 & 0.150 & 0.062 \\
\hline 350 & 7.01 & 7.12 & & & \\
\hline
\end{tabular}

\section{Quantum Yields at $298 \mathrm{~K}$.}

\begin{tabular}{ll}
\hline$\lambda / \mathrm{nm}$ & $\phi_{2}$ \\
\hline 248 & 0.28 \\
308 & 1.0 \\
325.5 & 0.92 \\
\hline
\end{tabular}

\section{Comments on Preferred Values}

Our previous recommendations (IUPAC, 1997) for the absorption cross sections were taken from the study of Spencer and Rowland (1978) which were limited to the wavelength range $186-390 \mathrm{~nm}$. The more recent studies of Burkholder et al. (1995) and Deters et al. (1998) extend the range to $500 \mathrm{~nm}$ and cover the temperature range $220-298 \mathrm{~K}$. At $298 \mathrm{~K}$ there is good agreement among the three studies; our preferred values are a mean of the values from Burkholder et al. (1995) and Deters et al. (1998). 
There is less good agreement between the studies of Burkholder et al. (1995) and Deters et al. (1998) on the temperature dependence of the absorption coefficients. At $230 \mathrm{~K}$ values of $\sigma$ obtained in the two studies (Burkholder et al., 1995; Deters et al., 1998) agree in the range $200-300 \mathrm{~nm}$ but differ by up to $25 \%$ in the range $300-500 \mathrm{~nm}$, and whereas Burkholder et al. (1995) find a small decrease in $\sigma$ in going from $298 \mathrm{~K}$ to $230 \mathrm{~K}$, over most of the wavelength range Deters et al. (1998) find an increase. The preferred values at $230 \mathrm{~K}$ are a mean of the values from Burkholder et al. (1995) and Deters et al. (1998).

The only quantum yield measurements are those of Harwood et al. (1998) who determined the $\mathrm{NO}_{3}$ quantum yield at 248, 308 , and $325.5 \mathrm{~nm}$, and also gave estimates of the $\mathrm{Br}$ and $\mathrm{BrO}$ quantum yields. Their values for the $\mathrm{NO}_{3}$ quantum yields are adopted as our preferred values.

\section{References}

Burkholder, J. B., Ravishankara, A. R., and Solomon, S.: J. Geophys. Res., 100, 16793, 1995.

Deters, B., Burrows, J. P., and Orphal, J.: J. Geophys. Res., 103, 3563, 1998.

Harwood, M. H., Burkholder, J. B., and Ravishakara, A R.: J. Phys. Chem. A, 102, 1309, 1998.

IUPAC: Supplement V, 1997 (see references in Introduction).

Spencer, J. E. and Rowland, F. S.: J. Phys. Chem., 82, 7, 1978. 
III.A5.120

$$
\mathbf{B r C l}+\mathbf{h} v \rightarrow \text { products }
$$

\section{Primary photochemical transitions}

\begin{tabular}{llll}
\hline Reaction & & $\Delta H / \mathrm{kJ} \mathrm{mol}^{-1}$ & $\lambda_{\text {threshold }} / \mathrm{nm}$ \\
\hline $\mathrm{BrCl}+\mathrm{h} v$ & $\rightarrow \mathrm{Cl}+\mathrm{Br}$ & 219 & 546 \\
& $\rightarrow \mathrm{Cl}\left({ }^{2} \mathrm{P}_{1 / 2}\right)+\mathrm{Br}$ & 229 & 521 \\
& $\rightarrow \mathrm{Cl}+\mathrm{Br}\left({ }^{2} \mathrm{P}_{1 / 2}\right)$ & 263 & 454 \\
\hline
\end{tabular}

\section{Absorption cross section data}

\begin{tabular}{llc}
\hline Wavelength range/nm & Reference & Comments \\
\hline $220-510$ & Seery and Britton, 1964 & (a) \\
$200-600$ & Maric et al., 1994 & (b) \\
$190-560$ & Hubinger and Nee, 1995 & (c) \\
\hline
\end{tabular}

\section{Comments}

(a) The authors used the same apparatus for the $\mathrm{BrCl}$ absorption cross sections at three different $\mathrm{Cl}_{2} / \mathrm{Br}_{2}$ mixing ratios as for the measurements of both the $\mathrm{Cl}_{2}$ and $\mathrm{Br}_{2}$ cross sections and an equilibrium constant $K_{\mathrm{BrCl}}=8.1$ for the equilibrium $\mathrm{Cl}_{2}+\mathrm{Br}_{2} \leftrightarrow 2 \mathrm{BrCl}$ (Evans et al., 1955). The resulting cross sections are slightly higher than the recommended value.

(b) The equilibrium constant $\mathrm{K}_{\mathrm{BrCl}}$ as well as the absorption spectrum of $\mathrm{BrCl}$ have been measured using twelve different $\mathrm{Cl}_{2} / \mathrm{Br}_{2}$ mixing ratios in nine overlapping spectral ranges of about $70 \mathrm{~nm}$ spectral width resulting in a spectral resolution of $0.2 \mathrm{~nm}$. At least ten independent spectra were recorded at different total pressures $\left(\mathrm{Cl}_{2}, \mathrm{Br}_{2}\right.$ and $\left.\mathrm{BrCl}\right)$. The interference from a pressure-dependent component of the $\mathrm{Br}_{2}$ vapor was negligible under the chosen experimental conditions. The value of $\mathrm{K}_{\mathrm{BrCl}}$ was iteratively adjusted until minimum deviation occurred between the observed and calculated absorption spectrum of $\mathrm{BrCl}$ in all the regions of overlap: $K_{\mathrm{BrCl}}=10.1 \pm 1.1$ at $298 \mathrm{~K}$ leads to a third law value of $\Delta H_{f}^{\circ}=14.31 \mathrm{~kJ} / \mathrm{mol}$.

(c) Mixtures of $\mathrm{Cl}_{2}$ and $\mathrm{Br}_{2}$ in 670 mbar of $\mathrm{Ar}$ were prepared in an evacuable gas flow line. The equilibrium concentrations have been obtained using $K_{\mathrm{BrCl}}=6.4$ (Mattraw et al., 1954). The low pressures used in the present study ( 0.2 to 12.0 mbar) minimized the interference of $\mathrm{Br}_{2}$ dimers. The limit to the red at $\lambda>500 \mathrm{~nm}$ is given by instrument noise. Graphical comparison between the measured spectrum and the results from the literature (Seery and Britton, 1964; Maric et al., 1994) shows only minor differences. The $\mathrm{BrCl}$ spectrum was deconvoluted using a semi-logarithmic gaussian distribution function into four components with maxima at 228.33 (UV band), $376.39\left(C^{1} \Pi_{1}\right), 454.92\left(B^{3} \Pi_{0}^{+}\right)$and $533.05 \mathrm{~nm}$ $\left(A^{3} \Pi_{1}\right)$.

No Quantum Yield Data available. 
Absorption cross sections of $\mathrm{BrCl}$ at $298 \mathrm{~K}$.

\begin{tabular}{llll}
\hline$\lambda / \mathrm{nm}$ & $\begin{array}{l}10^{20} \sigma / \mathrm{cm}^{2} \\
\text { molecule }\end{array}$ & $\lambda / \mathrm{nm}$ & $\begin{array}{l}10^{20} \sigma / \mathrm{cm}^{2} \\
\text { molecule }\end{array}$ \\
\hline 200 & 2.95 & 410 & 22.39 \\
210 & 4.27 & 420 & 17.78 \\
220 & 6.31 & 430 & 14.45 \\
230 & 6.61 & 440 & 12.59 \\
240 & 5.62 & 450 & 10.72 \\
250 & 4.07 & 460 & 9.33 \\
260 & 5.50 & 470 & 7.94 \\
270 & 1.29 & 480 & 6.31 \\
280 & 0.66 & 490 & 5.01 \\
290 & 0.39 & 500 & 3.39 \\
300 & 0.56 & 510 & 2.63 \\
310 & 1.51 & 520 & 1.66 \\
320 & 4.07 & 530 & 1.10 \\
330 & 9.12 & 540 & 0.66 \\
340 & 17.00 & 550 & 0.41 \\
350 & 28.18 & 560 & 0.25 \\
360 & 34.67 & 570 & 0.144 \\
370 & 41.69 & 580 & 0.832 \\
380 & 39.81 & 590 & 0.0479 \\
390 & 33.88 & 600 & 0.0251 \\
400 & 28.18 & & \\
\hline
\end{tabular}

Comments on Preferred Values

The data of Maric et al. (1994) are recommended because it is the most comprehehsive data set to date available which is internally consistent using an equilibrium constant $K_{\mathrm{BrCl}}=10.1 \pm 1.1$ at $298 \mathrm{~K}$ which is measured in the same study. The absorption cross sections of $\mathrm{BrCl}$ agree in the regions of overlap between the spectral fragments to better than $\pm 2 \%$, and it is estimated that the accuracy is better than $\pm 3 \%$ in the range $\lambda=200-550 \mathrm{~nm}$. In the range $550-600 \mathrm{~nm}$ the agreement between spectral fragments is better than $\pm 15 \%$ for an overall accuracy in this range of better than $\pm 20 \%$. Spectral deconvolution in terms of three contributing bands with maxima at 227.6, 372.5 and $442.4 \mathrm{~nm}$ has been obtained. Combining the values of $\sigma_{\mathrm{BrCl}}$ with the results of Sulzer and Wieland (1952) obtains the temperature and wavelength dependence of the UV/Vis absorption spectrum of $\mathrm{BrCl}$. A quantum yield of unity for the dissociation of $\mathrm{BrCl}$ is expected.

\section{References}

Evans, W. H., Munson, T. R., and Wagman, D. D.: J. Res. Natl. Bur. Std., 55, 147, 1955.

Hubinger, S. and Nee, J. B.: J. Photochem. Photobiol. A. Chem., 86, 1, 1995.

Maric, D., Burrows, J. P., and Moortgat, G. K.: J. Photochem. Photobiol. A. Chem., 83, 179, 1994.

Mattraw, H. C., Packucki, C. F., and Hawkings, N. J.: J. Chem. Phys., 22, 1117, 1954.

Seery, D. J. and Britton, D.: J. Phys. Chem., 68, 2263, 1964.

Sulzer, P. and Wieland, K.: Helv. Phys. Acta, 25, 653, 1952. 
III.A5.121

$$
\mathrm{Br}_{2}+\mathbf{h} v \rightarrow \text { products }
$$

\section{Primary photochemical processes}

\begin{tabular}{llll}
\hline Reaction & & $\Delta H^{\circ} / \mathrm{kJ} \mathrm{mol}^{-1}$ & $\lambda_{\text {threshold }} / \mathrm{nm}$ \\
\hline $\mathrm{Br}_{2}+\mathrm{h} v$ & $\rightarrow \mathrm{Br}\left({ }^{2} \mathrm{P}_{3 / 2}\right)+\mathrm{Br}\left({ }^{2} \mathrm{P}_{3 / 2}\right)$ & 193 & 620 \\
& $\rightarrow \mathrm{Br}\left({ }^{2} \mathrm{P}_{3 / 2}\right)+\mathrm{Br}\left({ }^{2} \mathrm{P}_{1 / 2}\right)$ & 237 & 505 \\
\hline
\end{tabular}

\section{Absorption cross section data}

\begin{tabular}{llc}
\hline Wavelength range/nm & Reference & Comments \\
\hline $220-750$ & Passchier et al., 1967 & (a) \\
$220-290$ & Wen and Noyes, 1972 & (b) \\
\hline
\end{tabular}

\section{Quantum yield data}

See Comments on Preferred Values.

\section{Comments}

(a) Spectra were obtained using a Beckman DU spectrophotometer equipped with a thermostatted optical cell. $\mathrm{Br}_{2}$ concentrations were determined by pressure measurement or by titration with $\mathrm{Na}_{2} \mathrm{~S}_{2} \mathrm{O}_{3}$. Values of the absorption cross section are given for temperatures of $298 \mathrm{~K}, 348 \mathrm{~K}, 423 \mathrm{~K}, 498 \mathrm{~K}, 573 \mathrm{~K}, 648 \mathrm{~K}$, and $613 \mathrm{~K}$. In the wavelength range $200-240 \mathrm{~nm}$ the measured cross sections are pressure dependent, attributed to $\mathrm{Br}_{4}$ formation. From the pressure dependences, values of the absorption cross sections for $\mathrm{Br}_{4}$ and $\mathrm{Br}_{2}$ were derived in the range 200-230 nm.

(b) Spectra were obtained with a Beckman DU spectrophotometer equipped with a cell of optical path length $9.8 \mathrm{~cm}$ and thermostatted to $303 \mathrm{~K} . \mathrm{Br}_{2}$ concentrations were derived by pressure measurements. Deviations from Beer's Law which were observed, and attributed to $\mathrm{Br}_{4}$ formation, were used to study the equilibrium between $\mathrm{Br}_{2}$ and $\mathrm{Br}_{4}$ and to derive values of $\sigma\left(\mathrm{Br}_{2}\right)$ corrected for $\mathrm{Br}_{4}$ absorption. 


\section{Preferred Values}

Absorption cross sections of $\mathrm{Br}_{2}$ at $298 \mathrm{~K}$.

\begin{tabular}{|c|c|c|c|}
\hline$\lambda / \mathrm{nm}$ & $\begin{array}{l}10^{20} \sigma / \mathrm{cm}^{2} \\
\text { molecule }\end{array}$ & $\lambda / \mathrm{nm}$ & $\begin{array}{l}10^{20} \sigma / \mathrm{cm}^{2} \\
\text { molecule }\end{array}$ \\
\hline 200 & 0.562 & 350 & 3.48 \\
\hline 205 & 0.723 & 355 & 5.63 \\
\hline 210 & 0.870 & 360 & 8.65 \\
\hline 215 & 0.983 & 365 & 12.7 \\
\hline 220 & 1.04 & 370 & 17.8 \\
\hline 225 & 1.06 & 375 & 23.9 \\
\hline 230 & 1.01 & 380 & 30.7 \\
\hline 235 & 0.925 & 385 & 37.9 \\
\hline 240 & 0.808 & 390 & 45.1 \\
\hline 245 & 0.676 & 395 & 51.8 \\
\hline 250 & 0.543 & 400 & 57.4 \\
\hline 255 & 0.422 & 405 & 61.6 \\
\hline 260 & 0.316 & 410 & 64.2 \\
\hline 265 & 0.229 & 415 & 65.1 \\
\hline 270 & 0.161 & 420 & 67.7 \\
\hline 275 & 0.180 & 425 & 60.8 \\
\hline 280 & 0.0728 & 430 & 60.1 \\
\hline 285 & 0.0471 & 435 & 57.1 \\
\hline 290 & 0.02398 & 440 & 54.0 \\
\hline 295 & 0.0188 & 445 & 51.2 \\
\hline 300 & 0.0124 & 450 & 48.7 \\
\hline 305 & 0.0101 & 455 & 46.7 \\
\hline 310 & 0.0135 & 460 & 45.1 \\
\hline 315 & 0.0274 & 465 & 43.8 \\
\hline 320 & 0.0626 & 470 & 42.8 \\
\hline 325 & 0.141 & 475 & 41.7 \\
\hline 330 & 0.299 & 480 & 40.3 \\
\hline 335 & 0.602 & 485 & 38.6 \\
\hline 340 & 1.14 & 490 & 36.6 \\
\hline \multirow[t]{2}{*}{345} & 2.05 & 495 & 34.3 \\
\hline & & 500 & 31.8 \\
\hline
\end{tabular}

\section{Quantum yields}

See Comments on Preferred Values.

\section{Comments on Preferred Values}

Maric et al. (1994) have evaluated the available absorption cross section data for $\mathrm{Br}_{2}$ and have fitted the most reliable data to an expression giving $\sigma$ over the range $200-600 \mathrm{~nm}$ as the sum of four terms each representing the contribution to $\sigma$ of one of the separate overlapping absorption bands of the spectrum. The data sets selected by Maric et al. (1994) were those of Passchier et al. (1967) and of Wen and Noyes (1972), which cover the whole wavelength range, are in excellent agreement and make due allowance for the deviations from Beer's Law which are observed in the 200-300 nm region, attributed to $\mathrm{Br}_{4}$ formation. The findings of Maric et al. (1994) are accepted and our preferred values for the absorption cross section at $298 \mathrm{~K}$ are calculated from the expression which they derived. They have also derived an extension of their expression for use at other temperatures. 
In a more recent study covering the range 190-600 nm, Hubinger and Nee (1995) have obtained values of $\sigma$ in excellent agreement with the expression of Maric et al. (1994) except in the $270-330 \mathrm{~nm}$ region where absorption cross sections are small and only upper limits could be given.

At wavelengths longer than $\sim 510 \mathrm{~nm}$ the spectrum consists of a banded region overlapping a continuum. High resolution spectroscopic studies (Zaraga et al., 1976; Hemenway et al., 1979) indicate rather smaller values for the contribution of the continuum absorption at long wavelengths than predicted by the expression of Maric et al. (1994).

Absorption of radiation in the range $200-510 \mathrm{~nm}$ is expected to lead to bond rupture with unit quantum efficiency, giving two ground state $\mathrm{Br}$ atoms or $\operatorname{Br}\left({ }^{2} \mathrm{P}_{3 / 2}\right)+\operatorname{Br}\left({ }^{2} \mathrm{P}_{1 / 2}\right)$, as confirmed by photofragment spectroscopic studies (Busch et al., 1969; Lindeman and Wiesenfeld, 1979). There are no direct measurements of the quantum yield but in a study of the photoinitiated bromination of ethene Kistiakowsky and Sternberg (1953) showed that the quantum yield of Br production is approximately independent of wavelength in the range $480-680 \mathrm{~nm}$.

\section{References}

Busch, G. E., Mahoney, R. T., Morse, R. J., and Wilson, K. R.: J. Chem. Phys., 51, 837, 1969.

Hemenway, C. P., Lindeman, T. G., and Wiesenfeld, J. R.: J. Chem. Phys., 70, 3560, 1979.

Hubinger, S. and Nee, J. B.: J. Photochem. Photobiol. A. Chem., 86, 1, 1995.

Kistiakowsky, G. B. and Sternberg, J. C.: J. Chem. Phys. 21, 2218, 1953.

Lindeman, T. G. and Wiesenfeld, J. R.: J. Chem. Phys., 70, 2882, 1979.

Maric, D., Burrows, J. P., and Moortgat, G. K.: J. Photochem. Photobiol A. Chem., 83, 179, 1994.

Passchier, A. A., Christian, J. D., and Gregory, N. W.: J. Phys. Chem., 71, 937, 1967.

Wen, W. Y. and Noyes, R. M.: J. Phys. Chem., 76, 1017, 1972.

Zaraga, F., Nogar, N. S., and Moore, C. B.: J. Mol. Spectrosc., 63, 564, 1976. 
III.A5.122

$$
\mathbf{H I}+\mathbf{h} v \rightarrow \text { products }
$$

Primary photochemical processes

\begin{tabular}{llll}
\hline Reaction & & $\Delta H^{\circ} / \mathrm{kJ} \mathrm{mol}^{-1}$ & $\lambda_{\text {threshold }} / \mathrm{nm}$ \\
\hline $\mathrm{HI}+\mathrm{h} v$ & $\rightarrow \mathrm{H}+\mathrm{I}$ & 298 & 401 \\
\hline
\end{tabular}

\section{Preferred Values}

\begin{tabular}{|c|c|c|c|}
\hline \multicolumn{4}{|c|}{ Absorption cross sections for $\mathrm{HI}$ at $298 \mathrm{~K}$} \\
\hline$\lambda / \mathrm{nm}$ & $\begin{array}{l}10^{19} \sigma / \mathrm{cm}^{2} \\
\text { molecule }^{-1}\end{array}$ & $\lambda / \mathrm{nm}$ & $\begin{array}{l}10^{19} \sigma / \mathrm{cm}^{2} \\
\text { molecule }\end{array}$ \\
\hline 200 & 61.0 & 275 & 12.4 \\
\hline 205 & 67.7 & 280 & 8.94 \\
\hline 210 & 73.8 & 285 & 6.37 \\
\hline 215 & 78.4 & 290 & 4.51 \\
\hline 220 & 80.8 & 295 & 3.17 \\
\hline 225 & 80.4 & 300 & 2.23 \\
\hline 230 & 77.4 & 305 & 1.52 \\
\hline 235 & 71.9 & 310 & 1.01 \\
\hline 240 & 64.6 & 315 & 0.653 \\
\hline 245 & 56.1 & 320 & 0.409 \\
\hline 250 & 47.0 & 325 & 0.247 \\
\hline 255 & 38.1 & 330 & 0.145 \\
\hline 260 & 30.0 & 335 & 0.083 \\
\hline 265 & 23.0 & 340 & 0.047 \\
\hline 270 & 17.2 & & \\
\hline
\end{tabular}

\section{Quantum yield data for HI photolysis}

$\phi=1.0$

\section{Comments on Preferred Values}

$\mathrm{HI}$ has a continuous absorption spectrum with an onset at about $327 \mathrm{~nm}$. The preferred values are based on the measurements of Campuzano-Jost and Crowley (1999). These values are in good agreement with the cross sections reported by Huebert and Martin (1968) and Ogilvie (1971). Earlier measurements of absorption cross-sections were reported by Goodeve and Taylor (1935) and Romand (1949).

The primary photochemical process forms $\mathrm{H}$ and I atoms with a quantum yield of about unity at 185 and $254 \mathrm{~nm}$ (Martin and Williard, 1964). The branching ratio for production of $\mathrm{I}\left({ }^{2} \mathrm{P}_{1 / 2}\right)$ and $\mathrm{I}\left({ }^{2} \mathrm{P}_{3 / 2}\right)$ was measured in Langford et al. (1998) as a function of the wavelength between 190 and $305 \mathrm{~nm}$.

\section{References}

Campuzano-Jost, P. and Crowley, J. N.: J. Phys. Chem. A, 103, 2712, 1999.

Goodeve, C. F. and Taylor, A. W. C.: Proc. Roy. Soc. A, 152, 221, 1935.

Huebert, B. J. and Martin, R. M.: J. Phys. Chem., 72, 3046, 1968.

Langford, S. R., Regan, P. M., Orr-Ewing, A. J. and Ashfold, M. N. R.: Chem. Phys., 231, 245, 1998.

Martin, R. M. and Williard, J. E.: J. Chem. Phys., 40, 2999, 1964. 
R. Atkinson et al.: Evaluated kinetic and photochemical data for atmospheric chemistry

Ogilvie, J. F.: Trans. Faraday Soc., 67, 2205, 1971.

Romand, J.: Ann. Phys. (Paris), 4, 527, 1949. 
III.A5.123

$$
\text { HOI }+\mathbf{h} v \rightarrow \text { products }
$$

\section{Primary photochemical processes}

\begin{tabular}{lllll}
\hline Reaction & & $\Delta H^{\circ} / \mathrm{kJ} \mathrm{mol}^{-1}$ & $\lambda_{\text {threshold }} / \mathrm{nm}$ \\
\hline $\mathrm{HOI}+\mathrm{h} v$ & $\rightarrow \mathrm{HO}+\mathrm{I}$ & $(1)$ & 236 & 507 \\
& $\rightarrow \mathrm{HI}+\mathrm{O}\left({ }^{3} \mathrm{P}\right)$ & $(2)$ & 366 & 327 \\
& $\rightarrow \mathrm{IO}+\mathrm{H}$ & $(3)$ & 415 & 288 \\
& $\rightarrow \mathrm{HI}+\mathrm{O}\left({ }^{1} \mathrm{D}\right)$ & $(4)$ & 555 & 216 \\
\hline
\end{tabular}

\section{Absorption cross section data}

\begin{tabular}{llc}
\hline Wavelength range/nm & Reference & Comments \\
\hline $280-500$ & Bauer et al., 1998 & (a) \\
$278-494$ & Mossinger et al., 1999 & (b) \\
\hline
\end{tabular}

\section{Quantum yield data}

\begin{tabular}{lclc}
\hline Quantum Yield & Wavelength $/ \mathrm{nm}$ & Reference & Comments \\
\hline$\Phi=1.05 \pm 0.13$ & 355 & Bauer et al., 1998 & (c) \\
\hline
\end{tabular}

\section{Comments}

(a) Laser photolysis of $\mathrm{H}_{2} \mathrm{O}$ at $240 \mathrm{~nm}$ was used to produce $\mathrm{HO}$ radicals in the presence of $\mathrm{I}_{2}$, and hence to produce HOI in situ. Absorptions were measured by a gated diode array, and at selected wavelengths by a photomultiplier. The HOI concentration was determined from the instantaneous $I_{2}$ loss. The spectrum consists of two unstructured bands at $340.4 \mathrm{~nm}$ $\left[\sigma_{\max }=(3.85 \pm 0.4) \times 10^{-19} \mathrm{~cm}^{2}\right.$ molecule $\left.{ }^{-1}\right]$

and $406.4 \mathrm{~nm}\left[\sigma_{\max }=(3.30 \pm 0.3) \times 10^{-19} \mathrm{~cm}^{2}\right.$ molecule $\left.{ }^{-1}\right]$.

(b) Same technique as in comment (a). Some irreproducibility in the $406 \mathrm{~nm}$ band was tentatively attributed to $\mathrm{I}_{2} \mathrm{O}$ formation.

(c) $\mathrm{HOI}$ was produced by pulsed laser photolysis of $\mathrm{HNO}_{3}$ at $248 \mathrm{~nm}$ to produce $\mathrm{HO}$ radicals in the presence of $\mathrm{I}_{2}$. A second $355 \mathrm{~nm}$ laser pulse interrogated the HOI produced and the photofragment product $\mathrm{HO}$ was observed by resonance fluorescence. Fresh reactants were introduced at each laser pulse. The quantity $\left\{\sigma^{\mathrm{HOI}} \phi(\mathrm{HO})^{\mathrm{HOI}}\right\}$ at $355 \mathrm{~nm}$ was determined which, with the measured value of $\sigma$ (see above), gave the cited value of $\phi$. 


\section{Preferred Values}

\section{Absorption cross sections of HOI at 295 K}

\begin{tabular}{llll}
\hline$\lambda / \mathrm{nm}$ & $\begin{array}{l}10^{19} \sigma / \mathrm{cm}^{2} \\
\text { molecule }\end{array}$ & $\lambda / \mathrm{nm}$ & $\begin{array}{l}10^{19} \sigma / \mathrm{cm}^{2} \\
\text { molecule }\end{array}$ \\
\hline 280 & 0.0077 & 390 & 2.66 \\
285 & 0.0226 & 395 & 2.98 \\
290 & 0.0589 & 400 & 3.22 \\
295 & 0.137 & 405 & 3.32 \\
300 & 0.286 & 410 & 3.27 \\
305 & 0.541 & 415 & 3.07 \\
310 & 0.926 & 420 & 2.75 \\
315 & 1.45 & 425 & 2.35 \\
320 & 2.07 & 430 & 1.92 \\
325 & 2.72 & 435 & 1.50 \\
330 & 3.29 & 440 & 1.13 \\
335 & 3.70 & 445 & 0.813 \\
340 & 3.85 & 450 & 0.563 \\
345 & 3.77 & 455 & 0.376 \\
350 & 3.47 & 460 & 0.242 \\
355 & 3.04 & 465 & 0.150 \\
360 & 2.58 & 470 & 0.0904 \\
365 & 2.21 & 475 & 0.0525 \\
370 & 1.98 & 480 & 0.0296 \\
375 & 1.94 & 485 & 0.0161 \\
380 & 2.07 & 490 & 0.0086 \\
385 & 2.33 & & \\
\hline
\end{tabular}

\section{Quantum Yields}

$\phi(1)=1.0$ in the wavelength range $280-490 \mathrm{~nm}$.

\section{Comments on Preferred Values}

The recommended values for the cross-sections are those given by Bauer et al. (1998). The data of Mossinger et al. (1999) are in good agreement with the exception of some systematically higher values in the $405 \mathrm{~nm}$ band. The original work of Jenkin, (1991) on which our previous evaluation, IUPAC (1997), was based, is qualitatively in agreement with the referred values.

\section{References}

Bauer, D., Ingham, T., Carl, S. A., Moortgat, G. K., and Crowley, J. N.: J. Phys. Chem. A., 102, 2857, 1998.

IUPAC, Supplement V, 1997 (see references in Introduction). Jenkin, M. E.: Ph.D. Thesis, University of East Anglia, 1991.

Mossinger, J. A.: J. Atmos. Chem., 34, 137, 1999. 
III.A5.124

$$
\text { IO }+\mathbf{h} v \rightarrow \text { products }
$$

\section{Primary photochemical processes}

\begin{tabular}{lllll}
\hline Reaction & & $\Delta H^{\circ} / \mathrm{kJ} \mathrm{mol}^{-1}$ & $\lambda_{\text {threshold }} / \mathrm{nm}$ \\
\hline $\mathrm{IO}+\mathrm{h} v$ & $\rightarrow \mathrm{I}+\mathrm{O}\left({ }^{3} \mathrm{P}\right)$ & $(1)$ & 240 & 500 \\
& $\rightarrow \mathrm{I}+\mathrm{O}\left({ }^{1} \mathrm{D}\right)$ & $(2)$ & 430 & 280 \\
\hline
\end{tabular}

\section{Absorption cross section data}

\begin{tabular}{llc}
\hline Wavelength range/nm & Reference & Comments \\
\hline 427.2 & Sander, 1986 & (a) \\
$340-450$ & Laszlo et al., 1995 & (b) \\
$340-480$ & Harwood et al., 1997 & (c) \\
$345-465$ & Atkinson et al., 1999 & (e) \\
$345-465$ & Bloss et al., 2001 & (d) \\
\hline
\end{tabular}

\section{Quantum yield data}

\begin{tabular}{lllc}
\hline Measurement & Wavelength/nm & Reference & Comments \\
\hline$\phi_{1}>0.09 \pm_{0.26}^{0.19}$ & 355 & Ingham et al., 2000 & (f) \\
\hline
\end{tabular}

\section{Comments}

(a) Flash photolysis-absorption spectroscopy study. Cross sections at the head of the 4-0 band at $427.2 \mathrm{~nm}$ were measured at six temperatures in the range $250 \mathrm{~K}$ to $373 \mathrm{~K}$. A strong temperature dependence was observed at temperatures $<315 \mathrm{~K}$, with $\sigma$ increasing with decreasing temperature.

(b) Pulsed laser photolysis-absorption spectroscopy study. A $\quad$ cross section of $\sigma(427.2 \mathrm{~nm})=(2.8 \pm 0.5) \times 10^{-17} \mathrm{~cm}^{2}$ molecule ${ }^{-1}$

at $298 \mathrm{~K}$ was obtained, at a resolution of $0.3 \mathrm{~nm}$.

(c) Pulsed laser photolysis-absorption spectroscopy study. Cross sections of $\sigma(427.2 \mathrm{~nm})=(3.0 \pm 0.4) \times 10^{-17} \mathrm{~cm}^{2}$ molecule ${ }^{-1}$ and $(3.6 \pm 0.5) \times 10^{-17} \mathrm{~cm}^{2}$ molecule ${ }^{-1}$ were reported for resolutions of $0.44 \mathrm{~nm}$ and $0.14 \mathrm{~nm}$, respectively, at $298 \mathrm{~K}$.

(d) Pulsed laser photolysis of $\mathrm{N}_{2} \mathrm{O}-\mathrm{CF}_{3} \mathrm{I}$ mixtures. IO radicals were detected by time-resolved CCD measurements of the postlaser pulse mixtures in the range $340 \mathrm{~nm}$ to $470 \mathrm{~nm}$. Cross sections of $\sigma(427.2 \mathrm{~nm})=(1.9 \pm 0.2) \times 10^{-17} \mathrm{~cm}^{2} \mathrm{molecule}^{-1}$

(resolution of $1.13 \mathrm{~nm}$ ) and $\sigma(395.5 \mathrm{~nm})=(5.7 \pm 0.5) \times 10^{-18} \mathrm{~cm}^{2}$ molecule ${ }^{-1}$

were reported. They also reported a small temperature dependence of the cross section at $427.2 \mathrm{~nm}$, based on an analysis of the differential cross section and taking into account the temperature and pressure dependence of the yield of IO radicals from the $\mathrm{O}\left({ }^{3} \mathrm{P}\right)+\mathrm{CF}_{3} \mathrm{I}$ reaction.

(e) Pulsed laser photolysis of $\mathrm{N}_{2} \mathrm{O}-\mathrm{CF}_{3} \mathrm{I}$ mixtures. IO radicals were detected by time-resolved cavity ring-down spectroscopy (CRDS) at $445.40 \mathrm{~nm}$ (band head of rotationally resolved 2-0 band) and $455 \mathrm{~nm}$ (maximum of the diffuse 1-0 band). Cross sections of $\sigma(445.40 \mathrm{~nm})=(7.3 \pm 0.7) \times 10^{-17} \mathrm{~cm}^{2}$ molecule ${ }^{-1}$

and $\sigma(455 \mathrm{~nm})=(7.3 \pm 0.8) \times 10^{-18} \mathrm{~cm}^{2}$ molecule ${ }^{-1}$ were obtained using absolute value of $1.05 \times 10^{-17} \mathrm{~cm}^{2} \mathrm{molecule}^{-1}$ at $298 \mathrm{~K}$ obtained by Laszlo et al. (1995) for the 2-0 band head at a resolution of $0.3 \mathrm{~nm}$. 
(f) Pulsed laser photolysis $(248 \mathrm{~nm})$ of $\mathrm{O}_{3}-\mathrm{I}_{2}$ mixtures, with photolysis of IO radicals by second laser pulse at $355 \mathrm{~nm}$ after a fixed time delay. $\left.\mathrm{O}^{3} \mathrm{P}_{\mathrm{j}}\right)$ detected by time-resolved RF. Quantum yield measured relative to $\mathrm{NO}_{2}$ photolysis at the same wavelength.

\section{Preferred Values}

\section{Absorption cross sections for IO at $298 \mathrm{~K}$ (averaged over 5nm intervals).}

\begin{tabular}{llll}
\cline { 2 - 3 }$\lambda / \mathrm{nm}$ & $\begin{array}{l}10^{18} \sigma / \mathrm{cm}^{2} \\
\text { molecule }^{-1}\end{array}$ & $\lambda / \mathrm{nm}$ & $\begin{array}{l}10^{18} \sigma / \mathrm{cm}^{2} \\
\text { molecule }^{-1}\end{array}$ \\
\hline 345 & 0.78 & 410 & 7.53 \\
350 & 1.00 & 415 & 5.18 \\
355 & 1.36 & 420 & 9.04 \\
360 & 1.85 & 425 & 4.17 \\
365 & 2.25 & 430 & 6.11 \\
370 & 2.99 & 435 & 6.92 \\
375 & 3.57 & 440 & 1.61 \\
380 & 4.42 & 445 & 4.94 \\
385 & 4.63 & 450 & 1.02 \\
390 & 5.65 & 455 & 2.36 \\
395 & 6.55 & 460 & 0.90 \\
400 & 6.407 & 465 & 0.39 \\
405 & 7.09 & & \\
\hline
\end{tabular}

$\sigma=3.6 \pm 0.3 \times 10^{-17} \mathrm{~cm}^{3}$ molecule ${ }^{-1} \mathrm{~s}^{-1}$ at head of $4-0$ band at $427.2 \mathrm{~nm}$ and resolution $0.14 \mathrm{~nm}$

\section{Quantum Yields}

$\phi(1)=1.0$ throughout the wavelength range $345-465 \mathrm{~nm}$.

\section{Comments on Preferred Values}

\section{Absorption Cross Sections.}

The measurements of the cross sections at the band head of the 4-0 band at 427.2 nm by Laszlo et al. (1995), Harwood et al. (1997), Bloss et al. (2001) are in fairly good agreement when the effects of resolution are taken into account. These data (Laszlo et al., 1995; Harwood et al., 1997; Atkinson et al., 1999) suggest a slightly higher value than the earlier data of Sander (1986), Stickel et al. (1988) and Cox and Coker (1983). We recommend a value of $\sigma(427.2 \mathrm{~nm})=(3.6 \pm 0.3) \times 10^{-17} \mathrm{~cm}^{2}$ molecule $\mathrm{e}^{-1}$

based on the measurements of Harwood et al. (1997) for the 4-0 band at high resolution (0.14 nm). The information from the studies of Harwood et al. (1997) and also of Atkinson et al. (1999) at $298 \mathrm{~K}$ on the IO band shape and cross section at high resolution can be used to calculate the expected intensity and shape of the bands at lower resolution, which shows that the recent studies are consistent with this recommendation.

The study of Laszlo et al. (1995) showed that the vibronic band structure is superimposed on a broad continuous absorption which maximizes at $\sim 400 \mathrm{~nm}$. Other recent studies (Harwood et al., 1997; Bloss et al., 2001) confirm the presence of the underlying continuum, which makes a significant contribution to atmospheric photolysis. Bloss et al. (2001) showed that IO absorption measurements in the $340 \mathrm{~nm}$ to $450 \mathrm{~nm}$ region can be influenced by the presence of an underlying absorption due to a product of the $\mathrm{IO}+\mathrm{IO}$ reaction, and this was accounted for in their reported values for $\sigma$ in the continuum region (Bloss et al., 2001). However Harwood et al. (1997) observed the same decay kinetics when IO was monitored in the continuum region at $390 \mathrm{~nm}$ suggesting no interference due to product absorption. The agreement is good in the reported overall shape of the IO absorption envelope in the continuum between $350-400 \mathrm{~nm}$ where resolution is unimportant, from the three studies. The absolute cross sections reported by Bloss et al. (2001) in the continuum at $390 \mathrm{~nm}$ are a factor of 0.67 lower than those from Laszlo et al. (1995) and Harwood et al. (1997). The preferred values for the IO cross sections averaged over $5 \mathrm{~nm}$ intervals in 
the $345 \mathrm{~nm}$ to $465 \mathrm{~nm}$ are the values given by Bloss et al. (2001), scaled upwards by a factor of 1.5 to compensate for the lower resolution-independent value of $\sigma(390 \mathrm{~nm})$, obtained in this study.

The temperature dependence of $\sigma(427.2 \mathrm{~nm})$ has been investigated by Sander (1986), Harwood et al. (1997) and Bloss et al. (2001). The studies of Harwood et al. (1997) and Bloss et al. (2001) did not reproduce the large increase in $\sigma$ with decreasing temperature below $315 \mathrm{~K}$ observed by Sander (1986) although values of $\sigma$ above $315 \mathrm{~K}$ are in good agreement (Sander, 1986; Harwood et al., 1997; Bloss et al., 2001). Bloss et al. (2001) found that the yield of IO from the O $\left({ }^{3} \mathrm{P}\right)+\mathrm{CF}_{3} \mathrm{I}$ reaction is apparently pressure and temperature dependent, and this was accounted for in deriving their expression for the small temperature dependence of $\sigma(427.2 \mathrm{~nm})$. Harwood et al. (1997) assumed a constant yield of $\mathrm{IO}$ from the $\mathrm{O}\left({ }^{3} \mathrm{P}\right)+\mathrm{CF}_{3} \mathrm{I}$ reaction which resulted in a temperature-independent cross section $\sigma$ at $427.2 \mathrm{~nm}$. Since the temperature dependence is clearly quite small, cross sections in the banded region at low resolution can be assumed to be temperature independent. Cross sections in the continuum region are assumed to be temperature and resolution independent.

\section{Quantum Yields.}

Turnipseed et al. (1995) observed LIF from the $(0,0),(2,0),(3,0)$ and $(2,1)$ bands of the $A^{2} \Pi_{3 / 2} \leftarrow X^{2} \Pi_{3 / 2}$ transition of IO. The spectra are predissociated and the dissociation lifetime is $<10 \mathrm{~ns}$ (Inoue et al., 1983). The lifetime of the upper state of IO formed in the A-X transition is thus so short that quenching, fluorescence and processes other than dissociation by reaction (1) must be negligible, and therefore the predominant fate of IO following light absorption is dissociation to O+I. The measurement of Ingham et al. (2000) in the continuum at $355 \mathrm{~nm}$ confirms this conclusion for that region.

\section{References}

Atkinson, D . B., Hudgens, J. W., and Orr-Ewing, A. J.: J. Phys. Chem. A, 103, 6173, 1999.

Bloss, W. J., Rowley, D. M., Cox, R. A., and Jones, R. L.: J. Phys. Chem. A, 105, 7840, 2001.

Cox, R. A. and Coker, G. B.: J. Phys. Chem., 87, 4478, 1983.

Harwood, M. H., Burkholder, J. B., Hunter, M., Fox, R. W., and Ravishankara, A. R.: J. Phys. Chem. A, 101, 853, 1997.

Ingham, T., Cameron, M., and Crowley, J. N.: J. Phys. Chem. A, 104, 8001, 2000.

Inoue, G., Suzuki, M., and Washida, N.: J. Chem. Phys., 79, 4730, 1983.

Laszlo, B., Kurylo, M. J., and Huie, R. E.: J. Phys. Chem., 99, 11701, 1995.

Sander, S. P.: J. Phys. Chem., 90, 2194, 1986.

Stickel, R. E., Hynes, A. J., Bradshaw, J. D., Chameides, W. L., and Davis, D. D.: J. Phys. Chem., 92, 1862, 1988.

Turnipseed, A. A., Gilles, M. K., Burkholder, J. B., and Ravishankara, A. R.: Chem. Phys. Lett., 242, 427, 1995. 
III.A5.125

$$
\mathrm{OIO}+\mathbf{h} v \rightarrow \text { products }
$$

\section{Primary photochemical processes}

\begin{tabular}{lllll}
\hline Reaction & & $\Delta H^{\circ} / \mathrm{kJ} \mathrm{mol}^{-1}$ & $\lambda_{\text {threshold }} / \mathrm{nm}$ \\
\hline $\mathrm{OIO}+\mathrm{h} v$ & $\rightarrow \mathrm{I}+\mathrm{O}_{2}$ & $(1)$ & 30 & 3987 \\
& $\rightarrow \mathrm{IO}+\mathrm{O}\left({ }^{3} \mathrm{P}\right)$ & $(2)$ & 288 & 415 \\
\hline
\end{tabular}

Absorption cross section data

\begin{tabular}{llc}
\hline Wavelength range/nm & Reference & Comments \\
\hline $465-667$ & Himmelmann et al., 1996 & (a) \\
549.1 & Spietz et al., 1998 & (b) \\
548.6 & Cox et al., 1999 & (c) \\
548.6 & Ingham et al., 2000 & (d) \\
$540-605$ & Ashworth et al., 2002 & (e) \\
\hline
\end{tabular}

Quantum yield data $\left(\Phi=\Phi_{1}+\Phi_{1}\right)$

\begin{tabular}{lllc}
\hline Measurement & Wavelength $/ \mathrm{nm}$ & Reference & Comments \\
\hline$\Phi_{1}<0.15$ & 532 & Ingham et al., 2000 & (f) \\
$\Phi_{2}<0.007$ & & & \\
\hline
\end{tabular}

\section{Comments}

(a) Flash photolysis of a mixture of $\mathrm{I}_{2}$ in $\mathrm{O}_{3}$ with time-resolved UV-visible absorption spectroscopy. In addition to IO bands between $21500 \mathrm{~cm}^{-1}$ and $26000 \mathrm{~cm}^{-1}$ ( $385 \mathrm{~nm}$ to $465 \mathrm{~nm}$ ), a new absorption spectrum between $15000 \mathrm{~cm}^{-1}$ and $21500 \mathrm{~cm}^{-1}$ ( $465 \mathrm{~nm}$ to $667 \mathrm{~nm}$ ) was observed, which was attributed to the OIO radical by comparison of the derived spectroscopic constants with the known values for $\mathrm{OClO}$ and $\mathrm{OBrO}$.

(b) Same technique as in comment (a). Fits to a complex mechanism yielded an estimate for $\sigma(\mathrm{OIO})=(3.5 \pm 1.5) \times 10^{-17} \mathrm{~cm}^{2}$ molecule ${ }^{-1}$ at $549.1 \mathrm{~nm}$.

(c) Pulsed laser photolysis of $\mathrm{N}_{2} \mathrm{O}-\mathrm{Br}_{2}-\mathrm{CF}_{3} \mathrm{I}$ mixtures at $193 \mathrm{~nm}$ with time-resolved UV-visible absorption spectroscopy using a charged-coupled-device detection system. The branching ratio for OIO formation in the IO self-reaction was determined to be $0.38 \pm 0.08$. This is based on an analysis assuming a branching ratio for OIO formation in the $\mathrm{IO}+\mathrm{BrO}$ reaction of 0.8, as reported by Bedjanian et al. (1998) from a DF study in which the co-product $\mathrm{Br}$ was measured. A corresponding absolute value of $\sigma(\mathrm{OIO})=(1.09 \pm 0.21) \times 10^{-17} \mathrm{~cm}^{2}$ molecule ${ }^{-1}$ at $548.6 \mathrm{~nm}$ was derived. Absorption bands were observed from $495 \mathrm{~nm}$ to $600 \mathrm{~nm}$.

(d) Pulsed laser photolysis of a mixture of $\mathrm{O}_{3}$ in $\mathrm{I}_{2}$ with UV-visible absorption spectroscopy and resonance fluorescence detection. A conservative minimum OIO cross section of $2.7 \times 10^{-17} \mathrm{~cm}^{2}$ molecule ${ }^{-1}$ at $548.6 \mathrm{~nm}$ was derived. Absorption bands were observed from $480 \mathrm{~nm}$ to $650 \mathrm{~nm}$.

(e) Pulsed laser photolysis-CRDS/UVS; both high resolution and broadband spectra reported. The high resolution spectrum shows no fine structure in the bands which are attributed to the $\mathrm{OIO}\left({ }^{2} \mathrm{~B}_{2}-{ }^{2} \mathrm{~B}_{1}\right)$ transition.

(f) Same experimental conditions as in comment (d). Photofragment spectroscopy was used to study the quantum yield for $\mathrm{O}\left({ }^{3} \mathrm{P}\right)$ production and for $\left.\mathrm{I}^{2}{ }^{2} \mathrm{P}_{J}\right)$ production following the photolysis of $\mathrm{OIO}$ at $532 \mathrm{~nm}$. $\mathrm{O}\left({ }^{3} \mathrm{P}\right)$ was not detected, allowing the authors to put an upper limit of $\sim 0.007$ on the value of $\Phi_{2}$ at $532 \mathrm{~nm}$. I $\left({ }^{2} \mathrm{P}_{J}\right)$ could not be detected in the single photon photolysis of OIO at $532 \mathrm{~nm}$, and an upper limit of $\sim 0.15$ on the value of $\Phi_{1}$ was derived. 


\section{Preferred Values}

\section{Absorption cross sections}

$\sigma(\mathrm{OIO})=(2.7 \pm 1.6) \times 10^{-17} \mathrm{~cm}^{2}$ molecule ${ }^{-1}$ at $\lambda=548.6 \mathrm{~nm}$

\section{Quantum yields}

$\Phi_{2}<0.007$ at $532 \mathrm{~nm}$

\section{Comments on Preferred Values}

The absorption spectrum of OIO in the strong visible absorption band between $\sim 480 \mathrm{~nm}$ and $660 \mathrm{~nm}$ is well established, but there is considerable disagreement between the absolute cross sections determined in the different studies, even when experimental errors and the effects of instrument resolution are accounted for. The values at $548.6 \mathrm{~nm}$ range from $(1.09 \pm 0.21) \times 10^{-17} \mathrm{~cm}^{2}$ molecule ${ }^{-1}$ to $(3.5 \pm 1.5) \times 10^{-17} \mathrm{~cm}^{2}$ molecule ${ }^{-1}$. The preferred absorption cross section is the lower limit value from the study of Ingham et al. (2000) and represents a compromise between the high and low values reported. The uncertainty covers the range of reported values.

Vibrational assignments of the $\tilde{\mathrm{A}}-\tilde{\mathrm{X}}$ band system and positions of the vibronic band centers between $15120 \mathrm{~cm}^{-1}$ and $20753 \mathrm{~cm}^{-1}$ (482 $\mathrm{nm}$ to $\left.661 \mathrm{~nm}\right)$ are tabulated in Himmelmann et al. (1996).

Dissociation of OIO into $\mathrm{O}\left({ }^{3} \mathrm{P}\right)+\mathrm{IO}$ following absorption in the $\tilde{\mathrm{A}}-\tilde{\mathrm{X}}$ band system can be excluded on thermodynamic grounds. This is confirmed by the results of Ingham et al. (2000) who were unable to detect $\mathrm{O}$ atoms and report an upper limit of 0.007 for $\Phi_{2}$ at $532 \mathrm{~nm}$. Ingham et al. (2000) also report an upper limit of $\sim 0.15$ on the value of $\Phi_{1}$, but the results of Ashworth et al. (2002) provide compelling evidence that the ${ }^{2} \mathrm{~B}_{2}$ upper state is strongly predissociated, and they report quantum calculations that efficient dissociation to $\mathrm{I}+\mathrm{O}_{2}$ can occur. This issue is unresolved and no recommendation is made for $\Phi_{1}$.

\section{References}

Ashworth, S. H., Allan, B. J., and Plane, J. M. C.: Geophys Res. Lett., 29, doi:10.1029/2001GL013851, 2002.

Bedjanian, Y., Le Bras, G., and Poulet, G.: J. Phys. Chem. A, 102, 10501, 1998.

Cox, R. A., Bloss, W. J., Jones, R. L., and Rowley, D. M.: Geophys. Res. Lett., 26, 1857, 1999.

Himmelmann, S., Orphal, J., Bovensmann, H., Richter, A. Ladstätter-Weissenmayer, A., and Burrows, J. P.: Chem. Phys. Lett., 251, 330, 1996.

Ingham, T., Cameron, M., and Crowley, J. N.: J. Phys. Chem. A, 104, 8001, 2000.

Spietz, P., Himmelmann, S., Gross, U., Bleck-Neuhaus, J., and Burrows, J. P.: A complex approach to investigate the chemistry and kinetics of $\mathrm{IO}_{\mathrm{x}}$ using flash photolysis and time-resolved absorption spectroscopy. 15th Int. Symp. Gas Kinetics, Bilbao, Spain, Sept. 1998. 
III.A5.126

$$
\mathbf{I C l}+\mathbf{h} v \rightarrow \text { products }
$$

\section{Primary photochemical transitions}

\begin{tabular}{llll}
\hline Reaction & & $\Delta H^{\circ} / \mathrm{kJ} \mathrm{mol}^{-1}$ & $\lambda_{\text {threshold }} / \mathrm{nm}$ \\
\hline $\mathrm{ICl}+\mathrm{h} v$ & $\rightarrow \mathrm{I}+\mathrm{Cl}$ & 211 & 567 \\
& $\rightarrow \mathrm{Cl}\left({ }^{2} \mathrm{P}_{1 / 2}\right)+\mathrm{I}$ & 221 & 540 \\
& $\left.\rightarrow \mathrm{Cl}+\mathrm{I}^{2} \mathrm{P}_{1 / 2}\right)$ & 302 & 396 \\
\hline
\end{tabular}

Absorption cross section data

\begin{tabular}{llc}
\hline Wavelength range/nm & Reference & Comments \\
\hline $220-600$ & Seery and Britton, 1964 & (a) \\
$210-530$ & Jenkin et al., 1990 & (b) \\
\hline
\end{tabular}

Quantum yield data

\begin{tabular}{lllc}
\hline Wavelength/nm & Quantum Yield & Reference & Comments \\
\hline $235.3-237.8$ & $\Phi\left(\mathrm{Cl}^{*}\right)=0.40$ & Tonokura et al., 1993 & (c) \\
248 & $\Phi\left(\mathrm{I}^{*}\right)=0.42$ & & \\
\hline
\end{tabular}

\section{Comments}

(a) Three measurements of the UV/Vis absorption spectrum have been performed in a $10 \mathrm{~cm}$ long quartz cell and the pressure was measured using a Pyrex spiral manometer. Runs with added $\mathrm{Cl}_{2}$ indicated the disproportionation reaction to be immeasurably slow under the prevailing experimental conditions. The uncertainty in the absorption cross section was $\pm 0.2 \times 10^{-20} \mathrm{~cm}^{2}$ molecule ${ }^{-1}$ throughout the wavelength range.

(b) Spectrum of a static purified gas sample of ICl using a CCD camera over the wavelength range 210-690 nm. Good agreement with the spectrum of Seery and Britton (1964) except in the range 290-360 nm where the measured values of the cross sections seem to be lower than Seery and Britton (1964) presumably owing to a $\mathrm{Cl}_{2}$ impurity. The value of the UV maximum $\sigma=5 \times 10^{-19} \mathrm{~cm}^{2}$ molecule ${ }^{-1}$ at $240 \mathrm{~nm}$ is slightly higher than in Seery and Britton (1964) by approximately $5-10 \%$.

(c) The stated relative quantum yields are consistent with the following measured concentration ratios observed in the diffusive molecular beam photodissociation experiment with REMPI detection of $\left[\mathrm{Cl}^{*}\right]$ and $[\mathrm{Cl}]$ and two-photon laser-induced fluorescence of $[\mathrm{I}]$ and $\left[\mathrm{I}^{*}\right]$, respectively: $\left[\mathrm{Cl}^{*}\right] /[\mathrm{Cl}]=0.68 \pm 0.10$ in the range $235.3-237.8 \mathrm{~nm}$ and $\left[\mathrm{I}^{*}\right] /[\mathrm{I}]=0.71 \pm 0.27$ at $248 \mathrm{~nm}$. By inference the quantum yield for the ground state process is 0.18 . 


\section{Preferred Values}

Absorption cross sections at $298 \mathrm{~K}$.

\begin{tabular}{llll}
\hline$\lambda / \mathrm{nm}$ & $\begin{array}{l}10^{20} \sigma / \mathrm{cm}^{2} \\
\text { molecule }\end{array}$ & $\lambda / \mathrm{nm}$ & $\begin{array}{l}10^{20} \sigma / \mathrm{cm}^{2} \\
\text { molecule }^{-1}\end{array}$ \\
\hline 220 & 21.3 & 420 & 28.9 \\
230 & 35.4 & 430 & 32.1 \\
240 & 44.0 & 440 & 35.4 \\
250 & 43.3 & 450 & 38.9 \\
260 & 35.3 & 460 & 41.7 \\
270 & 24.4 & 470 & 42.6 \\
280 & 15.4 & 480 & 40.9 \\
290 & 9.41 & 490 & 36.3 \\
300 & 6.08 & 500 & 29.4 \\
310 & 4.59 & 510 & 22.8 \\
320 & 4.01 & 520 & 16.4 \\
330 & 3.67 & 530 & 11.5 \\
340 & 3.29 & 540 & 8.00 \\
350 & 3.10 & 550 & 5.70 \\
360 & 3.52 & 560 & 4.32 \\
370 & 5.31 & 570 & 3.44 \\
380 & 8.79 & 580 & 2.83 \\
390 & 13.9 & 590 & 2.10 \\
400 & 19.0 & 600 & 1.76 \\
410 & 24.7 & & \\
\hline
\end{tabular}

\section{Comments on Preferred Values}

The listed cross sections are those from Seery and Britton..

\section{References}

Jenkin, M. E., Cox, R. A., Mellouki, A., Le Bras, G., and Poulet, G.: J. Phys. Chem., 94, 2927, 1990.

Seery, D. and Britton, D.: J. Phys. Chem., 68, 2263, 1964.

Tonokura, K., Matsumi, Y., Kawasaki, M., Kim, H. L., Fujimura, S., and Saito, K.: J. Chem. Phys., 99, $3461,1993$. 
III.A5.127

$$
\mathbf{I B r}+\mathbf{h} v \rightarrow \text { products }
$$

\section{Primary photochemical transitions}

\begin{tabular}{llll}
\hline Reaction & & $\Delta H^{\circ} / \mathrm{kJ} \mathrm{mol}^{-1}$ & $\lambda_{\text {threshold }} / \mathrm{nm}$ \\
\hline $\mathrm{IBr}+\mathrm{h} v$ & $\rightarrow \mathrm{I}+\mathrm{Br}$ & 178 & 672 \\
& $\rightarrow \mathrm{Br}\left({ }^{2} \mathrm{P}_{1 / 2}\right)+\mathrm{I}$ & 222 & 539 \\
& $\rightarrow \mathrm{Br}+\mathrm{I}\left({ }^{2} \mathrm{P}_{1 / 2}\right)$ & 269 & 445 \\
\hline
\end{tabular}

\section{Absorption cross section data}

\begin{tabular}{llc}
\hline Wavelength range/nm & Reference & Comments \\
\hline $220-600$ & Seery and Britton, 1964 & (a) \\
\hline
\end{tabular}

\section{Quantum yield data}

\begin{tabular}{lllc}
\hline Wavelength/nm & Quantum Yield & Reference & Comments \\
\hline 267 & $\Phi\left(\mathrm{Br}^{*}\right)=0.35$ & Kim et al., 1997 & (b) \\
267 & $\Phi\left(\mathrm{I}^{*}\right)=0.42$ & & \\
267 & $\Phi(\mathrm{I})=0.23$ & & \\
500 & $\Phi\left(\mathrm{Br}^{*}\right)=0.73$ & Haugen et al., 1985 & (c) \\
\hline
\end{tabular}

\section{Comments}

(a) Four measurements of the UV/Vis absorption spectrum have been performed in a $10 \mathrm{~cm}$ long quartz cell and the pressure was measured using a Pyrex spiral manometer. Runs with added $\mathrm{Br}_{2}$ indicated the disproportionation reaction to be unimportant under the prevailing experimental conditions. The uncertainty in the absorption cross section was $\pm 0.95 \times 10^{-20} \mathrm{~cm}^{2}$ molecule ${ }^{-1}$ throughout the wavelength range.

(b) The stated relative quantum yields are derived from the following measured concentration ratio observed in the diffusive molecular beam photodissociation experiment with REMPI detection of $\left[\mathrm{Br}^{*}\right]$ and $[\mathrm{Br}]$, respectively, within the same laser pulse: $\left[\mathrm{Br}^{*}\right] /[\mathrm{Br}]=0.54$ at $267 \mathrm{~nm}$. Center-stripe analysis of velocity profiles affords the stated quantum yields for the channels yielding ground-state $\mathrm{Br}\left(\Phi(\mathrm{I})=0.23, \Phi\left(\mathrm{I}^{*}\right)=0.42\right)$.

(c) Approximate value resulting from a time-resolved laser gain vs. absorption spectroscopy technique. 


\section{Preferred Values}

Absorption cross sections at $298 \mathrm{~K}$.

\begin{tabular}{llll}
\hline$\lambda / \mathrm{nm}$ & $\begin{array}{l}10^{20} \sigma / \mathrm{cm}^{2} \\
\text { molecule }\end{array}$ & $\lambda / \mathrm{nm}$ & $\begin{array}{l}10^{20} \sigma / \mathrm{cm}^{2} \\
\text { molecule }\end{array}$ \\
\hline 220 & 3.59 & 420 & 31.7 \\
230 & 5.70 & 430 & 44.8 \\
240 & 10.2 & 440 & 58.7 \\
250 & 16.7 & 450 & 71.9 \\
260 & 21.5 & 460 & 85.2 \\
270 & 23.1 & 470 & 98.5 \\
280 & 21.1 & 480 & 111 \\
290 & 16.8 & 490 & 120 \\
300 & 12.4 & 500 & 122 \\
310 & 7.95 & 510 & 116 \\
320 & 5.39 & 520 & 103 \\
330 & 3.36 & 530 & 85.9 \\
340 & 2.14 & 540 & 67.5 \\
350 & 1.45 & 550 & 52.3 \\
360 & 1.53 & 560 & 36.6 \\
370 & 2.37 & 570 & 27.2 \\
380 & 4.17 & 580 & 19.9 \\
390 & 6.96 & 590 & 14.6 \\
400 & 12.0 & 600 & 11.3 \\
410 & 20.5 & & \\
\hline
\end{tabular}

\section{Comments on Preferred Values}

The listed values are the only ones available.

\section{References}

Haugen, H. K., Weitz, E., and Leone, S. R.: J. Chem. Phys., 83, 3402, 1985.

Kim, Y. S., Jung, Y.-J., and Jung, K.-H.: J. Chem. Phys., 107, 3805, 1997.

Seery, D. J. and Britton, D.: J. Phys. Chem., 68, 2263, 1964. 
III.A5.128

$$
\mathbf{I}_{2}+\mathbf{h} v \rightarrow \mathbf{I}+\mathbf{I}
$$

Primary photochemical transitions

\begin{tabular}{llll}
\hline Reaction & $\Delta H^{\circ} / \mathrm{kJ} \mathrm{mol}^{-1}$ & $\lambda_{\text {threshold }} / \mathrm{nm}$ \\
\hline $\mathrm{I}_{2}+\mathrm{h} v$ & $\left.\rightarrow \mathrm{I}\left({ }^{2} \mathrm{P}_{3 / 2}\right)+\mathrm{I}^{2}{ }^{2} \mathrm{P}_{3 / 2}\right)$ & 151 & 792 \\
\hline
\end{tabular}

\section{Absorption cross section data}

\begin{tabular}{llc}
\hline Wavelength range/nm & Reference & Comments \\
\hline $430-620$ & Rabinowitch and Wood, 1936a & (a) \\
$420-800$ & Tellinghuisen, 1973 & (b) \\
$280-510$ & Bauer et al., 1998 & (c) \\
$180-750$ & Saiz-Lopez et al., 2004 & (d) \\
\hline
\end{tabular}

\section{Quantum yield data}

\begin{tabular}{lllc}
\hline Wavelength/nm & Wavelength/nm & Reference & Comments \\
\hline$\Phi=1$ & $370-650$ & Rabinowitch and Wood, 1936b & (e) \\
$\Phi=0.93 \pm 0.02$ & 501.0 & Brewer and Tellinghuisen, 1972 & (f) \\
$\Phi=0.70 \pm 0.03$ & 509.1 & & \\
$\Phi=0.62 \pm 0.02$ & 516.6 & & \\
$\Phi=0.66 \pm 0.04$ & 527.7 & & \\
$\Phi=0.72 \pm 0.02$ & 546.2 & & \\
$\Phi=0.67 \pm 0.03$ & 559.4 & & \\
$\Phi=0.59 \pm 0.03$ & 569.0 & & \\
$\Phi=0.33 \pm 0.01$ & 589.6 & & \\
$\Phi=0.35 \pm 0.01$ & 592.2 & & \\
$\Phi=0.54 \pm 0.02$ & 603.7 & & \\
$\Phi=0.67 \pm 0.04$ & 612.9 & & \\
$\Phi=0.88 \pm 0.05$ & 623.9 & & \\
\hline
\end{tabular}

\section{Comments}

(a) The visible absorption spectrum was determined from measurements made at a series of wavelengths over the range 430$620 \mathrm{~nm}$, at low resolution $(5-10 \mathrm{~nm})$, at room temperature $(\sim 293 \mathrm{~K})$. Experiments were carried out using 0.2 mbar pure $\mathrm{I}_{2}$ either in the absence of a bath gas, or in the presence of $670 \mathrm{mbar}$ of He, air or Ar. Cross sections between 500-570 nm increased in the presence of the bath gases, but showed no dependence on bath gas identity. The cross section reported at the absorption maximum in the absence of a bath gas (i.e., close to $500 \mathrm{~nm}$ ) was $\sim 2.8 \times 10^{-18} \mathrm{~cm}^{2}$ molecule ${ }^{-1}$.

(b) The visible-infrared absorption spectrum was determined from measurements made at $10 \mathrm{~nm}$ intervals over the wavelength range $420-800 \mathrm{~nm}$, at a resolution of $0.26 \mathrm{~nm}$. Measurements were made at room temperature $(295-300 \mathrm{~K})$ with pressures of purified $\mathrm{I}_{2}$ of up to $\sim 0.15$ mbar. The cross section reported at $500 \mathrm{~nm}$ (the beginning of the $\mathrm{B}^{3} \Pi \leftarrow \mathrm{X}^{1} \Sigma$ continuum) was $(2.19 \pm 0.07) \times 10^{-18} \mathrm{~cm}^{2}$ molecule ${ }^{-1}$.

(c) The ultraviolet-visible absorption spectrum was recorded over the range $280-510 \mathrm{~nm}$, at a resolution of $1.2 \mathrm{~nm}$, with cross sections reported at $436 \mathrm{~nm}$ and $500 \mathrm{~nm}$. Measurements were made at room temperature $(295 \pm 2 \mathrm{~K})$ with pressures of purified $\mathrm{I}_{2}$ up to 0.2 mbar. The cross section reported at $500 \mathrm{~nm}$ was $(2.25 \pm 0.09) \times 10^{-18} \mathrm{~cm}^{2}$ molecule ${ }^{-1}$.

(d) The ultraviolet-visible-infrared absorption spectrum was recorded using Fourier Transform spectroscopy over the wavelength range $182-750 \mathrm{~nm}$, at a resolution of $0.036 \mathrm{~nm}$ in the banded region $(500-650 \mathrm{~nm})$ and $1 \mathrm{~nm}$ elsewhere. Measurements were made at room temperature $(295 \mathrm{~K})$ in 1.013 bar air. The absorption maximum was recorded in the banded region at $533 \mathrm{~nm}$, with the cross section reported at $500 \mathrm{~nm}$ being $2.29 \times 10^{-18} \mathrm{~cm}^{2}$ molecule ${ }^{-1}$. 
(e) Photodissociation quantum yields were determined from the reversible decrease in extinction during steady state illumination of $\mathrm{I}_{2}$ vapour with a carbon arc or filament lamp. The use of appropriate filters allowed three broad band spectral regions to be considered for the photolysis radiation: $\sim 370-502 \mathrm{~nm}, \lambda_{\max }=460 \mathrm{~nm} ; \sim 480-590 \mathrm{~nm}, \lambda_{\max }=502 \mathrm{~nm}$; $\sim 503-$ $650 \mathrm{~nm}, \lambda_{\max }=565 \mathrm{~nm}$. The quantum yield in the first region (essentially the $\mathrm{B}^{3} \Pi \leftarrow \mathrm{X}^{1} \Sigma$ continuum) was assumed to be unity. No significant difference in quantum yield for the other regions was observed. Experiments were carried out with 0.2 mbar $\mathrm{I}_{2}$ in the presence of several hundred mbar of $\mathrm{He}, \mathrm{Ar}, \mathrm{H}_{2}$ and $\mathrm{N}_{2}$.

(f) Photodissociation quantum yields were determined from fluorescence detection of $\mathrm{I}\left({ }^{2} \mathrm{P}_{3 / 2}\right)$, during steady state photolysis of $\mathrm{I}_{2}$ at 12 wavelengths, using a tungsten lamp in conjunction with combinations of interference filters. The transmittance bandwidth varied from 0.3 to $1.4 \mathrm{~nm}$. The yields were determined relative to an assumed value of unity at $492 \mathrm{~nm}$, in the $\mathrm{B}^{3} \Pi \leftarrow \mathrm{X}^{1} \Sigma$ continuum. Low pressure experiments were carried out with $\mathrm{I}_{2}$ pressures up to $\sim 0.01$ mbar, to determine the zero pressure limiting quantum yields tabulated above. Experiments with up to 15 mbar $\mathrm{N}_{2}$ demonstrated that the dissociative yield tends to unity in the presence of higher bath gas pressures.

\section{Preferred Values}

Absorption cross sections for $I_{2}$ at $298 \mathrm{~K}$.

\begin{tabular}{|c|c|c|c|}
\hline$\lambda / \mathrm{nm}$ & $\begin{array}{l}10^{18} \sigma / \mathrm{cm}^{2} \\
\text { molecule }^{-1}\end{array}$ & $\lambda / \mathrm{nm}$ & $\begin{array}{l}10^{18} \sigma / \mathrm{cm}^{2} \\
\text { molecule }^{-1}\end{array}$ \\
\hline 400 & 0.029 & 565 & 1.54 \\
\hline 405 & 0.038 & 570 & 1.28 \\
\hline 410 & 0.043 & 575 & 0.955 \\
\hline 415 & 0.053 & 580 & 0.912 \\
\hline 420 & 0.058 & 585 & 0.729 \\
\hline 425 & 0.081 & 590 & 0.644 \\
\hline 430 & 0.133 & 595 & 0.588 \\
\hline 435 & 0.153 & 600 & 0.466 \\
\hline 440 & 0.199 & 605 & 0.422 \\
\hline 445 & 0.253 & 610 & 0.400 \\
\hline 450 & 0.327 & 615 & 0.336 \\
\hline 455 & 0.432 & 620 & 0.300 \\
\hline 460 & 0.560 & 625 & 0.276 \\
\hline 465 & 0.709 & 630 & 0.274 \\
\hline 470 & 0.880 & 635 & 0.220 \\
\hline 475 & 1.07 & 640 & 0.233 \\
\hline 480 & 1.29 & 645 & 0.222 \\
\hline 485 & 1.52 & 650 & 0.212 \\
\hline 490 & 1.75 & 655 & 0.203 \\
\hline 495 & 2.00 & 660 & 0.186 \\
\hline 500 & 2.24 & 665 & 0.170 \\
\hline 505 & 2.45 & 670 & 0.174 \\
\hline 510 & 2.62 & 675 & 0.156 \\
\hline 515 & 2.76 & 680 & 0.146 \\
\hline 520 & 2.78 & 685 & 0.137 \\
\hline 525 & 2.85 & 690 & 0.126 \\
\hline 530 & 2.82 & 695 & 0.106 \\
\hline 535 & 2.75 & 700 & 0.101 \\
\hline 540 & 2.60 & 705 & 0.074 \\
\hline 545 & 2.41 & 710 & 0.063 \\
\hline 550 & 2.25 & 715 & 0.059 \\
\hline 555 & 2.02 & 720 & 0.054 \\
\hline 560 & 1.74 & 725 & 0.031 \\
\hline
\end{tabular}




\section{Quantum Yields}

$\Phi=1.0$ throughout the wavelength range.

\section{Comments on Preferred Values}

\section{Absorption Cross Sections.}

The visible-infrared absorption spectrum of $\mathrm{I}_{2}$ has been the subject of a number of studies and discussions (Rabinowitch and Wood, 1936a; Calvert and Pitts, 1966; Tellinghuisen, 1973; Okabe, 1978; Bauer et al., 1998; Saiz-Lopez et al., 2004). The spectrum is dominated by the transition from the $\mathrm{X}^{1} \Sigma$ ground state into the bound $\mathrm{B}^{3} \Pi$ upper state, which results in rovibrational structure in the wavelength range $650-500 \mathrm{~nm}$, with the dissociative continuum at $\leq 499 \mathrm{~nm}$. There is also a weaker underlying continuum in the structured region, due to the transition to ${ }^{1} \Pi$ repulsive state.

The shape of the absorption spectrum at wavelengths $\leq 500 \mathrm{~nm}$ (i.e. essentially in the continuum), based on a number of studies (Rabinowitch and Wood, 1936a; Tellinghuisen, 1973; Bauer et al., 1998; Saiz-Lopez et al., 2004), is well determined. Measurements in the structured region of the spectrum have been found to be very sensitive to experimental conditions, depending on the absolute concentration of $I_{2}$ and on pressure of bath gas, at the spectral resolutions typically employed. Cross sections averaged over a wavelength interval in this region should tend towards the true value when partial saturation of rotational lines is avoided though use of very low $\mathrm{I}_{2}$ concentrations or at higher bath gas pressures when the lines become sufficiently broadened. The recent measurements of Saiz-Lopez et al. (2004), performed at high resolution and with high bath gas pressures, are therefore used to define the shape of the spectrum, with the preferred values based on their data averaged over $5 \mathrm{~nm}$ intervals.

The three most recent studies (Tellinghuisen, 1973; Bauer et al., 1998; Saiz-Lopez et al., 2004) report absorption cross sections in the pressure-independent continuum $(\lambda \leq 500 \mathrm{~nm})$ which are in excellent agreement, differing by less than $5 \%$ at $500 \mathrm{~nm}$. The present recommendation therefore adopts a reference value of $\sigma=2.24 \times 10^{-18} \mathrm{~cm}^{2}$ molecule ${ }^{-1}$ at $500 \mathrm{~nm}$, which is the average of the values reported in the three investigations.

\section{Quantum Yields.}

The measurements of Rabinowitch and Wood (1936b) are consistent with a unity quantum yield throughout the visibleinfrared spectrum at bath gas pressures greater than about 200 mbar. Brewer and Tellinghuisen (1972) report quantum yields well below unity in the structured region of the spectrum $(501-624 \mathrm{~nm})$ at low pressures in the absence of a bath gas, but observed significant increases (to $>0.9$ ) at $\mathrm{N}_{2}$ pressures of only 15 mbar. The results of these studies are interpreted in terms of collision induced transition from the bound $\mathrm{B}^{3} \Pi$ upper state into the unstable ${ }^{1} \Pi$ repulsive state, leading to the generation of $\mathrm{I}\left({ }^{2} \mathrm{P}_{3 / 2}\right)+\mathrm{I}\left({ }^{2} \mathrm{P}_{3 / 2}\right)$, as does the weaker underlying continuum transition $\left({ }^{1} \Pi \leftarrow \mathrm{X}^{1} \Sigma\right)$. A quantum yield of unity throughout the spectrum is therefore recommended for lower atmospheric conditions. A number of studies have also determined quantum yields for the production of excited state $\mathrm{I}\left({ }^{2} \mathrm{P}_{1 / 2}\right.$ ) atoms, which have been detected at wavelengths below $\sim 530 \mathrm{~nm}$ (Hunter and Leong, 1987; and references therein). Under atmospheric conditions, collisional quenching of $\mathrm{I}\left({ }^{2} \mathrm{P}_{1 / 2}\right)$ to ground state $\mathrm{I}\left({ }^{2} \mathrm{P}_{3 / 2}\right)$ occurs rapidly.

\section{References}

Bauer, D., Ingham, T., Carl, S., Moortgat, G. K., and Crowley, J. N.: J. Phys. Chem. A, 102, 2857, 1998.

Brewer, L. and Tellinghuisen, J.: J. Chem. Phys., 56, 3929, 1972.

Calvert, J. G. and Pitts Jr., J. N.: Photochemistry, Wiley, New York, p. 184, 1966.

Hunter, T. F. and Leong, C. M.: Chem. Phys., 111, 145, 1987.

Okabe, H.: Photochemistry of small molecules, Wiley, New York, p. 187, 1978.

Rabinowitch, E. and Wood, W. C.: Trans. Faraday Soc., 32, 540, 1936a.

Rabinowitch, E. and Wood, W. C.: J. Chem. Phys., 4, 358, 1936b.

Saiz-Lopez, A., Saunders, R. W., Joseph, D. M., Ashworth, S. H., and Plane, J. M. C.: Atmos. Chem. Phys., 4, 1443, 2004.

Tellinghuisen, J.: J. Chem. Phys., 58, 2821, 1973. 